\title{
Cardiovascular and nutritional state in peritoneal dialysis : a clinical and pathophysiological study
}

Citation for published version (APA):

Konings, C. J. A. M. (2002). Cardiovascular and nutritional state in peritoneal dialysis : a clinical and pathophysiological study. [Doctoral Thesis, Maastricht University]. Datawyse / Universitaire Pers Maastricht. https://doi.org/10.26481/dis.20021218ck

Document status and date:

Published: 01/01/2002

DOI:

10.26481/dis.20021218ck

Document Version:

Publisher's PDF, also known as Version of record

\section{Please check the document version of this publication:}

- A submitted manuscript is the version of the article upon submission and before peer-review. There can be important differences between the submitted version and the official published version of record.

People interested in the research are advised to contact the author for the final version of the publication, or visit the DOI to the publisher's website.

- The final author version and the galley proof are versions of the publication after peer review.

- The final published version features the final layout of the paper including the volume, issue and page numbers.

Link to publication

\footnotetext{
General rights rights.

- You may freely distribute the URL identifying the publication in the public portal. please follow below link for the End User Agreement:

www.umlib.nl/taverne-license

Take down policy

If you believe that this document breaches copyright please contact us at:

repository@maastrichtuniversity.nl

providing details and we will investigate your claim.
}

Copyright and moral rights for the publications made accessible in the public portal are retained by the authors and/or other copyright owners and it is a condition of accessing publications that users recognise and abide by the legal requirements associated with these

- Users may download and print one copy of any publication from the public portal for the purpose of private study or research.

- You may not further distribute the material or use it for any profit-making activity or commercial gain

If the publication is distributed under the terms of Article $25 \mathrm{fa}$ of the Dutch Copyright Act, indicated by the "Taverne" license above, 


\section{Cardiovascular and Nutritional State in Peritoneal Dialysis}

A Clinical and Pathophysiological Study 
(c) Constantiin J.A.M. Konings, Maastrictht 2002

ISBN 90-5278-360-8

Scientific studies in this thesis were supported by a research grant from Baxter Health Care The Netherlands BV.

Printing of this thesis was financially supported by Amgen, AstraZeneca, Baxter, Gambro, Genzyme Nederland, Novartis, Ortho Biotech, Pie Medical Benelux and Servier. 


\title{
Cardiovascular and Nutritional State in Peritoneal Dialysis
}

\section{A Clinical and Pathophysiological Study}

\author{
PROEFSCHRIFT \\ ter verkrijging van de graad van doctor \\ aan de Universiteit Maastricht, \\ op gezag van Prof. dr. A.C. Nieuwenhuijzen Kruseman, \\ Rector Magnificus, \\ volgens het besluit van het College van Decanen, \\ in het openbaar te verdedigen \\ op woensdag 18 december 2002 om 12.00 uur \\ door \\ Constantiin Jean Antoine Marie Konings \\ Geboren op 12 augustus 1963 te Roosendaal
}

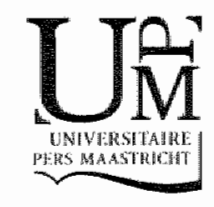




\title{
Promotor
}

Prof. dr. K.M.L. Leunissen

Co promotores

Dr. J.P. Kooman

Dr. F.M. van der Sande

Beoordelingscommissie

\author{
Prof. dr. ir. A.P.G. Hoeks (voorzitter) \\ Prof. dr. P.J.E.H.M. Kitslaar \\ Prof. dr. R.Th. Krediet (Universiteit van Amsterdam) \\ Prof. dr. N. Lameire (Universiteit van Gent) \\ Dr. ir A.M.W.J. Schols
}


Voor min voder 



\section{Contents}

Chapter 1 Introduction

Chapter 2 Arterial wall properties in patients with renal failure

Chapter 3 Assessment of fluid state in peritoneal dialysis patients

Chapter 4 Fluid state, blood pressure, and cardiovascular abnormalities in patients on peritoneal dialysis

Chapter 5 Fluid state in relation to peritoneal transport and residual renal function in CAPD patients: a longitudinal study

Chapter 6 Influence of fluid state on techniques used to assess body compasition in peritoneal dialysis patients

Chapter 7 Peritoneal glucose prescription is strongly related to changes in body composition in CAPD patients

Chapter 8 Effect of icadextrin on volume state, blood pressure and echocardiographic parameters: a randomized study

Chapter 9 Cut-off values for multifrequency bioimpedance analysis in the assessment of fluid state in patients on peritoneal dialysis: a hemodynamic evaluation

Chapter 10 General discussion

Chapter 11 Summary

Chapter 12 Samenvatting

Dankwoord 

Chapter 1

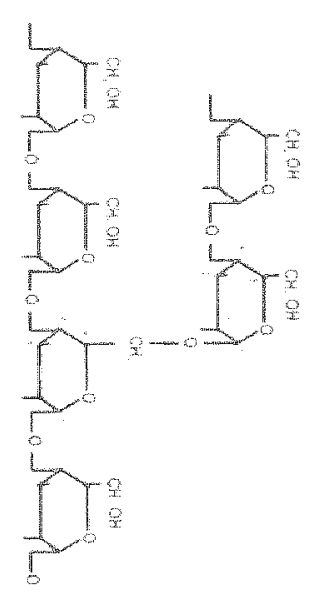

Introduction 


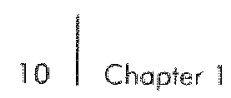




\section{Introduction}

In the course of evolution, the kidney has emerged from a simple canal by which waste products could be excreted in a constant salty environment with the same ellectrolyte composition of the extracellular fluid, into a very complicate organ which can maintain the milieu interior within very narrow limits despite large environmental fluctuations ${ }^{1,2}$, and also displays endocrine functions.

In patients with end-stage renal disease (ESRD), these functions are impaired, which leads, among others, to an accumulation of extracellular fluid, a derangement in acid-base and electrolyte state, and an accumulation of waste products ("uremic toxins").

Renal replacement therapies, such as hemodialysis (HD), can partly correct these abnormalities. HD is a very effective technique for rapid correction of electrolyte, fluid, and acid base state, and is efficient in the removal of small uremic toxins. $H D$ is performed by cleansing the blood through an artificial kidney. In this arfificial kidney, blood is separated by a semipermeable membrane from the dialysate, a purified solution with a balanced electrolyte and acid-base composition. Abnormalities of the blood are corrected by means of diffusion li.e. transport through concentration differences), whereas the excess water is removed by the application of a pressure gradient over the artificial kidney (convection). Generally, HD is performed 2-3 times a week for 3-5 hours. Despite its effectiveness, drawbacks of HD are its intermittent character, resulting on one hand in rapid and pronounced changes in the interior milieu during the dialysis treatment, which may lead to symptomatology, such as intra-dialytic hypotension, whereas on the other hand, uremic toxins and excess fluid again accumulate during the period between two dialysis sessions. Other drawbacks are the ineffective clearance of larger uremic toxins, and the high incidence of problems with vascular access.

By peritoneal dialysis (PD), the correction of the milieu interior occurs at a more continuous basis. The principle of PD resides in the exchange of water and solutes between the peritoneal capillaries and sterile fluid, which is infused into the peritoneal cavity through a catheter. After a certain time period the dwell time) during which the composition in the peritoneal cavity equilibrates with the plasma water, the fluid is drained and a new cycle is started.

Also with the use of PD, abnormalities of the blood are basically corrected by diffusion, whereas the excess of body water is removed by the application of an osmotic pressure gradient in the peritoneal fluid trough the use of different hyperosmotic glucose concentrations $17.36 \%, 2.27 \%$, or $3.86 \%$ [glucose $/ 1$, i.e. 75-214 mmol/l]).

Most commonly, 1.5 to 2.51 of peritoneal solution is manually replaced 4.5 times daily (continuous ambulatory peritoneal dialysis [CAPD]). Nevertheless, by the use of automated devices, it has become possible to perform these exchanges automatically with the use of a so-called cycler (mostly during the 
nighttime period), with, in most coses, one (or two) additional dwell(s) during the daytime period. Advantages of PD are firstly the fact that the treatment can be performed entirely outside the hospital by the patient itself, the absence of a wascular access, and the probability of maintaining residual renal function (RRF) during a longer period compared to $\mathrm{HD}$. It is also general practice to prescribe a less strict fluid restriction compared to $\mathrm{HD}$ due to the continuous removal of water. Disadvantages of the technique are the fact that PD, even when performed on a continuous base, may lead to less clearance of uremic toxins than HD, which may especially be a problem in large patients without RRF. Moreover, the presence of resorption of glucose from the peritoneal fluid (up to $75 \%$ is absorbed durng a 6-hour dwell ${ }^{4}$ may contribute to metabolic abnormalities and to the induction of structural abnormalities in the peritoneum (vide infra). Another common complication of PD is peritonitis, which most often responds well to treallment with antibiatics.

PD has, since the introduction of the basic concept by Moncrief and Popovich in $1976^{5}$, made a tremendous worldwide development. Aboul 15\% of the total number of dialysis patients ( $\$ 28 \%$ in the Netherlands) in industrial countries are managed on PD'. Nevertheless, in some countries like the USA, the relative percentage of patients on renal replacement therapy treated with PD appears to be declining, despite technical advances, such as an increase in patient and technique survival over the past 20 years and despite the fact that $P D$ in general is a less expensive therapy compared to HD. The reason for this phenomenon is not well understood, but is likely to be multifactorial and includes physician attitudes possibly based on interpretation of outcome data from recent surveys (vide supra), reimbursement issues, and difficulties in attaining clearance targets suggested by the recent quality initiatives dialysis outcome and quality improvenent (DOQI).

\section{Determinants of outcome in patients on renal replacement therapy}

Both HD- and PD patients have a greatly increased mortality risk compared to the general population, with reported 5-year survival rates between $35-60 \%{ }^{.}$ The main cause of montality in dialysis patients is cardiovascular disease." Cardiovascular disease in dialysis patients is characterized both by a high prevalence of atherosclerosis, as well as the frequent occurrence of abnormalities of the heart and large arteries (arteriosclerosis). The presence of these factors is strongly related to mortality in dialysis patients. ".11 Moreover, the prevalence of hypertension in dialysis patients is very high. ${ }^{12}$

Many of the cardiovascular abnormalities in dialysis patients appear to be interrelated. In HD patients, abnormalities of the large arteries appear to be strongly related to both left ventricular hypertrophy (LVH) and systalic blood pressure. The former might be explained by an increase in systalic stress to the left ventricle due to a reduction in buffering capacity of the arterial tree, whereas 
the relation between arterial wall abnormalities and systolic hypertension might also be explained by an augmentation of the pulse wave due lo a rapid forward and backward reflection in the stiffer arterial tree." Another important factor in the pathogenesis of both LVH and hypertension in dialysis patients appears to be fluid overload, resulting from the insufficient fluid removal during the dialysis procedure. ${ }^{13}$

Other factors which may be implicated in the increased cardiovascular montalify in dialysis patients are anemia, the presence of an arteriovenous fistula (in the case of HD), abnormalities in the calcium/phosphate metabolism and possibly, the accumulation of uremic toxins. "It should be stressed however, that the great majority of studies towards cardiovascular abnormalities in dialysis patients have been performed in HD patients, whereas only few studies have been performed in patients on PD. Nevertheless, as will be discussed later, the difference in treatment profile between $\mathrm{PD}$ and $\mathrm{HD}$ patients may lead to differences in the cardiovascular risk profile between both patient groups. Therefore, it is not clear whether assaciations observed in HD patients can always be extrapolated to PD patients.

A second factor which is strongly related to outcome in dialysis patients is malnutrition. ${ }^{15}$ It has been suggested that $18-56 \%$ palients of dialysis patients show signs of malnourishment. "The cause of malnutrition in dialysis patients is multifactorial. ${ }^{17,18}$ Firstly, the renal disease itself may lead to a reduction in appelite, possibly due to accumulation of appetite-suppressing factors. ${ }^{19}$ Moreover, mutrients may be lost through the artificial kidney or the peritaneal membrane. ${ }^{18}$ Metabolic acidosis, commonly present in uremic patients, was also found to play a role in the induction of protein breakdown and abnormalities in amino acid metabolism. ${ }^{18,20}$. An important determinant of malnutrition appears to be the presence of an inflammatory state (vide infra), which may lead both to muscle wasting and a reduction in appetite by the influence of cytokines. ${ }^{16}$ Moreover, inflammation may directly lead to a reduction in albumin synthesis and redistribution between intra- and extravascular compartments. ${ }^{2 i}$ The fact that malnutrition in dialysis patients is so multifactorial also explains why the clinical features of malnourishment in dialysis patients may vory from a gradual loss of lean body mass and body fat due to a reduction in protein-energy intake, to a complex picture including severe muscle wasting and a decline in serum albumin levels. ${ }^{18}$

A third important risk factor for mortality is the presence of an inflammatory state in dialysis patients, characterized by an increase in levels of C-reactive protein (CRP). ${ }^{15}$ As holds true for the other risk factors discussed previously, the cause of inflammation in dialysis patients is multifactorial and includes factors such as the dialysis treatment itself properties of the artificial membrane and bacterial contamination in the case of HD, and peritonitis and bioincompatibility of the peritoneal dialysis fluids in case of PD), co-morbid diseases, and the uremic state itself. ${ }^{122}$ An interesting new hypothesis tried to couple these three main determinants of mortality in dialysis patients and the suggested existence 
of a trias of malnutrition, inflammation, and atherosclerosis in dialysis patients (the MA syndrome). ${ }^{23}$

Finally, a fourth important factor related to outcome is dialysis adequacy. It has been showr both in HD and PD patients that removal of small uremic toxins such as urea and creatinine is related 10 outcome. ${ }^{24,25}$ However, as will be discussed later, in PD patients there is still ample discussion regarding the relative importance of delivered treatment dose versus that of the RRF.

\section{Outcome: hemodialysis versus PD patients}

There has been considerable debate in the dialysis community about the rellative merits of HD versus PD. Whereas earlier reports, mainly distilled from large databases or national registries suggested an equal to increased survival of patients on PD compared to HD patients, mainly in the mid-90's studies reported an increased mortality in $\mathrm{PD}$ patients. ${ }^{27}$ However, recent and more detailed analyses did not observe impontant differences in outcome between both treatment modalities ${ }^{t, 28,29}$, although there are templing data which suggest that PD may have a survival benefit ower HD during the first two years of therapy, which gets lost during the past years with even a tendency towards a decrease in survival compared to $\mathrm{HD}^{0,29,30}$ it has been suggested that the superior retention of RRF in PD compared to HD might be responsible for this phemamenon ${ }^{*}$, although there still remains uncertainty whether the decline of RRF actually differs between PD and HD patients. ${ }^{31,32}$ Newertheless, the possible survival benefit attributed to PD patients during the first years after start of dialysis has initiated the so-called stepped-care approach, in which dialysis treatment is initiated with PD and the patient is switched at a later stage (after loss of RRF) to $\mathrm{HD}^{33}$ It should be mentioned that until now, no randomised studies have been performed which compared hard outcome parameters between PD and HD, despite meticulous attempts. Therefore, the possible influence of case-mix on the observed data may not be negligible.

Also not much is known about the influence of $\mathrm{PD}$ on surrogate outcome parameters such as cardiovascular disease and malnutrition. In the following paragraphs, a short overview of the current knowledge with regard to cardiovascular and nutritional state in $\mathrm{PD}$ patients will be presented.

\section{Cardiovascular disease in PD patients}

Althaugh investigations towards the subject of cardiovascular disease is less widespread compared to research on this subject in $\mathrm{HD}$ patients, also in PD patients cardiovascular disease appears to be the predominant cause of death. ${ }^{34,35}$ In agreement with data in HD patients, also in PD patients, the prevalence of $\mathrm{LVH}$ is high and found to be associated with increased mortality. 9.36 Some studies suggested however, that LVH in HD patients may be less severe compared to PD patients ${ }^{37,38}$ and may even decrease during the first years of $\mathrm{PD}{ }^{39,40} \mathrm{On}$ the other hand, the prevalence of $\mathrm{LVH}$ actually was reported to be higher in patients on long-term PD treatment compared to $H D$ 
patients. ${ }^{41,42}$ Whether this phenomenon can be atributed to a loss of rend function in patients on long-term PD has not been established yet.

With regard to the determinants of LVH in PD patients, a paucity of data is present. It has been shown that hypertension plays an important role. ${ }^{3}$ it is likely that overtydration also might play an important role in the pathogenesis of LVH in PD patients ${ }^{42}$, although very few data on fluid balance in PD patients are present. Various authors have suggested a theoretical advance of PD due to the continuous fluid removal and the fact that residual diuresis and RRF is suggested to be better maintained. 45 Still, this does not comply with the huge consumption of antihypertensive agents in $\mathrm{PD}$ patients ${ }^{46} 4$ ? whereas a recent study even suggested that long-term PD patients are actually more overhydrated than HD parients. ${ }^{42}$ Moreaver, it has been reported that in $36 \%$ of PD patients, prior 10 transplantation, wedge and pulmonary artery pressures were elevated. ${ }^{4}$ Of interest, Lameire et al. found a stable plasma volume and blood pressure during the first wo years of PD, in contrast to a parallel increase in plasma valume and blood pressure in patients during the fourth and fitth year of PD. This is in agreement with findings by Menon ef all. "who observed ar improvement in blood pressure control during the first year after stanting PD treatment, followed by a gradual deteritoration during llater stages of treatment. ${ }^{50}$ It would be tempting to speculate that also the deterioration of blood pressure control during later stages of PD would be related to a deterioration in RRF.

Nevertheless, data with regard to the determinants of fluid state, blood pressure and LVH and fluid state in PD patients are limited, whereas with regard to arterial wall abnormalities, no data are present in PD patients.

Concluding, there appears to be a paucity of data with regard to fluid state and cardiovascular structure of PD patients, and on the relation between fluid state, bload pressure, and structural cardiovascular abnormalities in this population.

\section{Malnutrition in PD patients}

In PO patients, the prevalence of malnutrition appears to be thigh, and comparable to HD patients. Although the major causes of malnutrition are probably comparable to those in HD patients ${ }^{18.52}$, there are some factors which are specific for PD patients. Firstly, absorption of glucose from the peritoneal fluid may directly suppress appetite. ${ }^{53}$ Moreover, appetite may also be directly impaired by the presence of fluid in the peritoneal cavity per se. ${ }^{54}$ In contrast to a standard artificial kidney, a (small) amount of proteins may be lost through the peritoneal membrane $( \pm 9 \mathrm{~g} / \mathrm{day}){ }^{55}$

On the other hand, fat mass also appears to increase during the course of PD treatment. ${ }^{56.65}$ Although this may be related to an increased caloric load due to glucose absorption from the dialysate, if is not well known to which degree this phenomenon results in changes in body composition. It has also been suggested that genetic factors could play a role in this aspect, as the polymorphism in uncoupling protein-2, which influences metabolic rate, appeared to be a main determinant for changes in fat mass in PD patients. Although it is not well known whether changes in fat mass bear any relation to outcame ${ }^{62}$, it is of interest that in patients with a very strong increase in body fat mass on PD 
treatment, body cell mass is octually decreased. Moreover, increases in body fat mass may negatively influence the metabolic profile of these patients. 33,64 Concluding, the deferminants and consequences of changes in body composition in PD patients need to be further elucidated.

\section{Intermezzo: How to assess fluid state and body composition in PD patients?}

When assessing fluid state in dialysis patients, it is very important 10 use an accurate marker. Tracer dilution techniques are generally considered to be the most reliable techniques available to measure the magnitude of body water compartments (total body water, extracellular volume, plasma volume). Basically, a known amount of the marker is administered either orally or intravenously. After the time needed for the marker to equilibrate in the respective body water compartment, a plasma sample is taken and from the relation between the amount administered and the plasma concentration, the magnitude of the body water compartment is calculated. Tracer dilution techniques give a very reliable indication of the distribution of the volumes of body water compartments. ${ }^{65,66}$ Nevertheless, a disadvantage of tracer dilution techniques is the relative complexity of the method when used in clinical practice and the need for advanced laboratory facillities.

Bioimpedance techniques would be ideal to use in clinical practice because of their ease in application, operator-independence, and reproducibility. Bioimpedance analysis is based on the conductive properties of biologic tissues. The volume of conductive tissues can be deduced from the measurements of their resistance. Tissues that contain a combination of water and electrolytes are basically more conductive than bone, air-filled spaces, and fat, which cannot be measured directly by this method. ${ }^{67}$ Fairly recently, multifrequency bioimpedance analysis (MF-B $\mid A)$, has been introduced for the use in dialysis patients. ${ }^{\text {s }}$ Due to the use of multiple frequencies, MF-BIA is able to discriminate between intracellular- and extracellular water compartments. Af low frequencies, the cell membrane acts as a condensator and blocks the flow of the current through the cell, whereas at higher frequencies the current flows both through the intra-and extracellular space. 6 .

Despite the fact that MF-BIA was shown to measure body water compantments accurately in non-uremic subjects ${ }^{69}$, there remains uncertainty regarding the reliability of this technique in patients with abnormalities in fluid state, such as dialysis patients. Firstly, MF.BIA predicts the volume of total body water (TBW) and extracellular water (ECW) from a general mixture theory, assuming specific resistance values for ECW and intracellular water. ${ }^{6}$ These values, which are considered as constants by the device, may be directly influenced by abnormalities in fluid state. ${ }^{70.71}$ Moreover, MF-BIA considers the body as three conductive cylinders (arm, leg, and trunk), connected in series. In conductors connected in series, the conductors with the smallest cross-sectional are the extremities) will determine most of the resistance whereas the part with the largest cross-sectional area (trunk) will contribute little to the resistance, despite the fact that it contains a significant amount of body water. ${ }^{72}$ It has been 
suggested that the use of the segmental bioimpedance analysis (BIA), which measures more specific the trunk resistivity, may alleviate the latter problem. ${ }^{2}$ Both MF-BIA and segmental BIA have not yet been evaluated and compared with regard to the assessment of the absolute magnitude of body water compartments in PD patients.

Abnormalities in fluid state may also interfere with nutritional evaluation. The assessment of body composition is notoriously difficult in dialysis patients. It should be stressed that no technique available for daily clinical practice can be view as gold standard in the assessment of body composition. Dual energy $X$-ray absorptiometry (DEXA) is considered to be most closely related to reference techniques as neutron activation analysis. ${ }^{18,73}$ The principle of DEXA resides in the emission of low- and high energy $X$-ray beams, which are attenuated to a different amount by soft tissues and bone mass. ${ }^{74}$ DEXA estimates the body as a three compartment model, i.e. lean bady mass, fat mass, and bone cell mass.

A disadvantage of DEXA is the relatively high cost of the procedure, and the radiation exposure. Therefore, it would be advantageous if more simple markers could also be used in the assessment of body composition. MF-BIA has also been widely used to assess body composition. The calculation of lean body mass (more correctly: fat-free mass) by MF-BIA is derived from the extracellular and intracellular volume estimations, assuming specific densities for both intra- and extracellular volume. ${ }^{75} \mathrm{In}$ addition to the limitations discussed previously, also the assumption of body density may deviate in patients with large abnormalities in fluid state compared to healthy subjects. With anthropometric methods, the sum of skinfold thickness values at four sites can be used to calculate body density. ${ }^{18}$ The method is strongly operator dependent but appeared to correlate surprisingly well with DEXA measurements in renal transplant patients. ${ }^{74}$ Both techniques (MF-BIA and skinfold thickness) assume the body as a two compartment model (i.e fat mass and fat-free mass).

A limitation of all techniques discussed is the fact that lean body mass (or fatfree mass), which comprises the intra- and extracellular volume, may be strongly influenced by the hydration state of the patient. Nevertheless, no data are present on the influence of hydration state on the assessment of body composition in PD patients.

\section{Other factors related to outcome: RRF and peritoneal membrane state in PD patients}

There appear to be other factors influencing outcome, which are specific for PD. In a subanalysis of the CANUSA study ${ }^{25}$, which was the first study in PD patients that assessed the relation between weekly solute clearance and mortality in PD patients, also a relation between both peritoneal membrane characteristics and RRF with outcome was found. ${ }^{80}$ Although this observation has not been unequivocal ${ }^{77,78}$, and in some studies, appeared to be (partly) explained by a relation between transport state and co-morbidity ${ }^{79,80}$, it has been suggested that peritoneal membrane characteristics may directly influence outcome in PD patients, e.g. by contributing to abnormalities in cardiovascular and nutritional state. ${ }^{77,78,82}$ 
With ragard to RRF, in the CANUSA study, the importance of urinary solute clearance on outcome appeared to be even larger than the impartance of attained peritoneal solute clearance. ${ }^{26}$ Indeed, a recently published, large randomised study, could not show a benefit of an increase in peritoneal clearance on survival in PD patients. ${ }^{31}$ Moreover, the reports of a survival benefit of $\mathrm{PD}$ over $\mathrm{HD}$, solely during the first 2 years of therapy, when residual renal function is highest, might corroborate the importance of RRF as an important determinant of outcome in PD patients (see earlier paragraphs).

In the following paragraphs, peritoneal membrane characteristics and RRF will be discussed in more detail, with special emphasis for their potential relevance with regard to cardiowascular and nutritional complications.

\section{Peritoneal transport}

The peritoneal membrane consists principally of three layers, i.e the mesothelium, the interstitial tissue, and the microvessels. Recent insights suggest that the capillary wall is the most important structure for transport of both water and solutes. ${ }^{8}$ Likely, transport of solutes and waters occurs through three different kinds of pores. The percentage of large pares $(250 \mathrm{~A})$, which allows transport of macramolecules from blood to peritoneum, is probably very small, in contrast to so-called small pores $(40-50 \AA)$, which allow transpont of small solutes, and ultrasmall pores $(3-5 \mathrm{~A})$, which exclusively serve for the transport of water through aquaporins.

For the transport of small solutes, diffusion is the most important mechanism. although a small part is also transported by means of convection ("solvent drag") through net water transport. The rate of diffusion is determined by the concentration gradient and the so-called mass transfer area coefficient. The permeability of the peritoneum for small solutes, which appears to be mainly determined by the peritoneal vascular surface area, is most commonly assessed by the peritoneal equilibration test (PET). ${ }^{85,86}$ During this test, the relation between the dialysate-to-plasma (D/P) creatinine ratio is assessed after a 4-hour dwell, which gives on indication of the permeability of the peritoneal membrane for small solutes. On the basis of the results of the PET-test patients are generally classified into fou" "fransport" catagories: i.e. high, high average, low average, and low. When using this classification hawever, it should be nated that peritoneal clearance of small solutes are also dependent upon the drained volume. For example, in pattients with a high D/P creatinine ratio, the clearance of small solutes may be negatively influenced by an impaired ultrafiltration capacity (vide supra). Nevertheless, although the term "low" or "high" transporters are probably misnomers, the term is very commonly used in the literature and therefore will be maintained throughout this thesis.

During PD with standard glucose solutions, the main determinant of fluid removal is the osmotic gradient imposed by the glucose concentration of the peritoneal fluid. Other factors playing a role in the balance between fluid removal and absarption by the peritoneal membrane are the hydrostatic and oncotic pressure in the capillaries and lymphatic absorption. Fluid removal by standard glucose solutions probably occurs through the ultrasmall pores, which 
do not permit passage of glucose, and is therefore capable of inposing an asmotic gradient. Small pores are probably not important in fluid removal, as glucose can pass through these pores without much hindrance (i.e. the reflection coefficient is low). Ultrafiltration increases when the glucose concentration is higher, which is due to the fact that an increase in the peritoneal glucose concentration leads to higher asmatic gradients. ${ }^{84}$ During the dwell time, as glucose is progressively absorbed, the osmotic gradient between the peritoneal Fluid and the capillary gradient gradually diminishes. Patients with a high D/P creatinine ratio generally absorb glucase faster, which leads to a decreased capacity for fluid removal. The main determinant for this loss in ultrafiltration capacity appears to be an increase in vascular surface area. From experimental and clinical data, it is known that a prolonged exposition to glucose, and especially glucose degradation products, may play a rolle in these atterations. Studies in rats have shown diabetiform alterations in peritaneal capillaries after exposure to glucose in contrast to exposure with saline solutions, which may be mediated by trophic factors such as VEGF or TGF- $\beta$ and accumulation of adwanced glycation end-products. ${ }^{87.89}$ This is corroborated in clinical studies, in which the total exposure to peritoneal glucose was found to be related to an increased peritoneal permeability. This was also evident from peritoneal biopsies of long-term PD patients, in whom an increase in vessel density was found $\$ 7,90$ These observations might explain the fact why in many patients ultrafiltration capacity is gradually lost, which is a major reason of technique failure in patients who remain an PD for longer periads of time. ${ }^{8}$ It has been estimated that ultrafiltration failure (characterized by less than $400 \mathrm{ml}$ of fluid removal during a 4 hour diwell with $3.86 \%$ solution or less than $200 \mathrm{ml}$ during a 4 -hour dwell with a $2.27 \%$ solution) is present in $14-23 \%$ of PD patients ${ }^{86.91}$, with an increasing prevalence during the years. Indeed, athough other factors, such as an increase in lymphatic absorption ${ }^{8,91}$ and impaired channel-mediated water transport ${ }^{92}$ may also play a rolle in this aspect, the presence of a "high" transport state is probably the most important cause of ultrafiltration failure in PD patients. ${ }^{84,86,89,93}$ Nevertheless, the relation between peritoneal ultrafiltration capacity and peritoneal transpart state does not appear to be linear. ${ }^{86}$

Summarizing, changes in peritoneal membrane function are present in a substantial number of PD patients. The potential role ol these alterations in the pathogenesis of cardiovascular and nutritional state will be discussed later in this chapter.

\section{Residual renal function}

Studies towards the effect of treatment adequacy on outcome in PD patients have consistently shown an important effect of RRF on outcome. Recent studies even suggest that RRF might be more important than peritoneal clearance in terms of autcome. ${ }^{26}$ The reason for this phenomenon is not clear and, as discussed below, might rise questions beyond the additional effect of solute clearance alone. In most patients, RRF declines gradually during the course of treatment, which may be influenced by factors such as concomitant 
inflammation and expasition to nephrotoxic substances such as aminoglycoside antibiotics or contrast media.

\section{What could be the reason behind the influence of peritoneal transport function and RRF on outcome?}

Peritoneal transport function may have an effect on outcome through an effect on solute clearance, fluid removal and glucose absorption. ${ }^{81.82}$ The effect of peritoneal transport function on solute clearance is not straightforward. Whereas small solute clearance by diffusion would be expected to be higher in high transporters, the amount removed by convection may be actually less. ${ }^{76}$ The net balance on solute clearance is therefore not always easy to predict. ${ }^{84}$

As discussed previously, glucose is used to maintain an osmotic gradient beween the dialysate and blood to prowide ultrafiltation. The rate of glucose absorption in PD is determined by the permeability of the peritoneal membrane in combination with the dwell time and glucose concentration of the dialysate. In patients with a higher peritoneal transport rate, an increased glucase absorption may result, through a decline in the osmotic gradient, in ultrafiltration failure causing hypervolemia. In HD patients, hypervolemia was found to be an important factor for the development of hypertension, the major risk factor for LVH. $^{12,13,96}$ it has therefore been suggested ${ }^{95}$ that the relation between peritoneal transport state and outcome might be parlly related to overhydration. Nevertheless, there are no studies in PD patients, which assessed the relation between peritoneal membrane characteristics and cardiavascular staie using detailed markers.

With regard to mutritional state, the increased transport capacity of the peritoneal membrane results not only in enhanced systemic glucose absorption from the dialysate, but also in an increased peritoneal amino acid and albumin los ${ }^{95.97}$, which might, as discussed previously, on one hand lead to an increase in body fat mass, and on the other hand, to an impairment in appetite, as shown in experimental studies. 53 Until now, few studies have focused on the relation between nutritional state with peritoneal transport characteristics and RRF in PD patients. ${ }^{98,99}$ Im those studies however, controwersial data on the relation between peritoneal transport characteristics and nutritional state were reparted, except for the consistent inverse relation between peritoneal transport rate and serum albumin. 95,97,99,100 Nevertheless, studies performed lowards the relation between peritoneal transport and nutritional state were either cross-sectional in design or did not assess body composition and nutritional state in great detail.

The influence of RRF on outcome might be explained by the effect of solute removal. ${ }^{101}$ Still, a recent randomized study which increased peritoneal solute clearance failed to show an effect on outcome, suggesting that RRF may also exent other effects beyond solute clearance. 83 Firstly, it would appear logical, although detailed data are lacking, that fluid state is better maintained in those patients with additional RRF, which might also influence structural cardiovascular 
abnormalities. Moreover, the presence of RRF may also influence nutritional state, because less glucose is needed to maintain an optimal fluid state. ${ }^{8}$

Nevertheless, it should not be forgotten that the relation between peritoneal transport rate as well as RRF and outcome might also be influenced by other factors. Firstly, the presence of an inflammatory state or co-morbid disease, which was directly related to outcome in many studies, may have a direct effect on bath peritoneal membrane characteristics and on the decrease of the RRF. In patients with co-morbid disease at the start of dialysis therapy a higher peritoneal permeability for small solutes was already found to exist, compared with patients without co-morbid disease of the stant of dialysis therapy ${ }^{102}$. Although another study anly observed a relation between peritoneal transport characteristics and mortality in those patients with significant co-morbidity during $\mathrm{PD}$ treatment. ${ }^{80}$ Moreover, in patients in whom the $\mathrm{D} / \mathrm{P}$ ratio increased during the first years of dialysis ${ }^{94}$, RRF declined faster and levels of CRP were higher, which would suggest that inflammatory factors might influence both peritoneal transport characteristics and RRF.

Nevertheles, in general, the relation between both peritoneal transport rate and RRF with outcome parameters appears to be well established. Moreover, from a theoretical point of view, if is likely that both parameters may influence important surrogate outcome markers such as cardiavascular and nutritional stote.

If can be hypothesized that patients with higher transport state and those with loss of RRF are firstly more prone for overlyydration due to a reduced daily fluid removall, but also for abnormalities in nutritional state due to the higher peritoneal glucose concentrations needed to maintain fluid state. ${ }^{103}$ Nevertheless, there are still few studies which assessed the relation with peritoneal membrone characteristics and RRF with cardiovascular and nutritional markers.

\section{Icodextrin}

Few data exist with regard to fluid state in PD patients, there are ample arguments for a disturbance in volume state, especially in patients with ultrafiltration failure and loss of RRF. Although ultrafiltration may be improved with the use of high glucose concentrations in the peritoneal fluid, this also increases the inducing metabolic and nutritional abnormalities through glucose absorption. ${ }^{103}$ Icodextrin $7.5 \%$ is a glucose polymer produced by hydrolysis of starch $^{103}$, which is slowly absorbed through the peritoneal membrane and degraded to disaccharides and eventually glucose. Icadextrin, a solution isoosmatic with plasma, mainly exerts its effect on ultrafittration through an increase in oncotic pressure. Although the oncotic gradient imposed by icodextrin is relatively less than the osmotic gradient of high perilaneal glucose concentrations $^{84}$, its absolute effect on ultrafiltration is equivalent to that of a $3.86 \%$ glucose solution, and 3.5-5.5 times higher compared to a $1.36 \%$ solution, because ultrafiltration is more prolonged due to the slow absorbance of the glucose polymer. ${ }^{103.104}$ Therefore, icodextrin appears to be especially useful during long dwells. ${ }^{103}$ Side effects with the use of icodextrin are scarce 
and mainly include skin eruptions, which in most cases dissolve after freament is discontinued. ${ }^{\text {lus }}$ Occasionally, the occurrence of sterile peritonitis has been reported. ${ }^{106}$ Moreover, elevations of maltose and other oligosaccharides hove been reported. Although these findings do not coincide with any clinical symptomatology and return to baseline after cessation of treatment, icadextrin is advocated for use once daily. ${ }^{103}$

Despite the fact that there is ample evidence that icodextrin augments peritoneal ultrafiltration $107-199$, studies towards the effect of icadextrin on fluid state and blood pressure in PD patients are scarce. In the single published study, including patients on automated PD, which assessed the effect of icodextrin on fluid state in more detail, a beneficial effect of icadextrin on fluid state and blood pressure was observed. 109 Nevertheless, this study did not use a randomized design, did not apply reference techniques to assess volume state and did not assess the effect of icodextrin on cardiac structure.

Moreover, it is not well known which patients would benefit most of a potential effect of icodextrin. Although its effect appears to be most pronounced in potients with high peritoneal small solute clearance" 10 its effect on actual volume state and cardiovascular structure has not been studied in relation to peritoneal transporit state.

Summarizing, cardiovascular and nutritional abnormalities appear to be widespread in PD patients. In HD patients, if has been shown that abnormalities in fluid staie likely have a strong effect on the hemodynamic state Nevertheless, there appears to be a paucity of data with regard to the prevalence, determinants, and consequences of abnormalities in fluid state in the PD population. This is further hampered by the fact that fluid state is notoriously difficult to assess in a dialysis population.

Nevertheless, indirect evidence extrapolated from the literature suggests that in PD patients both residual renal function and peritoneal transport rate may be related both to cardiovascular and to nutritional abnormalities. It has been suggested, but not shown, that both an increased permeability of the peritoneal membirane for small solutes may lead to less effective fluid removal and eventually overhydration, left ventricular hypertrophy, and death. On the ather hand, the increased glucose absorption in patients with a more permeable membrane may on one hand lead to an increase in body fat mass, bup on the other hand to a reduction in lean body mass due to an impairment of appetite.

Therefore, there appears to be a need for glucose-free solutions in the maintenance of fluid balance in PD patients. The glucose polymer, icodextrin, exerts its effect on peritoneal ultrafiltration through the application of an oncatic gradient and was shown to be as effective as hypertomic glucose solutions in evoking peritoneal ultrafiltration. However, as yet there are no randomized studies towards the effect of icodextrin on fluid state and cardiovascular end. points in PD patients, nor is it entirely known, which patients would benefit most from administration of icodextrin. 
The hypotheses of the present thesis are that:

1. Cardiavascular abnarmalities are widely present in PD patients.

2. Cardiovascular abnormalities are related to abnormalities in fluid state.

3. Peritoneal transport and RRF are related to cardiowascular structure and abnormalities in fluid state.

4. Peritoneal transport and peritoneal glucose prescription are related to body composition.

5. The use of icadextrin results in an improvement in fluid state and cardiovascular abnormalities.

6. The effect of icodextrin is related to the transport state of the patient.

In chapter 2, arterial wall properties are compared between patients on renal replacement therapy and patients with different stages of renal disease.

In chapter 3, different methads to assess fluid state in PD patients are compared.

In chapter 4, the relation between fivid state, blood pressure, and cardiovascular abnormalities are assessed, whereas fluid state in PD patients are compared with renal transplant patients with stable renal function.

In chapter 5 , the rellation between peritomeal fransport state and RRF with fluid state and cardiac structure are assessed.

In chapter 6 , the influence of fluid state on different techniques to assess body composition are assessed.

In chapter 7 , the relation between body composition and peritoneal membrane transport state are studied.

In chapter 8, the effect of the prescription of icodiextrin on fluid state and cardiovascular struciure are evaluated.

In chapter 9, using the experience from the previous chapters cut-off values for MF-BIA in the assessment of fluid state are explored.

In chapter 10, in the general discussion, an overview will be presented of the findings of the thesis.

Chapter 11 presents the summary and conclusions of this thesis.

\section{Rationale for patient participation in the various chapters}

II should be mentioned that the number of patients included in the various chapters vary slightly. This is due to the fact that the data for chapters $2,3,4$, and 6 were analysed earlier in the stage of the thesis. This was also done because the results presented in these chapters were used to assess whether less complicated techniques (such as MF-BIA and anthropometry) cauld replace more elaborate and expensive techniques, such as fracer dilution methods and DEXA. All continious ambulatory PD (CAPD) patients analysed in chapters 5 and 7 also participated in the earlier chapters. In these observational studies only CAPD patients were analysed because differences in glucose absorption and sodium and fluid removal between automated PD (chronic cyclic PD [CCPD]) and CAPD may heavily influence fluid and nutritional state. For these chapters, 7 additional CAPD patients were included. In the randamized study presented in 
24 Chopter

chapter 8, all patients who participated in the chapters 5 and 7, and whom completed the longitudinal period, were included. Additional CAPD and CCPD patients were recruited to increase the pawer of the study.

In chapter 9, all CAPD patients who were described in the chopters 5 and 7 and the CCPD patients who were described in the chapters 3,4 and 6 were included, if plasma volume measurements were available. 


\section{References}

1. Smith HW. From fish to philosopher. Little, Brown. Boston, 1953

2. Natochin $\mathrm{Y}$. Evolutionary aspects of renal fundion. Kidney Int 1996; 49: $1539-1542$

3. Owen WJ, Pereira BJG, Sayegh MH (eds). Dialysis and Transplantation. WB Sanders Company. Phitadelphia 2000

4. Heimburger $O$, Waniewski J, Werynski $A$, Lindholm B. A quantitative description of solute and fluid transport during peritoneal dialysis. Kidney Int 1992; 41 : $1320-1332$

5. Popovich RP, Moncrief JW, Decherd JB. Pyle WK. The definition of a novel partable/wearable equilibrium peritoneal dialysis technique. A51O Trans 1976; 5: $64 A_{4}$

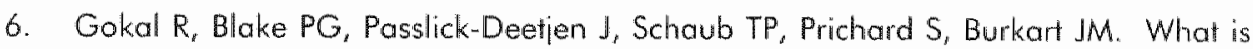
the evidence that peritoneal dialysis is underutilized as an ESRD therapy? Semin Dial $2002 ; 15: 149-161$

7. NKF-K/DOQI Clinical Practice Guidelines for peritoneal dialysis Adequacy: update 2000. Am I Kidney Dis. 2001; 37(Suppl 1): S65-S136.

8. Davies SJ, Phillips L, Griffiths. AM, Russell LH, Naish PF, Russell Gl. What really happens to people on long-term peritoneal dialysis? Kidney lint 1998; 54: $2207-2217$

9. Foley RN, Parfrey PS, Sarnak MI. Epidemiology of cardiovascular disease in chronic renal disease. I Anm Soc Nephrol 1998; 9(Suppl 12): Si6-23

10. Kooman JP, Leunissen KM. Cardiovascular aspects in renal disease. Curr Opin Nephrol Hypertens 1993; 2: 791-797

11. Meeus F, Kourilsky O, Guerin AP, Gaudry C, Marchails S., London GM. Pathophysiology of cardiovascular disease in hemodialysis patients. Kidney Int 2000; 76: $\$ 140-5147$

12. Luik AJ, Kooman JP, Leunissen KM. Hypertension in haemodialysis potients: is it only hypervoldemia? Nephral Dial Transplant 1997; 12: 1557.1560

13. Kooman JP, Leunissen KM, Luik AJ. Salt and hypertension in end-stage renal disease. Blood Purif 1998; 16:301-311

14. Locatelli F, Bommer J, London GM, Martin-Malo A, Wanner C, Yaqoob M, Zoccali C. Cardiovascular disease determinants in chronic renal failure: clinical approach and treatment. Nephrol Dial Transplant 2001; 16:459-468

15. Qureshi AR, Alvestrand $A$, Divino-Filho JC, Gutherrez $A$, Heimburger $O$, Lindholm $B$, Bergstrom J. Inflammation, malinutrition, and cardiac disease as predictors of mortality in hemodialysis polients. I Am Soc Nephrol 2002; 13 (\$1): \$28. \$36

16. Stenvinkel $P$, Lindhoim $B$. Heimburger $O$. New strategies for management of malnutrition in peritoneal dialysis patients. Perit Dial Int 2000; 20: 271-275

17. Kooman JP, Leunissen KM. Malnutrition in patients with end-stage renal disease: diagnosis, pathophysiology and treatment. Neth J Med 1997; 50(3): 120-132 
18. Locatelli F, Fouque D, Heimburger O, Drueke TB, Cannata-Andia JB, Harl WH, Ritz E. Nutritional strotus in dialysis patients: a European consensus. Nephrol Dial Transplant 2002; 17: 563-572

19. Anderstam B, Mamoun AH, Sodersten P, Bergstrom J. Middle-sized molecule fractions isolated from uremic uttrafiltrate and nomal urine inhibit ingestive behavior in the rat. I A,rm Soc Nephrol 1996; 7: 2453-2460

20. Koomon JP, Deulz NE, Ziilmans P, wan den Wall Bake $A_{r}$ Gerlag PG, van Hooff JP, Leunissen $\mathrm{KM}$. The influence of bicarbonate supplementation on plasma levels of branched-chain amino acids in haemadialysis patients with metabolic acidosis. Nephrol Dial Transplant 1997; $12: 2397-2401$

21. Yeun JY, Kaysen GA. Factors influencing serum albumin in dialysis patients. Am I Kidney Dis 1998; 32(6 S4): S118-\$125

22. Kaysen GA. The microinflammatory state in uremia: causes and potential consequences. J Am Soc Nephrol 2001; 12: 1549-1557

23. Stenvirkel $P$, Heimburger $O$, Paultre F, Diczfalusy U, Wang $T$, Berglund $L$. lagestrand T. Strong association between malnutrition, irflammation, and atherosclerosis in chronic renal failure. Kidney Int 1999; 55: 1899-1911

24. Gotch FA, Sargent JA. A mechanistic analysis of the National Cooperative Dialysis Study (NCDS). Kidney Int 1985; 28: 526-534

25. Canada-USA (CANUSA) Peritoneal Dialysis Sfudy Group. Adequacy of dialysis and nutrition in continuous peritoneal dialysis; association with clinical outcomes. J Am Soc Nephrol 1996; 7: 198-207

26. Bargman JM, Thorpe KE, Churchill DN; CANUSA Periloneal Dialysis Study Group. Relative contribution of residual renal function and peritoneal clearance to adequacy of dialysis: a reanclysis of the CANUSA study. I Am Soc Nephrol 2001; 12: $2158-2162$

27. Bloembergen WE, Port FK, Manger EA, Wolfe RA. A comparison of mortality between patients treated with hemodialysis and peritoneal dialysis. I Am Soc Nephrol 1995; 6: 177-183

28. Keshaviah $P$, Callins AJ, Ma JZ, Churchill DN, Thorpe KE Survival comparison between hemodialysis and peritoneal dialysis based on motched doses of delivered therapy. I Am Soc Nephrol 2002; 13 Suppl 1: S48-52

29. Schaubel DE, Morrison HI, Fenton SS. Comparing montality rates on CAPD/CCPD and hemodialysis. The Canadian experience: fact or fiction? Perit Dial Int 1998; 18(5): $478-484$

30. Foley RN, Paifrey PS, Harnett JD, Kent GM, O'Dea R, Murray DC, Barre PE. Mode of dialysis therapy and mortality in end-stage renal disease. 1 Am Soc Nephrol 1998; 9: $267-76$

31. Jager KJ, Merkus MP, Boeschoten EW, Dekker FW, Tijssen JG, Krediet RT; The Necosad Study Group. What happens to patients starting diclysis in the Netherlonds? Neth J Med 2001; 58: 163-173

32. McKane W, Chandna SM, Tattersall JE, Greenwood RN, Farrington K. Identical decline of residual renal function in high-flux biocompatible hemodialysis and CAPD Kidney Int 2002; 61:256-265 
33. Van Biesen W, Vanhaider RC, Veys N, Dhondt A, Lameire NH. An evaluation of on integrative care approach for end-stage renal disease patients. J Am Soc Nephrol $2000 ; 11: 116-125$

34. Lameïre $\mathrm{N}_{x}$ Vanholder RC, Van Loo A, Lambert MC, Vijt D, Van Bockstaele L,

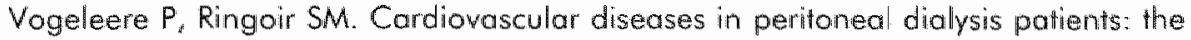
size of the problem. Kidney Int 1996; $56: 528-36$

35. Gokal R, Jakubowski C, King J, Hunt L, Bogle S, Biaillod R, Marsh F, Ogg C, Oliver D. Ward $M$, ef all. Outcome in patients on continuous ambulatory peritoneal dialysis and hoemodialysis: 4-year analysis of a prospective multicentre study. Lancet 1987 14; 2: 1105.1109

36. Silaruks $S$, Sirivongs $D$, Chunlertrith $D$. Left ventricular hypertrophy and dinical outcome in CAPD patients. Perit Dial Int 2000; 20:461-466

37. Foley RN, Parfrey PS, Kent GM, Harnett JD, Murray DC, Barre PE. Long-term evolution of cardiomyopathy in dialysis patients. Kidney lnt 1998; 54:1720-1725

38. Sezer S, Ozdemir N, Arat Z, Guz G, Sengul S, Akman B, Haberal A, Turan M, Haberal $M$. What hoppens after conversion of treatment to continuous ambulatory peritoneal dialysis fram hemodialysis? Adv Perit Dial 2000; 16:177-181

39. Levin A, Singer J. Thompson CR, Ross H, Lewis M.Prevalent left ventricular hypertrophy in the predialysis population: identifying opportunities for intervention. Am J Kidney Dis 1996: 27: 347-354

40. Leenen FH, Smith DL, Khanna R, Oreopoulos DG. Changes in left ventricular hypertrophy and function in hypertensive patients started on continuous ambulatory peritoneal dialysis. Am Heart J 1985; $110(1$ Pt 1): 102-106

41. Takeda K, Nakamoto M, Hirakata $H$, Baba M, Kubo M, Fujishima M. Disadvantage of long-tern CAPD for preserving cardiac performance: an echacardiagraphic study. Am I Kidney Dis 1998; 32: 482-487

42. Enia G, Mallamaci F, Benedetto FA, Panuccio V, Parlongo S, Cutrupi S, Giacone G, Cottini E, Tripepi G, Malatino LS, Zoccali C. Long-term CAPD patients are volume expanded and display more severe left ventricular hypertrophy than haemodialysis patients Nephrol. Dial Transplant 2001: 16: 1459-1464

43. Hannett ID, Parfrey PS, Griffiths SM, Gault MH, Barre P, Guttmann RD. Left ventricular hypertrophy in end-stage renal disease. Nephron 1988; 48: 107.115

44. Burkant JM. What is the evidence that peritoneal dialysis is underutilized as an ESRD therapy? Semin Dial 2002; 16:157.161

45. Cannato JB, Isles CG, Briggs JD, Junor BJR. Comparison of blood pressure control during hemadialysis and CAPD. Dial Transplant 1986; 15:675-679

46. Cocchi R, Esposti ED, Fobbri A, Lucatello A, Sturani A, Quarello F, Boero R, Bruno $M$, Dadone C, Favazza A, Scanziani R, Tommasi A, Giangrande A. Prevalence of hypertension in patients on peritoneal dialysis: results of an Italian multicentre study. Nephrol Dial Transplant 1999; 14:1536-1540

47. Velasquez MT, Lew SQ, von Albertini B, Mishkin GJ, Bosch JP. Control of hypertension is better during hemodialysis than during continuous ambulatory peritoneal dialysis in ESRD patients. Clin Nephrol 1997; 48: $341-3.45$

48. Issad B, Mouquet C, Bitker MO, Allouache M, Boumelou A, Rottembourg J, Jacobs C. Is overtyydration in CAPD pattients a contraindication to renal tronsplantation? Adv Perit Dial 1994; 10:68-72 
49. Lameire N, Van Biesen W.Importance of bload pressure and wolume contral in perifoneal dialysis patients. Perit Dial Int 2001; 21: 206-211

50. Menon MK, Waimark DM, Borgman JM, Vas SI, Oreopoulos DG.Long-tem blood pressure control in a cohort of peritoneal dialysis patients and its association with residual renal function. Nephrol Dial Transplant 2001; 16: 2207.2213

51. Stenvinkel $P$, Lindholm B, Heimburger $O$. New strategies for management of malnutrition in peritoneal dialysis patients. Perit Dial int 2000; 20:271.275

52. Bergstrom J, Lindholm B. Nutrition and adequacy of dialysis. How do hemodialysis and CAPD compare? Kidney Int Suppl 1993; 40:539-50

53. Zheng ZH, Sederholm F, Anderstam B, Qureshi AR, Wong T, Sodersten P, Bergstrom J. Lindholm B. Acute effects of pertioneal dialysis sialutions an appetite in non-uremic rats. Kidney Int 2001; 60: 2392-2398

54. Bergstrom J. Anorexia in dialysis patients. Semin Nephrol 1996; 16:222-229

55. Blumenkrantz MJ, Gahl GM, Kopple JD, Kandar AV, Jones MR, Kessel M, Coburn IW. Protein losses during peritoneal dialysis. Kidney Int 1981; 19:593-602

56. Jager KJ, Merkus MP, Huisman RM, Boeschoten EW, Dekker FW, Korevaar IC, Tijssen $J G$, Krediet RT. Wutritional status aver time in hemodialysis and peritoneal dialysis. NECOSAD Study Growp. J Am Soc Nephrol 2001; 12:1272 1279

57. Nordfors L, Heimburger $O$, Lonnqvist $F$, Lindholm $B$, Helmrich J, Schalling $M$, Stenvinkel P. Fat lissue accumulation during peritoneal dialysis is associated with a polymorphism in uncoupling protein 2. Kidney Int 2000; 57: 1713-1719

58. Jally $S$, Chatatalsingh $C$, Bargman J, Vas $S$, Chu M, Oreopoulas DG. Excessive weight gain during peritoneal dialysis. In \ Artif Organs 2001;24: 197-202

59. Fernstrom A, Hylander B, Moritz A, Jacabsson H, Rossner S. Increase of intraabdominal fat in patients treated with continuous ambulatory peritoneal dialysis. Perit Dial lnt 1998; 18: 166-171

60. Soreide R, Dracup B, Svarstad E, Iversen BM. Increased tatal body fat during PD treatment. Adv Perit Dial 1992; 8: 173-176

61. Briganti $M$, Emiliani $G$, Montanari $A$, Cocchi $R$, Bondi $A$, Fusarali M. Longitudinal assessment of body composition in CAPD patients using bioelectric impedance analysis. A comparison with hemodialysis patients. ASAlO J 1995: 41: M725-727

62. Hakim RM, Lowrie E. Obesity and mortality in ESRD. Is it good to be fat? Kidney Int $1999: 55: 1580-1581$

63. Thomas ME, Moorhead JF. Lipids in CAPD: a review. Contrib Nephrol 1990; 85: 92-99

64. Boeschoten EW, Struijk DG, Krediet RT, Arisz L. Metabolic disturbances in CAPD patients. Adv Perit Dial 1991; 7: 243-246

65. Van Kreel BK. Van der Vegt F, Meers M. Determination of total body water by a simple and rapid mass spectrometric method. J Mass Spectrom 1996; 31: 108-111

66. Van Kreel BK. An impraved bromide assay for the estimation of extracellular water volume by capillary gas chromatography. Clin Chim Acto 1994; 231: 117-128

67. Matthie J, Zarowitz B, De Lorenzo A, Andreoli A, Katzarski K, Pan G, Withers PJ. Analytic assessment of the various bioimpedance methods used to estimate body water. Appl Physiol 1998; 84: 1801-1816 
68. Katzarski $K$, Charra B, Laurent $G$, Lopot F, Diwno-Filho JC, Nisell J, Bergstrom J. Multifrequency biompedance in assessment of dry weight in haemodialysis. Nephrol Dial Transplant. 1996; 11 (S2): $\$ 20-23$

69. Hannan WJ, Cowen SJ, Plester CE, Fearon KCH, DeBeau A. Comparison of bioimpedance spectroscopy and multi-frequency bio-impedance analysis for the assessment of extracellular and total body water in surgical patients. Clinical Science 1995; 89: 651-658

70. Di lorio $B R_{n}$ Terracciano V, Bellizzi V. Bioelectrical impedance measurement: errors and artifacts. I Ren Nutr 1999; 9: 192-197

71. Ward LC, Elia M, Cornish BH. Potential errors in the application of mixture theory to multifrequency bioelectrical impedance analysis. Physiol Meas. 1998; 19:53-60

72. Zhu $F$, Schneditz D, Kaufmam AM, Levin NW. Estimation of bady fluid changes during peritoneal dialysis by segmental bioimpedance analysis. Kidney Int 2000 ; 57: 299.306

73. Kerr PG, Strauss BJG, Atkins RC. Assessment of the nutritiunal state of dialysis patients. Blood Purif 1996; 14:382-387

74. van den Ham EC, Kooman JP, Christiaans MH, Nieman FH, Van Kreel BK, Heidendal GA, Van Hooff JP. Body composition in renal transplant patients: bioimpedance analysis compared to isotope dilution, dual energy X-ray absorptiometry, and anthropometry. J Am Soc Nephrol 1999; 10:1067-1079

75. de Lorenzo A, Andreali A, Matthie J, Withers P. Predicting body cell mass with bioimpedance by using theoretical methods: a technological review. J Appl Physiol 1997:82: 1542-1558

76. Churchill DN, Thorpe KE, Nolph KD, Keshaviah PR, Oreopaulas DG, Page D. Increased peritoneal membrane transport is associated with decreased paltient and technique survival for continuous peritoneal dialysis patients. The Canada.USA (CANUSA) Peritoneal Dialysis Study Group. J Am Soc Nephral 1998; 9: 1285-1292

77. Diaz-Buxa JA, Lowrie $E G$, Lew $N L$, Zhang $S M$, Zhu $X$, Lazarus JM. Associates of mortality among peritoneal dialysis patients with special reference to peritoneal transport rates and solute clearance. Am J Kidney Dis 1999:33:523-534

78. Bloke $P G$, Stojimirovic B. Peritoneal dialysis adequacy and risk of death. Curr Opir Nephrol Hypertens 2001; 10: 749-754.

79. Park HC, Kang SW, Choi K H, Ha S K, Han D S, Lee H Y. Clinical outcome in continuaus ambulatory peritoneal dialysis patients is not influenced by high peritoneal transport status. Perit Diall int 2001; 2 ( (S3): S80-85

80. Chung $\mathrm{SH}_{*}$ Chu WS, Lee HA, Kim $Y H$, Lee 1S, Lindholm B, Lee HB. Peritoneal transport characteristics, comorbid diseases and survival in CAPD patients. Perit Dial Int 2000; $20: 541-547$

81. Blake PG. What is the problem with high transporters? Perit Dial Int 1997; 17: 317.320

82. Heaf J. Pathogenic effects of a high peritoneal transport rate. Semin Dial 2000; 13 : 188-193

83. Paniagua $R_{\text {r }}$ Amato D, Vonesh E, Correa-Rotter R, Ramos A, Moran J, Mujais S. Effects of Increased Peritoneal Clearances on Martality Rotes in Peritoneal Dialysis: ADEMEX, a Prospective, Randomized, Controlled Trial. J Am Soc Nephrol 2002; 13: $1307-1320$ 
$30 \mid$ Chapter 1

84. Krediet RT, Lindholm B, Rippe B.Pothaphysialogy of pertaneal membrane foilure. Perif Dial int 2000; 20 (S4): $522-42$

85. Twardowski ZJ, Nolph KD, Khanna R. Peritoned equilibration test. Perit Dial Int 1987; 7: 138-147

86. Davies S.Monitoring of lang-term peritoneal membrane function. Perif Dial Int $2001: 21: 225-230$

87. Davies \$J, Phillips L, Naish PF, Russell GI. Peritaneal glucose exposure and changes in membrane solute transport with time on peritoned dialysis. I Am Soc Nephrol $2001 ; 12: 1046-1051$

88. Krediet RT, Zweers MM, van der Wal AC, Struilk DG. Neoangiogenesis in the peritoneal membrane. Perit Dial Int 2000; 20 (S2): 519.525

89. De Vriese A S, Mortier S, Lameire N H. What happens to the peritoneal membrane in long-term peritoneal dialysis? Perit Dial Int 2001; 21 (S3): $59-518$

90. Mateissen MA, van der Wol AC, Hendriks PM, Zweers MM, Mulder J, Struilk DG. Krediet RT. Vascular and interstitial changes in the peritoneum of CAPD patients with peritoneal sclerosis. Perit Dial Int 1999; 19:517.525

91. Ho-dac-Pannekeet MM, Atasever B, Struilk DG, Krediel RT. Analysis of ultrafiltration failure in peritoneal dialysis pattients by means of silandard peritoneal permeability analysis. Perit Dial int 1997; 17: 144-150

92. Fusshaller $A$, zur Nieden S, Grabensee B, Plum 1. Peritoneal fluid and solute transport: influence of treatment time, peritoneal dialysis modality, and peritonitis incidence. J Am Soc Nephrol 2002; 13: 1055-1060

93. Heimburger O, Waniewski J, Werynski A, Tranaeus A, Lindholm B. Peritoneal transport in CAPD patients with permanent loss of ultrafiltration capacity. Kidney Int 1990; 38: 495-506

94. Chung SH, Heimburger O Stenvinkel P, Bergstram J, Lindholm B. Association between inflammation and changes in residual renal function and peritoneal transport rate during the first year of dialysis. Nephrol Dial Transplant 2001; 16: 2240-2245

95. Wang T, Heimburger O, Warviewski J, Bergstrom J, Lindholm B. Increased peritoneal permeability is assaciated with decreased fluid and small-solute removal and higher mortality in CAPD patients. Nephrol Dial Transplant 1998; 13: 1242-1249

96. Ozkahya M, Ok E, Cirit M, Aydin S, Akcicek F, Basci A, Dorhout Mees EJ. Regression of left ventricular hypertrophy in haemodialysis patients by wilrafiltration and reduced salt intake without anthypertensive drugs. Nephrol Dial Transplant 1998; 13: 1489.1493

97. Kagan A, Bar-Khayim $Y$. Role of peritoneal loss of albumin in the hypoalbuminemia of continuous ambulatiory peritoneal dialysis patients: relationship to peritoneal tronsport of solutes. Nephron 1995; 71:314-320

98. Szeto CC, Low MC, Wong TY, Leung CB, Li PK. Peritoneal transport status correlates with morbidity but not longitudinal change of nutritional stalus of continuous ambulatory peritoneal dialysis patients: a 2-year prospective study. Am J Kidney Dis $2001 ; 37: 329-336$ 
99. Kang DH, Yoon KI, Choi KB, Lee R, Lee HY, Han DS, Cho EY, Lee JH. Relationship of peritoneal membrane transpart characteristics to the nutritional status in CAPD patients Nephrol. Dial Transplant 1999; 14:1715-1722

100. Harty JC, Boulton H. Venning MC, Gokal R. Is peritoneal permeability an adverse risk foctor for malnutrition in CAPD patients? Miner Electrolyte Metab 1996; $22: 97$ 101

101. Aslam N, Bernardini J, Fried L, Piraino B. Peritoneal dialysis clearance can replace residual renal function. Perit Dial Int 2001; 21:263-268

102. Davies SJ, Phillips L. Naish PF, Russell Gl. Quantifying comorbidity in peritoneal dialysis patients and its relationship to other predictors of survival. Nephrol Dial Transplant 2002; 17: 1085-1092

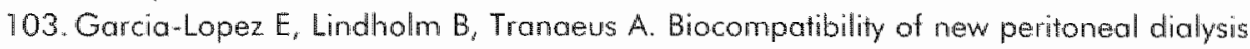
solutions: clinical experience. Perit Dial Int 2000; 20 (Suppl 5): S48-S56

104. Mistry CD, Gokal R, Peers E. A randomized multicenter dinical trial comparing isosmolar icodextrin with hyperosmolar glucose solutions in CAPD. MIDAS Study Group. Multicenter Investigation of Icodextrin in Ambulatory Peritoneal Dialysis. Kidney Int 1994; $46: 496-503$

105. Divino Fiho JC. Allergic reactions to icodextrin in patients with renal failure. Lancet 2000; $355: 1364 \times 1365$

106. Williams PF, Foggensteiner L. Sterile/Allergic pertonitis with icodextrin in CAPD patients. Perit Dial Int 2002: 22: 89.90

107. Posthuma N, ter Wee PM, Donker AJ, Oe PL, Peers. EM, Verbrugh HA. Assessment of the effectiveness, safety, and biocompatibility of icodextrin in aulomalted peritoneal dialysis. The Dextrin in APD in Amsterdam (DIANA) Group. Perit Dial Int 2000; 20 (Suppl 2): $\$ 106-5113$

108. Plum d, Gentile S, Verger C, Brunkhorst $R$, Bahner U, Faller B, Peeters J, Freida P, Struilk DG, Krediet RT, Grabensee B, Tranaeus A, Filho JC. Efficacy and safety of a $7.5 \%$ icodextrin peritoneal dialysis solution in patients treated with autlomated peritoneal dialysis. Am J Kidney Dis 2002; 39:862-871

109. Woodrow G, Oldroyd B, Stables G, Gibson J, Turney JH, Brownjohn AM. Effects of icodextrin in automated peritoneal dialysis on blood pressure and bioelectrical impedance analysis. Nephrol Dial Transplant 2000; 15:862-866

110. Arauja Teixeira MR, Pecails-Filho RF, Romao Junion JE, Sabbaga E, Marcondes MM, Abensur $H$. The relationship between ultrafiltrate volume with icodextrin and peritoneal transport pattern according to the peritoneal equilibration test. Perit Dial Int 2002; $22: 229-233$ 


\section{Chapter 2}

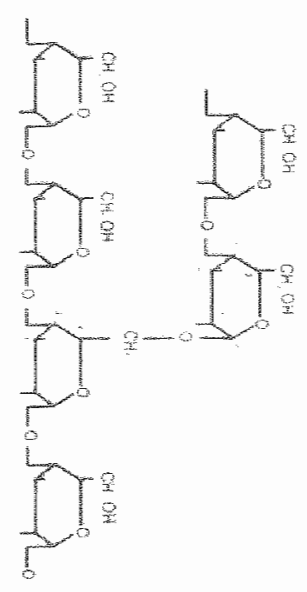

\section{Arterial wall properties in patients with renal failure}

CIAM Konings, RDommers, PL. Rensma, IP Kooman, APG Hoeks, L Konet, U Godxwo, FM von der Sonde, KMi Leunissen.

AnJ Kidney Dis 2002,39:1206-1212. 
34 Chopter 2

\section{Abstract}

Hemodialysis (HD) patients commonly exthibit abnormalities of the arierial system. Only: few studies have focused on arterial wall properties in patients with early stages of renal insufficiency and in patients on peritoneal dialysis (PD). In this study, the distensibility. coefficicient (DC) as a marker of arterial stiffening, and intima-media thickness (IMT) of the common caratid artery (CCA), as a surrogate marker of atherosclerosis, were assessed in 4 age-matched groups of patients: 18 HD patients, 36 PD patients, 30 patients with chronic renal failure (CRF) not yet on dialysis with a creatinine clearance (Cd) between 10 and $70 \mathrm{ml} / \mathrm{min}$, and 25 normotensive controls with normal renal function. Arterial wall properties were assessed by an automated vessel wall detection system.

In CRF and HD patients, but not in PD patients, the DC of the CCA was significantly reduced $\left(\rho<0.05\right.$ ) compared to controls (CRF: $12.6 \pm 7.510^{3} / \mathrm{kPa}, \mathrm{HD}: 11.6 \pm 7.610^{3}$ $/ \mathrm{kPa}$, and $\mathrm{PD}: 14.7 \pm 6.210^{-3} / \mathrm{kPa}$ compared to contrals: $\left.16.7 \pm 4.610^{3} / \mathrm{kPa}\right)$. In patients with CRF, a significant relation was found between $\mathrm{Ccl}$ and the $\mathrm{DC}(r=0.41 ; p=0.02)$. IMT was not different between CRF $(589 \pm 715 \mu \mathrm{m}), \mathrm{HD}(622 \pm 15 \mu \mathrm{m}), \mathrm{PD}$ patients $(585 \pm 121 \mu \mathrm{m})$ and controls $(668 \pm 150 \mu \mathrm{m})$. In conclusion, compared with controls, the DC of the CCA was found to be significamtly reduced in HD and CRF, but not in PD patients. In CRF patients the DC was significantly correlated to the CCl. IMT did not differ between any graup of renal patients and controls. 


\section{Introduction}

Cardiovascular mortality in hemadialysis (HD) patients is more than tenfold increased compared to the general population.' Abnormalities of the arterial system, represented both by a high prevalence of atherosclerotic disease and a reduced wall distensibility of the large arteries, are common in HD patients and were found to be related to cardiovascular morbidity and mortality. ${ }^{1.4}$ The relation between a reduced arterial wall distensibility and mortality in HD patients might be explained by the fact that a reduction in the buffering capacily (compliance) of the arterial system leads to an increased systolic stress, and therefore to left ventricular hypertrophy, an important predictor of mortality in this population. ${ }^{5}$

Although abnormalities in large arterial wall properties were studied in HD patients in various studies ${ }^{6.7}$, not many studies have addressed the relation between the existence of arterial wall abnormalities and the level of renal function in chronic renal failure (CRF). ${ }^{8}$ The fact that overt cardiovascular disecise is often already present at the start of dialysis therapy suggests that the development of vascular abnormalities starts early in the course of renal insufficiency", only few studies have provided corroborative data on arterial wall properties in patients with CRF not yet on dialysis. Moreover, little data as yet exist on arterial wall properties in peritoneal dialysis (PD) patients. ${ }^{10}$ With regard to the other spectrum of vascular disease, i.e. atherosclerosis, there is still some uncertainty whether this process is accelerated in chronic uremia. ${ }^{7}$

Recently it has become possible to detect subclinical atherasclerotic lesions with the use of echographic assessment of the intima-media thickness (IMT) of the caratid artery, whereas also distensibility of the large arteries can be assessed directly by ultrasound techniques. ${ }^{11,12}$ Several studies showed a clear relation between echographic assessment of the IMT and the histologic thickness. ${ }^{12,13}$ Moreover, in transwersal studies, the IMT was found to correllate not only with atherosclerotic lesions in the coronary, carotid, and femoral beds in symptomatic patients, but also with atherogenic risk factors in asymptomatic patients. ${ }^{14,15}$ Therefore, these data suggest that an increased IMT can be used as an early marker for atherasclerosis.

The hypotheses of the present study are that both atherosclerosis, characterized by an increase in IMT, and arterial stiffening characterized by a reduction in arterial compliance and distensibility develop early in the course of renal insufficiency and are more pronounced in patients with end-stage renal disease, treated with PD or HD.

Aims of the present study were therefore to compare arterial wall properties in the common caratid artery (CCA) in patients with CRF with various stages of renal insufficiency and patients on renal replacement therapy with those of agematched controls. 


\section{PATIENTS AND METHODS}

\section{Patients}

Thirty patients with CRF defined as a Col between 10 to $70 \mathrm{ml} / \mathrm{min}, 18 \mathrm{HD}$ patients, 36 PD patients and 25 normotensive controls were included in the study. All groups were age-matched. Patient characteristics are presented in Table 2.1. Exclusion criteria for the study were: cardiac failure (NYHA II and higher), unstable angina pectoris (NYHA II and higher), symptomatic stenosis of the carotid artery, type I diabetes mellitus, uncontralled hypertension (systolic blood pressure higher than $180 \mathrm{mmHg}$ or diastolic blood pressure higher than $105 \mathrm{mmHg}$ ), and acute renal insufficiency.

The protacol was approved by the local ethics committee and all patients gave written informed consent.

Table 2.1. Baseline patient characteristics

\begin{tabular}{|c|c|c|c|c|}
\hline & \multicolumn{4}{|c|}{ Potient group } \\
\hline & $\begin{array}{c}\text { CRF } \\
(n=30)\end{array}$ & $\begin{array}{c}P D \\
(n=36)\end{array}$ & $\begin{array}{c}H D \\
(n=18)\end{array}$ & $\begin{array}{l}\text { Controls } \\
(n=25)\end{array}$ \\
\hline \multicolumn{5}{|l|}{ Patient demogrophics } \\
\hline Age $(y)^{\circ}$ & $59.7 \pm 1.4 .4$ & $57.1 \pm 9.6$ & $60.1 \pm 11.9$ & $56.7 \pm 5.0$ \\
\hline Men/women & $21 / 9(70 / 30)$ & $20 / 16(56 / 44)$ & $11 / 7(61 / 39)$ & $18 / 7(72 / 28)$ \\
\hline \multicolumn{5}{|c|}{ Causes of renal insufficiency } \\
\hline Glomerulonephritis & $11(36.7)$ & $12(33.2)$ & $3(16.7)$ & \\
\hline Intersitifial disease & $4(73.3)$ & $2(5.6)$ & $3(16.7)$ & \\
\hline Polycystic disease & $2(6.7)$ & $2(5.6\}$ & $3(16.7)$ & \\
\hline Nephrosclerosis & $1(3.3)$ & $2(5.6)$ & $2(11.1)$ & \\
\hline Hypertension & $9(30)$ & $7(19.4)$ & $4(22.2)$ & \\
\hline Urological disorders & $3(10)$ & $6(16.7)$ & $2(11.1)$ & \\
\hline Diabetic nephropothy & $a(0)$ & $3(8.3)$ & $0(0)$ & \\
\hline Eci & 0101 & $2(5.6)$ & $1(5.5)$ & \\
\hline Macrovascuiar disease & $10(33.3)$ & $8(22.2)$ & $\gamma(38.9)$ & \\
\hline Diabetes mellitus (lype 2) & $1(3.3)$ & $4(11.1)$ & $2(11.11)$ & \\
\hline Smoking & 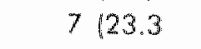 & $8(22.2)$ & $8(29.6)$ & $8(32)$ \\
\hline \multicolumn{5}{|c|}{ Artihypertensive medication use } \\
\hline Ace inhibitor & $9(30.0)$ & $9(25.0)$ & $4(22.2)$ & \\
\hline AT-1 ontagonist & $5(18.7)$ & $3(8.3)$ & $2(1) .1)$ & \\
\hline \multicolumn{5}{|c|}{ No. of antihypertensive drugs } \\
\hline 0 & $5(16.7)$ & $5(113.9)$ & $5(27,8)$ & \\
\hline 1 & $11(36.7)$ & $13(36.1)$ & $5(27.8)$ & \\
\hline 2 & $8(26.7)$ & $12\langle 33.3\}$ & $4(22.2)$ & \\
\hline 3 & $5(16.6)$ & $5(13.9)$ & 31167 & \\
\hline 4 & $1(3.3)$ & $1(2.8)^{\circ}$ & $1(5.6)$ & \\
\hline
\end{tabular}

Data are given in mean $\pm S D$, other data are given as numbers of patients. (\%).

Macrovascular disease was defined as the presence of symptomatic coronary or peripheral arterial disease. 


\section{Methods}

\section{Study design}

In this study, arterial wall properties were compared between healthy normotensive controls, patients with CRF and patients on renal replacement therapy (either on HD or PD), using a cross-sectional design.

\section{Measurement protocol}

Arterial wall properties (IMT and the arterial distensibility coefficient (DCI) of the right common carotid artery (CCA) were measured after a period of 15 minutes supine rest at room temperature. Measurements were performed in the recumbent position. Patients were asked not to smoke, eat or drink starting 4 hours before the measurements were performed, although for ethical reasons patients were allowed to take their regular medication.

\section{Dialysis schedule}

HD patients, scheduled on a maximum of one day between subsequent dialysis sessions, were measured directly before dialysis, because measurements after dialysis may be disturbed by the rapid changes in fluid and/or electrolyte state. Dialysis schedules were changed if necessary to perform measurements in the morning, such to avoid diurnal variations in the measured arterial wall properties. ${ }^{16}$ All HD patients were dialyzed with a standard dialysate calcium concentration of $1.50 \mathrm{mmol} / \mathrm{L}$. All HD patients and PD patients were treated according to the dialysis outcome and quality improvement (DOQl) guidelines, with respect to dialysis efficacy and treatment of anemia. ${ }^{17}$

\section{Blood pressure}

Arterial blood pressure (systolic blood pressure (SBP), diastolic blood pressure (DBP), and mean arterial blood pressure (MAP)) were measured with an automatic blood pressure monitor at the brachial artery (Dinamap $1486 \mathrm{SX}$, Critikon, Florida, USA) every 3 minutes. In healthy controls, CRF, and PD patients the right brachial artery, whereas in HD patients, the brachial artery contralateral to the arteriovenous fistula was used. Pulse pressure $(\triangle \mathrm{P})$ was calculated as SBP minus DBP.

\section{Arterial wall properties}

The distension of the right CCA was assessed using an automated echo-tracking system (Wail Track II, Pie Medical, the Netherlands). ${ }^{18}$ With this system the vessel walls are detected with the use of ultrasound, using a $7.5 \mathrm{MHz}$ linear array echo-probe. A sample volume is placed at the posterior and anterior walls of the CCA, 1 to $2 \mathrm{~cm}$ proximal of the bulbus. The raw radiafrequency datia are subsequently stored in a computer, after which the vessel wall motion during each heart cycle is tracked with the electrocardiographic trigger as reference 
fime-point. In this way the distension ( $\triangle D$ ) from diastole to systole, and the diameter (D) of the artery at end-diastole can be calculated. $\Delta \mathrm{D}$ was expressed as the mean of at least 7 consecutive reproducible cardiac cycles. With the use of $D$ the cross-sectional area ( $A$ and $\triangle A$ ) of the artery at the site of measurement can be derived. The distensibility coefficient (DC) was calculated using $\triangle P$ obtained in the brachial artery according to the following formula ${ }^{18}$ :

$$
D C=2(\Delta D / D) / \Delta P
$$

In an unselected subset of 12 PD patients, a correction for $\triangle P$ at the site of measurement was made using the distension waves obtained at the right $C C A .37,40$ In combination with this corrected $\triangle P$ obtained at the side of measurement at the right $C C A$, in this subset of patients the fallowing adaptated formula was used as recently described ${ }^{36}$ :

$$
D C=(\Delta A / A) / \Delta P=\left(2 \Delta D \cdot D+\Delta D^{2}\right) /\left(\Delta P \cdot D^{2}\right)
$$

The $D C$ calculated with the two different approaches gave a highly significant correlation ( $r=0.85 ; p=0.001)$. Because of this highly significant correlation and the complexity of the latter approach the first method described above was further used in this study.

The IMT was derived directly from the radiofrequency data and calculated as the median of at least 7 representative measurements. ${ }^{11,19}$ With regard to IMT measurements, the Wall Track system has a resolution of $0.01 \mathrm{~mm}$ and a repeatability coefficient of $0.069 \mathrm{~mm}$ in young patients and $0.109 \mathrm{~mm}$ in older patients. ${ }^{20}$ IMT area was calculated according to the formula ${ }^{23}$ :

$$
\text { IMT area }=\left((D / 2+\mid M T)^{2}-(D / 2)^{2}\right)
$$

\section{Laboratory parameters}

In the patient groups, blood samples were taken for assessment of hemoglabin (Coulter-Genis, California, U.S.A.), calcium, phosphate, albumin, and c-reactive protein (CRP) (all Syncron LX 20, Beckman Coulter, California, U.S.A.), parathormone (PTH) (IRMA assay, Nichols Institute Diagnostics, California, U.S.A.).

\section{Renal function and dialysis adequacy}

Creatinine clearance $(\mathrm{Cd})$ was used as a marker of renal function in the predialysis group and $\mathrm{Kt} / \mathrm{N}_{\text {ure }}$ as a marker of dialysis efficacy in the groups treated with renal replacement therapy. Ccl was calculated with the use of the Cockcroft and Gault formula. ${ }^{22}$ In the HD group $K t / N$ was calculated with the use of the method of Daugirdas (double pool model). ${ }^{23}$ In the PD patients $K I N N_{\text {urea }}$ was determined with the use of a computer model (PD adequest, Baxter, Lund,
Sweden). 


\section{Statistical analysis}

Differences in continuous variables between the various groups were analyzed by the Kruskal-Wallis test, and if significant, with the use of the Mann Whitney $U$ test. Differences in discrete variables were assessed with the Chi-Square test. The relation between different parameters was assessed using Pearson's $r$ test. When appropriate, a multiregression analysis was performed to assess the relative contribution of various variables on arterial wall properties. Calculations were made using SPSS-10 statistical software for Windows. All values are expressed as mean \pm SD. A p value less than 0.05 was considered significant.

\section{RESULTS}

Baseline characteristics, laboratory parameters and dialysis efficacy

The use of antihypertensive medication was higher in the PD group compared to $H D$ and CRF patients, although these differences were not significant. The presence of macrovascular disease, defined as the presence of symptomatic coronary or peripheral artery disease, did also not differ significantly between the different patient (CRF, $P D, H D$ ) groups, although it appeared to be somewhat higher in the CRF and HD groups (Table 2.1).

Laboratory parameters and $\mathrm{Kt} / \mathrm{N}_{\text {urea }}$ are displayed in Table 2.2. There were no significant differences between the three patient groups concerning the serum concentration of hemoglobin, phosphate, calcium and PTH. The serum concentration of albumin was significantly lower in the PD patients compared to $H D$ and CRF $(p<0.05)$. There was no significant difference in blood pressure between the three patient groups whereas the blood pressure was significantly lower in the control group compared to all patient groups.

Table 2.2. Blood pressure and laboratory parameters

\begin{tabular}{|c|c|c|c|c|}
\hline & \multicolumn{4}{|c|}{ Patient group } \\
\hline & CRF & PD & $H D$ & Control \\
\hline MAP (mmHg) & $101 \pm 16^{\circ}$ & $98 \pm 16^{\circ}$ & $97 \pm 17$ & $94 \pm 11$ \\
\hline $\mathrm{SBP}(\mathrm{mmHg})$ & $150 \pm 27$ & $143 \pm 26^{\circ}$ & $149 \pm 29^{\circ}$ & $126=12$ \\
\hline $\mathrm{DBP}(\mathrm{mm} \operatorname{mg})$ & $83 \pm 12^{\circ}$ & $80 \pm 11$ & $80+15^{\prime \prime}$ & $74 \pm 7$ \\
\hline Albumin $(g / L)$ & $40.5 \pm 3.3$ & $33.3 \pm 3.7^{2}$ & $37.3 \pm 5.0$ & \\
\hline PTH (pmol/L) & $14.8 \pm 21.4$ & $13.8 \pm 16.1$ & $19.8 \pm 27.4$ & \\
\hline Hemoglobin (mmol/L) & $7.5 \pm 1.2$ & $7.2 \pm 0.9$ & $6.9 \pm 1.1$ & \\
\hline Phosphate (mmol/L) & $1.3 \pm 0.4$ & $1.8 \pm 0.5$ & $1.6 \pm 0.4$ & \\
\hline Colcium (mmol/L) & $2.4 \pm 0.2$ & $2.4 \pm 0.2$ & $2.5 \pm 0.2$ & \\
\hline $\mathrm{CCl}$ & $33.6 \pm 0.2$ & & & \\
\hline Weekly Kt $N_{\text {ureas }}$ & & $2.2 \pm 0.5$ & $3.3 \pm 2.1$ & \\
\hline
\end{tabular}

Values expressed as mean $\pm S D$.

"p<0.05 compared to controls, " $p<0.05$ compared to CRF and HD. 


\section{Distensibility coefficient (DC)}

Data on the DC of the right CCA in the warious groups are summarized in Figure 2.1. Both in the HD, as well as in the group of patients with CRF, DC was significantly reduced compared with controls (HD. $11.6 \pm 7.6 \quad 10^{3} / \mathrm{kPa}$, CRF: $12.6 \pm 7.510^{-3} / \mathrm{kPa}$ versus controls: $16.7 \pm 4.610^{-3} / \mathrm{kPa} ; \mathrm{p}<0.011$. In the PD group the difference with controls was not significant $\left(14.7 \pm 6.210^{3} / \mathrm{kPa}\right.$ versus $16.7 \pm 4.610^{-3} / \mathrm{kPa}$; $\mathrm{ns}$ ). DC was significantly lower in $\mathrm{HD}$ compared to PD

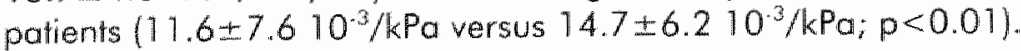

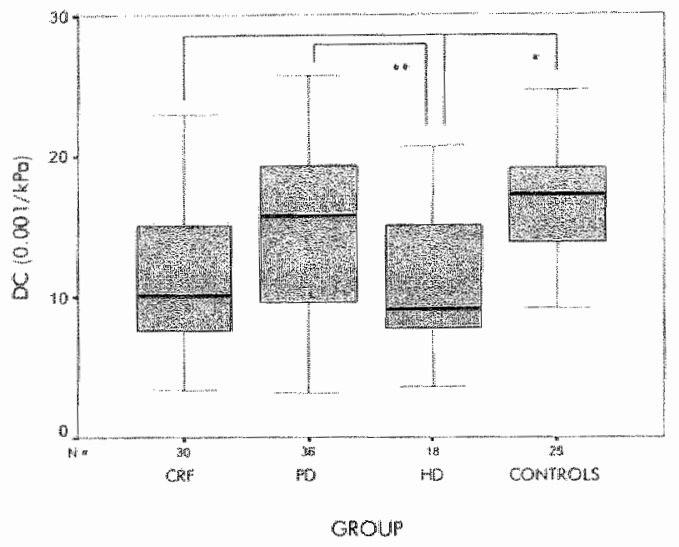

Figure 2.1. DC: Dist. Coeff. CCA.

$\mathrm{p}=0.03$, significant difference between CRF and PD patients versus controls $\because p=0.03$, significant difference between PD and HD patients

Covered boxes indicate $25-75 \%$ with median value, coptured bars indicate the range of data (excluding outliers).

In the overall group of renal patients, DC was significantly related to both age $(r=-0.66 ; p<0.01)$ and MAP $(r=-0.48 ; p<0.01)$, but there was no relation with any laboratory parameter. There was also no significant relation of the DC with any marker related to the Calcium/Phosphate metabolism. In the group of patients with CRF, the DC of the CCA wos significantly related to MAP $r=0.52$. $p=0.03)$. age $(r=-0.78 ; p<0.01)$, and $C d(r=0.43 ; p=0.02)$ (Figure 2.2). Linear multiple regression analysis showed that MAP $(t=-2.6 ; p=0.02)$, age $(t=-6.7 ; p<0.01)$, and $\mathrm{Cll}(t=2.1 ; \mathrm{p}=0.04)$ were independently related to distensibility.

\section{Intima media thickness (IMT)}

Both in the overall group irenal patients as well as in the group of patients with CRF, IMT was significantly related to age $\quad r=0.23 ; p=0.03$ and $r=0.49$; $p<0.01$, respectively), but not to any other parameter. IMT did not differ significantly between any group of PD, HD and CRF patients compared to controls PD: $585 \pm 121 \mu \mathrm{m}, \mathrm{HD}: 622 \pm 115 \mu \mathrm{m}, \mathrm{CRF}: 589 \pm 115 \mu \mathrm{m}$ versus 
controls $668 \pm 150 \mu \mathrm{m} ; \mathrm{ns}$ )(Figure $2.3 \mathrm{~A})$. There was also no significant difference in the IMT area between any group of renal patients and controls PD: $16.4 \pm 4.5$ $\mathrm{mm}^{2}, \mathrm{HD}: 18.0 \pm 4.8 \mathrm{~mm}^{2}, \mathrm{CRF}: 16.0 \pm 4.1 \mathrm{~mm}^{2}$ versus controls: $16.6 \pm 4.6$ $\mathrm{mm}^{2} ; \mathrm{ns}$, see Figure 2.3B).

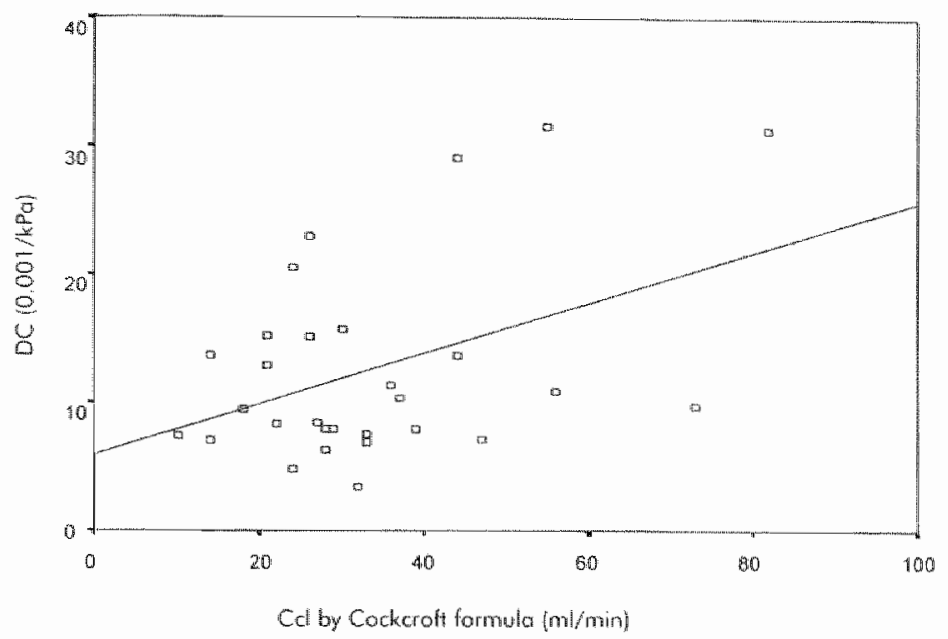

Figure 2.2. $r=0.42, p=0.02$
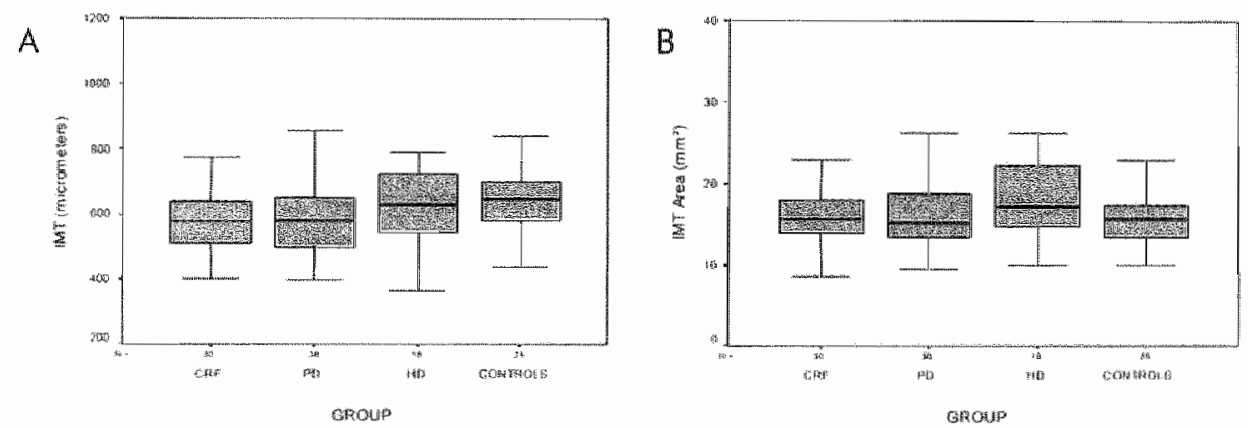

Figure 2.3. IMT and cross-sectional IMT area of the CCA.

Covered boxes indicate $25-75 \%$ with median value, captured bors indicate the ronge of data (excluding outliers).

\section{DISCUSSION}

The main findings of the present study were firstly that DC of the CCA was significantly reduced in HD and CRF patients compared to controls, which points to an increased stiffening of the large arteries over the entire spectrum of renal disease. Secondly, DC of the CCA was significantly related to renal function in CRF patients. Thirdly, IMT of the CCA as a surrogate marker of atherosclerosis 
was not found to be different between renal patients and controls in the present study.

The reduced arterial wall distensibility in HD patients compared with controls is in agreement with findings by various authors. 2.5 .24 .25 However, it is less well known that arterial distensibility is also reduced in patients with CRF, and also the significant relation between the DC of the CCA and the level of renal function has not been widely reported, although a recent publication of Mourad ef al." showed a significant relation between atterial wall properties and creatinine dearance even in patients with essential hypertension and milly disturbed renal function. An increased stiffening of the large arteries may have important clinical consequences, partly because of its relation to an increased systolic blood pressure and concentric left ventricular hypertrophy. ${ }^{5}$ Moreover, an increased stiffening of the large arteries was even found to be am important predictor of mortality in renal patients.?

The reason for the reduced CCA distensibility in renal patients is probably multifactorial. Part of the difference with regard to arterial distensibility between contrals and renal patients will certainly be explained by the fact that blood pressure levels in all three patient groups were higher compared to controls despite antihypertensive treatment. However, the influence of other factors than blood pressure per se on atterial wall distensibility is suggested by the observation that arterial distensibility was also found to be reduced in long-term mormotensive HD patients in the Tassin population ${ }^{26}$ and because of the fact that in our multiple regression analysis the level of renal failure was significantly related to CCA distensibility, independently from age and blood pressure. Indeed, the level of renal function per se appeared to be more significantly associated with the reduced arterial distensibility than secondary factors, such as the calcium/phosphate metabolism. ${ }^{2 ?}$

Interesting is the finding that also im renal patients, age is an independent determinant of both CCA distemsibility and intima media thickness, which is in agreement with the data of Blacher et al. ${ }^{28}$ This stresses the fact that graups. should be completely agemathed when arterial wall properties are to be compared.

In contrast to HD and CRF patients, DC was not signnificantly different between $\mathrm{PD}$ and control subjects, whereas it tended to be lower in HD patients compared to the PD group. Part of the difference might be explained by the fact that both in $\mathrm{HD}$ and CRF patients the prevalence of macrovascular disease was higher compared to the PD patients. It can also not be excluded that the use of antihypentensive medication, which tended to be higher in the PD population, might also have influenced arterial wall properties. ${ }^{29}$ Still, the relatively low number of patients in the present study does not allow any firm conclusions about differences in arterial wall properties between the various groups with renal failure.

Surprisingly, we did not find a difference in IMT, as a surrogate marker of atherosclerosis, beween the three groups of renal patients and controls, which is in agreement with the study of Savage ef al. ${ }^{30}$, but in some disogreement with 
other authors. ${ }^{5,31}$ In one study, London ef al. found a significantly higher IMT in dialysis patients compared to controls. ${ }^{5}$ Nevertheless, in this study, the mean difference in IMT between patients with end-stage renal disease and controls was rather small $(0.8$ versus $0.7 \mathrm{~mm})$. Also, those values were still far below IMT values associated with clinical disease in non-renal populations $(0.9-1.0 \mathrm{~mm})^{13}$ In contrast, a clearly increased IMT in HD patients has been reported by Kawagishi et al. ${ }^{31}$ However, in their study, more patients with macrovascular disease were included and not analyzed separately.

Using the IMT area, as suggested in a previous study ${ }^{21}$, there was also no significant difference between the different groups. Although the IMT area in our HD patients was in the same range as found in the study of Stenvinkel et al. ${ }^{21}$ in patients with end-stage renal disease, we were unable to find a significant difference with our control group. This might have been influenced by the selection of our controls, which was an unselected population sample, and were not all mainly healthy hospital staff like in the study of Stenvinkel ef al. ${ }^{21}$

Apart from the cross-sectional design, which precludes assessment of timedependent changes in the present study, several other limitations deserve attention. Firstly, as mentioned previously, the number of patients included was relatively low, which does not permit firm conclusions about differences between the various groups of renal patients.

Secondly, it should be stressed that only the arterial wall properties of the elastic CCA were assessed. This was done because earlier studies found arterial wall abnormalities to be more pronounced in central elastic large type capacitance arteries than in medium-sized muscular arteries. ${ }^{9,32}$ In addition, the variability of arterial wall assessment is larger in muscular-type arteries compared with elastic-type arteries. ${ }^{33}$ Thirdly, patients remained on antihypertensive medication whereas no control group with essential hypentensives were included. Nevertheless multiregression analysis showed that the level of renal function was correlated with arterial distensibility, independent from blood pressure. Finally, the use of CCA IMT as a marker of atherosclerosis deserves consideration. Although in studies in non-renal patients a clear association has been found with atherosclerotic vascular disease ${ }^{i 2, i 4}$, the fact that IMT or IMT area was not found to be increased in renal patients, should in our opinion not be taken as evidence against progressive atherosclerosis in this population.

In view of the recent findings on increased vascular calcifications in dialysis patients $^{30,34,35}$, it could be hypothesized that atherosclerosis in renal patients is somewhat different from other populations and more related to deposits of calcified products in the arterial wall, possibly in part mediated through disturbances in the calcium and phosphate homeostasis. The results of the present study raise some doubt whether measurement of the IMT in renal patients is the most appropriate method to assess atherosclerosis in this patient group.

In conclusion, in this cross-sectional study, CCA distensibility was reduced in CRF and $H D$ patients compared to normotensive controls, pointing towards an 
increased stiffening of the large arteries over a wide spectrum of renal disease. In patients with CRF a significant relation was found between renal function and DC of the CCA. No differences in IMT and IMT area, as surrogate markers of atherosclerosis, were observed between renal patients and controls. 


\section{References}

1. Wheeler DC. Cardiovascular disease in pathents with chronic renal failure. Lancet $1996 ; 348: 1673-1674$

2. Blacher $\downarrow$, Guerin AP, Pannier B, Marchais SJ, Safar ME, London GM. Impact of aortic stiffness on survival in end-siage renal disease. Circulation 1999; 11: $2434-2439$

3 London GM, Drueke TM. Atherosclerosis and arteriosclerosis in chronic renal failure. Kidney Int 1997; 51 : 1678-1695

4. Barenbrock $M$, Spieker $C$, Laske V. Heidenreich S, Hohage H, Bachmann J, Hoeks AP, Rahn KH. Studies of the vessel wall properties in HD patients. Kidney Int 1994 ; 45:1397-1400

5 Londan GM, Guerin AP, Marchais S., Pannier B et al. Cardiac and arterial interactions in end -stage renal disease. Kidney Int 1996; 50:600-608

6. Rostand SG, Drueke TB. Parathyroid hormone, vitamin D, and cardiovascular disease in chronic renal failure. Kidney Int 1999; 56: 383-392

7. Parfrey PS. Is renal insufficiency an atherogenic state? Refelections on prevalence, incidence and risk. Am J Kidney Dis 2001; 37: 154.156

8. Mourad JJ, Pannier B, Blacher J Rudnichi A, Benetos A, London GM, Safar ME. Creatinine clearance, pulse wave velocity, carotid compliance and essential hypertension. Kidney Int 2001; 59: 1834-1841

9 Foley RN, Palfrey PS, Haimet JD, Kent GM, Martin CJ ef al. Clinical and echocardiagraph disease in patients starting end-stage renal disease therapy. Kidney Int 1995; 47: 186-192

10. Meeus F, Kourilsky O, Guerin AP, Gaudry C, Marchais SJ, London M. Pathophysialogy of cardiovascular disease in hemodialysis patients. Kidney Int 2000; 58(S76): $5140-5147$

11. Willekes C, Hoeks APG, Bots ML, Brands PJ, Willigers JM, Reneman RS. Ewaluation of off-line automated intima-media thickness detection of the common carotid artery based on m-line signal processing. Ultrasound Med Bial 1999;25:57.64

12 Wendelhag I, Gustavsson T, Suurkula $M$, Berglund $G$, Wikstrand J. Ultrasound measurement of wall thickness in the caratid artery: fundamental principles and description of a computerized analysing system. Clinical physiology 1991, 11: $565-577$

13. Grobbee DE, Bots ML. Carotid artery intima-media thickness as an indicator of generalized atherosclerosis. J Intern Med 1994; 236:567-573

14 Chambless LE, Heiss G, Folsom AR, Rosamond W, Szklo $M$ et al. Association of coronary heart disease incidence with carotid arterial wall thickness and major risk factors: the atherosclerosis in communities (ARIC) study, 1987-1993. Am J Epidemiol 1997; $15: 483-494$ 
15 Wendelhag 1, Wiklund 0 , Wikstrand 1 . Atheroscleratic changes in the femaral and carotid arteries in familial hypercholesterolemia. Utrasonographic assessment of intima-media thickness and plaque occurrence. Arterioscler Thromb 1993; 13 : $[404-141]$

16 Kool MJ, Winen JA, Hoeks AP, Sirwijker Boudier HA, Van Bortel LM. Diumal pattern of vessel wall properties of large arteries in healthy men. J Hypertens 1991; 9 : 108-109

17. NKF-DOQh alinical practice guidelines for hemodialysis adequacy. National Kidney Foundation. Am J Kidney Dis 1997; 30 (S2): S15. S66

18. Reneman RS, Hoeks APG, Westerhof N. Non-inwasive assessment of artery wall properties in humans-methods and interpretation. Joumal of Vascular Investigation $1996 ; 2: 53-64$

19. Willekes C, Hoeks APG, Bots ML, Brands PJ, Willegers IM, Reneman RS. Evaluaion of off-line automated intima-media thickness detection of the common carotid artery based on M-lline signla processing. Ulirosound Med Biol 1999; 25: 57-64

20. Hoeks AP, Brands PJ, Smeets FA, Reneman RS. Assessment of the distensibility of supenficial anteries. Ultrasound Med Bial 1990; 6: 121-128

21. Stenvinkel $P$, Heimburger $O$, Paultry F, Diczfalusy, Wang $T$, Berlund $L$, Jogestrand $T$. Strong assaciation between malnutition, inflammation, and atherasclerosis in chronic renal failure. Kidney In 1999; 55:1899-1911

22. Cockcroft DW, Gawll MH. Prediction of creatinine clearance from serum creatinine. Nephron 1976; 16:31.41

23. Daugirdas JT, Depner TA, Gotch FA, Greene T, Keshaviah P, Levin NW, Schulman G. Comparison of methods to predict equilibrated $\mathrm{Kt} / \mathrm{V}$ in the HEMO Pilot Study. Kidney int 1997; 52 : 1395-1405

24. London GM, Marchais SJ, Safar ME, Genest AF, Guerin AP, Merivier F, Chedid K, London AM. Aortic and large artery compliance in end-stage renal failure. Kidney Int. 1990;37:137.142

25. Guerin AP, Blacher J, Panniaer B, Marchais SJ, Safar ME, London GM. Impact of Aorlic Stiffness Atfenuation on Surviwal of Patients in End-Stage Renal Failure. Circulation 2001; 103:987.992

26. Levin A, Foley RN. Cardiovascular disease in chronic renal insufficiency. Am $J$ Kidney Dis 2000; 36 (suppl 3): $\$ 24-530$

27. Luik A., Spek J, Charra B, van Bortel LMAB, Laurent J, Leunissen KML. Arterial compliance in patients on long treatment time dialysis. Nephral Dial Transplant 1997: 12: 2629-2632

28. Borenbrock M. Hausberg $M$, Kosch M, Kisters K, Hoeks AP, Rahn KH. Effect of typerparathyroidism on arterial distensibility in renal transplant recipients. Kidney Int $1998 ; 54: 210-215$

29. Blacher 3 , London GM, Safar ME, Mourad JJ. Influence of age and end-stage renal disease on the stiffness of carotid wall material in hypertension. J Hypertens 1999; 17: 237.244

30. London GM, Marchais SJ, Guerin AP, Metivier F, Safor ME, Fabiani F, Froment L. Salt and water retention and calcium blockade in uremia. Circulation 1990; 82: 105-113 
31. London GM, Pannier B, Vicaut E, Guerin AP, Marchais SJ, Safar ME, Cuche JL. Antihypertensive effects and arterial haemodymamic alterations during angiotensin converting enzyme inhibition. J Hypertens 1996;14:1139-1146

32. Cooke JP, Roositch E Jr, Andon NA, Loscalzo J. Drau VJ. Flow activates on endothelium potassium channel to release an endageneovis nitrowasodilator. J Clin Invest 1991;81: 1663-1671

33. Pannier B, Guerin AP, Marchais SJ, Metivier F, Safar ME, London GM. Postischemic vasodilation, endothelial activation, and cardiovascular remodeling in end-stage renal disease. Kidney Int 2000; 57: 1091-1099

34. Lévy BI, Benessiano J, Poitevin P, Safar ME. Endathelium-dependent mechanical properties of caratic artery in WKY and SHR. Circ Res 1990;66:321-328

35. Savage T, Clarke AL, Giles M, Tomson CR, Raine AE. Calcified plaque is common in the carotid and femaral arteries of dialysis patients without clinical vascular disease. Niephrol Dial Transplant 1998; 13: 2004-2012

36. Kawagishi T, Nishizawa $Y$, Konishi T, Kawasaki $K$, Emato $M$, Shoil $T$, Tabata $T$, Inove $T$. Morii $\mathrm{H}$. High-resolution B-made ultrasonography in evaluation of atherosclerosis in uremia. Kidney lnt 1995; 48:820-826

37. de Hoon ل. Migraine and anti-migraine drugs, facus on cardiovascular aspects. Thesis; chapter $2000 ; 2: 51.58$

38. Reneman RS, van Merode $\mathrm{T}$. Brands Pl, Hoeks A.PG. Inhomogeneties in anterial wall properties under normal and pathological conditions. J Hyperens 1992; 10:535-39

39. Mourad JJ, Girerd X, Boutouyrie P, Laurant S, Satar ME, London GM. Increased stiffness of radial artery wall material in end-stage renal disease. Hypertension $1997 ; 30: 1425-1430$

40. Van der Heijden-Spek JJ, Staessen JA, Fagard RH, Hoeks AP, Struilker Boudier HA, Van Bortel LM. Effect of Age on Brachial Wall Artery Properties Difers From the Aorta and Is Gender Dependent, a population study. Hypertension. 2000; 35: 637-642

41. Goodman WG, Goldin J, Kuizon BD, Yoon C, Gales B, Sider D, Wang Y, Chung J, Emerick $A$, Greaser L, Elashoff RM, Salusky IB. Caronary-Artery Calcification in Young Adults with End-Stage Renal Disease Who Are Undergoing Dialysis. N Engl I Med 2000; 342: 1478-1483

42. Guerin AP, London GM, Marchais S1, Mettivier F. Anterial stiffening and vascular calcifications in end-stage renal disease. Nephral Dial Tramsplant. 2000; 5 : 1014 1021

43. Van Bortel LM, Balkestein EJ, van der Heijden Spek Jd, Vanmolkot FH, Staessen JA, Kragten JA, Vredeveld JW, Scfor ME, Struịker Boudier HA, Hoeks A.P. Non-invasive assessment of lacal arterial pulse pressure: comparison of applanation tonometry and echo-tracking. J Hypertens 2001; 19: 1037.1044 
48 


\section{Chapter 3}

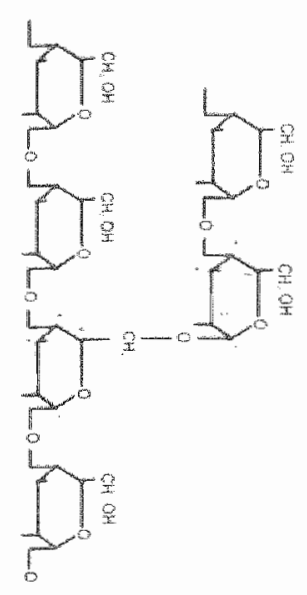

\section{Assessment of fluid state in peritoneal dialysis patients}

CJAM Konings, JP Kooman, M Schonck, PL Cox-Reipen, B wan Kreel, U Gladziwa, JWintz, PG Gerlag. SJ Hoonlie, JWolters, GAK Heidendal, FM van der Sande, KML Leunissen

Peril Dial int (Accepted for publication) 


\section{Abstract}

Techniques and formulae used to estimate volume state and body composition in patients on peritoneal dialysis (PD) may be affected by abnormalities in fluid state itself. Moreover, it has also been suggested that multitrequency bioimpedance analysis (MF-BLA) may nol assess trunk volume adequately. This was followed by the introduction of segmental BIA (E-BIA). In the present study, which included 40 patients 129 males, 11 females; 30 continuous ambulatiory PD [CAPD], 10 continuous cyclic PD [CCPD]), total body water (TBW) and extracellular water (ECW) assessed by MF-BIA were compared to tracer dilution techniques (TBW:deuterium oxide $\left[\mathrm{D}_{2} \mathrm{O}\right]$ and ECW:bromide [NaBr] and the Watson formula, whereas the agreement between the various techniques was related to hydration state [ECW [NaBr] body weight [BW] and TBW [D, O]:BW) and bady composition (dual energy X-ray absorptiometry [DEXA]. Moreover, body water compariments were related to left atrial diameter (LAD) and left ventricular end diastalic diameter (LVEDD) (echocardiography). In an unselected subset of 23 patients also I-BIA was performed.

TBW and ECW, assessed by tracer dilution techniques and by MF-BIA and E-BIA were significantly related to LAD and LVEDD. Despite highly significant correlations between the various techniques, a wide limit of agreement was obseved between tracer dilution techniques and MF-BIA ldifference between TBW [TBW D $\mathrm{D}_{2} \mathrm{O}$ - TBW MF-BIA] $2.0 \pm 3.9$ litres;

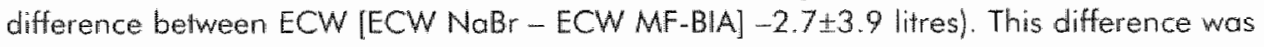
related to the relative magnitude of body water compartments $(r=0.70 ; p<0.05$ for ECW:BW, and $r=0.40 ; p<0.05$ for TBW:BW/. The agreement between tracer dilution and bioimpedance was not improved by the use of $\Sigma$-BIA (difference between ECW IECW $\mathrm{NaBr}-\mathrm{ECW} \sum-\mathrm{B}[\mathrm{A}] 3.7 \pm 2.9$ litres).

Also wide limits of agreements were observed between $D_{2} O$ and the Watson formula (difference between TBW [TBW $\mathrm{D}_{2} \mathrm{O}$-TBW Watson] $-2.3 \pm 3.3$ litres]. The difference between TBW $D_{2}$ O and TBW Watson was sigmificantly related to TBW: BW and also to the percentage of fat mass $(r=0.70$ and $r=0.53, p<0.05)$.

In conclusion, despite a significant relation to echocardiographic parameters, wide limits of agreement were found between both MF-BIA and L-BIA with dilution techniques in PD patients, which was partly due to the hydrotion state itself. The disagreements beween the Watson formula and tracer dillution methads were also related to the hydration state. 


\section{Introduction}

An adequate assessment of fluid state is of major impontance in peritoneal dialysis (PD) patients. Determination of fluid state serves firstly to detect overhydration, which is strongly related to hypentension and left ventricular hypentrophy (LVHI)', but is often difficult to detect by clinical methods. Moreover. total body water (TBW) may serve as a surrogate marker of urea distribution volume and is therefore also an impartant parameter for the assessment of diallysis adequacy. Multifrequency bioimpedance analysis (MF-BIA), which is able to discriminate between intra- and extracellular compartments, has been proposed as a marker of fluid state in dialysis patients, whereas anthropometric formulae (e.g Watson) are also widely used in order to assess TBW in dialysis patients." However, there remains uncertainty regarding the agreement of bioimpedance methods and anthropometric formula with tracer dilution techniques in dialysis patients. ${ }^{4 . ?}$ The reliability of anthropometric formulae may be impaired by abnormalities in fluid state and/or body composition whereas the relliability of BIA might be impaired because of the abnormal water distribution in these patients ${ }^{4.7}$, especially because standard "wrist-to ankle" BlA appears not to be able to measure trunk water adequately."

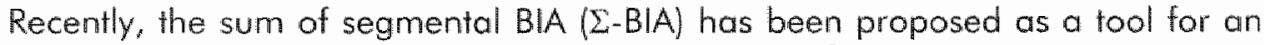
adequate assessment of trunk water in PD patients. ${ }^{8}$ However, 2 -BIA has never been evaluated in the assessment of the absolute magnitude of volume compartments in PD patients. Although the measurement of trunk volume may be of importance in the assessment of the absolute magnitude of bady fluid compartments (e.g. For determination of urea distribution volume), it is not well known whether the trunk volume is relevant from a hemodynamic point of view. Therefore, a comparison of both techniques with regard to their relation with alternative hemodynamic parameters such as left ventricular end diastalic diameter (LVEDD) might be appropriate and of clinical importance.

Aim of the present study in PD patients was firstly to study the agreement beiween tracer dilution techniques, the Watson formula and bioimpedance analysis and secondly to assess the influence of the relative magnitude of the body water compartments and body composition on the agreement beween the various techniques. Moreover, the hemodymamic relevance of the fluid parameters was studied by their relation with cardiac parameters and it was attempted to define reference values for MF-BIA in the assessment of avertydration. 


\section{Materials and methods}

\section{Study design}

In this multi-center study, the relation between different methods to determine fluid state and echocardiographic parameters was studied in a crass-sectional design.

Tracer dilution techniques and MF-BIA were compared with regard to the assessment of total body water (TBW) and extracellular water (ECW) in PD paitents. With regard to the assessment of TBW, also the Watson formula and dual energy $X$-ray absorptiometry (DEXA) were included. The agreement bewween the various techniques was also related to the relative magnitude of the body water compartments, which was respectively expressed as TBW and ECW, assessed by tracer dilution techniques, in relation to (divided by) gravimetric body weight (BW). The agreement between the various techniques was also related to the percentage of fat mass, assessed by DEXA. Moreover, the hemodynamic relevance of the fluid parameters was assessed by their relation with cardiac dimensions, measured by echocardiography.

Secondly, E-BIA, MF-BIA and tracer dilution techniques were compared with regard to the assessment of ECW, this to find out wether $\mathrm{E}$-BIA is superior in comparison with whole body MF-BIA in predicting ECW.

\section{Study protocol}

Patients were admitted to the research center at the dialysis department of the Academical Hospital of Maastricht in the early morning after an overnight fast. If patients had a filled abdomen over the night, PD fluid was first drained before the measurements were started. After admission, isotope dilution techniques and BlA measurements were performed. During this study period, patients were not allowed to eat or drink. At noon, patients were allowed to eat a light meal, of which the total amount of fluid did not exceed $200 \mathrm{ml}$. Hereafter, echocardiography was performed.

\section{Patients}

40 stable PD patients were included $(29$ males; 11 females; 30 continuous ambulatory PD (CAPD), 10 continuous cyclic PD (CCPD), recruted from 6 dialysis centers in the southeastern part of the Netherlands and one center in Germany. All patients were native caucasians except for one patient (creale). Patients with metal implants, and recent complications (e.g. malignancy or surgery), insulin dependent diabetes mellitus, and dyspnea or angina pectoris (NYHA III and higher) were excluded. Dry weight was assessed on climical grounds according to the treating physician, avoiding signs of overhydration, like an elevaled central venous pressure, peripheral or pulmonary edema. Patient characteristics are summarized in Table 3.1. 
All patients were included between $29^{\text {nd }}$ march 2000 and $2^{\text {nd }}$ march 2001.

Table 3.1. Potient characteristics.

\begin{tabular}{|c|c|c|}
\hline Meon age (years) & $53.6 \pm 12.4$ & $32-71$ \\
\hline Man/Woman & $29(73 \% / 1 \pi(27 \%)$ & \\
\hline Weight (kg) & $77.8 \pm 13.6$ & $45.0-112.5$ \\
\hline Body surface area $(B S A)\left(m^{2}\right)$ & $1.9 \pm 0.2$ & $1.3-2.4$ \\
\hline Body mass index (BMl) $\left(\mathrm{kg} / \mathrm{m}^{2}\right)$ & $26.0 \pm 3.6$ & $18.6-35.4$ \\
\hline Time on CAPD (months) & $27.1 \pm 17.3$ & $3.0-66.0$ \\
\hline Weekly Hotal Kt $N_{\text {yrea }}$ & $2.4 \pm 0.7$ & $1.4-5.0$ \\
\hline Weekly total $\mathrm{Col}\left(\mathrm{L} / 1.73 \mathrm{~m}^{2}\right)$ & $85.4 \pm 30.7$ & $44.5-179.2$ \\
\hline Residual GFR $(\mathrm{ml} / \mathrm{min})$ & $4.3 \pm 3.9$ & $0-148$ \\
\hline $\mathrm{D} / \mathrm{P}$ creatinine & $0.65 \pm 0.1$ & $0.45-0.90$ \\
\hline \multicolumn{3}{|l|}{ Cause renal insufficiency (number) } \\
\hline Glomerulonefritis & $19(47.5)$ & \\
\hline Glomeruloscherosis & $3(7.5)$ & \\
\hline Hypertension & $6(15.0)$ & \\
\hline Polycystic disease & $4(10.0)$ & \\
\hline Urological disorder & $6(15.0)$ & \\
\hline Unknown & $2(5.0)$ & \\
\hline
\end{tabular}

Data presented as mean 2 SD, also ranges are shown or numbers; numbers in bracklets are percentages; $\mathrm{Ccl}$ : creatinine clearance; GFR: glomerular filtration rate.

$\Sigma$-BIA was also performed in all 23 patients $(15$ male, 8 female; mean age $53.5 \pm 11.5$ years) who entered the study between $23^{\text {th }}$ august 2000 and $2^{\text {nd }}$ march 2001.

Informed consent was abtained from each patient, and the study was approved by the Ethics Committee of the Maastricht University Hospital.

\section{Study parameters}

\section{Fluid state}

\section{Tracer dilution}

Patients received an orally administered dose of deuterium oxide $\left(D_{2} \mathrm{O}\right)$ of $25 \mathrm{ml}$ $\left(99 \% \mathrm{D}_{2} \mathrm{O}\right.$, Sigma Chemicals, St. Lovis, USA) and $30 \mathrm{mll}(150 \mathrm{mmol})$ sodium bromide $(\mathrm{NaBr}$, pharmacological department, Academical Hospital Maastricht, The Netherlands). Dose bottles were washed out and the rinse water was also ingested by the patients to ensure that all $\mathrm{D}_{2} \mathrm{O}$ and $\mathrm{NaBr}$ were consumed. Enrichements of $\mathrm{D}_{2} \mathrm{O}$ and $\mathrm{NaBr}$ in the body fluid were measured in serum. Immediately before $\mathrm{D}_{2} \mathrm{O}$ and $\mathrm{NaBr}$ intake, a (background) blood sample was taken. After the equilibration time of 4 hours a second blood sample was collected. The concentration of $\mathrm{D}_{2} \mathrm{O}$ and $\mathrm{NaBr}$ in serum was determined by isolope ratio mass spectrometry and gas chromatography respectively. ${ }^{9}, 10 \mathrm{D}_{2} \mathrm{O}$ and $\mathrm{NaBr}$ dilution spaces were calculated from respectively the enrichment of 
$\mathrm{D}_{2} \mathrm{O}$ and $\mathrm{NaBr}$ after 4 hours. TBW was calculated as the $\mathrm{D}_{2} \mathrm{O}$ dilution space corrected for the exchonge of $\mathrm{D}_{2} \mathrm{O}$ with nonaquaous compariments by first dividing the dilution space by 1.04 and thereafter multiplying by 0.94 for the concentration of water in the serum." ECW was calculated as the $\mathrm{NaBr}$ dilution space corrected for intracellular penetration of $\mathrm{NaBr}$ in erythrocytes, leukacytes and secretory cells, for unequal $\mathrm{NaBr}$ concentrations in the extracellular fluids (Gibbs-Donnan effect) and for the concentration of water in the serum. Therefore, NaBr dilution space was multiplied by $0.90 * 0.94 * 0.95$ respectively, resulting in a correctionfactor of $0.80 .^{12}$

Body water compartments were normalized for body weight in this chapter. This was done in arder to express the relative magnitude of these compartments. For the assessment of fluid state, normalization against body surface area or height might be more appropriate (see the chapters 6 and 9).

The reproducibility of the $\mathrm{NaBr}$ assay was tested by relating ECW measurements obtained in 30 PD patients with an interval of 4 months, yielding a coefficient of variation of $15 \%$. Also with regard to TBW the coefficient of variation was $9.4 \%$.

\section{Multifrequency bioimpedance analysis}

Bioimpedance measurements were performed in a standard fashion while the patient was lying supine on a flat, nonconductive bed for at least 15 minutes. Multifrequency $(5.500 \mathrm{KHz})$, imperceptible currents were introduced at distal electrodes on the hands (just proximal to the phalangeal-metacarpal joint in the middle of the dorsal side of the hand) and the feel (iust proximal to the transverse, metatarsal, arch on the superior side of the foot), and resistances. were measured by proximal electrodes (to the wrist midway between the styloid process, to the ankle midway between the malleoli). TBW and ECW were predicted from the Hanai mixture theory (using a Cole-Cole model), ${ }^{13}$, In this model watter compartments are directly calculated from resistance values, assuming specific resistances of ECW and intra-cellular water (ICW). Specific resistances ( $\rho$ ) of ECW and ICW are provided by the manufacturer for men: $\rho E C W=215, \quad \rho l C W=824$, for women $\rho E C W=206, \quad \rho / C W=797),{ }^{13}$ The bioimpedance analyzer used in this study was the Xitron $4000 \mathrm{~B}$ (Xitron Technologies Inc, San Diego, USA). Predictive calculations were made with sofiware provided by the manufacturer of the Xitron $4000 \mathrm{~B} .{ }^{15}$

\section{Sum of segmental BIA $(\Sigma-B \mid A)$}

L-BlA was performed as described by Zhu ef al. ${ }^{8}$ In short, two electrodes were placed on the dorsal surfaces of the hand and foot on the same side of the body. Sensing electrodes were placed on the ipsilateral side as the injecting electrodes, which were placed on the wrist, the shoulder, the buttock, and the ankle. The patients were in a supine position for at least 15 minutes. Bioimpedance was measured in the arm, trunk, and leg segment, and between the wrist and the ankle using the Xitron $4000 \mathrm{~B}$ analyzer. The duration of the cycle of measurements was 1 minute. Using multiple frequencies ranging from $5.500 \mathrm{kHz}$, extracellular resistance was calculated using the modeling technique 
supplied by the manufacturer. Segmental ECW was calculated according to the formula: $E C W_{S}=k_{S} \times\left(1 / \sigma_{E C W}\right) \times\left(L_{s}{ }^{2} / R_{S}\right)$, where $\sigma_{E C W}$ is the conductivity of the extracellular fluid, $L_{s}$ is the length of the segment, $R_{5}$ is the resistance of the segment, and $k_{s}=1$ for the arm and the leg, and $k_{5}=4$ for the trunk. The sum of segmental $E C W$ is calculated as $2\left(E_{C W} W_{\text {arm }}+E W_{\text {ieg }}\right)+E C W_{\text {trunk. }}{ }^{8}$

\section{Anthropometric formula}

TBW according to the Watson formula ${ }^{16}$ is calculated as follows: Males: $T B W=2.447+(0.09156 \times$ age $)+(0.1074 \times$ height $)+(0.3362 \times$ weight $)$. Females: $T B W=-2.097+0.1069 \times$ height $)+(0.3362 \times$ weight $)$.

\section{Echocardiography}

Leff atrial (LA) diameter and LVEDD were assessed by two-dimensional echocardiography wich was performed using a Hewlett Packard 5500 ultrasound system with standard imaging transducers with a frequency ranging from 1.6 to $3.2 \mathrm{MHz}$.

\section{Dual energy $X$-ray absorptiometry}

DEXA measurements were performed in order to determine fat mass and bone cell mass (BCM), the latter as a correction factor for ECW as proposed by Fisch ef al. ${ }^{17}$ Total body water was allso assessed by DEXA by multiplying lean body mass by 0.73 . Although DEXA is specifically designed to assess body composition in a three compartment model (fat mass, lean body mass, body cell mass; vide infra), total body water can be deduced from lean body mass because DEXA assumes a hydration siate of the lean bady mass of $73 \% .^{18}$ Therefore, TBW assessed by DEXA was assessed by multiplying lean body mass by 0.73 .

\section{Statistical analysis}

Data are expressed as mean $\pm S D$. Correlations between body water compariments measured by the different methods were estimated by the use of Pearson product moment correlations. P-values $<0.05$ were considered significant. Bland and Altman plots ${ }^{19}$ were used to visually assess agreement between the different methods.

\section{Results}

Total body water: relation between $D_{2} O, M F-B \mid A$, Watson formula and isotope dillution

The mean values for fluid parameters, assessed by the various techniques, are displayed in Table 3.2. 


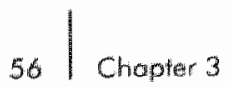

Table 3.2. Fluid state, assessed by different techniques, and cardiac parameters

\begin{tabular}{|c|c|c|c|}
\hline & mean & standard deviation & range \\
\hline TBW & 38.8 & 8.0 & $21.9 \cdot 54.3$ \\
\hline TBW & 36.6 & 7.6 & $20.2-50.0$ \\
\hline TBW & 41.1 & 6.9 & $24.6-56.0$ \\
\hline ECW & 18.4 & 6.2 & $10.6-35.6$ \\
\hline ECW & 21.1 & 4.5 & $11.7-32.9$ \\
\hline ECW & 14.0 & 2.6 & $9.7-19.8$ \\
\hline $\mathrm{TBW}_{020}: \mathrm{BW}(\%)$ & 49.1 & 7.1 & $33.1-66.4$ \\
\hline $\mathrm{ECW}$ & 23.2 & 6.4 & $14.4-51.3$ \\
\hline LA diameter (mm) & 44.2 & 5.0 & $33-55$ \\
\hline LVEDD (mm) & 50.4 & 5.6 & $40 \cdot 64$ \\
\hline
\end{tabular}

TBW =total body water; $\quad E C W=$ extracellular water; $\quad$ NF-BIA-multifrequency bioimpedance; $\Sigma-B I A=$ segmental $B I A ; D E X A=$ dual energy $X$-ray absorptiometry: $\mathrm{NaBr}=$ sodium bramide; $\mathrm{D}_{2} \mathrm{O}=$ deuterium oxide; $L A$ diameter $=$ left atrial diameter; $\angle V E D D=$ left ventricular end-diastalic diameter; Data for $\Sigma$-BIA available for 23 patients.

The correlation coefficients between the different techniques are summarized in Table 3.3. In general, MF-BIA tended to underestimate TBW according to $\mathrm{D}_{2} \mathrm{O}$ (mean difference $\mathrm{D}_{2} \mathrm{O}$-MF-BIA: $2.0 \pm 3.9$ litres (range -9.2 to 10.7) (Figure 3.1A) whereas the Watson formula tended to overestimate TBW according to $\mathrm{D}_{2} \mathrm{O}$ (mean difference $\mathrm{D}_{2} \mathrm{O}$-Watson: $-2.3 \pm 3.3$ litres (range -13.0 to 3.9) (Table 3.4). DEXA tended to slightly underestimate $\mathrm{D}_{2} \mathrm{O}$ values, whereas the limits of agreement were less wide compared to the other techniques (mean difference $\mathrm{D}_{2} \mathrm{O}$-DEXA: $0.9 \pm 3.0$ litres [range -6.4 to 6.8 ]). The discrepancy between TBW, as respectively asssessed by $D_{2} \mathrm{O}$ and MF-BIA, was significantly related to the relative magnitude of the TBW (TBW $\left.\mathrm{D}_{2} \mathrm{O}: \mathrm{BW}\right)(r=0.40, p<0.05)$ (Figure 3.1B). The same held true for the discrepancy between TBW assessed by $D_{2} \mathrm{O}$ and the Watson formula $(r=0.74 ; p<0.05)$ (Figure $3.1 \mathrm{C})$. The difference between $\mathrm{D}_{2} \mathrm{O}$ and DEXA was not related to the magnitude of the TBW compartment.

The discrepancy between $D_{2} O$ and $M F-B I A$ was not related to the percentage of fat moss, in contrast to the discrepancy between $D_{2} O$ and the Watson formula, which was significantly related to the percentage of fat mass $(r=-0.53 ; p<0.05)$ (Figure 3.2A). 
Table 3.3. Correlation coefficients between fluid state, assessed by different techniques, and cardiac dimensions

\begin{tabular}{|c|c|c|c|c|c|c|}
\hline & $\mathrm{TBW}_{020}$ & TBW & TBW & $E C W_{\mathrm{NaBr}}$ & $E C W_{M F-(2) A}$ & ECW \\
\hline TBW & & & 0.93 & & & \\
\hline TBW & 0.88 & & 0.92 & & & \\
\hline TBW & 0.91 & 0.85 & 0.88 & & & \\
\hline TBW DEXA & 0.93 & 0.92 & & & & \\
\hline ECW & & & & & & 0.68 \\
\hline ECW & & & & 0.79 & & 0.92 \\
\hline LA dilameter & 0.42 & 0.53 & 0.43 & 0.53 & 0.55 & 0.43 \\
\hline LWEDD & 0.44 & 0.57 & 0.64 & 0.45 & 0.63 & 0.54 \\
\hline
\end{tabular}

For all correlations: $p<0.05 ; \mathrm{TBW}=$ total body water; $E C W=$ extracellular water; $M F$ $B \| A=$ multifrequency bioimpedance; $\Sigma-B \mid A=$ segmental $B \mid A_{i}$ DEXA = dual $X-r a y$ absorptiometry; $\mathrm{NaBr}=$ sodium bromide, $\mathrm{D}_{2} \mathrm{O}=$ deuterium oxide; LA diameter =left atrial diameter; $L V E D D=$ left ventricular end-diastolic diameler; Data for $\Sigma$-BIA available for 23 patients.

\section{Extracellular water (ECW): relation between $\mathrm{NaBr}$ and $\mathrm{MF}-\mathrm{BIA}$}

The mean values for ECW, assessed by the various techniques, are also displayed in Table 3.2. The correlation coefficients between the different techniques are summarized in Table 3.3. In general, MF-BIA tended to overestimate ECW according to $\mathrm{NaBr}$ (mean difference $\mathrm{NaBr}-\mathrm{MF}-\mathrm{BIA}:-2.7 \pm 3.9$ litres (range; -9.0 to +10.1 ) (Figure 3.2B). The discrepancy between ECW, as respectively asssessed by $\mathrm{NaBr}$ and $M \mathrm{~F}-\mathrm{B} \mid \mathrm{A}$, was significantly related to the relative magnitude of the ECW compartment ( $E C W$ NaBr: BW $[r=0.70$; $p<0.051$ ) (Figure $3.2 \mathrm{C}$ ). This also held true when height was used as normalization parameter $(r=0.70 ; p<0.05)$.

Extracellular water: relation between $\mathrm{NaBr}, \mathrm{MF}-\mathrm{BIA}$, and $\mathrm{E}-\mathrm{BI} \mathrm{A}$

In the subgroup of 23 patients in which $\Sigma-B \mid A$ and $\mathrm{NaBr}$ dilution were performed, the correlation coefficient between ECW, assessed by $\mathrm{NaBr}$ and MFBIA was $0.74(p<0.05)$ (Figures 3.2D), whereas the correlation between $\mathrm{NaBr}$ and $\Sigma$-BIA was $0.70(p<0.05)$. The correlation coefficient between MF-BIA and $\Sigma$-BIA was $0.92(p<0.05)$. The mean difference between $\mathrm{NaBr}$ and MF-BIA in this subgroup was $-2.8 \pm 2.8$ litres [range -6.0 to 6.4 ], whereas the mean difference between $\mathrm{NaBr}$ and $\Sigma$-BIA was $3.7 \pm 2.9$ litres [range -0.7 to 13.3] (Figure 3.2E). The mean difference between MF-BIA and $\Sigma$-BIA was 6.9 [3.910.1 ] litres. 

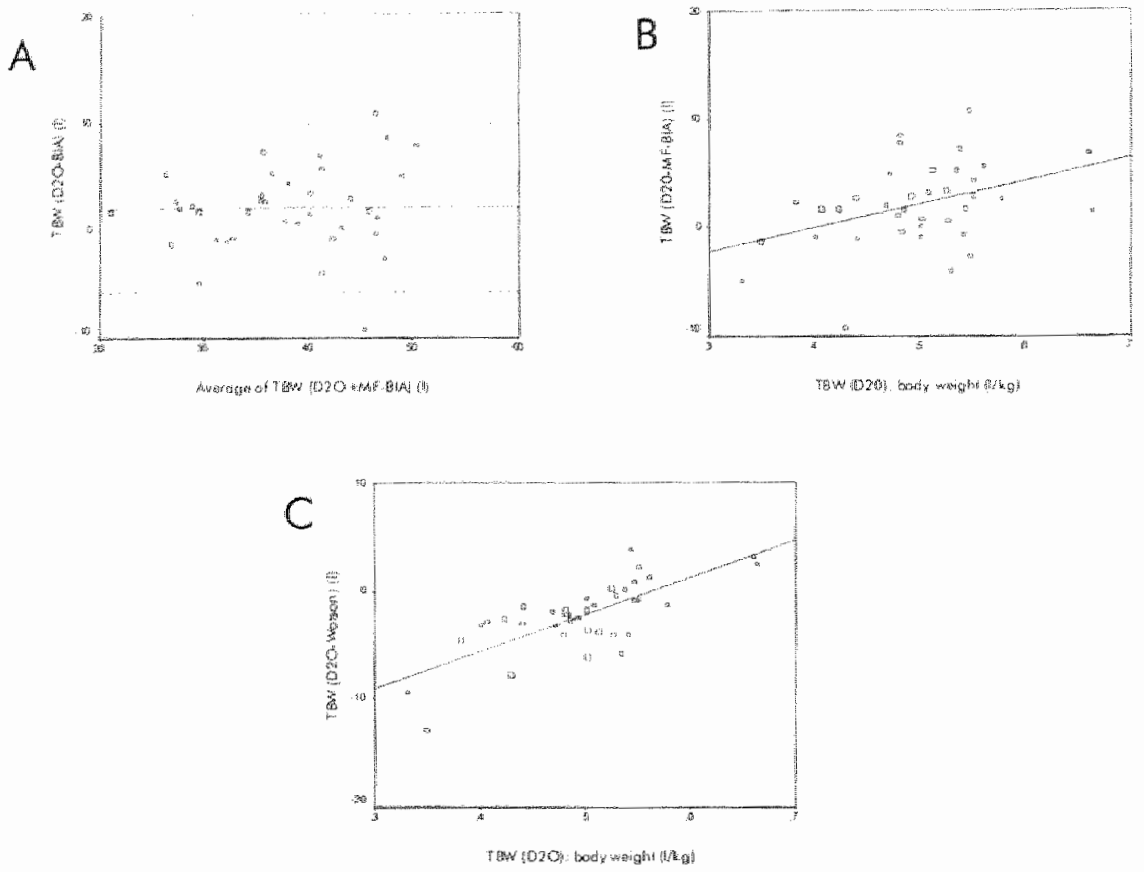

Figure 3.1. $\quad \mathrm{B} B \mathrm{~B}=$ total body water; $\mathrm{MF} \cdot \mathrm{BI} A=$ multifrequency biompedance; $\mathrm{D}_{2} \mathrm{O}=$ deuterium oxide.

A. Limits of agreernent between TBW, assessed by $D_{2} O$ and MF-BIA.

B. Discrepancy in the assessment of TBW by $D_{2} O$ and $M F \cdot B I A$, in relation to the relative magnitude of the TBW compartment $r=0.40$, p<0.05)

C. Discrepancy in the assessment of tbw by $\mathrm{D}_{2} \mathrm{O}$ and Watson, in relation to the relative magnitude of the TBW compartment $(r=0.74$, $p<0.05)$

Table 3.4. Differences in estimation of fluid state, assessed by different techniques

\begin{tabular}{lrc}
\hline TBW [D,O]-TBW [MF-BIA] & $2.0 \pm 3.9$ & {$[-9.2$ to 10.7$]$ litres } \\
TBW [D, O]-TBW [Watson] & $-2.3 \pm 3.3$ & {$[-13.0$ to 3.9$]$ litres } \\
TBW [D,O]-TBW [DEXA] & $0.9 \pm 3.0$ & {$[-6.4$ to 6.8$]$ litres } \\
ECW [NaBr]-ECW [MF-BIA] & $2.7 \pm 3.9$ & {$[-9.0$ to 10.1$]$ litres } \\
ECW [NaBr]-ECW [E-BIA] & $3.7 \pm 2.9$ & {$[-6.0$ to 6.4$]$ litres } \\
ECW [MF-BIA]-ECW [E.BIA] & $6.9 \pm 1.5$ & {$[3.9$ to 10.1$]$ litres } \\
\hline
\end{tabular}


A

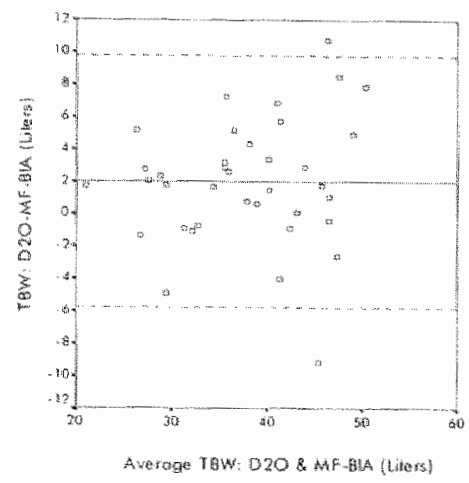

$\mathrm{C}$

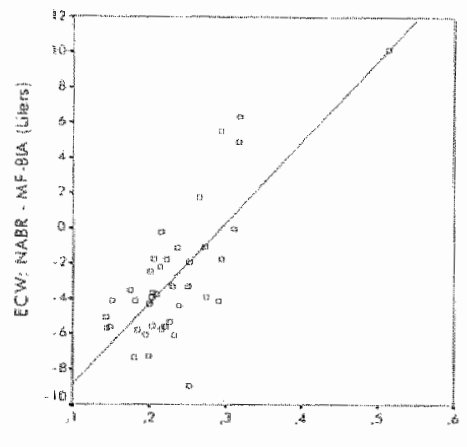

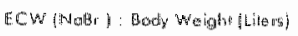

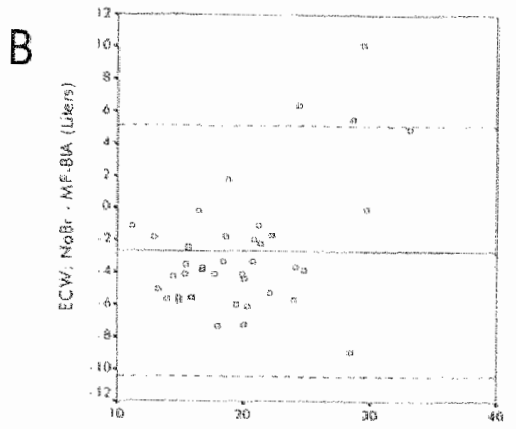

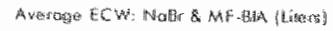

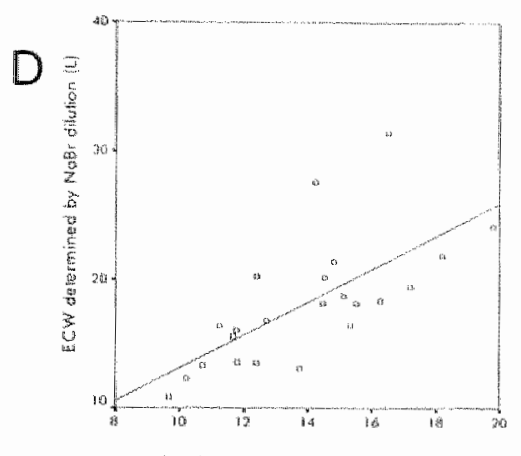

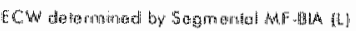

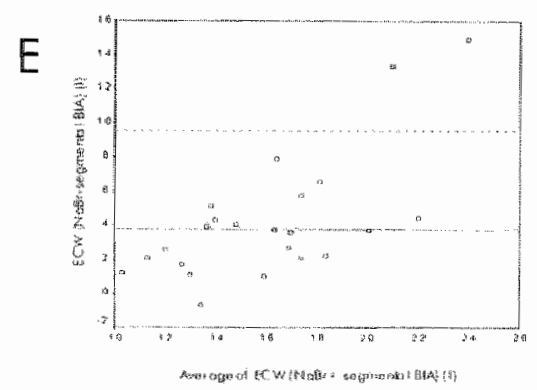

Figure 3.2. TBW=total body water; $E C W=$ extracellullar water; MF.BIA = multifrequency bioimpedance; $\mathrm{NaBr}=$ sodium bromide; $\mathrm{D}_{2} \mathrm{O}=$ = deuterium oxide.

A. Discrepancy in the assessment of TBW by $\mathrm{D}_{2} \mathrm{O}$ and the Watson formula, in relation to the percentage of body fat $(r=-0.53, p<0.05)$.

B. Limits of agreement between ECW, assessed by NaBr and MF-BLA.

C. Discrepancy in the assessment of $\mathrm{ECW}$ by $\mathrm{NaBr}$ and $\mathrm{MF}-\mathrm{BI} \mathrm{A}_{\text {, }}$ in relation to the relative magnitude of the ECW compartment $(r=0.70$, $\mathrm{p}<0.051$.

D. Correlation between ECW, assessed by $\mathrm{NaBr}$ and segmental $\mathrm{BI} A$ $(r=0.68, p<0.05)$.

E. Discrepancy in the assessment of ECW by $\mathrm{NaBr}$ and segmental BIA. 


\section{Relation between fluid state and echocardiographic parameters}

As displayed in Table 3.3, all parameiers of fluid state were significantly related to LA and LVEDD.

\section{Discussion}

The main findings of the study were firstly the highly significant correlation, but also the wide limits of agreement between tracer dilution techniques with both E-BIA and MF-BIA as well as the Watson formula and secondly the influence of the relative magnitude of the body water compartments on the relation between fracer dilution techniques with MF-BIA and the Watson formula. Moreover, despite a significant correlation to echocardiographic parameters, it appeared to be difficult to establish cutoff values for MF-BIA with reasonable sensitivity and specificity.

The wide limits of agreement between bioimpedance and tracer dilution techniques in dialysis patients, despite good correlations, are in agreement with earlier studies. ${ }^{8,20,21}$ In the present study, BIA techniques did even not appear to have significant advantages over the Watson formula regarding the prediction of TBW, which is in disagreement with the data of Cooper and Wong ${ }^{422}$ but in agreement with the results of Arkouche ef al. ${ }^{6}$

Still, regarding the agreement between MF-BIA and tracer dilution techniques in the assessment of TBW, also the limitations of dilution techniques have to be taken into account. It is known from studies in healthy subjects that the accuracy for the assessment of ECW by $\mathrm{NaBr}$ space is not absolute ( $\pm 5 \%$ ). Whereas in healthy subjects the accuracy of $\mathrm{D}_{2} \mathrm{O}$ by continuous fllow isotope ratio mass spectroscopy is excellent with regard to the measurements of $\operatorname{TBW}(1.6 \%)^{1}$. Arkouche et al. found a mean difference of $4.3 \%$ between TBW measurements with $\mathrm{D}_{2} 0$ dilution in $\mathrm{PD}$ patients. Nevertheless, in view of the high reproducibility of the dilution methods, even after o prolonged period, and in view of the very strong relation between TBW assessed by DEXA and tracer dilution techniques, which exceeded those obtained with bioimpedance and the Watson formula, this showed to our opinion the solidity of the dilution techniques used in our laboratory.

With regard to the assessment of ECW and TBW, it is interesting that the disagreement between MF-BIA and tracer dilution techniques was strongly related to the relative magnitude of the body water compartments, wich is in agreement with our previously performed study in hemadialysis patients. ${ }^{20}$ This can be explained by the fact that MF.B.A considers the body as three conductive cylinders (arm, leg, and trunk), connected in series. In conductors connected in series, the conductors with the smallest cross-sectional the extremities] will contribute most of the resistance whereas the part with the largest cross-sectional 
area (trunk) will contribute less to the resistance, despite the fact that may comprise a significant amount of (excess) body water. ${ }^{23,24}$

The discrepancy between tracer ditution measurements and the Watson formula is interesting. In the present study, the Watson formula appeared to overestimate TBW, which is in agreement with the study of Woodrow ef al ${ }^{25}$ but in disagreement with others.4,22,26 These discrepant findings are likely due to the effect of the hydration state on the reliability of the Wotson formula. In agreement with the results of both Johansson and Wong ${ }^{4,7}$, in the present study Watson formula underestimated TBW in patients with higher body hydration (thase with increased TBW:BW), which can be explained by the fact that the Watson formula assumes a normal hydration state. ${ }^{47}$ Thus also the agreement between the Watson formula and deuterium oxide is highly dependent upon the hydration state of the patient. Another important factor in the reliability of Watson appears to be body composition, as in patients with o thigh percentage of body fat, the Watson formula strongly overestimated TBW, which is also very much in line with the data of Johansson."

The limitations of standard MF-BIA in the assessment of fluid state have already been recagnized by several authors who hypothesized that $\Sigma$-BIA was superior to standard whole body MF-BIA in the assessment of trunk wolume. ${ }^{8}$ in those studies, the ability of $\Sigma$-BIA to detect changes in extracellular trunk volume was found to be superior to MF.BIA. Regrettably in the present study, with regard to the assessment of the absolute magnitude of the extracellular volume compartment, $\sum-B \mid A$ did not appear to be superior to MF-BIA as the limits of agreement between $\Sigma$-BIA and bromide dilution were as wide as those observed for MF-BIA. Given these facts, it appears that the use of $\Sigma$-BlA holds no advantage over MF-BIA for the assessment of fluid state in PD patients, also taking the relative complexity of the method into account.

Despite the wide limits of agreement between MF-BIA and tracer dilution techniques, the relation between TBW and ECW assessed by the techniques, and LA and LVEDD was at least comparable. This would suggest that MF-BIA could be a relevant clinical toal in the assessment of hydration state in PD patients. The disagreement with regard to the assessment of absolute volume compartments, and the highly significant relation between MF-BIA and cardiac dimensions would suggest that MF-BIA mainly assesses the fluid compartments which are actively implicated in the hemadynamic regulation. Indeed, it has been shown that during stable conditions, much of the fluid stored in the splanchnic circulation is inactive ("unstressed") from a hemodynamic point of view." 27,28 However, this does not preclude the importance of this compartment, which serves as a blood reservoir (unstressed volume) which can be mobilized by means of active and passive vasoconstriction in times of hemadynamic stress (e.g. during a decline in blood volume), ${ }^{28}$

Drawback of the present study is the foct that patients with severe heart fallure and insulin-dependent diabetes mellitus were excluded. This was done firstly because severe theart failure may strongly influence the relation between 
extracellular volume and cardiac parameters, whereas patients with insulin dependent diabetes were excluded because of the possible influence of diabetes mellitus on the distribution between body fluid comportments. ${ }^{29}$ If is acknowledged that these exclusion criteria therefore do not permit an extrapolation of the interpretation of the present data for the entire dialysis population.

Lastly, although $\Sigma-B \mid A$ was not performed in all patients, it should be stated that as described in the methods section this group composed an unselected group of patients.

Concluding, with regard to the assessment of total body water and extracellular volume in PD patients, a wide limit of agreement was observed between tracer dilution methods and MF-BIA, which was partly related to the relative magnitude of the bady water compartments. The relation was found not to improve by the application of $\Sigma$-BIA. Also the disagreement between the Watson formula and tracer dilution methods was found to be related to the hydration state, but also to body composition.

Nevertheless, the significant relation between MF-BIA and cardiac parameters suggests that this technique may still be relevant as a clinical tool in the assessment of fluid state in PD patients. 


\section{References}

1. Dorhout Mees EJ. Cardiovascular aspects of dialysis treatment, the importance of volume contral. Kluwer Academical Publishers 70: table 7.1., 2000

2. Katzarski $K$, Charra B, Lourent G, Lopot F, Divino-Filho JC, Nisell J, Bergstrom J. Multifrequency bioimpedance in assessment of dry weight in haemodialysis. Nephrol Dial Transplant 1996; 111(52): $\$ 20-\$ 23$

3. Jaeger JQ. Mehta RL. Assessment of dry weight in hemodialysis: An overview. J Am Soc Nephrol 1999; 10:392-403

4. Wong KC, Xiong DW, Kerr PG, Borownicar DJ, Stroud DB, Atkins RC, Strauss BJ. $\mathrm{K} 3 \mathrm{~N}$ in CAPD by different estimations of $\mathrm{V}$. Kidney Int 1995; $48: 563-569$

5. Woodrow G, Oldroyd B, Turney JH, Davies PS, Day JM, Smith MA. Measurement of total body water by bioelectrical impedance in chronic renal failure. Eur J Clin Nutr $1996 ; 50: 676-681$

6. Arkouche W, Fouque D, Pachiaudi $C$, Normand $S$, Laville $M$, Delawari $E_{*}$ Riou JP, Traeger J, La Ville M. Total body water and bady composition in chronic peritoneal dialysis patients. J Am Soc Nephrol 1997; 8: 1906-1914

7. Joharusson AC, Samuelsson O, Attman PO, Bosaeus 1, Haraldsson B. Limitations in anthropometric calculations of total body water in patients on peritoneal dialysis. I Am Soc Nephrol 2001; 12:568-573

8. Zhy Fx Schneditz D, Kaufman AM, Levin NW. Estimation of body fluid changes during peritoneal dialysis by segmental bioimpedance analysis. Kidney Int 2000; 57: $299-306$

9. Van Kreel BK, Van der Vegt F, Meers M. Determination of total body water by a simple and rapid mass spectrometric method. J Mass Spectrom 1996; 31 : 108-111

10. Van Kreel BK. An improved bromide assay for the estimation of extracellular water volume by capillary gas chromatography. Clin Chim Acta 1994; 231 : 117-128

11. Schoeller DA, Van Santen E, Petersan DW, Dietz W. Jaspen I, Klein PD. Total body water measurements in humans with ${ }^{18} \mathrm{O}$ and ${ }^{2} \mathrm{H}$ labeled water. Am $J$ Clin Nutr $1980 ; 33: 2686 \cdot 2693$

12. Miller ME, Cosgriff JM, Forbes GB. Bromide space determination using anionexchange chromatography for measurement of bromide. An J Clin Nutr 1989; 50: |68-17|

13. De Lorenzo A, Andreoli A, Matthie J, Withers P. Predicting body cell mass with bioimpedance by using theoretical methods: a teclonological review. J Appl Physiol $1997 ; 82: 1542-1558$

14. Matthie J, Zarowitz B, De Lorenzo A, Andreali A, Katzarski K, Pan G, Withers PJ. Analytic assessment of the various bioimpedance methods used to estimate body water. Appl Physiol 1998; 84: 1801-1816

15. Operaling manual Xitron $4000 \mathrm{~B}$ bio-impedance spectrum analyser system. Xitron Technologies NC, San Diego CA, USA 
64 Chapter 3

16. Watson PE. Watson ID, Batt RD. Total body water volumes for adult males and females estimated from simple anthropometric measurements. Am I Clin Nutr $1980 ; 33: 27-39$

17. Fisch BJ, Spiegel.DM. Assessment of excess fluid distribution in chronic hemodialysis patients using bioimpedance spectroscopy. Kidney Int 1996; 49: 1105-1109

18. Roubennoff $\mathbb{R}$, Kehayjas $J 1$, Dawson-Hugehes $B$, ef al. Use of dual-energy $x$-ray absorptiometry in body-composition studies: "not yet a gold standard". Am J Clin Nutr 1993:58:589-591

19. Bland JM, Altman DG. Statistical methods for assessing agreement between two methods of clinical measurement. Lancel 1996; 8: 307-310

20. Cox.Reifven PL, Kooman JP, Soeters PB, van Der Sande FM, Leunissen KM. Role of bioimpedance spectroscopy in assessment of body water compartments in hemodialysis patients. Am J Kidney Dis 2001: 38: 832-838

21. van den Ham EC, Kooman JP, Christiaans MH, Nieman FH, Van Kreel BK, Heidendal GA, Van Hooff JP. Body compasition in renal transplant patients: bioimpedance analysis compared to isotope dilution, dual energy $X$-ray absorptiometry, and anthropometry. J Am Soc Nephrol 1999; 10: 1067.1079

22. Cooper BA, Aslani A, Ryan M, Zhw FY, Ibels LS, Allen BJ, Pollock CA. Comporing different methods of assessing body composition in end-stag e renal failure. Kidney Int $2000 ; 58: 408-416$

23. Dumler F. Ulse of bioelectric impedance analysis and dual-energy $X$-ray absorptiometry for monitoring the nutritional status of dialysis patients. ASAIO J $1997 ; 43: 256-260$

24. Di lorio BR, Terracciano V, Bellizzi V. Bioelectrical impedance measurement errors: and artifacts. J Ren Nutr 1999; 9: 192-197

25. Woodrow G, Oldroyd B, Turney JH, Davies PSW, Day JME, Smith MA. Measurement of fotal body water and urea kinetic modelling in perilloneal dialysis. Clin Nephrol $1997 ; 47: 52-57$

26. Dahl NV, Foote EF, Kapoian T, Steward CA, Sherman RA. Measuring total body water in peritoneal dialysis patients using an ethand dilution technique. Kidney Int $1999 ; 56: 2297-2303$

27. Risoe C, Tan W, Smiseth OA. Effect of carotid sinus baroreceptor reflex on hepatic and splenic vascular capacitance in vagotomized dogs. Am J Physial 1994; 266: $H 1528-1533$

28. Rothe CF. Venous system: physiology of capacitance vessels. In: Handbook of Physiology, 1983. Sect 2. Cordiovascular system. Vol 3. Peripheral circulation and organ blood flow. Chapt 13. American Physiological Society, Bethesda, pp 397.452

29. Oomen PH, Jager J, Hoogenberg K, Dullart RP, Reitsma WD, Smit AJ. Capillany permeability is increased in normo-and microalbuminuric type 1 diabetic patients: amelioration by ACE-inhibition. Eur J Clin Invest 1999; 29: 1035-1040 


\section{Chapter 4}

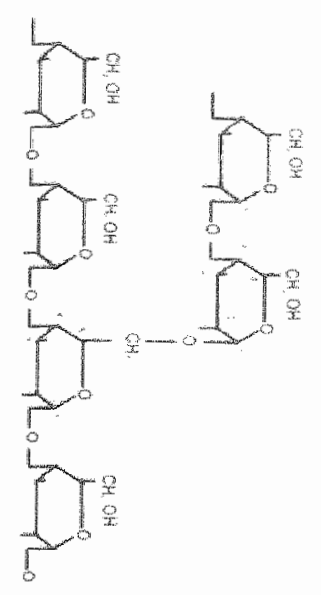

\section{Fluid state, blood pressure, and cardiovascular abnormalities in patients on peritoneal dialysis}

CJAM Komings, JP Koomon, W Schonck, Rommers, E Cherrex, AP Polmans-Meulemans, APG Hoeks, B wan Kreel, U Godriwa. Mvan der Sonde, KML Leunissen

Perit Did Int 2002: 22: 477-487. 


\section{Abstract}

Hypertension, reduced arterial distensibitity caefficient (DC) and left ventricular hypertrophy (LH) are risk factors for mortality in hemodialysis (HD) patients. However. few studies have focused on the relation between fluid state, blaod pressure (BP), and cardiovascular abnormalities in peritoneal dialysis (PD) patients. This siudy was designed firstly to assess the fluid state in PD palients compared to a control population of stable renal transplant (RTX) patients using tracer dilution techniques, secondly to study the relation between fluid state, blood pressure (BP) and arterial wall abnormalities, thirdly to assess the deferminants of cardiac structure and lastly to compare office and ambulatory BP measurements with regard to cardiac abnormalities. 40 stable PD patients (30 continuous ambulatory PD [CAPD], 10 continuous cyclic PD [CCPD], with a mean $K t / N_{\text {ureo }}$ of $2.4 \pm 0.7$, and 77 stable RTx patients were included in the study. Fluid state was assessed by tracer dilution techniques (extracellular water (ECW): bromide dilution; total body water (TBW): deuterium axide; plasma volume (PV: dextran 70). Echocardiagraphy was pertormed to assess left ventricular mass [LVM), left ventricular end-diastolic diameter (LVEDD) and relative wall thickness (RWT) as indicotiors of LVH, echography of the common carotid artery (CCA) was performed to assess DC. Both office and 24-hour ambulatory BP were performed.

Fluid state, as assessed by ECW corrected for bady surface area (BSA), was significanily different between PD and RTx patients $\left(9.4 \pm 2.6\right.$ vs $\left.8.6 \pm 1.2 \mathrm{l} / \mathrm{m}^{2}, \mathrm{p}<0.05\right)$. In $37.5 \%$ of the PD patients ECW:BSA was above the $90^{\text {in }}$ percentile of the RTx patients. Fluid state corrected for BSA, either assessed by TBW, ECW and PV was significantly related to diastolic BP (DBP) $(r=0.35, r=0.37, r=0.53 ; p<0.05)$. DC of the CCA was related to systitic BP $(S B P)(r=-0.36 ; p<0.05)$. ECW was significantly related to $\operatorname{LVEDD}(r=0.41$, $p<0.05)$ as marker of eccentric LVH, whereas DC was related to RWT ( $r=-0.53$, $p<0.001$ as marker of concentric LVH. An abnormal daymight BP rhythm, which was not related to fluid state, was observed in $65.0 \%$ of patients. Ambulatory DBP and SBP. but not office DBP and SBP, were related to LVM $(r=0.43, r=0.46 ; p<0.07)$.

In conclusion, a large proportion of PD patients with treatment prescription according to Dialysis outcome and quality improvement (DOQ) guidelines were found to be overhydrated in comparison with a stable population of RTX patients. Fluid state was significantly related to DBP and eccentric LVH, whereas DC of the CCA was significantly related to SBP and concentric LVH. In contrast to ambulatory BP, affice BP was not related to LVM. 


\section{Introduction}

In patients with end stage renal disease (ESRD), cardiovascular disease (CVD) is by far the most common cause of death. Cardiac abnormalities, such as left ventricular hypertrophy (LVH), are strongly related to morbidity and mortallity. "In hemadialysis (HD) patients, several studies have shown a relation between fluid overload, hypertension, and cardiac abnormalities ${ }^{2.3}$, despite the fact that interpretation of these data is complicated by the continuously changing fluid state in these patients. Moreover, abnormalities of the large arteries, resulting in a reduced arterial distensibility and compliance were also found to be related to both systolic hypertension and changes in cardiac structure. ${ }^{4}$ In contrast, few detailed data exist on the fluid state of peritoneal dialysis (PD) patients, nor on the relation between fluid state, blood pressure, and structural cardiovascular abnormalities in this population. Various authors have suggested a theoretical advantage of PD due to the continuous fluid removal and the fact that residual diuresis is often better maintained ${ }^{5,6}$, although this does not comply with the huge consumption of antitypertensive agents in the population of PD patients? whereas a recent study even suggested that PD patients are actually more overhydrated than HD patients. ${ }^{8}$ Recent studies also showed that for an adequate assessment of fluid state in HD and PD patients, tracer dilution techniques are necessary. 9.10

Clinical practice single office measurements are used to estimate blood pressure (BP). However, at least in HD and renal transplant (RTX) patients, a wide variability between single office measurements and 24-hours BP was observed. ${ }^{11.14}$ It is however not well known whether ambulatory BP measurements have an advantage over office measurements with regard to their relation with end organ damage, e.g. cardiac abnormalities, in stable PD potients.

The aims of the present study were fourfold. Firstly to assess the fluid state in PD patients compared to a control population of stable RTx patients using various dilution techniques. Secondly to study the relation belween fluid state, blood pressure and anterial wall abnormalities. Thirdly to assess the determinants af cardiac structure and lastly to compare office and ambulatory BP measurements with regard to the existence of cardiac abnormalities in a cohort of stable PD patients.

\section{Patients}

In this multi-center study which was performed in six hospitals, farty stable PD patients were included (29 males; 11 females; 30 continuous ambulatory PD [CAPD], 10 continuous cyclic PD [CCPD]). Patients with metal implants, and recent complications (e.g. malignancy or surgery), insulin-dependent diabetes 
mellitus (IDDM), and congestive heart fallure or caronary artery disease (NYHA III and higher) were excluded. Mean age of the patients was $53.6 \pm 12.4$ years [ronge 32-71].

Patients with severe cardiac falure and/or coronary artery disease were excluded because the underlying disease might severely influence relations bewween fluid averload, bload pressure and cardiac structure and therefore obscure potentialiy important relations in a group of PD patients without cardiac failure. Insulin dependent diabetics were not included because the increased transcapillary escape rate for albumin in this population might interfere with the reliability of measurements of plasma volume. ${ }^{\text {is }}$

Dry-weight was assessed on clinical grounds according to the treating physician. with no signs of averhydration, avoiding an elevated central venous pressure, peripheral or pulmonary edema. Al PD patients were treated according to the dialysis outcome and quality improvement (DOQI) guidelines ${ }^{16}$, they had a mean K $\mathrm{N} N$ ureo of $2.4 \pm 0.7$.

Also included in this study were 77 RTx patients, with a stable renal function (mearn creatinine clearance $60.2 \pm 20.5 \mathrm{ml} / \mathrm{min}$ ) under maintenance immunosuppressive therapy for at least 2 years. ${ }^{17}$ Creatinine clearamce in this group was calculated by the use of the formula of Cockroft and Gault. ${ }^{18}$ Informed consent was obtained from each patient, and the study was approved by the Ethical Committee of the Academical Hospital of Maastricht. Patient demagraphics are demonstrated in Table 4.1 and 4.2.

\section{Methods}

\section{Study design}

In this multi-center study, which included patients from four dialysis centers in the south eastern part of the Netherlands, one dialysis center in Germany, and the Academical Hospital of Maastricht, the relation between fluid state, blood pressure, echocardiographic parameters and arterial wall abnormalifies was studied in a cross-sectional design.

\section{Study protocol}

Patients were admitted to the research center at the dialysis department of the Academical Hospital of Maastricht in the early morning after an overnight fast. If patients had a filled abdomen over the night, PD fluid was first drained betore the measurements were started. After admission, tracer dilution measurements were pertormed and office BP was measured. During this study period, patients were not allowed to eat or drink. At noon, patients were allowed to eat a light meal, of which the tolal amount of fluid did not exceed $200 \mathrm{ml}$. Hereafter, echocardiography was performed, followed by 24-hour ambulatory blood pressure measurements. 
Table 4.1. Patient demographics PD patients

Man/woman

CAPD/CCPD

Age (years)

Weight $(\mathrm{kg})$

Body surface area (BSA) $\left(\mathrm{m}^{2}\right)$

Body mass index $(\mathrm{BM}) /\left(\mathrm{kg} / \mathrm{m}^{2}\right)$

Time on CAPD (months)

24 Hours PD fill volume ( $\mathrm{ml} / 24 \mathrm{hrs}$ )

24 Hours PD glucose admin. (gr/24 hrs)

Weekly $\mathrm{Kt} / \mathrm{N}_{\text {ure }}$

Weekly Creatimine Clearance $\left(1 / 1.73 \mathrm{~m}^{2}\right)$

Residual Glom. filtration rate $(\mathrm{ml} / \mathrm{min}))^{\circ}$

Residual Diuresis ( $\mathrm{ml} / 24 \mathrm{hrs}$ )

Periltoneal Ultrafiltration ( $\mathrm{ml} / 24 \mathrm{hrs}$ )

Total Body $\left(\mathrm{D}_{2} \mathrm{O}\right)(\mathrm{L})$ Water

Plasma Valume (Dextran 70)(1)

D/P creatinine

$\mathrm{Hb}(\mathrm{g} / \mathrm{d})$

PTH (pmol/l)

Cause renall insufficiency

Glomerulonephritis

Glomerulosclerosis

Hypertension

Polycystic disease

Urological disorder

Unknown

Antihypertensive medication use

ACE winhibitor

AT-1 antagonist

B-blocker

a-blocker

Calcium channel blocker

Anti-hypertensive medication use

o

1

2

3

4
Number $(\%)$

$29(73) / 11(27)$

$30 / 10$

$$
\text { Mean } \pm \text { SD }
$$

$53.6 \pm 12.4$

$77.8 \pm 13.6$

$1.9 \pm 0.2$

$26.0 \pm 3.6$

$27.1 \pm 17.3$

$10268 \pm 2781.9$

$191.1 \pm 63.3$

$2.4 \pm 0.7$

$85.4 \pm 30.7$

$4.3 \pm 3.9$

$945.6 \pm 943.3$

$1017.0 \pm 978.8$

$38.3 \pm 7.7$

$3.2 \pm 0.7$

$0.65 \pm 0.1$

$11.8 \pm 1.4$

$12.0 \pm 11.1$

Range

$32-71$

$45.9-112.5$

$1.3-2.4$

$18.6-35.4$

$3.0-66.0$

$5000-18500$

$68.0 \cdot 306.5$

1.4. 5.0

44.5-179.2

0- 14.8

0- 4400

$-1600-3800$

$21.9-54.3$

$2.0 \pm 4.6$

$0.45 \pm 0.90$

$9.2-14.8$

$0.8-40.3$

Number of pts $(\%)$

$19(47.5)$

$3(7.5)$

$6(15.0)$

$4(10.0)$

$6(15.0)$

$2(5.0)$

Number of pts (\%)

$17(41.5)$

$4(9.8)$

$30(73.2)$

$12(29.3)$

$16(39.0)$

Number of pts

$5(12.5)$

$10(25.0)$

$12(30.0)$

$9(22.5)$

$4(10.0)$

"Residual Glom.Filtration rate calculated by kinetic modelling by the use of PD adequest. ${ }^{18}$ ACE-inhibitor: angiotensin converting enzym blocking agent; AT-1 antagonist: angiotensin I blocking agent; $\beta$-blocker: beta receptor blocking agent; $\alpha$ blacker: alfa receptor blocking agent. 
Table 4.2. Patient demogrophics renal fransplant patients

$\begin{array}{lcc} & \text { Number }(\%) & \\ \text { Male/female } & 42(54.5) / 35(45.5) & \\ & \text { Mean } \pm 50 & \text { Range } \\ \text { Age (years) } & 51.0 \pm 11.7 & 25.5-78.2 \\ \text { Man/woman } & 42(54.5) / 35(45.5) & \\ \text { Weight (kg) } & 69.8 \pm 12.8 & 43.5-99.5 \\ \text { Body surface area }(\mathrm{BSA})\left(\mathrm{m}^{2}\right) & 1.8 \pm 0.2 & 1.4-2.2 \\ \text { Body mass index }(\mathrm{BM})\left(\mathrm{kg} / \mathrm{m}^{2}\right) & 24.8 \pm 4.8 & 16.7-42.2 \\ \text { Creatinine clearance }\left(\mathrm{m} / / \mathrm{min}^{\prime}\right. & 60.2 \pm 20.5 & 31.0-114.0\end{array}$

"Creatinine clearance calculated by the formula of Cackroft and Gault."

\section{Study parameters}

\section{Peritoneal transport state}

Within a maximum of two months before entry of the study the transport state of the peritoneal membrane was characterized using a standard peritoneal equilibrium test after a four hour dwell with a $2.27 \%$ glucose containing PD solution. At entry of study, on the same day, a 24 -hour collection of the dialysis fluid and the urine was performed to calculate the $K+/ N_{\text {urea }}$ and the weekly creatinine clearance narmalized to $1.73 \mathrm{~m}^{2}$ body surface area (BSA) and the residual glomerular filtration rate (rGFR). All calculations were made using PD Adequest software. 19

\section{Fluid stare}

Patients received an orally administered dose of deuterium axide $\left(D_{2}\right.$ O) of $25 \mathrm{ml}$ (99\% $\mathrm{D}_{2} \mathrm{O}$, Sigma Chemicals, St. Lowis, USA) and $30 \mathrm{ml}(150 \mathrm{mmol})$ sodium bromide (NaBr, pharmacological department, Academical Hospital Maastricht, the Netherlands). Dose bottles were washed out and the rinsed water was also ingested by the patients to ensure that all $\mathrm{D}_{2} \mathrm{O}$ and $\mathrm{NaBi}$ were consumed. Enrichments of $\mathrm{D}_{2} \mathrm{O}$ and $\mathrm{NaBr}$ in the body fluid were measured in serum. Immediately before $\mathrm{D}_{2} \mathrm{O}$ and $\mathrm{NaBr}$ intake, a (background) bload sample was taken. After the equilibration time of 4 hours a second blood sample was collected. The concentration of $\mathrm{D}_{2} \mathrm{O}$ and $\mathrm{NaBr}$ in serum was determined by isotope ratio mass spectromeiry and gas chromatography respectively. ${ }^{20,21} \mathrm{D}_{2} \mathrm{O}$ and $\mathrm{NaBr}$ dilution spaces were calculated from respectively the enrichment of $\mathrm{D}_{2} \mathrm{O}$ and $\mathrm{NaBr}$ after 4 hours. Tolal body water (TBW) was calculated as the $\mathrm{D}_{2} \mathrm{O}$ dilution space corrected for the exchange of $\mathrm{D}_{2} \mathrm{O}$ with nonaquaous compartments and for the concentration of water in the serum by first dividing the dilution space by 1.04 and thereafter multiplying it by $0.94 .^{22}$ The extracellular water compartment, i.e, extracellular water(ECW) was calculated as the $\mathrm{NaBr}$ dilution space corrected for intracellular penetration of $\mathrm{NaBr}$ in erythrocytes, leukocytes and secretory cells, for unequall $\mathrm{NaBr}$ concentrations in the extracellular fluids (Gibbs-Donnan effect), and for the concentration of water in the serum; therefore, $\mathrm{NaBr}$ dilution space was multiplied by the following correction factor: $0.90 * 0.95 * 0.94=0.80^{22,23}$ 
Plasma volume (PV) was determined by the disappearance of dextran-70 out of the circulation, after an intravenous injection. During one hour, every 15 minutes blood samples were taken to calculate a lineair disappearance line, with an extrapolation of $P V$ at $\dagger=0 .{ }^{24}$

\section{Normalization of parameters}

Regarding the relation with blood pressure, fluid state was normalized for body surface area (BSA), although the optimal normalization procedure for fluid state is not well known in dialysis patients. ${ }^{25}$ Earlier studies showed a better correlation with hemodynamic variables when BSA instead of body weight was used for normalization. ${ }^{26}$ When comparing ECW between PD and RTx patients, also height was used as normalization procedure.

The 90th percentile of ECW corrected for BSA in the group of RTx patients was used as an arbitrary cut off point for overhydration. PD patients with a volume state below the $25^{\text {th }}$ percentile of the ECW corrected for BSA that of the RTx patients were classified as being underhydrated.

Regarding the relation with echocardiographic parameters, fluid state was not normalized because, except for left ventricular mass index (LVMi), echocardiographic parameters are generally not corrected for BSA. Nevertheless, as body structure per se may be related to echocardiographic parameters, BSA was included in a multiregression analysis.

\section{Echocardiography}

Two-dimensional echocardiography was performed using a HP Sonos 5500 ultrasound system (Hewlett Packard, U.S.A.) with standard imaging transducers with a frequency varying from 1.6 to $3.2 \mathrm{MHz}$. Parameters included in the analysis were LVM, LVMi, left ventricular end-diastolic diameter (LVEDD) as a parameter of left ventricular eccentric hypertrophy, and relative wall thickness (RWT) as a parameter of concentric left ventricular hypertrophy.

LVM was calculated according to the formula of Devereux and Reichek ${ }^{27}$ : LVM $=1.04\left((\text { LVEDD + IVS-EDWT + PW-EDWT })^{3}-(\text { LVEDD })^{3}\right)-13.6$

RWT was calculated according to the formula: RWT $=(2 * P W-E D W T) / L V E D D)$.

PW-EDWT: posterior wall end-diastolic wall thickness, IVS-EDWT: interventricular septall end-diastolic wall thickness. ${ }^{28}$

\section{4-hour ambulatory BP}

In all patients, 24-hour BP measurements were performed using a Spacelabs oscillometric BP monitor (Redmond, WA, USA). BP was measured every 15 minutes from $7 \mathrm{a} . \mathrm{m}$ till $11 \mathrm{p} . \mathrm{m}$ and every 30 minutes from 11 p.m till $7 \mathrm{a} . \mathrm{m}$. Measurements were only included if more than $85 \%$ of the readings were successful. If not, the measurement was repeated. For the separation of dayand nighttime blood pressures, "fixed" hours were taken: $7 \mathrm{a.m}$ till $11 \mathrm{p.m}$ for daytime and $111 \mathrm{p} . \mathrm{m}$ till $7 \mathrm{a} . \mathrm{m}$ for nighttime BP. ${ }^{13}$ Values larger than $135 \mathrm{mmHg}$ for ambulatory systolic and $85 \mathrm{mmHg}$ for ambulatory diastolic blood pressure (DBP) were used as criteria for hypertension. ${ }^{29}$ An abnormal day-night blood pressure rhythm was defined as a decline in the mean arterial pressure (MAP) of less than $10 \%$ during the night. ${ }^{14,29}$ 


\section{Office blood pressure}

Arterial blood pressure (systolic blood pressure (SBP), DBP and mean arterial pressure (MAP)) were measured with an automatic BP monitor af the brachial artery (Dinamap 1486 SX, Critikon, Florida, USA), after a period of 15 minutes supine rest. Pulse pressure (AP) was calculated as SBP minus DBP.

\section{Arterial wall properties}

The distension and diameter of the right common carotid artery (CCA) was assessed using an automated echo-tracking system (Wall Track $\mathrm{H}_{\text {, Pie Medical, }}$ the Netherlands) ${ }^{30}$ With this system the vessel walls are detected with the use of ultrasound, using a $7.5 \mathrm{MHz}$ linear array echo-probe. A sample volume is placed at the posterior and anterior walls of the CCA, 1 to $2 \mathrm{~cm}$ proximal below the bulb. The raw radiafrequency data are subsequently stored in a computer, after which the vessel wall motion during each heart cycle is tracked with the EKG trigger as reference time-point. In this way the distension $(\Delta D)$ of the artery and diameter (D) at end diastole can be calculated. $\Delta \mathrm{D}$ was expressed as the mean of at least 7 consecutive reproducible cardiac cycles. Distensibility and compliance were expressed as distensibility (DC) and compliance coefficient (CC) using the pulse pressure $(\triangle P)$ obtained in the brachial artery according to the following formula's: $D C=2(\Delta D / D) / \Delta P, C C=(\pi D \Delta D) /(2 \Delta P))^{31,32}$ Pulse pressure was assessed by the Dinamap described above.

\section{Laboratory parameters}

In the group of PD patients, blood samples were taken for the assessment of hemoglobin (Coulter-Genis, California, U.S.A.), and parathormone (PTH) (IRMA assay, Nichols Institute Diagnostics, California, U.S.A.).

\section{Statistical analysis}

Data are expressed as mean $\pm S D$. Correlations between body water compartments measured by the different methods were estimated by the use of Pearson product moment correlations. P-values $<0.05$ were considered significant. If appropriate, a lineair multiregression analysis was used with LVM as independent variable. The variables were included by forward selection. The following variables were included in the lineair multiregression analysis: 24 -hour MAP, DC, BSA and ECW:BSA. Calculations were made using SPSS 10 statistical software for Windows. To show limits of agreement between different methods to measure blood pressure, Bland and Altman plots were used. ${ }^{33}$

\section{Results}

\section{Difference in fluid state between PD and transplant patients}

ECW was significantly different between PD and RTx patients $(18.3 \pm 6.4$ । ws. $15.5 \pm 2.91 ; p=0.002)$, also when corrected for BSA $\left(9.4 \pm 2.6 \mathrm{l} / \mathrm{m}^{2}\right.$ vs. $8.6 \pm 1.2$ 
$\| / \mathrm{m}^{2} ; \quad p=0.03$ ) (Figure 4.1) and for ECW corrected for height (ECW:height) $(10.5 \pm 3.2 \mathrm{l} / \mathrm{m}$ versus $9.2 \pm 1.6 \mathrm{l} / \mathrm{m}[\mathrm{p}=0.02])$.

The 90th percentile of ECW corrected for BSA was $9.91 / \mathrm{m}^{2}$ in the group of RTX patients, indicating that 15 patients out of the 40 PD patients $(37.5 \%)$ were found to be overhydrated, this without overt clinical signs of overhydration $190^{\text {th }}$ percentile for ECW:height in RTx patients $10.8 \mathrm{~V} / \mathrm{m} .33 \%$ of PD patients overhydrated according to this limit). Nevertheless, despite the significant difference, a wide overlap existed in fluid state between PD patients and RTx patients as is demonstrated in Figure 4.1.
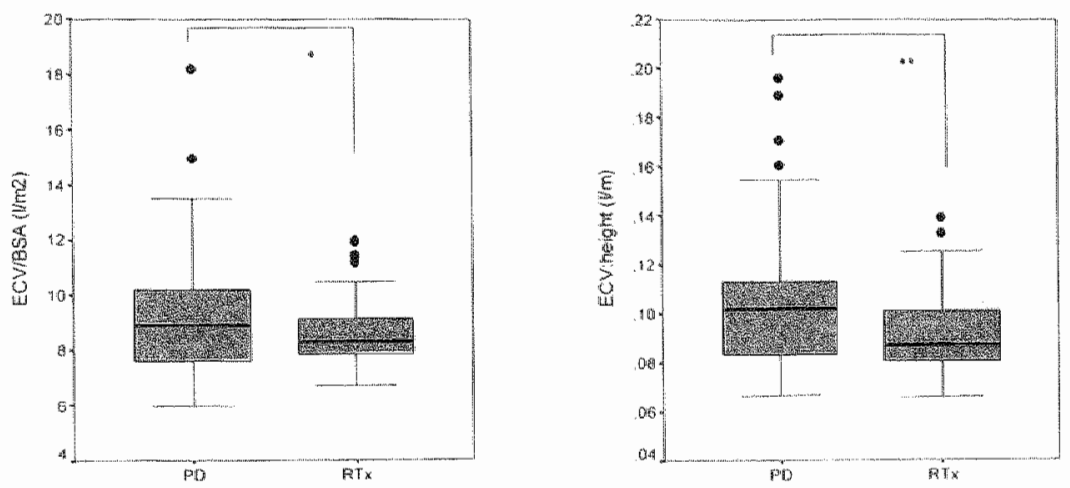

Figure 4.1. Difference in fluid state of PD and RTx patients.

* $p=0.03, * * 0=0.02$. Covered boxes indicate $25.75 \%$ with median value, captured bars indicate the range of data, excluding outliers.

A significant inverse relation between total $\mathrm{Kt} / \mathrm{N}_{\text {ureo }}$ and the volume state expressed by ECW:BSA $(r=-0.38 ; p=0.015)$ was observed. rGFR was found to be strongly related to the total $K t / N_{\text {ureo }}(r=0.76 ; p<0.0001)$ and also significantly to $E C W: B S A(r=-0.37 ; p=0.02)$. On the contrary a pasitive relation between peritoneal ultrafiltration volume and ECW:BSA was observed $(r=0.34$, $p=0.031$.

\section{Determinants of BP}

Ambulatory and office BP values for PD patients are summarized in Table 4.3. Although there was a good correlation between office and ambulatory $B P$ measurements (for DBP: $r=0.73$, and for SBP: $r=0.81$; both $p<0.05$ ), limits of agreement between these variables were quite wide. The mean difference between 24-hour ambulatory SBP and office SBP was $-14.9 \mathrm{mmHg} \pm 15.0$ (range -65.0 to 8 ), the mean difference between 24-hour ambulatory DBP and office DBP was $-2.33 \mathrm{mmHg} \pm 8.0$ (range -20 to 15 ). 
Table 4.3. Results PD patients: blood pressure, fuid state, arterial destensibility, cardiac dimensions

\begin{tabular}{|c|c|c|}
\hline & Mean $\pm S D$ & Range \\
\hline \multicolumn{3}{|l|}{$\mathrm{BP}$} \\
\hline \multicolumn{3}{|l|}{24 hrs ambulatory BP } \\
\hline $\mathrm{DBP}(\mathrm{mm} H \mathrm{H})$ & $80.9 \pm 17.8$ & $62-105$ \\
\hline $\operatorname{SPP}(\mathrm{mmHg})$ & $132.1 \pm 17.8$ & $100-172$ \\
\hline \multicolumn{3}{|l|}{ Day time ambulatory BP } \\
\hline DBP (mmting) & $82.5 \pm 10.0$ & $64-106$ \\
\hline $\operatorname{SBP}(\mathrm{mmHg})$ & $133.4 \pm 17.2$ & $104-171$ \\
\hline \multicolumn{3}{|l|}{ Night time ambulatary BP } \\
\hline DBP $($ monig $)$ & $76.3 \pm 12.0$ & $53 \cdot 105$ \\
\hline $\mathrm{SBP}(\mathrm{mmHg})$ & $127.1 \pm 20.0$ & $85 \cdot 176$ \\
\hline \multicolumn{3}{|l|}{ Office BP } \\
\hline $\mathrm{DBP}(\mathrm{mmH} / \mathrm{g})$ & $83.3 \pm 10.3$ & $56-102$ \\
\hline $\mathrm{SBP}(\mathrm{mmH})$ & $147.3 \pm 24.4$ & $99 \cdot 217$ \\
\hline \multicolumn{3}{|l|}{ Fluid state } \\
\hline TBW $\left(\mathrm{D}_{2} \mathrm{O}\right)(1)$ & $38.3 \pm 7.7$ & $21.9-54.3$ \\
\hline PV (Dextran70)(I) & $3.2 \pm 0.7$ & $2.0-4.6$ \\
\hline \multicolumn{3}{|l|}{ ECW NaBr $(1)$} \\
\hline ECW: NaBr: BSA $\left(I / \mathrm{m}^{2}\right)$ & $9.1 \pm 2.1$ & $6.0-15.0$ \\
\hline ECW: height & $10.5 \pm 3.2$ & $6.6 \cdot 19.6$ \\
\hline \multicolumn{3}{|l|}{ Arterial distensibity } \\
\hline$D C(0.001 / \mathrm{kPa})$ & $16.0 \pm 6.5$ & $3.9-33.2$ \\
\hline $\mathrm{CC}\left(\mathrm{mm}^{2} / \mathrm{kPo}\right)$ & $0.8 \pm 0.33$ & $0.18-1.69$ \\
\hline \multicolumn{3}{|l|}{ Cardiac dimensions } \\
\hline $\operatorname{LVM}(g)$ & $225.6 \pm 48.3$ & $126-325$ \\
\hline LVEDD $(m \mathrm{~mm})$ & $50.3 \pm 5.6$ & $40-64$ \\
\hline
\end{tabular}

For used abbreviations see text. Values represent as mean SD, ranges also given.

The correlations and limits of agreement are displayed in scatter and Bland and Altman plots in Figure 4.2 and 4.3 .

20 patients $(50.0 \%)$ had values larger than $135 \mathrm{mmHg}$ for ambulatory SBP and $85 \mathrm{mmHg}$ for ambulatory DBP, and were hypentensive according to the used criteria for hypertension, despite the use of antihypertensive medication.

No significant relation was found between markers of fluid state and affice BP. TBW was significantly related to 24-hour DBP when corrected for BSA $(r=0.35$, $p<0.05$ ). The relation beween TBW (corrected for BSAl and 24-hour SBP did not reach significance. ECW was significantly related to 24 -hour diastolic $B P$ when corrected for BSA $(r=0.37 ; p<0.05)$ (Figure 4.4). The relation between ECW conected for BSA and 24-hour SBP did not reach significance. PV was significantly related with 24-hour DBP, when corrected for BSA $(r=0.53$; $p=0.001)$. The relation between PV (corrected for BSA) and 24-hour systolic BP did not reach significance. Twenty-six $(68.4 \%)$ patients had a decline of their MAP during the night of less than $10 \%$ and were classified as non-dippers. No significant difference in fluid state was abserved between the group of dippers and non-dippers. 

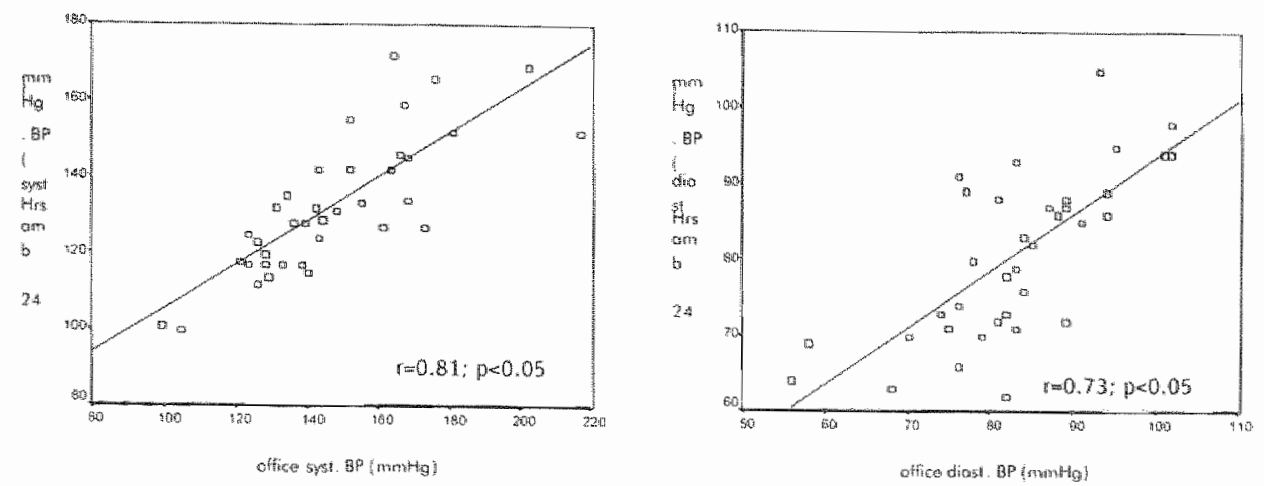

Figure 4.2. Correlation between office BP and 24-hour ambulatory BP.
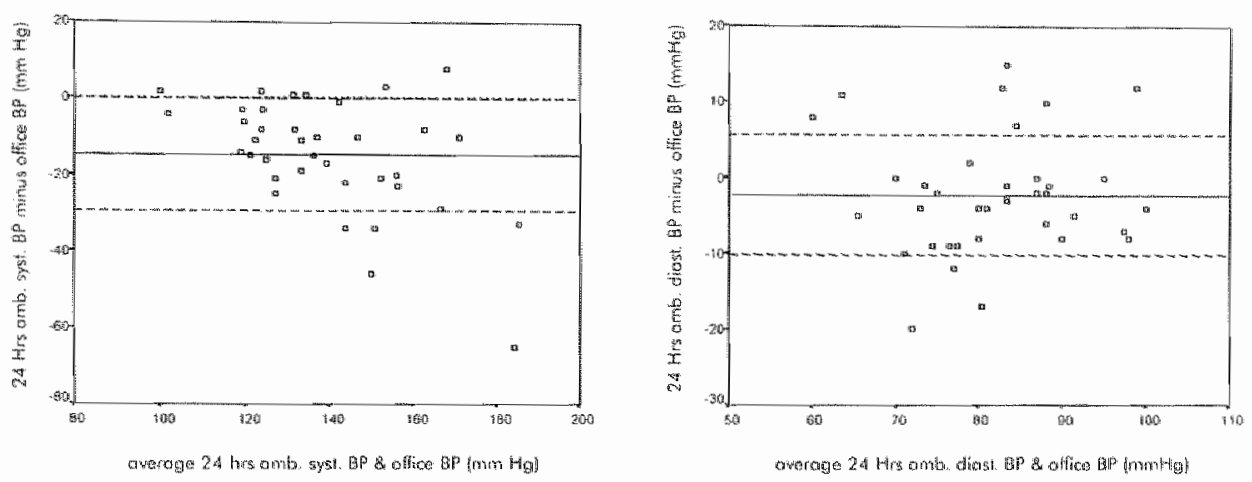

Figure 4.3. Difference between office BP and 24-hour ambulatory BP.

Despite the significant relation between volume state and $\mathrm{BP}$, also in $14 \mathrm{PD}$ patients who were classified as being underhydrated by the used definition, BP was elevated despite the use of antihypertensive medication in 5 out of these 14 $(36.0 \%)$ patients.

Regarding the relation between arterial wall characteristics and $B P, D C$ of the CCA was significantly related to 24 hour SBP $(r=-0.36, p<0.05)$ but not to 24 hour DBP. The relation between CC and SBP did not reach significance.

\section{Determinants of cardiac structure}

Both 24-hours SBP and DBP were significantly related to LVM $(r=0.43$; $p=0.006$, respectively $r=0.46 ; p=0.003$ ) (Figure 4.5), and $L V M i \quad(r=0.45$; $p=0.003$, respectively $r=0.40 ; p=0.012)$. LVEDD was negatively related to RWT $(r=-0.68, p<0.001)$.

Regarding fluid state, both PV $(r=0.60)$, ECW $(r=0.45)$ and TBW $(r=0.44)$ were significantly related to LVM $(p<0.05)$ and also to $L V E D D(r=0.64(P V) ; r=0.41$ (ECW) and $r=0.55$ (TBW), $p<0.05$ ), but not to RWT. 
$76 \mid$ Chapter 4

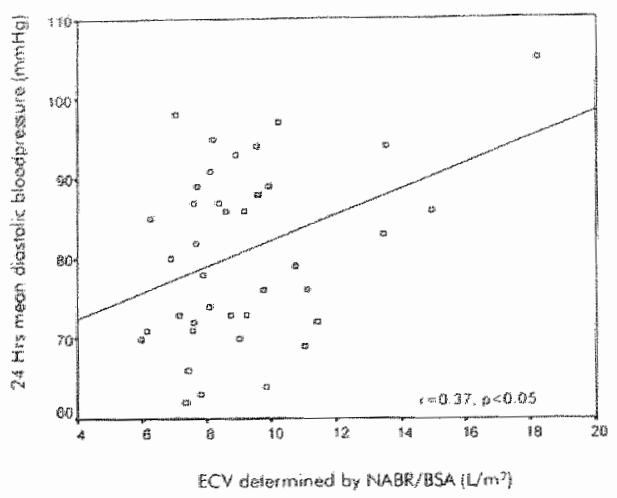

Figure 4.4. Relation between ECW:BSA and 24-hour DBP
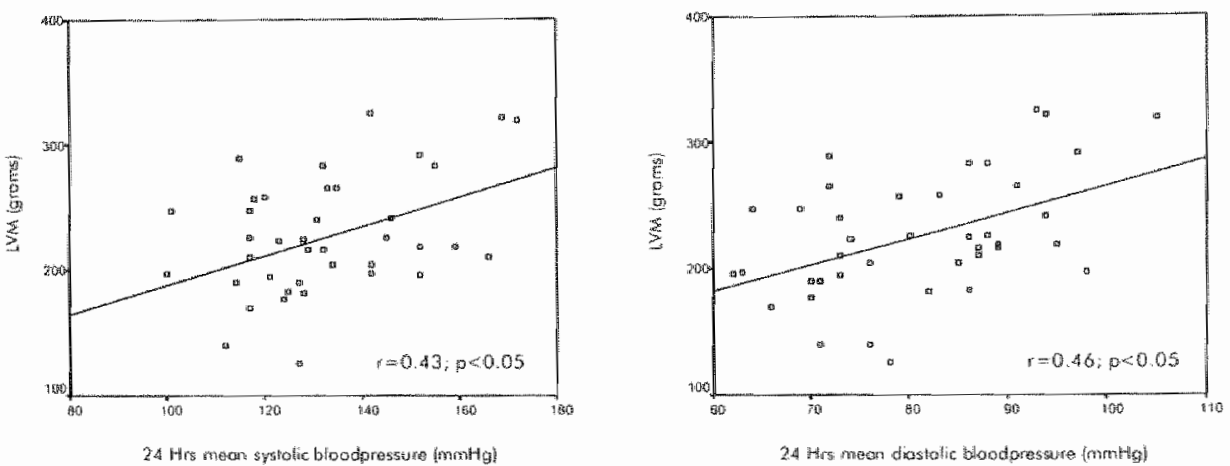

Figure 4.5. Relation between 24-hour 5BP \& DBP ws LVM
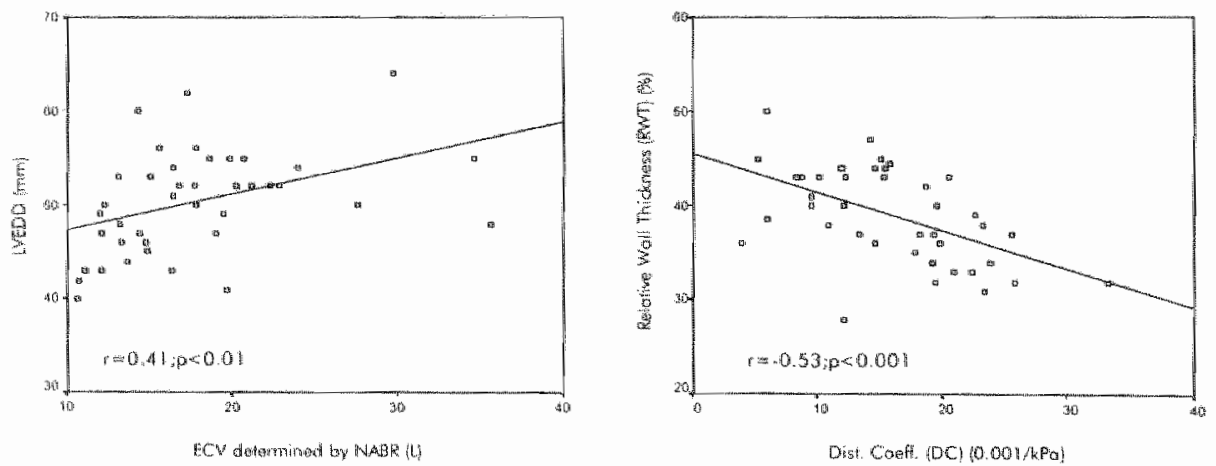

Figure 4.6. Relation between ECW and LVEDD and relation between DC and RWT 
DC and CC were significantly related to RWT $(r=-0.53, p<0.001, r=-0.42$, $p=0.008$ ) (Figure 4.6). Hemaglobin and PTH were not significantly related to any cardiac parameter.

In the lineair multiregression model, 24-hours MAP, DC and BSA acted as independent variables related to $L V M \quad(t=3.1, t=2.4$ and 2.3 , resp.; $p<0.05)$. ECW: BSA was nearly significant in this model $(t=1.9, p=0.06)$.

\section{Discussion}

The main findings of the present study are fourfold: firstly the presence of overhydration in a significant number of PD patients who are treated according to the DOQI guidelines, secondly the fact that, in contrast to office BP, ambulatory BP was related to LVH, thirdly the relation between ambulatory DBP on one hand and fluid state and arterial wall abnormalities and SBP on the other hand, and lastly the observation that eccentric LVH is mainly related to fluid state whereas concentric LVH is mainly related to structural abnormalities of the large crteries.

Using a cohort of stable age-matched RTx patients as a control population, over one third (37.5\%) of PD patients was overhydrated according to the $90^{\text {th }}$ percentile for ECW:BSA of RTx patients. Although it can be argued that RTx patients are not the optimal control subjects and that this cut-off point is arbitrary chosen, and is by no means absolute, it should only be regarded as an indicator for the existence of overhydration in a significant proportion of PD patients in comparison with RTx patients who were in stable condition and had a mean creatinine clearance of $60.2 \pm 20.5 \mathrm{ml} / \mathrm{min}$, which makes it highly unlikely that abnormalities in fluid state due to renal disease per se would occur in this cohort. We believe that it can be defended to use RTx patients as a control group, also because the use of healthy subjects without any history of renal disease as controls subjects for PD patients might introduce flaws, e.g. because of their great difference in terms of body composition. Fluid state was assessed in both groups with tracer dilution techniques performed in the same laboratory. Interestingly, as can be seen from Figure 4.1, the variation in fluid state of PD patients was much wider compared to RTx patients.

If PD patients were divided according to their fluid state into two groups (i.e., overhydrated versus not overhydratedj, a wide overlap in their D/P ratio, residual diuresis and rGFR was observed. Nevertheless, $K_{t} / N_{\text {ursa }}$ and rGFR were significantly and inversely relared to ECW:BSA. The fact that, as might be expected, rGFR was inversely related to ECW:BSA whereas peritoneal ultrafiltration volume was actually positively related to this parameter might indicate that the relation between $\mathrm{K}+\mathrm{N}_{\text {weu }}$ and volume state is more explained by the rGFR than by the dialysis prescription. It is tempting to speculate on the role of the liberal salt and water intake in this aspect. We believe that the present 
findings may certainly emphasize closer attention to these factors in the volume regulation of $\mathrm{PD}$ patients.

The second finding of the study is the significant relation bewween BP on one hand, and fluid state and arterial wall properties on the ather hand. These relations were abserved despite the fact that the great majority of patients used antihypertensive medication. No marker of fluid state (TBW, ECW or PV) was clearly superior regarding the relation with BP. Regarding fluid state and BP, the relation was stronger for DBP thon for SBP. The relation between overhydration and DBP hypertension is in agreement with the concept of Guyton, who proposed that an increase in body fluid leads to an autoregulatory increase in peripheral wascular resistance in order to keep fissue perfusion canstant. ${ }^{34}$ It should however be stated that the hemadynamic mechanism of the influence of overhydration on BP cannot be deduced from the present study firstly because wascular resistance was not measured in the present study and secondly because most patients were on antihypertensive medication. Nevertheless, from the present study, overhydration appeared not to be the only factor involved in the pathogenesis of hypertension in PD patients, as a significant number of PD patients with a ECW:BSA below the $25^{\text {th }}$ percentile of that of the RTx patients still were found to be hypertensive.

Systolic hypertension was strongly related to arterial distensibility, which is in line with data in HD patients and in patients with essential hypertension. ${ }^{4,35}$ Systolic hypertension and reduced arterial distensibility may be interrelated, as an increase im SBP itself may lead to a reduction in distensibility whereas a reduction in distensibility may lead to an increase in SBP due to an increased stiffness of the arterial wall. $3^{55}$

Both ambulatory SBP and DBP were strongly related to LVH. This however only held true for ambulatory BP and not for office BP, which is in agreement with the superior predictive value of ambulatory BP measurements in a population with essential hypertension. It may be hypothesized that the lack of agreement beween office $\mathrm{BP}$ and $\mathrm{LVH}$ is further enhanced by the disturbed day-night $\mathrm{BP}$ rhythm found in a large propontion of our patients, yielding an increased BP load in these patients. Nevertheless we admit that the use of ambulatory BP measurements may not be suitable for routine clinical practice. An interesting subject for future studies might be to assess the relation between home $\mathrm{BP}$ measurements and cardiac structures in PD patients.

As was to be expected from a theoretical point of view, fluid state was related to left ventricular end diastalic diameter as a parameter of eccentric hypertrophy, whereas altered wall properties of the CCA were mainly related to concentric hypertrophy. The latter can be explained by the fact that a reduction in arterial wall distensibility (a marker of the elastic properties of the arterial wall) leads fo an increase in systolic stress to the heart. ${ }^{37}$

In contrast to other studies in patients with end-stage renal failure, hemoglobin lewels were not related to cardiac structure, which is probably explained by the 
fact that in most of the patients in the present study, hemoglobin levels were well in the range as proposed by DOQI guidelines. ${ }^{16}$

The fact that overhydration appears to be widely prevalent in PD patients and the finding that fluid overload had a major effect on both BP and cardiac parameters, despite the overwhelming use of antihypertensive agents in our population, leads to the question how fluid overload should be better controlled in the PD population. In a recent study, Gunal et al. observed an impressive improvement in BP regulation with salt restriction and the use of hypertonic dialysis solutions, which resulted in a significant reduction in residual renal clearance ${ }^{3}$, and this might be of importance in view of the strong relation between residual renal clearance and mortality. ${ }^{38}$ Neither the sludy of Gunal ef al. $^{3}$, nor the present study presents a solution to this dilemma. There is some circumstantial evidence that the role of salt and fluid restriction in PD patients is not fully appreciated.

An increased use of hypertanic high concentrations glucose containing PD solutions might have an adverse effect on the structure of the peritoneal membrane ${ }^{39}$ and may contribute to metabolic abnormalities. Preliminary studies have shown promising results of polymeric solutions on fluid state and BP regulation in HD patients. ${ }^{3}$. Future studies are needed to assess the advantages and drawbacks of polymeric or alternative PD solutions on fluid state and $B P$ regulation in PD patients. Above the clinical implication of the relation between altered arterial wall properties, systolic hypertension and concentric LVH remains to be elucidated. Nevertheless it should be mentioned that an increase in pulse wave velocity, as a marker of stiffness of the arterial tree, was clearly found to be related to mortality in HD patients. ${ }^{40}$. Interestingly, those patients, who responded with an improvement in pulse wave velocity towards treatment with an angiotensin converting enzyme (ACE) inhibitor, had a significantly improved survival compared to patients who did not."

Drawbacks of the present study are its cross-sectional nature and the fact that a high number of patients used anthypertensive medication. Nevertheless, as the study comprised an unselected group of patients abtained from various dialysis centers, this reflects common daily practice in our region. Moreover, the high prevalence of hypertension is in agreement with a large Italian multi-centre study, which included more than 500 PD patients, of whom $88 \%$ used antihypertensive medication. ${ }^{d z}$ The fact that a large proportion of the PD patients used antihypertensive medication including ACE inhibitors, might have interfered with the relations between fluid state, BP, and cardiovascular structure observed in the present study. However, because of ethical reasons antihypertensive medication was not stopped. On the other hand the present study shows that, even in a cohort of patients using (multiple) antihypertensive agents, fluid state is still a significant determinant of BP and cardiac structure.

In conclusion, overhydration is present in a significant percentiage of PD patients despite treatment prescription according to dialysis outcome and quality initiative (DOQI) guidelines. Fluid state is significantly related to both DBP and eccentric 
$\mathrm{LVH}$, whereas arterial wall abnormalities are more closely related to SBP and concentric LVH. Both ambulatory SBP and DBP are significantly related to echocardiographic abnormalities, whereas such a relation was not abserved for office BP measurements. 


\section{References}

1. Foley RN, Parfrey PS, Harnet JD, Kent GM, Martin CJ, Murray DC, Barre PE. Clinical and echocardiographic disease in patients starting end-stage renal disecse therapy. Kidney Int 1995; 47: 186-192

2. Dionisio P, Valenti M. Bergia R, Caramello $E$, Stramignoni $E$, Bento IM, Pellerey $M$, Bajardi $P$. Influence of the hydration state on blood pressure values in a group of patienis on regular maintenance hemodialysis. Bload Purif 1997; 15:25-33

3. Gunal Al, Duman S, Ozkahya M, Toz H, Asci G, Akcicek F, Basci A. Strict volume control normalizes hypertension in perizoneal dialysis patients. Am J Kidney Dis $2001 ; 37: 588-593$

4. London GM, Marchiais SJ, Safar ME, GenesI AF, Guerin AP, Metivier F, Chedid K, London AM. Aortic and large artery compliance in end-stage renal failure. Kidney Inf 1990; $37: 137-142$

5. Lysaght MJ, Vonesh EF, Gotch F, et al. The influence of dialysis treatment madality on the decline of remaining renal function. ASAIO Trans 1991; 37: 598-604

6 . Lang $S M$, Bergner $A$, Topfer $M$, Schiffi $H$. Preservation of residual renal function in dialysis patients: effects of dialysis-technique-related factors. Perit Dial In $2001 ; 21$ : 52-57

7. Velasquez MT, Lew SQ, von Albertini B, Mishkin GJ, Bosch JP. Control of hypertemsion is better during hemodialysis than during continuous ambulatory peritoneal dialysis in ESRD patients. Clin Nephrol 1997; 48:341-345

8. Giuseppe Enia, Francesca Mallamaci, Francesco A. Benedetto, Vincenzo Panuccio, Saveria Parlango, Sebastiano Cutrupi, Giuseppe Giacone, Emilio Cottini, Giovanni Tripepi, Lorenzo S. Malatina, and Carmine Zoccali. Long-term CAPD patients are volume expanded and display more severe left ventricular hypertrophy than haemodialysis patients. Nephrol Dial Transplant 2001; 16:1459-1464

9. Jahansson AC, Samuelsson O, Per Aftman O, Bosaeus 1, Haraldsson B. Limitations in Anthropometric Calculations of Total Body Water in Patients on Peritoneal Dialysis JAm Soc Nephrol 2001: 12: 568-573

10. Cox-Reijuen $\mathrm{PL}$, Kooman JP, Soeters PB, van der Sande FM, Leunissen KM. Role of bioimpedance spectroscopy in assessment of body water compartments in hemodialysis patients. Am J Kidney Dis 2001;38:832-838

11. Luik AJ, Struijk DG, Gladziwa U, von Olden RW, van Hooff JP, de Leeuw PW, Leunissen KM. Diumal blood-pressure variations in haemadialysis and CAPD patients. Nephrol Dial Transplant 1994; 9: 1616.1621

12. Kooman JP, Gladziwa U, Bocker G, Winen JA, wan Bortel L, Luik AJ, de Leeww PW, van Hooff JP, Leunissen KML. Blood pressure during the interdialytic period in haemodialysis patients: estimation of representative blood pressure values. Nephrol Dial Transplant 1992; 7: 917-923

13. Mansoor GA, White WB. Ambulatory blood pressure monitoring is a useful clinical tool in nephrology. Am $\Downarrow$ Kidney Dis 1997; 30:591-605 
14. Kooman JP, Christiaans MH, Boots JM, Van Der Sande FM, Leunissen KM, wan Hooff JP. A comporison between office and ambulatory blood pressure measurements in renal transplant patients with chronic transplant nephropothy. Am J Kidney Dis 2001; $37: 1170-1176$

15. Zietse R, Derkx FH, Weimar W, Schalekamp MA. Effect of atrial natriuretic peptide on renal and vascular permeability in diabeles mellitus. J Am Soc Nephrol 1995; 5 : 2057.2066

16. NKF-DOQl clinical practice guidelines for hemodialysis adequacy. National Kidney Foundation. Am J Kidney Dis 1997; 30 (52): $515-566$

17. Van Den Ham EC, Kooman JP, Christiaans MH, Nieman FH, Van Kreel BK, Heidendal GA, Van Hooff JP. Body composition in renal transplant patients: biompedance andysis compared to isotope dilution, dual energy $X$-ray absorptiometry, and anthropometry. J Am Soc Nephrol 1999; 10: 1067-1079

18. Vonesh EF, Burkart \&, MoMurray SD, Williams PF. Peritoneal dialysis kinetic modeling: validation in a multicenter clinical study. Perit Dial Int 1996; 16:471-481

19. Cackeroft DW, Gault MH. Prediction of creatinine clearance from serum creatinine. Nephron 1976; 16:31-4!

20. Van Kreel BK, Van der Vegf F, Meers M. Determination of total body water by a simple and rapid mass spectrometric method. J Mass Spectrom 1996; 31: 108-111

21. Van Kreel BK. An improved bromide assay for the estimation of extracellular water volume by capillary gas chromatography. Clin Chim Acta 1994; 231: 117-128

22. Schoeller DA, Van Santen E, Peterson DW, Dietz W, Jaspen J, Klein PD. Total body water measurements in humans with 180 and $2 \mathrm{H}$ labeled water. Am IClin Nutr $1980 ; 33: 2686-2693$

23. Miller ME, Cosgriff MM, Forbes GB. Bromide space determination using anionexchange chromatography for measurement of bromide. Am I Clin Nutr 1989; 50: $168-171$

24. Van Kreel BK, wan Beek E, Spaanderman ME, Peeters LL. A new method for plasma volume measurements with unlabeled dextran-70 instead of 1251 - labeled albumin as an indicator. Clin Chim Acta 1998; 6: 71-80

25. Konings CIAM, Kooman IP. Schonck M, wan der Sande FM, Leunissen KML. The influence of hydration on techniques used to assess fluid state and body composition in peritoneal dialysis. Perit Dial Int (in press)

26. Cheriex EC, Leunissen KM, Janssen JH, Mooy JM, van Hooff JP. Echography of the inferior wena cava is a simple and reliable tool for estimation of 'dry weight' in haemodialysis patients. Nephral Dial Transplant 1989; 4:563-568

27. Devereux RB, Reichek N. Echocardiogrophic determination of left ventricular moss in man. Anotomic walidation of the method. Circulation 1977; 55:613-618

28. Schiller NB, Shah PM. Crowford $M$, DeMaria $A_{r}$ Devereux $R$, Feigenbaum $H$, Gutgesell $H$, Reichek N, Sahn D, Schnittger I, et al. Recommendations for quantitation of the left ventricle by two-dimensionol echacardiography. American Society of Echocardiography Committee on Standards. Subcommittee on Quantitation of Two-Dimensional Echocardiogurams. J Am Soc Echocardiogr 1989; 2: $358-367$

29. Staessen IA, OBrien ET. Development of diagnostic thresholds for automated measurement of blood pressures in adults. Blood Press Monit 1999; 4: $127-136$ 
30. Reneman RS, Hoeks APG. Westerhof N. Non invasive ossessment of artery wall properties in humans-methods and interpretation. Joumal of Vascular Invest 1996; 2: 53-64

31. Hoeks APG, Brands. PJ, Smeets FAM, Reneman RS. Assessment of the distensibility of superficial arteries. Wltrasound Med Biol 1990: 16:121-128

32. Reneman RS, wan Merode T, Brands PI, Hoeks APG. Inhomogenities in arteriall wall properties under normal and pathological conditions. J Hypert 1992; 10 (S6): 535 39

33. Bland $M$ M, Altman DG. Statistical Methods far assessing agreement between two methads og elinical measurement. Lancet $1986 ; 8: 307-310$

34. Manming RD Jr, Guyton AC. Dynamics of fluid distribution between the blood and interstitium during overtydration. Am J Physiol 1980; 238: 645-651

35. Mourad JJ, Pannier B, Blacher J, Rudnichi A, Benetos A, London GM, Safar ME. Creatinine clearance, pulse wave velocity, carotid compliance and essential hypertension. Kidney Int 2001; 59: 1834-1841

36. Verdecchia P, Schillaci G, Reboldi G, Franklin SS, Porcellati C. Different prognostic impact of 24 -hour mean blood pressure and pulse pressure on stroke and coronary artery disease in essential hypertension. Circulation $2001 ; 29 ; 2579-2584$

37. London GM, Guerin AP, Marchais SJ, Pannier B, Safar ME, et al. Cardiac and arterial interactions in end-stage renal disease. Kidney Int 1996; 50:600-629

38. Gotch FA. The CANUSA study. Canada-USA. Perit Diall Int 1997; 17 (S2): 5111 $\$ 114$

39. Davies SJ, Phillips L, Naish PF, Russell Gl. Peritoneal glucose exposure and changes in membrone solute transport with time on peritoneal dialysis. I Am Soc Nephrol $2001 ; 12: 1046-1051$

40. London GM, Blacher J, Pannier B, Guerin AP, Marchais SJ, Safar ME. Arterial wave reflections and survival in end-stage renal failure. Hypertension 2001; 38: 434-438

41. Guerin A.P, Blacher 1, Pannioer B, Marchais SJ, Safar ME, London GM. limpact of Aortic Stiffness Attenuation on Survival of Patients in End-Stage Renal Failure. Circulation 2001; 103: $987-992$

42. Cocchi R, Esposti ED, Fabbri A, Lucatello A, Sturani A, Quarello F, Boero R, Bruno M, Dadone C, Favazza A, Scanziani R. Tammasi A, Giangrande A. Prevalence of hypertension in patients on peritoneal dialysis: results of an ltalian multicentre study. Nephrall Dial Transplant 1999; 14:1536-15.40 
84. Chapter 4 


\section{Chapter 5}

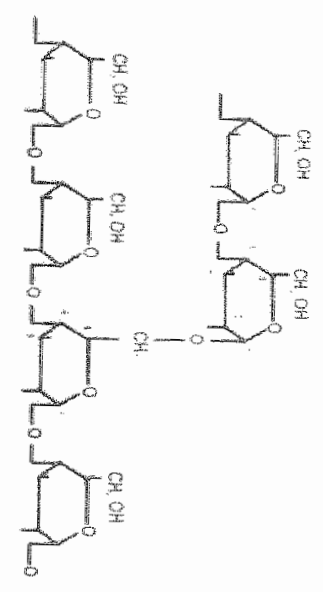

\section{Fluid state in relation to peritoneal transport and residual renal function in CAPD patients: a longitudinal study}

CJAM Konngs, JP Kooman, MS Shondk, DG Struik, U Glodrwa, SW Hoontie. FM van der Sonde. RT Krediet. Khl Leunissen (Nephrol Did Transpl: in press) 


\section{Abstract}

Both peritoneat transport characteristics as well as residual renal function are found to be related to outcome in patients treated with continuous ambulatory peritoneal dialysis ICAPDI. It has been suggested that part of this relation might be explained by an effed of both parameters on the fluid state in CAPD patients or by the relation between inflammation and peritoneal transport. In the present study, the relation between fluid state fextracellular water $[E C W]$; peritoneal transport characteristics $[2.27 \%$ glucose dialysate/plasma creatinine $[\mathrm{D} / \mathrm{P}]$ ratiol); residual renal function (residual glomerular filtration rate [rGFR] determined by urine collection), and inflammation (C-reactive protein [CRP]) was assessed in 37 CAPD patient, in a cross-sectional and longitudinal design. Finally 25 patients completed this study.

In the cross-sectional part, ECW corrected for height (ECW:height) was inversely related to $r G F R \quad r=-0.40 ; p=0.016]$, whereas during the longitudinal part, $D / P$ was related to the change in ECW $(r=-0.40 ; p=0.05)$. Neither $D / P$, nor $r G F R$ were related to $C R P$, whereas a significant relation was abserved between ECW:height and CRP $(r=0.58$; $p=0.0001)$. When the patients were dichotomized according to their $r G F R(<2$ or $>2$ $\mathrm{m} / \mathrm{mm}$, a highly significant difference in fluid state was abserved between these groups (ECW:height: $12.5 \pm 3.8 \mathrm{l} / \mathrm{m}$ versus $9.2 \pm 2.2 \mathrm{l} / \mathrm{m}^{2}$ respectively; $p=0.003$ ), despite a significantly larger daily peritoneal glucose prescription $(216.3 \pm 60.0 \mathrm{gram} / 24 \mathrm{hrs}$ versus $156.5 \pm 53.0 \mathrm{gram} / 24 \mathrm{Hrs} ; p=0.004)$ and peritoneal ultrafiltration volume $(1856 \pm 6.44$ $\mathrm{ml} / 24 \mathrm{Hrs}$ versus $658 \pm 781 \mathrm{~m} / 24$ His respectively; $p=0.0001$ ) in the group with a rGFR $<2 \mathrm{ml} / \mathrm{min}$ compared to the group with a $r G F R>2 \mathrm{ml} / \mathrm{min}$.

Concluding, fluid state was significantly rellated to peritoneal transport characteristics and rGFR. The larger ECW:height in CAPD patients with a negligible rGFR existed despite a higher peritoneal ultrafiltration valume and higher peritoneal glucase prescription. These findings raise doubt on the fact whether fluid state in these patients with a diminished rGFR can be adequately maintained on standard glucose solutions without an additional sodium and fluid restriction. The preliminary relation between CRP and fluid state found in the present study might suggest a relation between averhydration and inflammation. 


\section{Introduction}

Interest in the transport characteristics of the peritoneal membrane has increased since the subanalysis of the CANUSA study, in which a high transport state, characterized by a high dialysate/plasma creatinine (D/P) ratio', was. found to be an independent risk factor for montality. Following this observation. also other studies showed an increased mortality in so-called high transporters, although in some studies, this anly appeared to hold true for patients with comorbid disease. ${ }^{2,3}$

Due to the finding that peritoneal fluid removal is less in patients with a more permeable peritoneal membrane whereas albumin loss is higher, it has been suggested that the relation between transport state and mortality might be partly rellated to overhydration, which is an important risk factor for hypertension and left ventricular hypertrophy. ${ }^{3,5}$

Another factor found to be related to outcome in dialysis patients is residual renal function (RRF), which has been attributed by an effect of RRF on both total solute clearance and fluid state. ${ }^{6}$

Until now, few studies have focused on the relation between fluid state with peritoneal transport characteristics and RRF in continuous ambulatory peritoneal dialysis (CAPD) patients." Moreover, in those studies, which have been performed ${ }^{8}$, fluid state was not assessed in great detail.

Another factor which has been widely implicated in the increased mortality in dialysis potients is the presence of an inflammatory state. ${ }^{9}$ it has been hypothesized that peritoneal transport state might be influenced by inflammation, although the only study which addressed this topic failed to confirm this hypothesis. "In order to gain more insight in the pathogenesis of important determinants for outcome in peritoneal dialysis patients, the aim of the present study was to assess the relation between fluid state, peritoneal transport characteristics, RRF and inflommation in a cohort of peritoneal dialysis patients using both a cross-sectional and a longitudinal design.

\section{Study design}

In this multi-center study, including patients from 6 dialysis centers, fluid state, peritoneal transport, residual renal function, peritoneal ultrafiltration volume, glucose prescription, and C-reactive protein were related in a cross-sectional design. Moreover, parameters were compared after arbitrary dividing patients in two groups according to residual renal function, measured at baseline (residual glomerular filtration rate [rGFR] $<2$ or $>2 \mathrm{ml} / \mathrm{min}$ ).

After the baseline investigations, patients were followed longitudinally during four months after which the same investigations were performed, not changing the treatment regimen. Eligible patients, who did not meet the exclusion criteria. 
were asked to porticapte in the study. Exclusion criteria were: acute intercurrent infection, malignancy and cardiac fallure (NYHA > 11 ).

\section{Patients}

In the crossmsectional part of the study, 37 CAPD patients were included. The baseline characteristics of these patients are given in Table 5.1. The causes of renal insufficiency were: glomerulonephritis: 18 patients, glomerulasclerosis: 3 patients, hypertension: 6 patients, polycystic disease: 4 patients, urological disorder 3 patients, diabetes mellitus: 2 patients, scleraderma: 1 patient.

Of the included patients, 25 completed the longitudinal part of the study. The reason for drop out in the longitudinal part of the study were: 4 patients underwent a renal transplant procedure during follow up, 2 patients had an peritonitis during follow up, 2 patients switched to hemodialysis because of technique failure, 3 patients did not refurn for the second measurement, and in 1 patient PD was stopped because of return of renal function. All patients were only treated with standard glucose containing peritoneal solutions (Dianealor: Baxter, Lund, Sweden). The glucose concentration was prescribed at the discretion of the treating physician. None of the patients had clinical signs of overhydration.

Table 5.1. Patient demographics

\begin{tabular}{|c|c|}
\hline & Number \\
\hline \multirow[t]{2}{*}{ Male/Fiemale } & $26 / 11$ \\
\hline & Mean $\pm S D$ \\
\hline Agle (years] & $55.2 \pm 11.8$ \\
\hline Weight $(\mathrm{kg})$ & $78.4 \pm 15.8$ \\
\hline Body surface area $(B S A)\left(m^{2}\right)$ & $1.9 \pm 0.2$ \\
\hline Time on CAPD (months) & $22.6 \pm 18.5$ \\
\hline Weekly Ki $N_{\text {ureers }}$ & $2.4 \pm 0.7$ \\
\hline Weakly creatinine clearance $\left(L / 1.73 \mathrm{~m}^{2}\right)$ & $86.4 \pm 33.4$ \\
\hline PGFR (ml/min) & $4.3 \pm 4.2$ \\
\hline D/P creatinine & $0.68 \pm 0.10$ \\
\hline Serum abumin $(\mathrm{g} / \mathrm{L})$ & $32.0 \pm 4.4$ \\
\hline Creactiva protein (mg/L) & $7.1 \pm 13.0$ \\
\hline 24.hours SBP (mmig) & $130.5 \pm 15.8$ \\
\hline 24. hours DBP (mmHg) & $78.7 \pm 10.4$ \\
\hline Number of contihypertensive agents & $1.7 \pm 1.8$ \\
\hline
\end{tabular}

\section{Study protocol}

Patients were admitted to the research center at the dialysis department of the Academical Hospital of Maastricht in the early morning after an overmight fast. If patients had a filled abdomen over the night, PD fluid was first drained before the measurements were started. After admission, fluid state was determined by tracer dilution. During the equilibration period, patients were not allowed to eat 
or drink. At noon, patients were allowed to ect a light meal, of which the total amount of fluid did not exceed $200 \mathrm{ml}$.

\section{Study parameters}

\section{Peritaneal transport characteristics}

At inclusion of the crass sectional part of the study, the transport characteristics of the peritoneal membrane were characterized using a standard peritoneal equilibrium test (PET) after a 4 hour dwell with a $2.27 \%$ glucose solution. At the day of investigation, 24-hours collection of the dialysis fluid and the urine was perfarmed to calculate dialysis adequecy rGFR: $K t / N_{i, n e a}$ and weekly creatinine clearance normalized to $1.73 \mathrm{~m}^{2}$ body surface area (BSA). All calculations were made using PD adequest software. ${ }^{10}$

Peritoneal ultrafiltration volume and glucose prescription

Peritoneal ultrafiltration volume was calculated from the 24 hours dialysate collection performed at the day of investigation. The 24-hours peritoneal glucose dosage prescription was calculated from the volume and glucose concentration of the prescribed PD fluid.

\section{Fluid state}

Patients received an arally administered dose of $30 \mathrm{~m} / 1150 \mathrm{mmol}$ ) sodium bromide (NaBr, pharmacological department, Academical Hospital Marastricht, the Netherlands). Dose bottles were washed out and the rinsed water was also ingested by the patients to ensure that all $\mathrm{NaBr}$ was consumed. The enrichments of $\mathrm{NaBr}$ in the body fluid was measured in serum. Immediately before $\mathrm{NaBr}$ intake, a (background) blaod sample was taken. After the equilibration time of 4 hours a second blaod sample was collected. The concentration of bromide in serum was determined by gas chromatography." Bromide dilution space was calculated from the enrichment of bromide after 4 hours. The extracellular water compartment, i.e. extracellular volume (ECW) was calculated as the $\mathrm{NaBr}$ dillution space corrected for intracellular penetration of $\mathrm{NaBr}$ in erythrocytes, leukocytes and secretory cells, for unequal $\mathrm{NaBr}$ concentrations in the extracellular fluids (Gibbs-Donnan effect), and for the concentration of water in the serum; therefore, $\mathrm{NaB}$ r dilution space was multiplied by the following correction factor: $0.90^{*} 0.95^{*} 0.94=0.80^{12}$

Normalization of parameters

Regarding the relation with blood pressure, fluid state was normalized for height and BSA, although the optimal normalization procedure for fluid state is not well known in dialysis patients. BSA was also used, because an earlier study showed the best relation between ECW and hemadynamic variables when BSA was used for normalization. 13

\section{4-hour ambulatory blood pressure}

In all patients, 24-hour blood pressure (BP) measurements were performed using a Spacelabs ascillometric BP monitor (Redmond, WA, USA). BP was measured every 15 minutes from 7 a.m till 11 p.m and every 30 minutes from 11 p.m till 7 a.m. 
$90 \mid$ Chapter 5

\section{Inflammatory parameters}

In all PD patients, blood samples were taken for the assessment of albumin and C-reactive protein (CRP) (Syncron LX 20, Beckman Coulter, California, U.S.A.I. The detedion limit of the CRP assay was a value of $2 \mathrm{mg} / \mathrm{ml}$.

\section{Siatistics}

Correlations between the different parameters were estimated by the use of Pearson product moment correlations. Differences during the follow up period were estimated by the use of the paired standard T-test. Differences between groups were ossessed by the unpaired Student's T-test.

Calculations were made using SPSS 10 statistical software for Windows. P-values $<0.05$ were considered significant. Data are expressed as mean $\pm S D$.

\section{Results}

\section{Peritoneal transport characteristics}

In the cross-sectional part, an inverse relation was observed between the D/P ratio and the peritoneal ultrafiltration volume $(r=-0.37 ; p=0,02)$, but not between $D / P$ and daily glucose prescription. Also no relation was observed between $D / P$ and the time on dialysis. $D / P$ was also not found to be related to the ECW:BSA and ECW:height in the cross-sectional part. Nevertheless, during the four months follow-up period, a significant relation between the D/P and the change in the ECW ( $r=0.40, p=0.04)$ was observed (Figure 5.1). The change in ECW was significantly related to the change in systalic blood pressure (SBP) $(r=0.45 ; p=0.03)$ but not to diastolic blood pressure (DBP).

\section{Residual renal function}

In the cross-sectional part, rGFR was significantly related th the time on dialysis treatment $(r=-0.44 ; p=0.003)$ (Figure 5.2). There was a significant inverse relation between rGFR with ECW:BSA and ECW:height $(r-0.48 ; p=0.003)$, and $r=-0.40(p=0.016)$. When patients were arbritary divided according to $r G F R$ $(<2$ or $>2 \mathrm{ml} / \mathrm{min})$, ECW:BSA $(p=0.001)$ and ECW:height were significantly higher in the group with $r G F R<2 \mathrm{ml} / \mathrm{min}$ (Figure 5.3$)(\mathrm{p}=0.003$ ), despite a significantly higher peritoneal ultrafiltration volume and peritoneal glucose prescription (Table 5.2 ). 
Fluid state, peritoneal transport and residual renal function 91

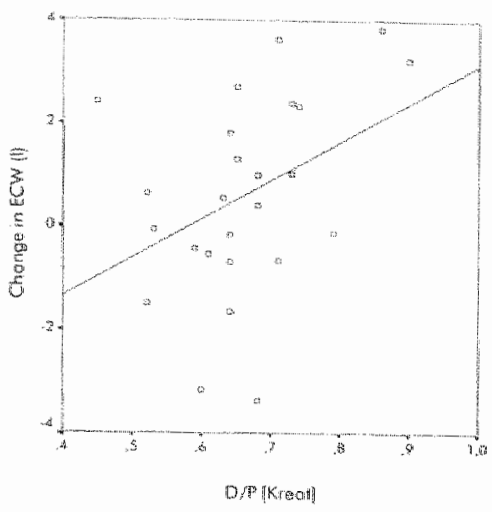

Figure 5. 1. D/P versus the change in ECW during four months follow-up. $r=0.40, p=0.04$

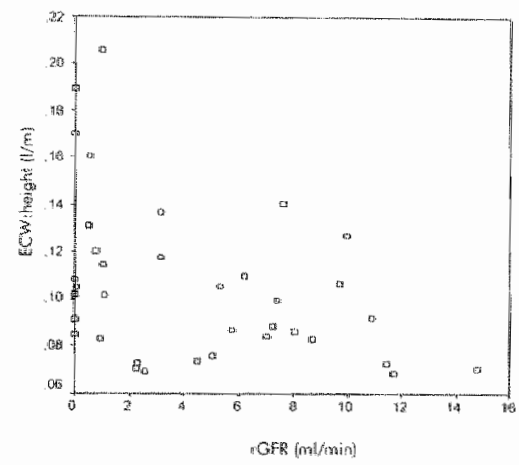

Figure 5.2. rGFR in relation to fluid state (ECW:height) $r=0.40, p=0.016$

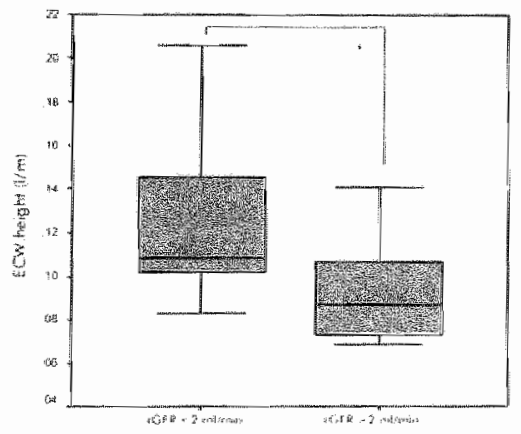

Figure 5.3. ECW in patients with rGFR below $2 \mathrm{ml} / \mathrm{min}$ and llarger than $2 \mathrm{~m} / \mathrm{min}$ $p=0.003$.

Covered boxes indicate $25.75 \%$ with median value, captured bars indicate the range of data (excluding outliers). 
92 Chapter 5

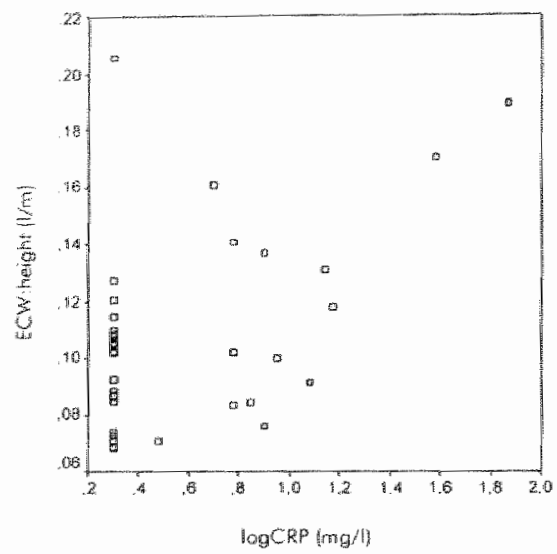

Figure 5.4. LogCRP in relation to fluid state (ECW:height) $r=0.47 ; p<0.001$

\section{Inflammation}

CRP was not significantly related to either D/P or rGFR. There was a significant relation between CRP with ECW:BSA $(r=0.41)$ and ECW:height $(r=0.54$, $p<0.001)$, which also held true for the relation with logCRP $(r=0.47$; $p<0.001)$ (Figure 5.4). The relation remained significant when the outliers had been removed from the analysis. Serum albumin was inversely related to D/P $(r=0.38 ; p=0.02)$, but not to ECW:BSA and ECW:height.

Table 5.2. Comparison between patients with rGFR $<2 \mathrm{ml} / \mathrm{min}$ and $\mathrm{rGFR}>2 \mathrm{ml} / \mathrm{min}$

\begin{tabular}{|c|c|c|c|}
\hline & $\begin{array}{c}\mathrm{rGFR}<2 \mathrm{~m} / / \mathrm{min} \\
\mathrm{m}=15\end{array}$ & $\begin{array}{c}\mathrm{rGFR}>2 \mathrm{ml} / \mathrm{min} \\
n=22\end{array}$ & p \\
\hline ECW:BSA $(1 / \mathrm{m} 2)$ & $11.0 \pm 3.2$ & $8.2 \pm 1.4$ & 0.001 \\
\hline ECW:height $(1 / \mathrm{m})$ & $12.5 \pm 3.8$ & $9.3 \pm 2.2$ & 0.003 \\
\hline Time on $\mathrm{PD}$ & $31.9 \pm 17.4$ & $16.7 \pm 6.5$ & 0.016 \\
\hline Periloneal ultrafiltration volume $(\mathrm{ml} / \mathrm{day})$ & $1856 \pm 644$ & $658 \pm 781$ & 0.0001 \\
\hline Peritoneal glucose prescription (g/day) & $216.3 \pm 60.0$ & $156.5 \pm 53.0$ & 0.004 \\
\hline Residual diuresis (m//day) & $270 \pm 566$ & $1438 \pm 1213$ & 0.001 \\
\hline Serum albumin $(g / h)$ & $31.5 \pm 3.08$ & $32 \pm 5.2$ & ns \\
\hline C-reachive protein (mg/l) & $11.4 \pm 19.7$ & $4.1 \pm 3.5$ & ns \\
\hline 24-hour SBP (mmHg) & $130.8 \pm 19.4$ & $130.3 \pm 13.1$ & ns \\
\hline 24-hour DBP $(\mathrm{mmHg})$ & $77.6 \pm 11.4$ & $79.5 \pm 9.9$ & ns \\
\hline Number of ontihypertensive agents & $1.3 \pm 1.0$ & $1.9 \pm 1.1$ & ns \\
\hline Weekly KIN & $2.0 \pm 0.3$ & $2.7 \pm 0.8$ & ns \\
\hline $\operatorname{rGFR}(\mathrm{ml} / \mathrm{min})$ & $0.40 \pm 0.45$ & $6.9 \pm 3.4$ & 0.0001 \\
\hline$D / P$ creatinine & $0.69 \pm 0.11$ & $0.67 \pm 0.11$ & ns \\
\hline
\end{tabular}




\section{Discussion}

The main findings of the study were firstly the significant relation between fluid state with peritoneal transport characteristics and rGFR, secondly the significantly higher ECW in patients with a rGFR below $2 \mathrm{ml} / \mathrm{min}$ despite a significantly higher daily peritoneal glucose prescription and peritoneal ultrafiltration volume compared to patients with a higher RGFR, and finally the significant relation between fluid state and CRP levels.

The relation between peritoneal transport characteristics (D/P) and ECW, which only became apparent during the longitudinal part of the study, was not wery pronounced. Nevertheless, it appears likely that the relation between the $D / P$ ratio, measured at the start of the study, and the change in ECW during the follow-up period is explained by a reduced fluid removal caused by a higher permeable peritoneal membrane, which is also suggested by the inverse relation between $D / P$ and daily peritoneal ultrafiltration volume. Despite the rather weak correlation, these findings suggests that a more permeable peritoneal membrane is a risk factor for progressive overhydration, as could be expected from a theoretical point of view.

The relation between rGFR and fluid state appeared to be more pronounced. Indeed, when patients were dichotomized in two subgroups according to rGFR, a highly significant difference in fluid state was observed between the two groups. It was remarkable that the higher ECW in the patients with a rGFR below $2 \mathrm{ml} / \mathrm{min}$ occurred despite a significantly higher peritoneal ultrafiltration volume (nearly approaching 2 liters/day), and a higher 24-hours glucose prescription. Although it should be acknowledged that a cut-off point of $2 \mathrm{ml} / \mathrm{min}$ is arbitrary, the present study suggests that it may be difficult to maintain normohydration in CAPD patients with negligible renal function with the use of standard glucose solutions without a stronger emphasis on sodium and fluid restriction.

In contrast with the strong relation between rGFR and fluid state observed in the cross-sectional part, rGFR was not related to the change in ECW during the 4 months period. Although this may seem counterintuitive, it can be hypothesized that the lack of such a relation is explained by the fact that in patients with a negligible rGFR, ECW is stabilized at a higher level by the use of more concentrated glucose solutions, without reaching normohydration. This might also explain why ECW is not normalized in patients with an absent rGFR despite a nearly comparable daily fluid removal as observed in patients with a rGFR higher than $2 \mathrm{ml} / \mathrm{min}$.

Regarding inflammation, no relation between peritoneal transport characteristics and CRP was observed. These results should be interpreted with some caution, because in the present study, CRP was nol assessed with an ultra-sensitive assay. Nevertheless, the absent relationship between CRP and peritoneal transport characteristics is in agreement with earlier observations by Wang et al."

An interesting finding of the present study is the significant relation between CRP levels and fluid state. Although the limitations of our CRP assay have already been outlined, and the present data should, also in view of the skewed 
distribution of the CRP dato, be regarded as highly preliminary, pathophysiological basis for the present findimgs might be found in eai abservations in non-uremic patienis ${ }^{14,15}$ in which an increase in inflammat was obsened in patients with congestive heart failure. In these patients, it , hypothesized that gut edema, resulting from overhydration, might lead to increased passage of endotoxins from the intestines into the blood. Whether also holds true for our patient group is highly speculative and should addressed in mare detail in future studies. Another explanation for the relat between fluid state and CRP might be the loss of body cell mass, induced inflammation, which may lead to a state of overhydration when "dry weight not adjusted.

Drawbacks of the present study are the shorf follow-up period, the relatin small number of patients included and the large number of dropouts in longitudinal part. The first drawback is however interent to the complexity : the expense of the methodology. Moreover, in a study including relatively sn numbers of patients, longer follow-up periods will undoubtedly lead to a mc percentage of drop-outs, as was indeed already apparent. Another point criticism might be the fact that transport characteristics were only assessed by D/P ratio, assessed at the start of the study. Nevertheless, this approach w chosen because the D/P ratio still appears to be the most widely used test measure peritoneal transport characteristics and was used in most other stud assessing the influence of transport state on outcome parameters in patients. ${ }^{2.7}$ Moreover, when laoking at the results in more detail, in sol patients ECW decreased during the follaw-up period despite the fact that the prescription was not changed. The reason for this finding is not entirely cle Neventheless, we belief that it is not due to methadological problems, since 1 very strong relation between ECW measurements at baseline and after 4 mon follow-up is a strong argument for the reliability of the bromide assay.

One might question if changes in sodium or fluid intake may have playec role. It should be mentioned that neither sodium intake, nor urinary a peritoneal sodium removal were measured in the present study. Therefore, 1 results presented in this paper should be regarded as preliminary, and shor be followed by a more detailed study, which also fakes these, potentially w important, parameters into account.

It should also be pointed out that patients were included with different dialy duration. Therefore, the folllow up period of 4 months, which was used in eo patient, is somewhat arbitrary. However, including e.g. only incident patie would have made it impossible to study the effect of rGFR on fluid state, becon of the disturbed fluid state which is often present when dialysis therapy initiated.

Concluding, in the present study, fluid state was significantly related peritaneal transport characteristics and rGFR. Compared to patients with a rG larger than $2 \mathrm{ml} / \mathrm{min}$. ECW was significantly higher in CAPD patients with negligible rGFR despite a higher peritoneal ultrafiltration valume and glucc prescription. These findings raise doubt on the fact whether fluid state in patien with negligible residual renal function can be adequately maintained 
standard glucose solutions without additional sodium and fluid restriction. The relation between CRP and fluid state found in the present study might suggest a relation between overhydration and inflammation. 


\section{References}

1. Churchill DN, Thorpe KE, Nolph KD, Keshavich PR, Oreopoulos DG, Page D. Increased peritoneal membrane transport is associated with decreased patient and technique sumival for continuous peritoneal dialysis patients. The Canada-USA (CANUSA) Peritoned Dialysis Study Group. J Am Soc Nephrol 1998; 9: 1285-1292

2. Cueto-Manzano AM, Quintana-Pina E, Correa-Rotter R. Long-term CAPD surwiwal and analysis of montallty risk factors: 12-year experience of a single Mexican center. Perit Dial Int 2001; 21: 148-153

3. Chung SH, Chu WS, Lee HA, Kim YH, Lee 1S, Lindhalm B, Lee HB. Peritoneal transport characteristics, comarbid diseases and CAPD patients. Perit Dial int 2000; 20:541-547

4. Wang $T$, Heimburger $O$, Cheng HH, Bergstrom J, Lindhollm B. Does a high peritoneal transport rate reflect a state of chornic inflammation? Perit Dial Int 1999. 19: 17.22

5. Ozkahya M, OkE, Cirit M, Aydin S, Akcicek F, Basci A, Dorhout Mees EJ. Regression of left wentricular ypertrophy in haemadialysis patients by ultrafiltration and reduced salt intake without antihypertensive drugs. Nephrat Dial Transplant 1998; 13: 1489 . 1493

6. Shemin D, Bostom AG, Laliberty P, Dworkin LD. Residual renal function and mortality risk in hemodialysis patients. Am J Kidney Dis 2001; 38: 85-90

7. Chung SH, Heimburger O, Stenvinkel P, Bergstrom I, Lindholm B. Association between inflammation and changes in residual renal function and peritoneal transport rate during the first year of dialysis. Nephrol Dial Transplant 2001; 16: 2240-2245

8. Jones $\mathrm{CH}_{*}$ Smye SW, Newstead CG, Will EJ, Davison AM. Extracellular fluid volume determined by bigelectric impedance and serum albumin in CAPD patients. Nephrol Dial Transplant 1998; 13: 393-397

9. Stenvinkel P, Heimburger $O$, Poultry F, Diczfolusy, Wang $T$, Berlund L, Jogestrand T. Strong association between malnutrition, inflammation, and atherosclerosis in chronic renal failure. Kidney Int 1999; 55: 1899-1911

10. Vonesh EF, Burkart d, MCMurray SD, Williams PF. Peritoneal dialysis kinetic modeling: validation in a multicenter clinical study. Perit Dial Int 1996;16:471-481

11. Van Kreel BK. An improved bromide assay for the estimation of extracellular water valume by capillary gas chromatography. Clin Chim Acta 1994; 231: 117-128

12. Miller ME, Cosgriff JM, Forbes GB. Bromide space determination using anionexchange chromatography for measurement of bromide. Am J Clin Nutr 1989; 50: 168.171

13. Konings CJAM, Kooman JP, van der Sande FM, Leunissen KML. Fluid status, blood pressure, and cardiavascular abnormalities in patients on peritoneal dialysis. Pent Dial Int $2002 ; 22: 477.487$ 
14. Haverkate F, Thompsan SG, Pyke SD, Gallimore JR, Pepys MB. Production of C. reactive protein and risk of coronary events in stable and unstable angina. European Concerted Action on Thrombrosis and Disabilities Angina Pectoris Study Group. Lancet 1997; 15:349:462-466

15. Niebauer I, Valk HD, Kemp M, Dominguez M. Schumann RR, Rauchhaus M, PooleWilson SD. Endotoxin and immune activation in chronic heart fallure: a prospective cohort study. Lancet 1999; 353: 1838-1842 



\section{Chapter 6}

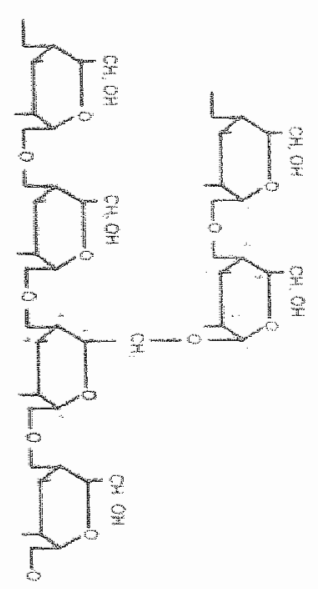

\section{Influence of fluid state on techniques used to assess body composition in peritoneal dialysis patients}

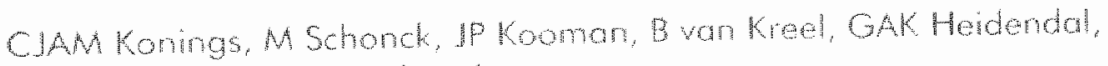
FMvan der Sande, KML Leunisser?

(Perit Did ht: in press? 
Ioo $\mid$ Chapter 6

\section{Abstract}

A reliable assessment of mutritional state in peritoneal dialysis (PD) patients is of great imporiance. Nevertheless, techniques used to assess body composition in patients on PD moy bee affected by abnormalities in fluid state. Aim of the study was firstly to compare different techniques used to evaluate body composition and to assess the influence of fluid state an the assessment of body composition, the second aim was to assess the relationship of handgrip muscle strength and the nutritional state of the patient. In $40 \mathrm{PD}$ patients, dual energy $X$-ray absorptiometry (DEXA), multi frequency bioimpedance analysis (MF-BIA) and anthropometry were compared with regard to the evaluation of bady composition (fot mass and leon body mass 【LBM] derived by DEXA or fat-free mass [FFM] derived by MF-BIA, and anthropametry]. The influence of the fluid state on the measurement of $\angle B M / F F M$ by the various lechniques was assessed by their relation to left ventricular end-diastolic diameter (LVEDD), assessed by echocardiography, and by estimating the ratio between extracellular water (ECW) and total body water (TBW). assessed by bromide and deuterium dilution, in relation to LBM. The relevance of the handgrip muscle strength as a nutritional parameter was assessed by its relation to LBM/FFM and other nutritional parameters.

Despite highly significant correlations, wide limits of agreement were present regarding the assessment of body composition between the various techniques (expressed as \% bodwweight): LBM (DEXA)-FFM (MF-BIA): 2.7 $\pm 11.8 \%$, LBM (DEXA)-FFM (Anthropomelry): $-5.7 \pm 7.8 \%$, fat mass (DEXA)-(MF-BIA) $-3.1 \pm 8.0 \%$, fat mass (DEXA)-(Anthropometry): $2.9 \pm 7.2 \%$ which were most pronounced for anthropometry. The ratio between ECW and LBM (DEXA) was $0.36 \pm 0.08 \mathrm{l} / \mathrm{kg}$ (range 0.25-0.67), and the patio between TBW and LBM $0.75 \pm 0.06 \mathrm{l} / \mathrm{kg}$ (nange $0.63-0.86$ ), which shows the variability in hydration state of LBM/FFM between individual patients. LBM/FFM measured by all three techniques were significantly related to LVEDD, suggesting an important influence of hydration state on this parameter. Handgrip muscle strength was significantly related to LBM/FFM, as measured by all three techniques, but not to other nutritional parameters.

In conclusion, wide limits of agreement were found between various techniques used to assess body composition in PD patients, which appeared to be smaller for MF-BHA than for anthropometry. The assessment of body composition was found to be strongly influenced by hydration state. Handgrip muscle strenght is well related to body composition, but not to other nutritional parameters. 


\section{Introduction}

An adequate assessment of nutritional state is of main importance in peritoneal dialysis (PD) patients, in view of the strong relation between malnutrition and mortality in renal patients. Ideally, nutritional assessment should be based on a defailed measurement of body composition as well as on the evaluation of functional parameters, such as handgrip muscle strength and global parameters of nutrition, such as serum albumin and subjective global assessment (SGA) ${ }^{1.3}$ With regard to body composition the most frequently used techniques in dialysis patients appear to be multifrequency bioimpedance analysis (MF-B|A|), dual energy $X$-ray absorptiometry (DEXA) and anthropometry. ${ }^{2.5}$

However, there remains uncertainty about the relliability of techniques used to assess body composition in PD patients, especially in view of the high prevalence of abnormalities in fluid state in dialysis patients, which may, from a theoretical point of view, predominantly have a large influence on the evaluation of lean body mass (LBM) estimated by DEXA, and fat-free mass (FFM) assessed by MFBIA or anthropometry..$^{6.9}$ However, untill now, the influence of fluid state is not well considered in the nutritional assessment of PD patients. The primary airn of the present study was to compare various techniques used to assess body composition in PD patients and also to assess the influence of fluid state on LBM/FFM. Moreover, the usefulness of handgrip muscle strength as a nutritional parameter was assessed by its relation with other nutritional parameters.

\section{Materials and methods}

\section{Study design}

With regard to the assessment of body composition, the following techniques were compared: anthropometry, MF-BIA and DEXA. The influence of hydration state on these parameters was assessed by their relation with an echacardiographic parameter (left ventricular end-diastolic diameter [LVEDD]). Extracellullar water (ECW), estimated by a tracer dilution method, was used to assess the relative contribution of the ECW compartment to LBM (DEXA). Moreover, handgrip muscle strength (HGS), which was related to body composition assessed by these techniques was related to other nutritional parameters.

\section{Study protocol}

Patients were admitted to the research center in the early morming after an overnight fast, with "empty" abdomen. After admission, bromide dilution and MF-BIA were performed, followed by the assessment of the other nutritional parameters (except DEXA). During this study period, patients were not allowed to 
$102 \mid$ Chopter

eat or drink. At noon, patients were allowed to eat a light meal, of which the rotal amount of fluid did not exceed $200 \mathrm{ml}$. Hereafter, DEXA and echocardiography were performed.

\section{Patients}

Forty PD patients, from six centers in our region, were included (29 males; 11 females). Patienis with metal implants, and recent complications (e.g. malignancy or surgery), diabetes mellitus, and dyspnea or angina pectoris (NYHA III and higher) were excluded. Other patients whom were eligible were asked to participate in the study.

Patient characeteristics are displayed in Table 6.1. Informed consent was obtained from each patient, and the study was approved by the Ethics Committee of the Maastricht University Hospital, The Netherlands.

Table 6.1. Patient demographics

\begin{tabular}{lc} 
Mean age (years) & $53.6 \pm 12.4$ \\
Man/Woman & $29(73 \% / 11(27 \%)$ \\
CAPD/CCPD & $30(75 \%) / 10(25 \%)$ \\
Weight (kg) & $77.8 \pm 13.6$ \\
Body surface area (BSA) $\left(\mathrm{m}^{2}\right)$ & $1.9 \pm 0.2$ \\
Body mass index (BM) $\left(\mathrm{kg} / \mathrm{m}^{2}\right)$ & $26.0 \pm 3.6$ \\
Time on CAPD (months) & $27.1 \pm 17.3$ \\
Weekly total Kt/Nurea & $2.4 \pm 0.7$ \\
Weekly total creatinine clearance $\left(\mathrm{L} / 1.73 \mathrm{~m}^{2}\right)$ & $85.4 \pm 30.7$ \\
Residual GFR (ml/min) & $4.3 \pm 3.9$ \\
D/P creatinine & $0.65 \pm 0.1$ \\
Subjective global assessment & $5.5 \pm 0.8$ \\
Cause renal insufficiency (number) & \\
Glomerulonefritis & $19(47.5)$ \\
Glomerulosclerosis & $3(7.5)$ \\
Hypertension & $6(15.0)$ \\
Polycystic disease & $4(10.0)$ \\
Urological disorder & $6(15.0)$ \\
Unknown & $2(5.0)$ \\
\hline
\end{tabular}

\section{Study parameters}

Dual energy X-ray absorptiometry (DEXA)

DEXA (DPX-L [Lunar Radiation Corp., Madison, WI]) was used for measurement of fat mass (FM). LBM (comprising muscle, inner organs and body water) and bone mineral densify. Measurements were performed in a standard fashion while the patient was lying in a supine position. From a $X$-ray source and K-edge filter below the patient, $X$-ray beams of stable energy radiation of 38 and 70 $\mathrm{KeV}$ were emitted. The composition of the soft-tissue was estimated by the ratio of beam attenuation at lower energy relative to the higher energy in soft-tissue pixels; this ratio is inversely and linearly related to the percentage fat. ${ }^{10} \mathrm{LBM}$ is estimated by subtracting body fat and bone cell mass from body weight. 


\section{Anthropometry}

Body weight was measured to the nearest 0.1 kilogram using a balance scale. Body height was measured to the nearest 0.5 centimeter with the patient standing, back to a stadiometer.

Skinfold measurements were used to estimate total body fat mass. Skinfold thickness was measured to the nearest $0.1 \mathrm{~mm}$ by a skinfold caliper. Measurements were made at the non-dominant side of the body at four sites: biceps, triceps, subscapula and iliac crest. Skinfolds were measured three times; thereafter, the sum of the individual skinfolds was averaged. The logarithm of the sum of the four skinfolds was used in age-and gender specific regression equations of Durnin and Womersly " to compute body density (D). Fat mass was computed as body weight $(\mathrm{kg}) \times([4.95 / \mathrm{D}]-4.5)$; FFM $(\mathrm{kg})$ as body weight $(\mathrm{kg})$ fat mass $(\mathrm{kg})$.

\section{Multifrequency bioimpedance analysis}

Bioimpedance measurements (Xitron 4000B: Xitron Technologies Inc, San Diego, USA) were performed while the patient was lying supine on a bed for at least 15 minutes. Multifrequency $(5-500 \mathrm{KHz})$ currents were introduced at distal electrodes an the hands and the feet in a standard fashion, and resistances were measured by proximal electrodes. Intracellular water $(\| C W)$ and ECW were predicted from the Hanai mixture theory (using a Cole-Cole model). ${ }^{12}$ In this model water compartments are directly calculated from resistance values, assuming specific resistances of ECW and ICW. Specific resistances of ECW and $I C W$ are provided by the manufacturer (for men: $\mathrm{EECW}=215, \mathrm{plCW}=824$, for women $\rho E C W=206, \rho l C W=797) .{ }^{20} \mathrm{FFM}$ is derived from the $\mathrm{ECW}$ and $1 \mathrm{CW}$, after multiplication with a constant factor $\left(\mathrm{D}_{\mathrm{ECW}}=1.45 \mathrm{~kg} / \mathrm{l}\right.$ for males and $1.48 \mathrm{~kg} / \mathrm{l}$ for females) and ICV (D $D_{\text {ICW }}=1.31 \mathrm{~kg} / 1$ for males and $1.23 \mathrm{~kg} / \mathrm{l}$ for females), according to calculations and assumptions provided by the manufacturer: $F F M=\left(D_{E C W} \cdot X E C W\right)+\left(D_{C W} \times \mid C W\right)$. FM is calculated as body weight minus FFM. ${ }^{13}$

\section{Handgrip muscle strength (HGS)}

HGS was evaluated in the dominant arm using the Harpenden dynamometer (British Indicators Ltd). HGS measurements were repeated three limes. The greatest value was used for analysis.

Subjective global assessment (SGA)

SGA was assessed on a seven-point scale, ranging from severely malnourished (1) to well nourished (7). ${ }^{14}$

\section{Tracer dilution techniques}

Patients received an orally administered dose of deuterium oxide $\left(D_{2} O\right)$ of $25 \mathrm{ml}$ ( $99 \% \mathrm{D}_{2} \mathrm{O}$, Sigma Chemicals, St. Lovis, USA) and $30 \mathrm{ml}(150 \mathrm{mmol})$ sodium bromide $(\mathrm{NaBr}$, pharmacological department, University Hospital Maastricht, the Netherlands). Enrichments of $\mathrm{NaBr}$ in the body fluid were measured in serum. Immediately before $\mathrm{NaBr}$ intake, a (background) blood sample was taken. After the equilibration time of 4-hour a second blood sample was collected. The concentration of $\mathrm{D}_{2} \mathrm{O}$ and $\mathrm{NaBr}$ in serum was determined by isotope ratio mass 
spectrometry and gas chramatography respectively. $15 \mathrm{NaBr}$ dilution spaces were calculated from the enrichment of bromide affer 4 -hour. Total body water (TBW) was calculated as the $\mathrm{D}_{2} \mathrm{O}$ dilution space corrected for the exchange of $\mathrm{D}_{2} \mathrm{O}$ with nonaqueous compartments and for the concentration of water in the serum by first dividing the dilution spoce by 1.04 and thereafter multiplying it by 0.94 . The ECW was calculated as the $\mathrm{NaBr}$ dilution space corrected for intracellular penetration of $\mathrm{MaBr}$ in erythrocytes, leukocytes and secretory cells, for unequal NaBr concentrations in the extracellular fluids (Gibbs-Donnan effect), and for the concentration of water in the serum; therefore, $\mathrm{NaBr}$ dilution space was multiplied by the following correction factor: $0.90 * 0.95 * 0.94=0.80 .^{16}$

\section{Echacardiography}

LVEDD was assessed by a two-dimensional ultrasound system with standard imaging tronsducers (Hewlett Packard 2500 or 5500).

\section{Statistical analysis}

Data are expressed as mean $\pm \mathrm{SD}$. Correlations between body compartments measured by the different methods were estimated by the use of Pearson product moment correlations. For the correlation with SGA, also the Spearman's rank-test was used. P-values $<0.05$ were considered significant. Bland and Altman plats ${ }^{17}$ were used to visually assess agreement between the different metthods. Multiregression analysis was performed to separate the effects of LBM from those of body size on LVEDD.

\section{Results}

\section{Relation between techniques used to assess body composition}

Correlation coefficients between various techniques used to assess body compasition are summarized in Table 6.2. limits of agreement between various techniques to assess body composition are summarized in Table 6.3 .

Table 6.2. Correlations between the warious techniques used to assess body composition

\begin{tabular}{|c|c|c|c|c|}
\hline & $\angle B M_{\text {otx }}$ & FFM $_{\text {MFF }}$ & $F M_{\text {MAF BA }}$ & $F M_{\text {A }_{3} \text { thisoponeity }}$ \\
\hline $\begin{array}{l}\text { LBM } \\
\text { DEREA }\end{array}$ & & 0.92 & & \\
\hline $\begin{array}{l}\text { FFM } \\
\text { FFM }\end{array}$ & $\begin{array}{l}0.92 \\
0.83\end{array}$ & 0.82 & & \\
\hline $\begin{array}{l}F M_{D E X A} \\
F M_{\text {DAFEAA }}\end{array}$ & & & 0.88 & 0.82 \\
\hline
\end{tabular}

For all correlations: $p<0.001$

The correlation coefficient between $\angle B M$ (DEXA) and FFM (MF-BIA) was 0.93, between LBM (DEXA) and FFM (Anthropometry) 0.86, and between FFM (Anthropometry and MF-BIA) 0.84 [all $p<0.001]$ ). Limits of agreement between 
LBM (DEXA) and FFM (MF-BIA), expressed as percentage of body weight, were $2.7 \pm 11.8 \%$ (Figure 6.1) between LBM (DEXA) and FFM (Anthropometry) $-5.7 \pm 7.8 \%$ (Figure 6.2) and between FFM (MF-BIA) and FFM (Anthropometry) $-8.3 \pm 14.1 \%$

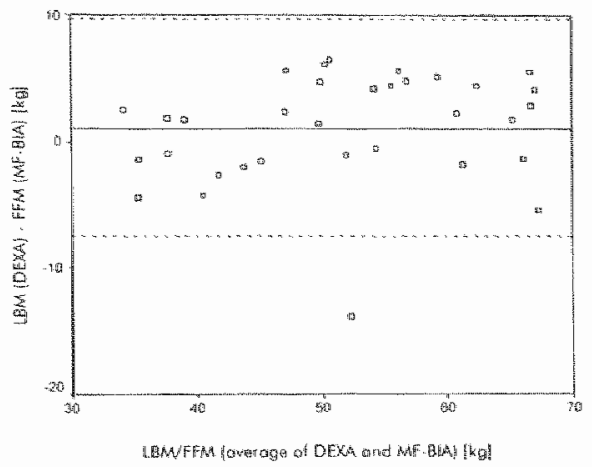

Figure 6.1. Limits of agreement between LBM assessed by DEXA and FFM assessed by MF-BIA

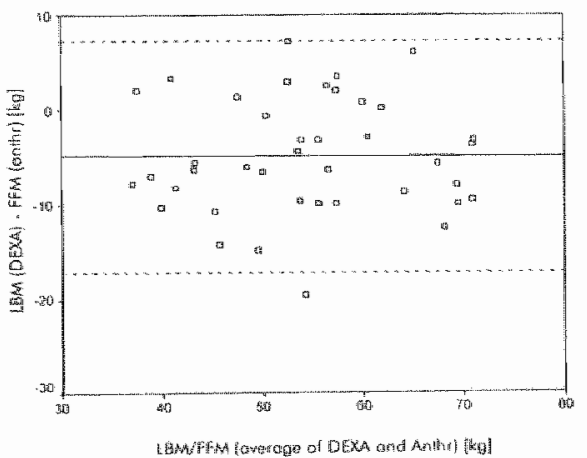

Figure 6.2. Limits of agreement between LBM assessed by DEXA and FFM, assessed by anthropometry

With regard to FM, the correlation coefficient between DEXA and MF-BIA was 0.88, between DEXA and anthropometry 0.78, and between anthropometry and MF-BIA 0.74 (all $p<0.001$ ). Limits of agreement between DEXA and MF-BIA, expressed as percentage of body weight were $-3.1 \pm 8.0 \%$ (Figure 6.3 ), between DEXA and anthropometry $2.9 \pm 7.2 \%$ (Figure 6.41 , and between MF-BIA and anthropometry $-4.8 \pm 10.9 \%$. 
Table 6.3. Differences in estimation of body composition, assessed by the different techniques

\begin{tabular}{lcc}
\hline & Mean $\pm S D$ & Ronge \\
LBM (DEXA)-FFM (MF-BIA) & $1.1 \pm 4.3$ & $(-13.8$ to 6.5$) \mathrm{kg}$ \\
LBM (DEXA)-FFM (Anthropomery) & $-4.9 \pm 6.1$ & $(-19.6$ to 7.2$) \mathrm{kg}$ \\
FFM (MF-BIA)-FFM (Anthropometry) & $-5.1 \pm 6.6$ & $(-18.3$ to 7.7$) \mathrm{kg}$ \\
FM (DEXA)-(MF-BIA) & $-4.4 \pm 4.5$ & $(-12.0109 .0) \mathrm{kg}$ \\
FM (DEXA)-(Anthropometry) & $1.5 \pm 5.3$ & $(-10.71015 .3) \mathrm{kg}$ \\
FM (MF-BIA)-(Anthropometry) & $5.6 \pm 6.3$ & $(-7.7$ to 18.3$) \mathrm{kg}$ \\
\hline
\end{tabular}

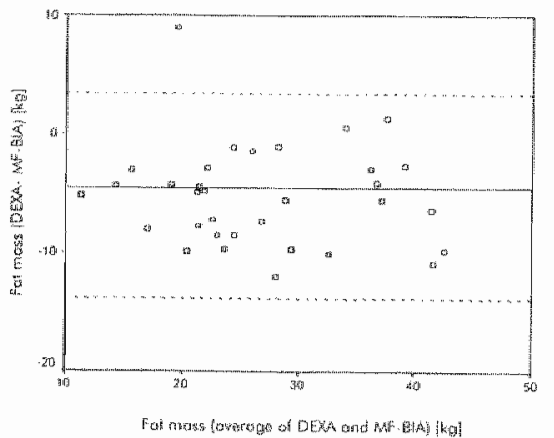

Figure 6.3. Limits of agreement between FM assessed by DEXA and MF-BIA

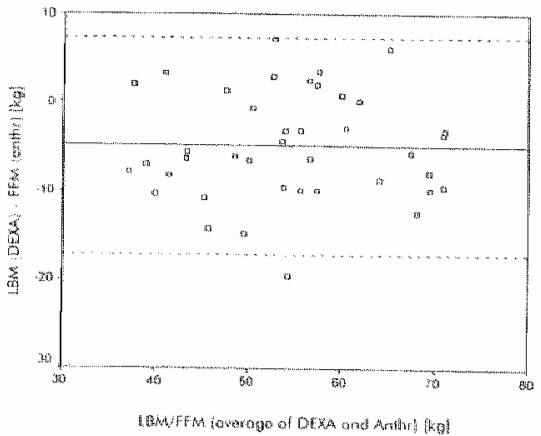

Figure 6.4. Limits of agreement between FM assessed by DEXA and Anthropometry 


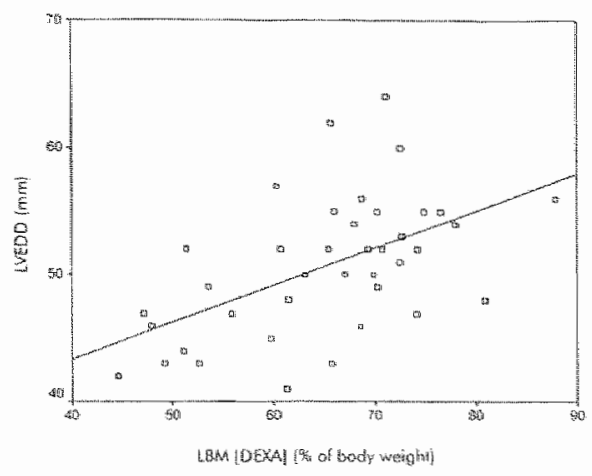

Figure 6.5. Relation between LBM [DEXA] as percentage of bady weight, and LVEDD

Relation between body composition and hemodynamic parameters

Mean value for LVEDD is $50.3 \pm 5.6 \mathrm{~mm}(40-64)$. In 9 patients (23\%), LVEDD was $\geq 55 \mathrm{~mm}$, indicating severe left ventricular dilatation.

LBM/FFM assessed by DEXA, anthropometry, and MF-BIA were significantly related to LVEDD $(r=0.60, r=0.56$, and $r=0.51 ; p<0.05)$, also when expressed as a percentage of body weight $(r=0.54, r=0.36$, and $r=0.46 ; p<0.05)$, showing the influence of hydration state on parameters used to assess body composition in PD patients (Figure 6.5). The relation remained significant when both the LBM, assessed by DEXA and BSA, as a parameter of body size, were entered in multiregression analysis $(L B M ; t=3.23 ; p<0.001, B S A ; t=-0.35$; $\mathrm{p}=$ ns).

Relations between ECW and hemodynamic parameters in the same cohort of patients are described elsewhere (chapter 4).

The amount of LBM, measured by DEXA, consisting of ECW (mean $0.36 \pm 0.08$ $1 / \mathrm{kg}$ ) varied widely between 0.25 and $0.67 \mathrm{l} / \mathrm{kg}$, which shows the variability in hydration state of LBM/FFM between individual patients. This is also reflected by the wide difference in the ratio between TBW and LBM (mean 0.75 0.06 ; range $0.63-0.86 \mathrm{l} / \mathrm{kg})$.

Relation between body composition, handgrip strength, and SGA

HGS was significantly related to LBM assessed by respectively DEXA, MF-BIA, and anthropometry, respectively $r=0.62 ; p<0.001, r=0.63 ; p<0.001$, and $r=0.58 ; p<0.001$.

HGS was not related to SGA or serum albumin, whereas SGA was positively related to $F M$, assessed by DEXA and MF-BIA $r=0.31$ and $r=0.46$; respectively $r=0.36$ and $r=0.25$. 


\section{Discussion}

The main results of the present study are firstly the strong relation, but large limits of agreement, between bady composition assessed by respectively DEXA. MF-BIA and anthropometry, secondly, the strong relation between echocardiographic parameters and $\angle B M$ or FFM, indicating an important influence of hydration on techniques used to assess body composition in PD patients, and thirdly the significant relation between HGS and LBM. With regard to the wide limits of agreement in the assessment of body composition between the various techniques, it should be mentioned that neither technique should be considered as "gold standard", athough in recent literature DEXA was shown to be mast closely related to the reference technique of neutron activation analysis. DEXA also assesses body composition in more detail compored to MF-BIA and anthropometry, as DEXA assumes the body as a three compartment madel, consisting of LBM, FM and bone cell mass, whereas MF-BIA, and anthropometry assumes the body as a two-compartment model, consisting of FFM and FM. Limits of agreement between DEXA and MF-BIA in the assessment of body composition were not widely different from those observed in stable renal transplant patients in an earlier study. ${ }^{16}$ This despite the fact that in the calculation of FFM by MF-BIA the assumptions of the specific resistances may deviate in patients with large abnormalities in fluid state compared to healthy subjects, apart from the fact that MF.BIA probably does not assess trunk volume adequately. 90 On the other hand, the disagreement between DEXA and anthropometry appeared to be larger in PD patients compared to the renall transplant patients. It cannot be excluded that this is partly due to the fact that the assumption for body density in anthropometric formulae is violated by changes in fluid state. MF-BIA structurally overestimates FM compared to DEXA. In contrast to DEXA, which estimates FM directly, FM by MF-BIA is calculated by subtracting FFM from body weight. FFM is derived from the estimation of intraand extracellular resistance. Therefore, in the calculation of FFM, MF-BIA does not distinguish between bone cell mass and "LBM". Thus, because bone cell mass is not taken into account, FM is overestimated. Therefore, if is also more appropriate to speak of FFM instead of LBM in the assessment of body composition by MF-BIA. The same holds true for anthropometry, which primarily estimates FM, but also does not take bone cell mass into account.

Fluid state appeared to have a large effect on the estimation of body composition, as shown by the significant relation between LVEDD and LBM or FFM assessed by all studied techniques. Moreover, the relative contribution of ECW and TBW on LBM appeared to be highlly variable and will remain an unpredictable factor when fluid state is nat assessed in detail. Many of the patients included in the present study were actually overhydrated, as in $37.5 \%$ of the patient presented in this study, ECW was above the $90^{\text {th }}$ percentile of stable renal transplant patients (see chapter 4 ). Moreover, in nearly $25 \%$ of the patients under study, severe left ventricular dilatation was present. 
We believe that this observation warrants a correction for ECW when LBM has to be assessed in detail, e.g. for research purposes. This presents a dilemma, as the reliability of MF-BIA with regard to the assessment of the absolute magnitude of body water compartments appears to be reduced in overhydrated patients. ${ }^{9,21}$ Therefore, we suggest that when changes in bodly composition have to be assessed in detail in PD patients, LBM assessed by DEXA should be used and corrected for ECW measured by tracer dilution techniques, thus achieving a four-compartment model for body composition.

Lastly, in agreement with the results from Heimbürger et al in patients with chronic renal failure, HGS was significantly related to LBM assessed by all techniques, suggesting that this simple parameter may be a relevant marker in the nutritional evaluation of PD patients. ${ }^{2}$ HGS may be especially important in the follow-up of nutritional state in renal patients. Nevertheless, HGS was not related to SGA, whereas SGA itself was weakly related only to FM in our cohort of patients. This may be explained firstly by the fact that our population was relafively well nourished, as patients with severe co-morbid diseases were excluded from the study, and secondly by the fact that the SGA score is strongly dependent on changes in nutritional state, which were not detected in this crosssectional study.

Apart from its cross-sectional nature, a drawback of the study is that only relatively stable patients were included, excluding those with severe co-morbid diseases and cardiac failure. This was done because firstly because intrinsic heart disease could heavily influence cardiac parameters and thus, the associations in the present study, and secondly, because severe co-morbid disease could lead to rapid changes in fluid state and body composition and thus flaw the effects of the renal failure. Therefore, the results of the study may not be directly extrapolated to all PD patients. Nevertheless, apart from the exclusion criteria, the patient group represented a fairly unselected sample.

Concluding, despite a highly significant relation between DEXA, MF-BIA, and anthropometry in the assessment of body composition, limits of agreement between these techniques appeared to be wide. Nevertheless, MF-BIA appears to be preferable over anthropometry. All techniques appeared to be strongly affected by fluid state, which warrants a correction for ECW when body composition has to be assessed in detail. HGS was strongly related to body composition, suggesting that this simple parameter may be relevant in nutritional evaluation of PD patients. 


\section{References}

1. Avram MM, Goldwasser P, Erroa M, Fein PA. Predictors of survival in continuous ambulatory peritoneal dialysis patients: the importance of prealbumin and other nutritional and metabolic markers. Am J Kidney Dis 1994; 23:91-98

2. Heimburger O, Qureshi AR, Blaner WS, Berglund L. Stenvinkel P. Hand-grip muscle strength, lean body mass, and plasma proteins as makkers of nutritional status in patients with chronic renal failure close lo start of dialysis therapy. Am J Kidney Dis 2000; 36: 1213-1225

3. Qureshi AR, Alvestrand A, Danielsson A, Divino-Filho $\ C$, Gutierrez A, Lindholm B, Bergstrom 1. Factors predicting malnutrition in hemodialysis patients: a crosssectional study. Kidney Int 1998; 53: 773-782

4. Dumler F. Use of bioelectric impedance analysis and dual-energy $X$-ray absarptiometry for monitoring the mutritional siatus of dialysis patients. ASAIO J $1997 ; 43: 256-260$

5. Stall S, Ginsberg NS, Lynn RI, Zabetakis PM. Bioelectrical impedance onalysis and dual energy $x$-ray absorptiometry to monitor nutritional status. Perit Dial Int 1995; 15: 5: $559-\$ 62$

6. Arkouche W, Fouque D, Pachiaudi C, Normand S, Laville M, Delawari E, Riou JP, Traeger J, La Ville M. Total body water and body composition in chronic peritoned dialysis patients. J Am Soc Nephrol 1997; 8: 1906-1914

7. Roubennoff R, Kehayias JJ, Dawson-Hugehes B, Heymsfield SB. Use of dual-energy $x$-ray absorptiometry in body-composition studies: nat yet a "not yet a gold standard". Am J Clin Nutr 1993; 58: 589-591

8. Ward LC, Elio M, Cornisch BH. Potential errors in the application of mixture theory to multifrequency bioelectricall impedance analysis. Physial Meas 1998; 19:53-60

9. Cox-Reijven PL, Kooman JP, Soeters PB, van Der Sande FM, Leunissen KM. Role of bioimpedance spectroscopy in assessment of body water compartments in hemodialysis patients. Am J Kidney Dis 2001; 38: $832-838$

10. Mazess RB, Barden HS, Bisek JP, Hanson J. Dual-energy $x$-ray absorptiometry for total bady and regional bone-mineral and soft-tissue composition. Am J Clin Nutr $1990 ; 51: 1106-1112$

11. Dumin NGA, Womersly J. Body fat assessed from tolal body density and its estimation from skinfold thickness measurements in 481 men and women aged from 16 to 72 years. Br J Nutr 1974; 32:77-94

12. De Lorenzo A, Andreoli A, Matthie J, Withers P. Predicting body cell mass with biompedance by using theoretical methods: a technological review. $₫$ Appl Physiol $1997: 82: 1542-1558$

13. Operating manual Xitron $4000 B$ bio-impedance spectrum analyser system. Xitron Technologies INC, San Diego CA, USA

14. Visser R, Dekker FW, Boeschoter EW, Stewens $P$, Krediet RT. Reliability of the 7-point Subjective Global Assessment scale in assessing nutritional status of dialysis patients. Adv Perit Dial 1999; 15:222-225 
15. Van Kreel BK. An improved bromide assay for the estimation of extracellular water volume by capillary gas chromatography. Clin Chim Acta 1994; 231 : 117-128

16. van den Ham EC, Kaoman JP, Christiaans MH, Nieman FH, Van Kreel BK, Heidendal GA, Van Hooff JP. Body composition in renal transplant patients: biompedance analysis compared to isolope dilution, duol energy $X$-ray absorptiometry, and anthropometry. J Am Soc Nephrol 1999; 10: 1067-1079

17. Bland IM, Altman DG. Shatistical methods for assessing agreement between two methods of clinical measurement. Lancet 1986; 1: 307.310

18. Kerr PG. Strauss BJG, Atkins RC. Assessnment of the nutritiunal state of dialysis patients. Blood Purif 1996; 14: 382.387

19. Lo WK, Prowant BF, Moore HL, Gamboa SB, Nolph KD. Flynn MA, Londeree B, Keshaviah P, Emerson P. Comparison of different measurements of lean body mass in normal individuals and in chronic peritoneal dialysis patients. Am J Kidney Dis $1994 ; 23: 74-85$

20. Zhu F, Schneditz D, Kaufman AM, Levin NW. Estimation of body fluid changes during peritoneal dialysis by segmental bioimpedance analysis. Kidney Int 2000 ; $57: 299-306$

21. Konings CJAM, Kooman JP, Schonck M, Cox-Reipen PL, wan Kreel B, Glodziwa U Wintz $\rfloor$, Gerlog PG, Hoorntje SJ, Wolters J, Heidendal GAK, van der Sande FM, Leunissen KML. Assessment of fluid state in hemodialysis patients. Perit Dial int (in press) 
112 


\section{Chapter 7}

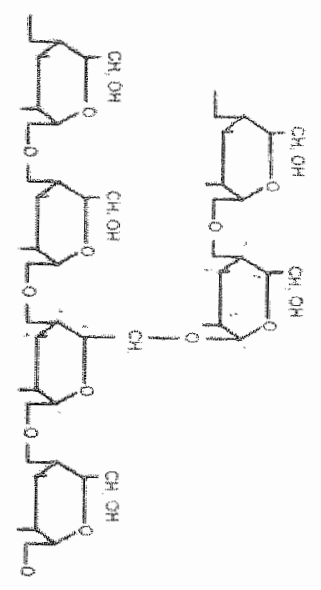

\section{Peritoneal glucose prescription is related to changes in body composition in CAPD patients}

CIAM Konings, JP Koomon, M Sthonck, OG Sruik. FM von der Sonde, KM Leunissen

Submited for publication 


\section{Abstract}

It has been suggested thai peritoneal transport characteristics may influence nutritional and metabolic state in continuous ambulatory peritoneal dialysis (CAPD) patients because of higher dialysate glucose concentrations needed to maintain fluid state. In the present study, the relation between peritoneal transport characteristics and peritoneal glucose prescription with body composition and metabolic parameters was assessed in stable CAPD patients. Thirty-silx CAPD pettients were included in the cross-sectional study of which the longitudinal study was completed by 24 patients. Body composition was assessed by dual energy X-ray absorptiometry and corrected for valume state (exiracellular water [ECW]): determined by bromide dilution). Regarding the metabolic profile; albumin, lipid parameters, insulin and insulin-like growth factor were assessed.

In the cross-sectional study, the daily peritoneal giucose prescription was significantly related to body mass index $(r=0.40 ; p=0.019)$ and to protein catabolic rate $r=0.38$; $p=0.0261$, but not to the percentage of body fat. In contrast, daily peritoneal glucose prescription was highly significant related to the change in body fal $(r=0.53 ; p=0.012)$ and inversely to the change in body cell mass during the longitudinal part of the siudy $(r=-0.56 ; p=0.007)$. Daily peritoneal glucose load was inversely related to HDLcholesterol $(r=-0.41 ; \mathrm{p}=0.016)$, whereas body fat corrected for body weight was related to serum triglycerides $(r=0.35 ; p=0.03)$. Except for serum albumin, dialysate/plasma creatinine ratio was not related to any nutritional or metabolic parameter.

In conclusion peritoneal transport characteristics were not directly related to nutritional or metabolic parameters. In contrast, peritoneal glucose absorption prescription was significantly reloted to the increase in body fat but also to the decline in body cell mass during a four months follow up period. These results suggest that dialysate glucose on one hand may lead to a decline in body protein stores by a lass of appetite and on the other hand to an increase in body fat by an increased callory laad. Both glucose prescription and body fat were significantly related to abnomalities in the lipid profile. 


\section{Introduction}

Interest in the transport characteristics of the peritoneal membrane has increased since the subanalysis of the CANUSA study, in which a high transport state, characterized by a high dialysate/plasma creatinine (D/P) ratio ${ }^{1,2}$, was found to be an independent risk factor for mortality. Following this observation, also other studies showed an increased mortality in so-called high transporters, although in some studies, this only appeared to hold true for patients with comorbid disease. ${ }^{3}$

It has also been suggested that transport characteristics might be related to the nutritional state of the patient. Such an effect may be caused by an increased loss of body prateins and amino acids. ${ }^{4}$ On the other hand, from a theoretical point of view, the increased absorption of glucose from the peritoneal fluid may lead to an increase in body fat, despite a reduction in appetite. ${ }^{4,5}$ An increase in body fat in peritoneal dialysis patients may also have metabolic consequences and may be involved in abnormalities in lipid state as frequently observed in dialysis patients.

Until now, few studies focused on the relation between nutritional state with peritoneal transport characteristics and residual function in continuous ambulatory peritonal dialysis (CAPD) patients. ${ }^{6.8}$ Moreover, in those studies body composition and nutritional state were not assessed in great detail.

Aim of the present study was to assess the relation between peritoneal transport characteristics and peritoneal glucose prescription with body composition and metabolic abnormalities in CAPD patients, using both a cross-sectional and a longitudinal design.

\section{Study design}

In this multi-center study, firstly peritoneal transport, nutritional and metabolic parameters were related in a cross-sectional design. After the cross-sectional part of the study at inclusion, patients were followed longitudinally during four months after which body composition was assessed again, not changing the treatment regimen. Exclusion criteria were: acute intercurrent infection, malignancy and cardiac failure (New York Heart Association >II) and metal implants.

\section{Patients}

In the cross-sectional part of the study, 36 stable CAPD patients were included (for in- and exclusion criteria: see chapter 5). In one patient, with a metal 
implant, who was included in chopter 5, DEXA could not be performed, this patient was not included in this study

The baseline characteristics of these patients are given in Table 7.1.

Of the included patients, 24 completed the longitudinal part of the study. The reason for drop out in the longitudinal part of the study were: 4 patients underwent a renal transplant procedure during follow up, 2 patients had an peritonitis during follow up, 2 patients switched to hemodialysis because of technique failure, 3 patients did not return for the second measurement and in 1 patient CAPD was stopped because of return of renal function.

Table 7.1. Patient demagraphics

\begin{tabular}{|c|c|}
\hline & Number \\
\hline \multirow[t]{2}{*}{ Mole/Female } & $25 / 11$ \\
\hline & Meon \pm SD \\
\hline Age (years) & $55.1 \pm 11.9$ \\
\hline Weight $(\mathrm{kg})$ & $78.7 \pm 15.9$ \\
\hline Body surface area $\left(\mathrm{m}^{2}\right)$ & $1.91 \pm 0.23$ \\
\hline Time on CAPD (months) & $23.2=18.5$ \\
\hline Weekdy Rt/Nuras & $2.4 \pm 0.7$ \\
\hline Weakly Creatinine Clearance $\left[\left(1 / 1.73 \mathrm{~m}^{2}\right)\right.$ & $85.5 \pm 33.4$ \\
\hline Protein catabolic rate (gram $1 . \mathrm{kg}$ ) & $0.96 \pm 0.24$ \\
\hline Residual Glomerular. Filtration rate $(\mathrm{ml} / \mathrm{min})$ & $4.2 \pm 4.2$ \\
\hline D/P creatinine & $0.68 \pm 0.11$ \\
\hline Daily glucose prescription (gram) & $180.4 \pm 63.5$ \\
\hline
\end{tabular}

\section{Study protocol}

Patients were admitted to the research center at the dialysis department of the Academical Hospital of Maastricht in the early morning after an overnight fast. PD fluid was first drained before the measurements were started. After admission, tracer dilution measurements were performed and office blood pressure (BP) was measured. During this study periad, patients were nat allowed to eat or drink. At noon, patients were allowed to eat a light meal, of which the total amount of fluid did not exceed $200 \mathrm{ml}$.

\section{Study parameters}

\section{Peritoneal transport state}

At inclusion of the cross-sectional part of the sludy, the dialysis- and clearance characteristics of the peritoneal membrane were characterized using a standard peritoneal equilibrium test after a 4 hour dwell with a $2.27 \%$ glucose solution 
(dialysate/plosma ${ }_{\text {creatinine }}[\mathrm{D} / \mathrm{P}]$ rafio). Hereatter a 24-hours collection of the dialysis fluid and the urine was performed to calculate the $\mathrm{Kt} / \mathrm{N}_{\text {erea }}$, normalized protein catabolic rate (nPCR), weekly creatinine clearance normalized to 1.73 $\mathrm{m}^{2}$ body surface area (BSA) and residual glomerular filtration rate (rGFR). All calculations were made using PD adequest sofftware."

\section{Nutritional parameters}

\section{Dual energy X-ray absorptiometry (DEXA)}

DEXA was used for measurement of whole-body composition, including fat mass, lean soft tissue mass (comprising muscle, inner organs and body water) and bone mineral density. The equipment used in this study was DPX-L (Lunar Radiation Corp., Madison, WI).

DEXA measurements were performed in a standard fashion while the patient was lying in a supine position. Fram a $X$-ray source and $K$-edge filter below the patient, $X$-ray beams of stable energy radiation of 38 and $70 \mathrm{KeV}$ were emitted. Attenuation of the $X$-rays was measured with a detector situated above the patient. Transverse scans of the body were made from top to toe. For each transverse scan, about 120 pixel elements with a size of approximately 5 to $10 \mathrm{~mm}$ were used, yielding data on the attenuation ratio. Approximately 40 to $45 \%$ of the pixels over the body contain bone and soft tissue, 55 to $60 \%$ contain soft-tissue alone. ${ }^{9}$ Bone mass was estimated from the ratio of the attenuation at low energy peaks relative to attenuation at high energy peaks through bone containing pixels after correction for the overlying soft-tissue. The composition of the soff-tissue was estimated by the ratio of beam attenuation at lower energy relative to the higher energy in soft-tissue pixels; this ratio is inversely and linearly related to the percentage fat. ${ }^{10}$ By the use of these estimations the lean body mass (LBM) and the fat mass (FM) were determined. In the cross-sectional parameters, LBM and FM were corrected for body weight.

\section{Correction for fluid state}

As LBM, assessed by DEXA, does not differentiate between extracellular and intracellular water and because abnormalities in fluid state may be widely prevalent in CAPD patients", it was corrected for extracellular water (ECW), assessed by bromide dilution (vide infra). The parameters obtained (LBM minus ECW) is referred to as body cell mass. In the cross-sectional analysis, body cell mass is corrected for body weight.

\section{Fluid state}

Patients received an orally administered dose of $30 \mathrm{mi}(150 \mathrm{mmol})$ sodium bromide $(\mathrm{NaBr}$, pharmacological department, Academical Hospital Maastricht, the Netherlands). Dose bottles were washed out and the rinsed water was also ingested by the patients to ensure that all $\mathrm{NaBr}$ was consumed. The enrichments of $\mathrm{NaBr}$ in the body fluid was measured in serum. Immediately before $\mathrm{NaBr}$ intake, a (background) blood sample was taken. After the equilibration time of 4 hours a second blood sample was collected. The concentration of bromide in 
$118 \mid$ Chapter 7

serum was determined by gas chromatography " $\mathrm{NaBr}$ dilution space was calculated from the enrichment of $\mathrm{NaBr}$ after 4 hours. The extracellular water compartment, i.e. ECW was calculated as the $\mathrm{NaBr}$ dilution space corrected for intracellular penetration of $\mathrm{NaBr}$ in erythrocytes, leukocytes and secretory cells, for unequal Nabr concentrations in the extracellular fluids (Gibbs-Donnan effect), and for the concentration of water in the serum; therefore, $\mathrm{NaBr}$ dilution space was multiplied by the following correction factor: $0.90 * 0.95 * 0.94=0.80$. $^{13}$

\section{Laboratory parameters}

In all PD patients, blood samples were taken for the assessment of albumin, $c$. reaclive protein (CRP), serum albumin, insulin, insulin-like growth factor I (IGF1), and the lipid profile (total cholesterol, LDL- and HDL-cholesterol, triglycerides) (all Syncron LX 20, Beckman Coulter, California, U.S.A.).

\section{Statistics}

Correlations between the different parameters were estimated by the use of Pearson product moment correlations. Calculations were made using SPSS 10 statistical software for Windows. P-values $<0.05$ were considered significant. Data are expressed as mean $\pm S D$.

\section{Results}

Peritoneal transport state, peritoneal glucose prescription and body composition

Parameters are summarized in Table 7.2. Daily peritoneal glucase prescription was not significantly related to $\mathrm{D} / \mathrm{P}$, but was found to be related to $\mathrm{rGFR}$ $(r=0.44 ; p=0.009)$. 
Table 7.2. Nutritional and metabolic parameters

\begin{tabular}{lc}
\hline & Number \\
\hline Bady weight $(\mathrm{kg})$ & $78.7 \pm 15.9$ \\
Body mass index $\left(\mathrm{l} / \mathrm{m}^{2}\right)$ & $26.4 \pm 4.5$ \\
Body fot $(\mathrm{kg})$ & $24.5 \pm 9.4$ \\
Percentage of bady fat $(\%)$ & $31.8 \pm 9.8$ \\
Lean body mass $(\mathrm{kg})$ & $50.8 \pm 11.2$ \\
Extracellular volume $(\mathrm{l})$ & $1.8 .1 \pm 6.6$ \\
Bady cell mass $(\mathrm{kg})$ & $32.8 \pm 8.0$ \\
Serum albumin $(\mathrm{g} / \mathrm{L})$ & $32.0 \pm 4.5$ \\
C-rreactive protein $(\mathrm{mg} / \mathrm{L})$ & $7.2 \pm 13.3$ \\
Total cholesterol $(\mathrm{mmol} / \mathrm{L})$ & $5.6 \pm 1.4$ \\
LDL-cholesterol $(\mathrm{mmol} / \mathrm{L})$ & $3.23 \pm 1.09$ \\
HDL-cholesterol $(\mathrm{mmol} / \mathrm{L})$ & $1.30 \pm 0 / 56$ \\
Serum triglycerides $(\mathrm{mmol} / \mathrm{L})$ & $2.3 \pm 1.3$ \\
\hline
\end{tabular}

In the cross-sectional part, $D / P$ ratio was not related to any nutrifional parameter, except for serum albumin $(r=-0.38 ; p=0.02)$, also nat when males and females were analyzed seperately. $D / P$ was also not related to the change in bady composition during the 4-month follow-up period. rGFR was not related to nutritional indices.

Also daily glucose prescription was not related to any nutritional parameter in the cross-sectional part, except for body mass index $(r=0.40 ; p=0.029)$ and $n P C R(r=-0.38 ; p=0.026)$. However there was a significant relation between glucose load and the change in body fat during the follow-up period $(r=0.53$; $p=0.012)$ (Figure 7.1) and an inverse relation to the change in body cell mass $(r=-0.56 ; p=0.007$ ) (Figure 7.2).

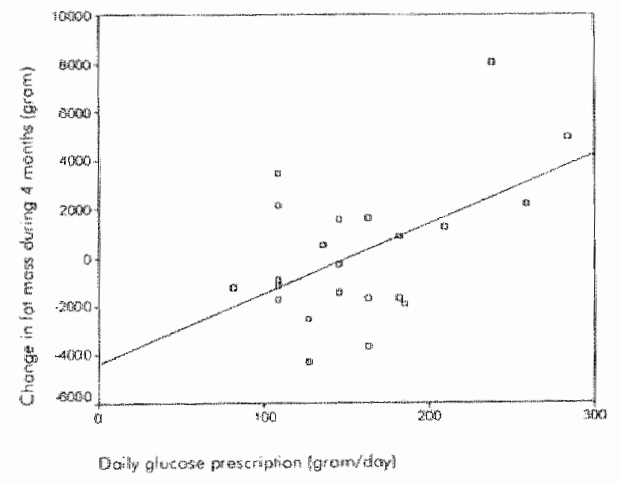

Figure 7.1. Daily peritoneal glucose prescription and the change in body fat during four months follow-up, $r=0.53 ; p=0.012$ 
$120 \mid$ Chapker 7

Peritoneal transport state, glucose prescription and body composition in relation to metabolic abnormalities

Daily peritoneat glucose load was inversely related to HDL-cholesteral $(r=-0.41$; $p=0.016)$, whereas body fat corrected for body weight was related to serum triglycerides $(r=0.35 ; p=0.03)$. $D / P$ was not related to any other metabolic parameter.

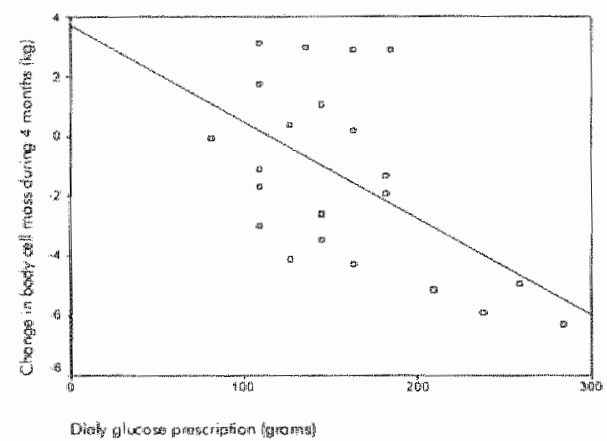

Figure 7.2. Daily peritoneal glucose prescription and the change in body cell mass during four months follow up

\section{Discussion}

The main findings of the present study were the relation between daily peritoneal glucose prescription and changes in body fat and body cell mass during a four months follow-up period, the absence of any relation between the $D / P$ and any nutritional or metabolic parameter, except for serum albumin, and the weak but significant relation between body fat as well as daily glucose prescription with lipid abnormalities.

Regarding the relation between peritoneal transport with nutritional and metabolic state, it has been suggested that a high peritoneal transport rate might lead to malnutrition due to an increased loss of albumin and amino acids by the more permeable membrane as well as by the higher glucose absorption, which might impair dietary protein intake. ${ }^{5}$ On the other hand, the higher glucose absorption might lead to an increase in bady fat and therefore to metabolic abnormalities. ${ }^{4}$ Despite of the inclusion of fairly detailed parameters of body composition, no significant relation between peritoneal transportt characteristics and nutritional state was observed, except for the inverse relation between the D/P ratio and serum albumin, which is probably caused by the increased albumin loss in patients with a more permeable peritoneal membrane. ${ }^{14}$ The absent relation between peritoneal transport characteristics and nutritional parameters is in disagreement with the study of Kang et al ${ }^{3}$ but in 
accordance with other studies. ${ }^{6.7}$ Possibly, the absent relation between peritoneal transport and nutritional parameters may be explained by the fact that the small increase in albumin loss in high transporters may not result in clinically apparent changes in nutritional state, whereas the peritoneal glucose load is not only dependent on the membrane characteristics of the peritoneum but also on other factors such as the residual renal function.

Despite the relatively short follow-up period, daily peritoneal glucose prescription was significantly related to an increase in body fat and a decrease in body cell mass during the four months fallow up period, suggesting that the dialysis prescription may have a strong effect on the nutritional profile of the patient. The fact that, in contrast to the longitudinal study, daily glucose prescription was not related to bady composition in the cross-sectional study may be explained by the large inter-individual differences in body size and composition.

The increase in FM in CAPD patients found in the present study is in accordance with earlier studies. ${ }^{16-20}$ Nevertheless, to our knowledge, this is one of the few studies showing a relation between peritoneal glucose prescription and changes in body fat in CAPD patients. ${ }^{20}$ Interestingly peritoneal glucose prescription was significantly related to the rGFR but not to the D/P ratio, suggesting that the maintenance of residual renal function may also have nutritional and metabolic consequences, apart from the strong influence on hydration state found in a recent study from our group. ${ }^{21}$

Remarkably, an inverse relation between daily glucose prescription and changes in body cell mass was observed during the relatively short follow-up periad. We believe that one of the strengths of the present study is that LBM, which consists of both intra- and extracellular water, and therefore is particularly affected by abnormalities in fluid state", was corrected for ECW assessed by tracer dilution fechniques. The relation between the daily glucose prescription and the decline in body cell mass has a basis in recent experimental studies, in which glucose containing peritoneal dialysate was found to have a strong appetite suppressing effect. ${ }^{5}$ This is also suggested by the inverse relation between the glucose prescription and protein catabolic rate found in the present study.

Due to its relatively small number of patients included and the short follow-up period, one must be cautious with drawing major clinical implications from the present study. Nevertheless, it appears prudent to hypothesize that dialysate glucose on one hand may lead to a decline in body protein stores by a loss of appetite and on the other hand to an increase in body fat by an increased calory load. Moreover, regarding the relation between serum triglycerides with body composition and the inverse relation between HDL cholesterol and the daily glucose prescription in PD patients, this variable may have significant and untoward effects on the metabolic profile of the CAPD patient. It should be acknowledged that the latter relations were fairly weak, whereas a relation between peritoneal glucose prescription and serum triglycerides, which might have been expected from a theoretical point of view ${ }^{2 !}$, was lacking. The 
observed relation between nutritional state, dialysis prescriptian and metabolic parameters may have been somewhat disturbed by the fact that some of the patients used lipid lowering drugs.

As already mentioned above, drawbacks of the present study are the shor follow-up periad, the relatively small number of patients included and a large number of dropouts in the longitudinal part. The first drawback is howewer inherent to the complexity and the expense of the methodology used in the present study. Moreover, in a study including relatively small numbers of patients, longer follow-up period will undoubtedly lead to a maior percentage of drop-outs, as was indeed already apparent in the present study. In addition, only daily peritoneal glucose prescription, but not glucose absorption was assessed in the present study.

Another point of criticism might be the fact that transport characteristics were only assessed by the D/P ratio. This approach was chosen because the D/P ratio still appears to be the most widely used test to assess peritoneal manspont characteristics and was used in most other studies assessing the influence of transport state on outcome parameters in PD patients." Moreover, despite the fact that rGFR was not directly related to nutritional parameters, residwal renal function may still be an important factor in the nutritional state of PD patients. Firstly, rGFR is an important determinant of glucose prescription during PD, secondly, a decline in rGFR may from a theoretical point of view, contribute to a decline in body cell mass because of a reduction in appetite ${ }^{23}$. It is not impossible that a longer follow-up period would have been needed to explore the latter factor.

Concluding, peritoneal glucose prescription was found to be significantly related to an increase in body fat but also to a decline in body cell mass during a four months follow-up period. These results suggest that dialysate glucose on one hand may lead to a decline in body protein stores by a loss of apperite and on the other hand to an increase in body fat by an increased calary laad. Both glucose prescription and body fat were significantly related to abnomalifies in the lipid profile. Peritoneal transport characteristics were not directly related to nutritional or metabolic parameters. 


\section{References}

1. Churchill DN, Thorpe KE, Nolph KD, Keshawiah PR, Oreopoulos DG, Page D. Increased peritoneal membrane transport is associated with decreased patient and technique survival for continuous peritoneal dialysis patients. The Canada-USA (CANUSA) Peritoreal Dialysis Study Group. J Am Soc Nephrol 1998;9:1285-1292

2. Cuelo-Manzano AM, Quintana-Pina $E_{*}$ Correa-Rotter $R$. Long-ferm CAPD survival and analysis of mortality risk factors: 12-year experience of a single Mexican center. Perit Diallint $2001 ; 21: 148.153$

3. Chung SH, Chu WS, Lee HA, Kim YH, Lee IS, Lindholm B, Lee HB. Peritoneal transport characteristics, comorbid diseases and CAPD patients. Perit Dial int 2000; 20: $541-547$

4. Burkart JM. Effeci of peritoneal dialysis prescription and peritoneal membrane transport characteristics an nutritional status. Perit Dial Int 1995; 15: \$20.35

5. Zheng ZH, Sederholm F, Anderstam B, Qureshi AR, Wang T, Sodersten P, Bergstrom $I_{r}$ Lindholm B. Acute effects of peritoneal dialysis solutions on appetite in non-uremic rats. Kidney Int 2001; 60: 2392-2398

6. Harly JC, Boulton $H$, Venning MC, Gokal R. Is peritoneal permeability an adverse risk factor for malnutrition in CAPD patients? Miner Electrolyte Metab 1996; 22: $97-101$.

7. Szeto CC, Law MC, Wong TY, Leung CB, Li PK. Peritoneal transpont status correlates with morbidity but not longitudinal change of nutritional status of continuous ambulatory peritoneal dialysis patients: a 2-year prospective study. Am I Kidney Dis $2001: 37: 329-336$

8. Kang DH, Yoon KI, Choi KB, Lee R, Lee HY, Han DS, Cho EY, Lee JH. Relationship of peritoneal membrane transport characteristics to the nutritional status in CAPD patients Nephrol Dial Transplant 1999; 14:1715-1722

9. Vonesh EF, Burkart J, MoMurray SD, Williams PF. Peritoneal dialysis kinetic madeling: validation in a multicenter dinical study. Perit Dial int 1996; 16:471-481

10. Mazess RB, Barden HS, Bisek JP. Hanson J. Dual-energy x-ray absorpliomelry for total body and regional bone-mineral and soft-tissue composition. Am J Clin Nutr $1990 ; 51: 1106-1112$

11. Kanings CJAM, Kooman JP, van der Sande FM, Leunissen KML. The relation between fluid status and structural cardiac abnormalities in patients on peritoneal dialysis (PD). Perit Dial lnt 2002 in press)

12. Van Kreel BK. An improved bromide assay for the estimation of extracellular water volume by copillary gas chromatography. Clin Chim Acto 1994; 231: 117-128

13. Miller ME, Cosgriff JM, Forbes GB. Bromide space determination using anionexchange chromatography for measurement of bromide. Am J Clin Nutr 1989; 50: $168-171$ 
14. Nakamoto H, Imai H, Kawanishi H, Nakamoto M. Minakuchi d, Kumon S, Waranabe S, Shiohira $Y$, Ishii $T$, Kawahara T, Suzuki H. Low serum albumin in elderly continuous ambulatony peritoneal dialysis potients is atributable to high permeability of peritoneum. Adv Perit Dial 2001; 17: 238-243

15. Jager KJ, Merkus MP. Huisman RM, Boeschoten EW. Dekker FW, Korevaar JC, Tijssen JG, Krediet RT. Nutritional status over time in hemodialysis and peritoned dialysis. NECOSAD Study Group. IAm Soc Nephrol 2001; 12:1272-1279

16. Nordtors $L_{r}$ Heimburger $O$. Lonnqvist $F$, Lindholm $B$, Helmrich J, Schalling $M_{*}$ Stenvinkel $P$. Fat fissue accumulation during peritoneal dialysis is associated with o polymorphism in uncoupling protein 2. Kidney Int 2000; $57: 1713-1719$

17. Fernstrom A, Hylander B, Moritz A, Jacobsson H, Rossiner S. Increase of intraabdominal fat in patients treated with continuous ambulatory peritoneal dialysis. Perit Dial Int 1998; $18: 166-171$

18. Soreide $R$, Dracup $B$, Swarstad $E$, Iversen BM. Increased total body fat during PD treatment. Adv Perit Dial 1992; 8: 173-176

19. Briganti $M$, Emiliani $G$, Montenari $A$, Cocchi $R$, Bondi $A$, Fusaroli $M$. Longitudinal assessment of body composition in CAPD patients using bioelectric impedance analysis. A comparison with hemadialysis patients. ASAlO J 1995; 41: M725-727

20. Maurer O, Saxenhofer H, Jaeger P, Casez JP, Descoeudres C, Horber FF. Six-imonth overnight administration of intraperitoneal amino acids does not improve lean mass. Clin Nephrol 1996; 45: 303-309

21. Konings CJAM, Hameleers P, Kooman JP, van der Sande FM, Leunissen KML. Relation between peritoneal transport, inflammation, and fluid state in patients on peritoneal dialysis. Perit Dial Int 2002; 22 (S1): S.46

22. Bredie SI, Bosch FH, Dernacker PN, Stalenhoef AF, wan Leusen R. Effects of peritoneal dialysis with an overnight icadextrin dwell on parameters of glucose and lipid metabolism. Perit Diall int 2001; 21: 275-281

23. Kopple JD, Greene T, Chumlea WC, Hollinger D, Maroni BJ, Merrill D, Scherch LK, Schulman $G$, Wang SR, Zimmer GS. Relationship between nutritional status and the glomerular filtration rate: results from the MDRD study. Kidney Int 2000; 57 ; 1688 1703 


\section{Chapter 8}

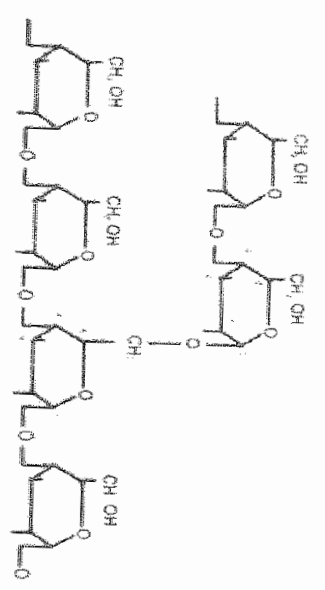

\section{Effect of icodextrin on volume state, blood pressure and echocardiographic parameters: a randomized study}

CHAMKonings, JP Kooman, M Schonck, U Gladzwa, Whit, PG Gerlag. Su Hoonife, Wolters, Man der Sande, KML Leunssen Koney in: in press) 


\section{Abstract}

Overhydration is a risk factor for hypertensian and left ventricular hypertrophy in peritoneal dialysis (PD) patienfs. Recenfly, a high prevalence of subclinical overhydration was abserved in PD patients. Aim of the present open-label randomized study was to assess the effect of a icadextrin $7.5 \%$ solution on fluid state fextracellular water [ECW: bromide dilution], blood pressure regulation [24-hours ambulatory measurements] and achocardiographic parameters) during a study periad of four months, and to relate the effect to peritoneal membrane characteristics ( $D / P$ creatinine ratio). Forty PD patients (22 icodextrin, 18 contrals) were randomized to either treatment with icodextrin during the long dwell or standard glucose solutions. Thirty-two patients (19 icodextrin, 13 controls) completed the study.

The use of icodextrin resulted in a significant increase in daily ultrafiltration valume $(744 \pm 767 \mathrm{ml}$ versus $1670.1038 \mathrm{ml} p=0.012)$ and a decrease in ECW $117.5 \pm 5.2$ versus $15.8 \pm 3.8 \mid p=0.035)$. Also the change in ECW between controls and patients treated with icadextrin was significant $(-1.7 \pm 3.3$ versus $+0.9 \pm 2.2, p=0.013)$. The effect of icadextrin on ECW was not related to peritoneal membrane characteristics, but significantly related to the fluid state of the patients (ECW:height) $(r=-0.72 ; p<0.0001$ ). Left ventricular mass (IVM) decreased significantly in the icodextrin-treated group $[241 \pm 53$ versus $228 \pm 42$ grams; $p=0.03]$, but not in the control group.

Concluding, in this randamized open label study, the use of icodextrin resulted in a significont reduction in ECW and LVM. The effect of icodextrin on ECW was not related to peritoneal membrane characteristics, but was related to the initial fluid state of the patient. 


\section{Introduction}

Cardiovascular disease is the single most common cause of death in dialysis patients. One of the known risk factors for cardiovascular montality is left ventricular hypertrophy $(\mathrm{LVH}) .{ }^{.}$Although the pathophysiology of $\mathrm{LVH}$ is undoubtedly multifaciorially determined, overhydration is known to play a major role, at least in hemodialysis patients. ${ }^{2,3}$ Recently, we and others showed a huge prevalence of subclinical overhydration in peritoneal dialysis (PD) patients, despite the fact that patients were adequatelly dialyzed according to dialysis outcome and quality improvement (DOQ1) guidelines. ${ }^{4,5}$ Importantly, volume state was related to both hyperfension and eccentric LVH. ${ }^{5}$

It has been suggested that the use of a glucose polymeric solution, icodextrin $7.5 \%$, is able to improve volume state in peritoneal dialysis patients due to an improved and prolonged ultrafiltration, especially during long dwells, ${ }^{6,7}$ However, studies towards the effect of icodextrin on volume state in peritoneal dialysis patients are scarce, whereas in the single published study, including patients on automated peritoneal dialysis, which assessed the effect of icodextrin on fluid state in more detail, did not use a randomized design, did not apply reference techniques to assess volume state and did not assess the effect of icodextrin on cardiac structure."

Moreover, it is not well known which patients would benefit most of a potential beneficial effect of icodextrin. From a theoretical point of view, especially patients with a more permeable peritoneal membrane (so-called high transporters) ${ }^{9}$, would be expected to benefit, although in a recent study of our group the effect of residual renal function on volume state appeared as important as the effect of membrane permeability (see chapter 5). Moreover, the enhanced ultrafiltration imposed by icodextrin might influence diuresis and therefore counteract any potential beneficial effects of icodextrin in those patients with significant residual function.

Aims of the present sludy were firstly to compare the effect of icodextrin on volume state, blood pressure and cardiac structure in a randomized open-label design using detailed methodology and secondly to assess the effects of icodextrin in relation to membrane permeability, residual renal function and volume state in an unselected group of peritoneal dialysis (PD) patients.

\section{Patients}

Forty stable PD patients were included (29 males: 11 females). Patients with recent complications (e.g. peritonitis, malignancy or surgery), and congestive heart failure or coronary artery disease (New York Heart Assaciation III and higher) were excluded. Patient characteristics are displayed in Table 8.1. Apart from the mentioned exclusion criteria, no selection criteria were applied. 
128 Chopter 8

Patients with severe cardiac failure and/or coronary artery disease were excluded because the underlying disease might severely influence relations beween tuid overload, blood pressure and cardiac structure and therefore obscure potentially important effects of icodextrin. Dry weight was assessed on clinical grounds according to the treating physician, avoiding signs of overhydration, i.e. an elevated central venous pressure, peripheral or pulmonary edema. The treatment goals for treament adequacy were set according to the DOQA guidelines. Potients were treated with $1.36 \%$ glucose solutions for the long dwell.

\section{Study design}

Patients were recruited from five dialysis centres in the south eastern part of the Netherlands, and one dialysis centre in Germany. In this open-label randomized multi-centre study, unselected PD patients were randomized towards treatment with either the continuation of their PD prescription with standard glucose solutions, or treatment with icodextrin during nighttime (in continious ambulatory PD [CAPD] patients) or daytime (in continious cycling PD [CCPD] patients). No other interventions in the dialysate prescription were performed during the study period. At the start of the study and after a follow-up period of four months, volume state, blood pressure, and echocardiographic parameters were assessed.

Table 8.1. Patient demographics

\begin{tabular}{|c|c|c|}
\hline Group & $\begin{array}{c}\text { Icodextrin } \\
(n=22)\end{array}$ & $\begin{array}{l}\text { Control } \\
(n=18)\end{array}$ \\
\hline Male/Female & $14 / 8$ & $15 / 3$ \\
\hline \multirow[t]{2}{*}{ CAPD/CCPD } & $16 / 6$ & $15 / 3$ \\
\hline & MeantSD [range] & \\
\hline Age (years") & $52.7 \pm 10.9[35-69]$ & $56.4 \pm 11.6[36-71]$ \\
\hline Weight $(\mathrm{kg})$ & $77.6+13.6[46.1-98.1]$ & $79.8 \pm 14.8[54.1 .109 .1]$ \\
\hline Body surface area $\left(\mathrm{m}^{2}\right)$ & $1.9 \pm 0.2[1.34-2.20\}$ & $2.0 \pm 0.2[1.59-2.34]$ \\
\hline Time on PD (monttis) & $19.1 \pm 15.8[3-47]$ & $25.1 \pm 18.0[4-66]$ \\
\hline Weekly $\mathrm{Kt} / \mathrm{N}$ & $2.5 \pm 0.6[1.6-4.3]$ & $2.4 \pm 0.7[1.7 \cdot 5.0]$ \\
\hline Weekly Creatimine Clearance (L/1.73 m²) & $85.6 \pm 40.0[67.4-170.5]$ & $67.2 \pm 33.4[6.5 .3 \cdots 134.3 \rrbracket$ \\
\hline Residal Diuresis (m/24 Hrs) & $1131 \pm 1099[0-4000]$ & $1031 \pm 84910-34901$ \\
\hline Residual glomerular filtration rate (nnl/nin) & $5.4 \pm 3.6[0-13.8]$ & $4.1 \pm 3.2[0.14 .1]$ \\
\hline D/P creatinine & $0.64 t 0.11[0.45 \cdot 0.90]$ & $0.65 \pm 0.09[0.47-0.79]$ \\
\hline Serum albumin $(g /)$ & $31.6 \pm 3.5[23.4-37.5]$ & $31.8 \pm 2.8[27.4-38.1]$ \\
\hline Hemoglobin (mmol/1) & $7.2 \pm 0.8[5.5 .8 .7]$ & $7.3 \pm 0.6[6.4-8.6]$ \\
\hline C-reactive protein $(\mathrm{mg} / \mathrm{L})$ & $11.4 \pm 19.5[2-89]$ & $8.3+10.2[2-37]$ \\
\hline 24-thour systolic blood pressure (mmHg) & $135.6 \pm 20.6[100-177]$ & $136.9 \pm 18.5[105 \cdot 177]$ \\
\hline 24-hour diastalic blaad pressure $[\mathrm{mmHg}$ ) & $81.2 \pm 11.9[56-105]$ & $84.2 \pm 10.6[64-107]$ \\
\hline Number of antihypertensive agents & $2.0 \pm 1.1[0.4\rfloor$ & $1.9 \pm 1.2[0-4]$ \\
\hline \% potients on antihypertensive treatment & 90.9 & 89.9 \\
\hline
\end{tabular}

Data for potients whom were enrolled in the sludy 
The study was approved by the ethics committee of the University Haspital Maastricht, The Netherlands. All patients signed informed consent.

Randomization procedure and power analysis

Patients were randomised with the use of sealed envelopes. The primary outcome variable was the difference in ECW between icodextrin-treated patients and the control group. In order to deted a difference of 3 litres $(\alpha=0.05,1$. $\beta=0.20$ ) between the icodextrin- and control groups, 33 patients would be needed. However, because we wished to include as much patients as possible (maximum of 50) to maximize power, 50 envelopes were available for randomization. As we learned that additional inclusion of patients in our region was not possible, we terminated the study after the inclusion of 40 patients.

\section{Study protocol}

Patients were admitted to the research centre at the dialysis department of the University Hospital of Maastricht in the early morning after an overnight fast. PD fluid was first drained before the measurements were started. After admission, tracer dilution measurements were performed and office blood pressure was measured. During this study period, patients were not allowed to eat or drink. At noon, patients were allowed to eat a light meal, of which the total amount of fluid did not exceed $200 \mathrm{ml}$. Hereafter, echocardiagraphy was performed, followed by 24 -hour ambulatory blood pressure measurements.

Peritoneal dialysate and urine collections were performed the day before the study. Patients randomised to icodextrin used this solution during the long dwell fie the nighttime dwell in CAPD patients and the daytime dwell in CCPD patients).

\section{Study parameters}

\section{Peritoneal ultrafiltration}

Peritoneal ultrafiltration was assessed with the use of the 24-hours dialysate collection, performed the day before the start and the day before the end of the study.

\section{Peritoneal transport state}

Within a maximum of two months before entry of the study the transport state of the peritoneal membrane was characterized using a standard peritoneal equilibrium test after a four hour dwell with a PD solution containing $2.27 \%$ of glucose. At entry of the study, on the same day, a 24 hours collection of the dialysis fluid and the urine was performed to calculate the $\mathrm{Kt} / \mathrm{N}_{\text {urea }}$ and the weekly creatinine clearance normalized to $1.73 \mathrm{~m}^{2}$ body surface area (BSA) and the residual glomerular filtration rate (rGFR). All calculations were performed using PD Adequest software. ${ }^{10}$ 


\section{Body weight and body composition}

in order to obtain maximal accuracy, changes in body weight were assessed by dual energy X-ray absorptiomefry (DEXA)." DEXA [DPX-L (Lunar Radiation Corp., Madison, Wly] was used for measurement of fat mass, lean body mass (comprising muscle, inner organs and body water) and bone mineral density. Body weight was measured by DEXA because this method allows a very precise measurement of body weight, which is not influenced by clothing, which could disturb the assessment of discrete weight changes. Moreover it allows a distinction bewreen changes in lean body mass and fat mass (vide supra). It has been shown in dialysis patients that DEXA measurements were linearly related to conventional gravimetric weight procedures and were able to predict small changes in body weight accurately (12). In the present study, the correlation coefficient between body weight measured by DEXA and by conventional gravimetric scales was $r=0.98$ ( $p<0.0001)$. DEXA measurements were performed in a standard fashion while the patient was lying in a supine position. From a X-ray source and K-edge filter below the patient, X-ray beams of stable energy radiation of 38 and $70 \mathrm{KeV}$ were emitted. The composition of the sofftissue was estimated by the ratio of beam attenuation at lower energy relative to the higher energy in soft-fissue pixels; this ratio is inversely and linearly related to the percentage fat. ${ }^{12}$ Body weight was computed by summation of body fat, lean body mass, and bone cell mass. In patients randamized as controls, the coefficient of wariation of body weight assessed by DEXA between the start and end of the study was $3.2 \%$.

\section{Fluid state}

Patients received an orally administered dose of $30 \mathrm{ml}(150 \mathrm{~mm}$ ) sadium bromide $\mathrm{NaBr}$, pharmacological department, Academical Hospital Maastricht. The Netherlands). Enrichments of $\mathrm{NaBr}$ in the body fluid were measured in serum. Immediately before $\mathrm{NaBr}$ intake, a (background) blood sample was taken. After the equilibration time of 4 hours a second blood sample was collected. The concentration of $\mathrm{NaBr}$ in serum was determined by gas chromatography. ${ }^{13} \mathbb{N a B r}$ dilution spaces were calculated from the enrichment of bromide after 4 hours. The extracellular water compartment (ECW) was calculated as the NaBr dilution space corrected for intracellular penetration of $\mathrm{NaBr}$ in erythrocytes, leukocytes and secretory cells, for unequal NaBr concentrations in the extracellular fluids (Gibbs-Donnan effect), and for the concentration of water in the serum; therefore, NaBr dilution space was multiplied by the following correction factor: $0.90^{*} 0.95^{*} 0.94=0.80 .^{14}$ In patients randomized as controls, the coefficient of wariation of ECW between the start and end of the study was $12.6 \%$.

\section{Normalization of parameters}

Regarding the relation between the effect of icodextrin with regard to the initial fluid state of the patient, extracellular volume was normalized both for body surface area (BSA) and height, because the optimal normalization procedure for fluid state is not well known in dialysis patients. ${ }^{15}$ 


\section{Echocardiography}

Two-dimensional echocardiography was performed using a HP Sonos 5500 ultrasound system (Hewleft Packard, U.S.A.) with standard imaging transducers with a frequency varying from 1.6 to $3.2 \mathrm{MHz}$. Parameters included in the analysis were left ventricular mass (LVM) and left ventricular end-diastolic diameter (LVEDD) as a parameter of left ventricular eccentric hypertrophy. LVM was calculated according to the formula of Devereux and Reichek ${ }^{13}$ : LVM $=1.04\left[(\text { LVEDD + IVST + PWT })^{3}-(\text { LVEDD })^{3}\right]-13,6$.

IVST = intraventricular septum thickness, PWT = posterior wall thickness.

\section{4-hour ambulatory BP}

In all patients, 24-hour BP measurements were performed using a Spacelabs oscillometric BP monitor (Redmond, WA, USA). BP was measured every 15 minutes from 7 a.m till 11 p.m and every 30 minutes from 11 p.m till 7 a.m. Measurements were only included if more than $85 \%$ of the readings were successful. If not, the measurement was repeated. For the separation of dayand nighttime blood pressures, "fixed" hours were taken: 7 a.m till 11 p.m for daytime and 71 p.m till 7 a.m. for nighttime blood pressures. ${ }^{17}$

\section{Statistics}

Data are expressed as mean $\pm S D$. Differences between the icodextrin and control groups were assessed with the unpaired Student $t$-test. Changes within groups were assessed with the paired Student t-test. For data, which were not normally distributed (ultrafiltration volume, rGFR, residual diuresis, total daily fluid removal, peritoneal glucose prescription, C-reactive protein), nonparametric tests were used (respectively Mann-Whitney and Wilcoxon tests).

Correlations between variables were estimated by the use of Pearson product moment correlations. P-values $<0.05$ were considered significant.

\section{Results}

Of the forty patients that were included in the study, twenty-two patients were randomized to use icodextrin, 18 patients were randomized into the control group. Thirty-two patients [19 icodextrin, 13 controls] completed the study. Three patients dropped out in the icodextrin group lone patient switched to hemodialysis because of technique failure, one patient had a recovery of the renal failure and CAPD was stopped, one patient developed a hypersensitivity reaction during the use of icodextrin (exfoliative dermatitis wich was completely resolved after stopping the icodextrin). In the contral group 5 patients dropped out (two patients underwent a renal transplantation during follow up, two 
132 Chopter 8

potients developed a peritonitis, one patient was switched to hemodialysis beccuse of technique failure.

Data for ECW and ambulatory blood pressure are available for all patients, and for echocardiagraphy in all but one patient. Urine collections were missing in three patients in the icodextrin group and two patients in the control group. Data presented in Table 8.2 comprise those who ended the study.

Table 8.2

\begin{tabular}{|c|c|c|c|}
\hline & \multicolumn{2}{|c|}{ Icodextrin-treated group $(n=19)$} & \multirow[b]{2}{*}{$p$} \\
\hline & Start & End & \\
\hline$E C W(M)$ & $17.5 \pm 5.2[9.0-29.0]$ & $15.8+3.8[8.3-23.9]$ & 0.035 \\
\hline UF-volume (m) & $744+767[-400-2500]$ & $1670 \pm 1038[200.4420]$ & 0.012 \\
\hline Residual diuresis (m) & $1131 \pm 1099[0.4000]$ & $913+962[0.3800]$ & 0.005 \\
\hline Daily fluid removal (mil) & $1854 \pm 908[400-3800]$ & $2381 \pm 1188[340-4858]$ & 0.031 \\
\hline Residual GFR (ml/min) & $4.8+3.2[0.9 .0]$ & $3.4+3.0[0-9.3]$ & 0.010 \\
\hline Syslolic BP (mmHg) & $138 \pm 21[100-177]$ & $135 \pm 28[100-194]$ & ns \\
\hline Diastolic BP $(\mathrm{mm} H \mathrm{~g})$ & $82 \pm 12[56.70 .5]$ & $80 \pm 11[54-108]$ & ns \\
\hline LYM $|g|$ & $241.2 \pm 52.6[125-346]$ & $228.3+41.8[120-307]$ & 0.031 \\
\hline LVEDD (mm) & $51.6 \pm 6.0[38-62]$ & $50.8+5.7[37-60]$ & ns \\
\hline Lean brody mass (kg) & $51.8 \pm 11.2[29.5-69.5]$ & $50.7=11.3[27.7-70.0]$ & 0.014 \\
\hline Fat mass ( $(\mathrm{kg})$ & $22.1 \pm 8.9[9.9 \times 42.5]$ & $21.0 \pm 9.1[8.2-42.8]$ & $n s$ \\
\hline Glucose prescribed $(g / d)$ & $200 \pm 99[82-524]$ & $161 \pm 96[61-490]$ & 0.000 \\
\hline Body weight $(\mathrm{kg})$ & $76.6 \pm 13.8[42.2-95.7]$ & $74.9 \pm 14.5[37.3-93.4]$ & 0.002 \\
\hline C-reactive protein $(\mathrm{mg} / \mathrm{l})$ & $12.9 \pm 20.6[2-89]$ & $8.2 \pm 8.2[2-30]$ & $n s$ \\
\hline Hemoglobin (mmol/l) & $7.2 \pm 0.7[5.5-8.7]$ & $7.5 \pm 1.0[6.1-9.8]$ & ns. \\
\hline \multirow[t]{2}{*}{ Serum albumin $(\mathrm{g} / \mathrm{l})$} & $32.1 \pm 3.3[23.4-37.5]$ & $31.9 \pm 4.6 \llbracket 79.1-38.0 \rrbracket$ & ns \\
\hline & \multicolumn{2}{|c|}{ Control group $(n=13)$} & \\
\hline ECW $(\|)$ & $16.5 \pm 3.6[10.9 \cdot 22.1]$ & $17.4 \div 4.7[11.1 .25 .6]$ & ins \\
\hline UF-volume $(\mathrm{ml})$ & $907 \pm 787[-820-2355]$ & $1063 \pm 960[-1320-2000]$ & ns \\
\hline Residual diuresis (m) & $1061 \pm 890[0-3490]$ & $948 \pm 858[0-3100]$ & ns \\
\hline Daily fluid removal (mll) & $1968+980[580-3790]$ & $2001 \pm 1230[-370-4080]$ & rys \\
\hline Residual GFR (m/ $/ \mathrm{min}$ ) & $4.5 \pm 3.5[0-74.1]$ & $4.1 \pm 4.3[0-16.4]$ & mis \\
\hline Systolic BP $(\mathrm{mmH} H \mid$ & $138+21[105-177]$ & $133 \pm 22[94 \times 177]$ & $\mathrm{ms}$ \\
\hline Diastalic BP (mmHa) & $85 \pm 12[64-107]$ & $80 \pm 11[59-95]$ & ms \\
\hline LVM $(g)$ & $219 \pm 42[158.310]$ & $220 \pm 41 / 170-3201$ & ns \\
\hline LVEDD (mm) & $48.5 \pm 4.7\lceil 42-56\rfloor$ & $49.5 \pm 3.9[43-57]$ & ns \\
\hline Lean body mass (kg) & $51.8 \pm 9.9[34.4-63.8]$ & $52.9 \pm 9.9[36.8-71.4]$ & ns \\
\hline Fat mass $\{\mathrm{kg}\}$ & $24.6 \pm 9.8[8.7-40.5]$ & $24.0 \pm 8.3[7.9-35.5]$ & ns \\
\hline Glucose prescribed $(g / d)$ & $174 \pm 58[68-259]$ & $174+58[68-259]$ & ns. \\
\hline Body weight $(\mathrm{kg})$ & $79.6 \pm 11.7[59.6-104.9]$ & $80.0 \pm 13.] 58.0-110.5]$ & $\mathrm{ns}$ \\
\hline C-reactive protein (ing/l) & $4.5 \pm 3.9[2-15]$ & $4.4 \pm 4.4[2-16]$ & $\mathrm{ns}$ \\
\hline Hemoglobin /mmol/li) & $7.1 \pm 0.6[6.4-8.6]$ & $7.3 \pm 0.5[6.5-8.3 \rrbracket$ & $n s$ \\
\hline Serum albumin $(g / \|$ & $32.1 \pm 3.3[23.4-37.5]$ & $31.6 \pm 3.8[22.0-37.0]$ & ns \\
\hline
\end{tabular}

Dato for the patients who completed the sfudy; meantSD frangel; ECW=extracellular water; UF. volume $=$ peritoneal ultafiltation volume; $B P=b l o o d$ pressure; $Q F R=$ glomerular filtration rote: LWM $=$ left ventricular mass; LVEDD=lett ventricular end-diastolic dometer; Glucose prescribed daily pertioneal glucose prescription, Daily fhid removal sum of perithenel fluid removal and diuresis. 
Effect of icodextrin on fluid state, body weight, blood pressure, and echocardiographic parameters

Variables for ECW, 24-hour ambulatory blood pressure, LVM and LVEDD are summarized in Table 8.2. In contrast to the control group. ECW declined significantly in the group treated with icodextrin. Also the change in ECW between the icodextrin-treated and control group was significantly different [Figure 8.1] $(-1.7 \pm 3.3$ versus $+0.9 \pm 2.2$ liter; $p=0.013)$. Also body weight decreased in the icadextrin-treated group, in contrast to control subjects $(p<0.03$ for the difference between groups). The relation between the change in body weight and ECW did not reach significonce $(r=0.30)$.

24-hour blood pressure did not change significantly in the icodextrin-treated and control groups. Nevertheless, LVM decreased in the icodextrin-treated group, in contrast to the control group [Figure 8.2]. Still, no direct relation between changes in ECW or body weight with changes in LVM was observed. Although the change in LVEDD in the icodextrin-treated group was not significant, there was a significant relation between the change in LVEDD and LVM $(r=0.69 ; p=0.001)$.

Relation between fluid state, peritoneal membrane characteristics, and the effect of icodextrin

In icodextrin-treated patients, there was no relation between peritoneal membrane characteristics and the decline in ECW, but a highly significant relation between the initial fluid state of the patient, expressed as ECW:BSA, and the change in ECW was observed $(r=-0.75 ; p<0.001)$ This relationship also remained significant when the initial fluid state was expressed as ECW:height $(r=-0.72 ; p=0.001)$ (Figure 8.3).

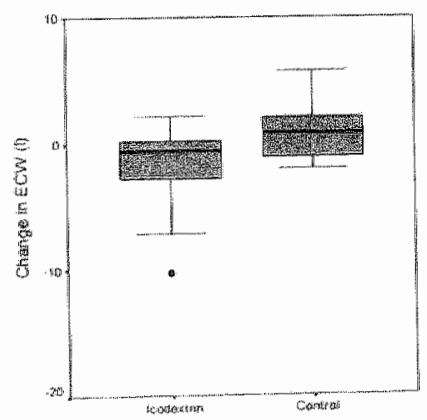

Figure 8.1. Change in ECW in the icodextrin-treated and control group
ECW $=$ extracellular water. Difference between lcodextrin and Control group at $p=0.013$. Box indicates $25^{\text {th }}$ and $75^{\text {th }}$ percentiles thick line is median valuel, capped bars indicale minimum and maximum value (excluding outliers) 


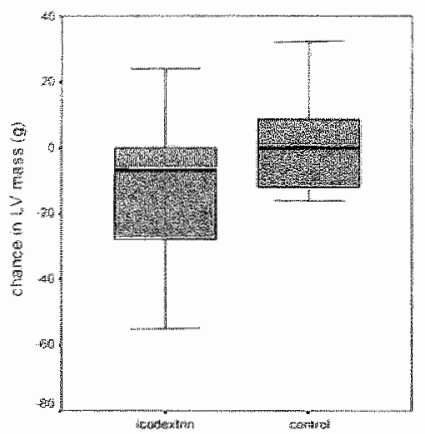

Figure 8.2. Change in LV-mass in the icodextrin-treated and control group.

$L Y=$ left ventricular. Difference between Icodextrin and Control group at $p=0.050$. Box indicates $25^{\text {th }}$ and $75^{\text {th }}$ percentiles (thick line is median value), capped bars indicate minimum and maximum value (excluding outliers!

\section{Effect of icodextrin on residual diuresis and residual GFR}

Residual diuresis declined significantly in the icodextrin-treated group (Table 8.21. rGFR decreased slightly, but significantly, in the icodextrin-treated group but not in the control group.

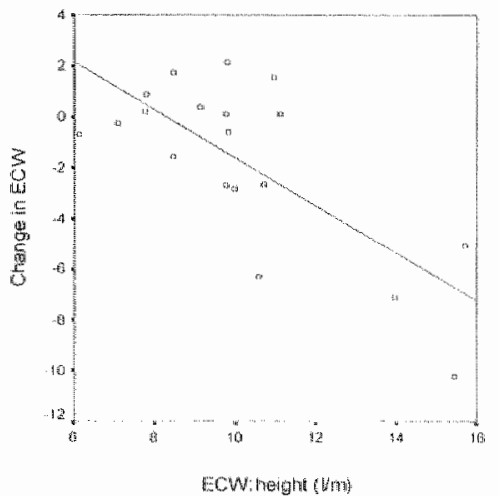

Figure 8.3. Relation between the initial fluid state and the change in ECW after treatment with icodextrin

ECW =extracellular water; $r=0.72 ; p=0.001$

\section{Discussion}

The main results of this open-label randomized study are the significant effect of icodextrin on extracellular volume, assessed by tracer dilution techniques, and 
the significant relation between the initial fluid state of the patient and the effect of icodextrin on extracellular volume.

In contrast to the control group, extracellular volume declined significantly in the group treated with icodextrin, with a highly significant difference between the control and icodextrin treated groups. The decline in extiacellular volume is. explained by the impressive effect of icodextrin on peritoneal ultrafittration. The effect of icodextrin on ultrafiltration volume and extracellular volume is in agreement with the study of Woadrow et al. in patients on automated peritoneal dialysis. However, this study was a non-randomized study using biompedance measurements as a marker of volume state. In the present study, we chose to use tracer dilution techniques in the assessment of volume state, as the reliability of volume measurements by bioimpedance appears to be especially compromised in overhydrated patients. ${ }^{18,19}$ In contrast to Woodrow et al, we did not observed a significant effect on 24-hour ambulatory blood pressure measurements. ${ }^{8}$ it is possible that absence of a significant effect of icodextrin on blood pressure regulation might be explained firstly by the fact that, in line with a recent survey of patients on peritaneal dialysis ${ }^{20}$, most of aur patients used antihypertensive medication, which may have blunted the effect of changes in volume state, and secondly that other factors than fluid state, such as arterial wall properties, have an important effect on blood pressure in PD patients. ${ }^{5}$ In the icodextrin group, LVM decreased significantly, in contrast to controls.

In addition to the decline in ECW and the reduction in LVM, also body weight and lean body mass declined in the icodextrin-treated patients, whereas body weight remained stable in the control group. It is most likely that the decline in body weight and lean body mass also reflects an improvement in fluid state. The fact that the relation between the change in bady weight and ECW did not reach significance might be due to the variation in ECW measurements. Another explanation for this phenomenon might reside in the fact that, even during a relatively short time period, changes in body composition, unrelated to fluid state may occur in PD patients. ". In a recent analysis, we abserved significant changes in body cell mass and fat mass in individual patients during a 4-month follow-up period (see chapter 7 ).

Moreover, the fact that in the icodextrin-treated group as a whole, ECW, body weight and LVM all changed significantly in the same direction, appears a strong argument for a beneficial effect of icodextrin on fluid state in unselected PD patients. Body fat mass did not decrease in the icadextrin-treated group. despite the reduction in peritoneal glucose prescription. This might be explained by the fact that the follow-up time was relatively short or by the fact that the reduction in glucose prescription ( 140 grams/day) was too small to achieve a significant reduction in body fat.

The effect of icadextrin on ECW was not related to peritoneal membrane characteristics but highly significantly related to volume slate, i.e. much more pronounced in patients with an expanded ECW compartment. The mechanisms behind this phenomenon cannot be elucidated from the present study. One 
could speculate that the effect of icodextrin on peritoneal ultrafiltration is most pronounced in overhydrated patients, e.g. due to a higher peritoneal capillary pressure. Another hypothetical explanation could reside in the possibility that the increased peritoneal ultrafiltration by icodextrin would result in increased thirst and woter intake in normovolemic patients, counteracting the effect on volume state.

The fact that icodextrin was most effective in patients with an expanded ECW leads to the problem of the diagnosis of overhydration in peritoneal dialysis patients. Although this problem is beyond the scope of the present study, it should be mentioned that clinical examination appears to be insufficienty sensitive for this purpose, as a high prevalence of subclinical overhydration. assessed by tracer dilution methods, was observed in an unselected group of PD patients with adequate treament according to DOQI guidelines with dry weight prescription according to the clinical judgement of the physician. 4.5 We admit that the use of tracer dilution techniques is not suitable for daily clinical practice. As already mentioned, multifrequency broimpedance analysis MF-BIA, which is a simple and non-inwasive tool, carries the disadvantage of a lack af agreement with tracer dilution techniques, especially in overhydrated patients. ${ }^{3} .99$ In a recent study by our group in peritoneal dialysis patients, it was not possible to find a cull-oft point for (MF-BIA), which could predict left ventricular dilatation with adequate sensitivity and specificity. ${ }^{16}$ Additional studies, including an adequate sample of control subjects, should be carried out in order to find whether it is passible to elucidate a cut-off point for MF-BIA measurements which also carries a predictive value for hemodynamic abnormalities in PD patients (see chapter 10).

A potential point of concern is the fact that residual diuresis declined in the icodextrin group, although this phenomenon was also observed, although to a lesser degree, in patients treated with a standard treatment regimen, the latter possibly due to the progressive decline in renal function normally observed in dialysis patients. ${ }^{22}$

Possibly, part of this phenomenon might be explained by reduction in so-called pressure diuresis, stimulated by overtydration. ${ }^{23}$ Nevertheless, the small but significant decline in rGFR observed in the icodextrin group connot be neglected. Whather the observed dedine in rGFR outweighs the beneficial effect of icodextrin on fluid state cannot be answered from the present study.

Drawbacks of the present study are the relatively shorf follow-up period, which was chosen because longer follow-up periods in dialysis patients may result in significant dropout due to factors such as transplantation and morbidity. We strould also point to the foct that in the present study, both patients on CAPD and CCPD were included, although the potenticl disturbing effects of this factor are counteracted by the randomized treatment design. Moreover, patients with severe cardiac failure and other underying pathology, who might especially benefit from the effects of icodextrin, were not included in the present study because of the potential overwhelming effect of the underlying disease on ECW. 
Another potential drawback of the study is the fact that icodextrin dwells were compared with $1.36 \%$ glucose solutions. Use of $1.36 \%$ glucose solutions for long dwells is standard procedure in our region, due to the potential negative effects of high glucose absorption on the metabolic profile of the patient and because of the potentially negative effects of high glucose concentrations on the structure of the peritoneal membrane. ${ }^{24}$ Moreover, one should keep in mind that also side effects have been described with the use of icodextrin, such as skin eruptions, which also occurred in one of our patients, and sterile peritonitis. ${ }^{25,20}$ According to the small number of available literature data and the widespread use of icodextrin solutions, the incidence of these complications is probably small. ${ }^{27}$

Concluding, in this randomized study, the use of icodextrin during the long dwell resulted in a significant increase in peritoneal ultrafiltration and an improvement in fluid state and LVM during a four months period compared to a control group using standard glucose solutions. The effect of icodextrin was not found to be related to peritoneal membrane characteristics, but was rellated to the initial fluid state of the patient. 


\section{References}

1. Foley RN, Parfrey PS, Harnett JD, Kent GM, Martin CJ, Murray DC, Barre PE. Clinical and echocardiographic disease in patients starting end-stage renal disease therapy. Kidney Int 1995; $47: 186-192$

2. Dionisio P, Valenti M, Bergic $R$, Caramello $E$, Stramignoni $E$, Berto $\| M$, Pellerey $M_{n}$ Bajardi $P$. Influence of the hydration state on bload pressure values in a group of patients on regulor mointenance hemodialysis. Blood Purif 1997; 15: 25-33

3. Gunal Al, Duman S, Ozkahya M, Toz H, Asci G, Akcicek F, Basci A. Strict wolume control normalizes hypertension in peritoneal dialysis patients. Am J Kidney Dis $2001: 37: 588-593$

4. Enia $G$, Mallamaci F, Benedetto FA, Panuccio V, Parlongo $S$, Cutrupi S, Giacone $G$, Cottini $E$, Tripepi G, Malatino LS, Zoccali C. Long-tern CAPD patients are wolume expanded and display more severe left ventricular hypertrophy than haemadialysis patients Nephrol. Dial. Transplant. 16: 1459-1464

5. Konings CJAM, Kooman JP, Schonck $M$, Dammers $\mathbb{R}_{*}$ Cheriex $E$, PalmansMeulemans A, Hoeks APG, van Kreel B, Gladziwa U, van der Sande FM, Leunissen KML. Fluid status, blood pressure, and cardiovascular abnormalities in patients on peritoneal dialysis. Perit Dial Int 2002;22:477-487

6. Posthuma N, ter Wee PM, Donker AJ, Oe PL, Peers EM, Verbrugh HA. Assessment of the effectiveness, safely, and biocompatibility of icodextrin in automated pertoned dialysis. The Dextrin in APD in Amsterdam (DIANA) Group. Perit Diall Int 2000;20 (S2):5106-113

7. Johnson DW, Arndt $M$, OShea A, Watt $R$, Hamilton J, Wincent $K$. lcodextrin as salvage therapy in peritoneal dialysis patients with refractory fluid overload. BMC Nephrol $2001 ; 2: 2$

8. Woodrow G, Oldroyd B, Stables G, Gibson J, Turney JH, Brownjohn AM. Effects of icodextrin in automated peritoneal dialysis on blood pressure and bioelectrical impedance analysis. Nephrol Dial Transplant 2000; 15:862.866

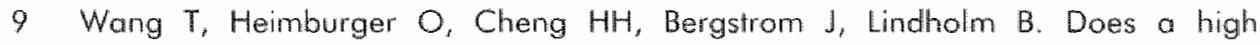
peritoneal transpart rate reflect a state of chronic inflammation? Perit Dial Int 1999; $19: 17.22$

10. Vonesh EF, Burkart J McMurray SD, Williams PF. Peritoneal dialysis kinetic modeling: walidation in a multicentre clinical study. Perit Dial Int 1996; 16:471-481

11. Lohman TG. Dual Energy $X$ uray absorptiometry. In: Human body composition. Roche AF, Heymsfield SB, Lohman TG (Eds). P' 63-78. Human Kinetics, Champaign, USA.

12. Mazess RB, Barden MS, Bisek JP, Hanson J. Dual-energy X-ray absorptiometry for total body and regional bone-mineral and soft-tissue composition. Am $\Downarrow$ Clin Nutr $1990 ; 51: 1106-1112$.

13. Van Kreel BK. An improved bromide assay for the estimation of extracellular water volume by capillary gas chromatography. Clin Chim Acta 1994; $231: 117-128$ 
14. Miller ME, Cosgriff JM, Forbes GB: Bromide space determination using anion. exchange chromatography for measurement of bromide. Am J Clin Nuir 1989; 50:168-171.

15. Konings CJAM, Kooman JP, Schonck M, MD, Cox-Reijven PL, van Kreel B, Gladziwa U, Wirtz J, Gerlag PGG, Hoorntje St, Wolters J, Heidendal GAK, van der Sande FM. Leunissen KML. Assessment of fluid state in peritoneal dialysis patienis. Perit Dial Int 2002 (in press)

16. Devereux $\mathrm{RB}$, Reichek $\mathrm{N}$. Echocardiagraphic determination of left ventricular moss in man. Anatomic validation of the method. Circulation $1977 ; 55: 613-618$

17. Kooman IP, Christiaans MH, Boots IM, Van Der Sande FM, Leunissen KM, van Hooff IP. A comparison between office and ambulatory blood pressure measurements in renal transplant patients with chronic transplant nephropathy. Am J Kidney Dis 2001;37:1170-1176

18. van den Ham EC, Kooman JP, Christiaans MH, Nieman FH, Van Kreel BK, Heidendal GA, Van Hooff JP. Body composition in renal transplant patients: bioimpedance analysis compared to isotope dilution, dual energy $X$-ray absorptiometry, and anthropometry. J Am Soc Nephrol. 1999; 10:1067-1079

19. Cox-Reijven PL, Kooman JP, Soeters PB, van Der Sande FM, Leunissen KM. Role of bioimpedance spectroscopy in assessment of body water compartments in hemodialysis patients. Am J Kidney Dis 2001,38:832-838

20. Cocchi R, Esposti ED, Fabbri A, Lucatello A, Sturani A, Quarello F, Boero R, Bruno M. Dadone C, Favazza A, Scanziani R, Tommasi A, Giangrande A. Prevalence of hypertension in patients on peritoneal dialysis: results of an llallian multicentre study. Nephrol Dial Transplant 1999; 14: 1536-1540

21. Jager KJ, Merkus MP, Huisman RM, Boeschoien EW, Dekker FW, Korevaar JC, Tijssen JG, Krediet RT. Nutritional status over ime in hemodialysis and peritoneal dialysis. NECOSAD Study Group. JAm Soc Nephrol 2001; 12: 1272-1279

22. Lysaght MJ, Vonesh EF, Gotch $F$, ef al. The influence of dialysis treatment madality on the decline of remaining renal function. ASAIO Trans 191; 37:598-604

23. Granger IP, Alexander BT, Llinas M. Mechanisms of pressure natriuresis. Curr Hypertens Rep 2002; 4: 152-159

24. Davies SJ, Phillips L, Naish PF, Russell Gl. Peritoneal glucose exposure and changes in membrane solute transport with time an peritoneal dialysis. J Am Soc Nephral 2001: 12: 1046-1051

25. Williams PF, Foggensteiner $L$. Sterile/Allergic peritonitis with icodextrin in CAPD patients. Perit Diall lnt, 2002; $22: 89.90$

26. Ail-Hoquil IA, Crawford R. Acute generalized exanthematous pustulosis induced by lcodextrin. Br J Dermatal 2001; 21:414-415

27. Divino Fiho JC. Allergic reactions to icodextrin in patients with renall failure. Lancet 2000; $355: 1364-1365$ 


\section{Chapter 9}

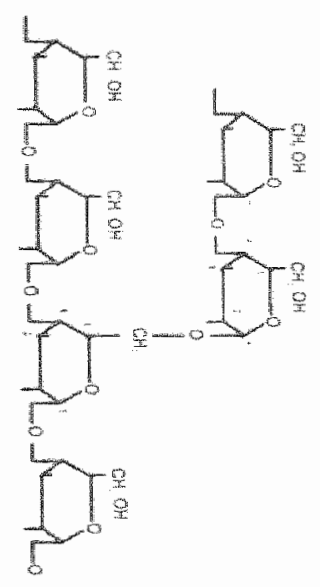

Cut-off values for
multifrequency
bioimpedance analysis in
the assessment of fluid
state in patients on
peritoneal dialysis: a
hemodynamic evaluation

CWA Konings, J van den Kerkhove, JP Kooman, Evan den Hom, M Schonck. FM von der Sonde, KML Leunissen 


\section{Abstract}

The relevance of multifrequency bioimpedance onalysis (MF-BIA) in the assessment of fluid state in pertoneal dialysis (PD) patients is still not fully elucidated. Most imporiantly, it is not known whether cut-off value derived from a contral population bear any relation with other relevant hemadynamic markers in a PD population. Aim of the present study was firstly to distillicte cut-aff walues for extracellular water (ECW) and secondly, to assess the relevance of these cul-off values by their relation with other hemodynamic parameters. $60^{\text {th }}, 75^{\text {th }}$ and $90^{\text {th }}$ percentiles of ECW corrected for height were obtained in stable renal iransplan $\{R T x$; patients $(n=77$; mean creatinine clearance $60.2 \pm 20.5$ $\mathrm{m} / \mathrm{min}$ ) and used in PD patients as cut-off values for the prediction of the hemodynamic state, assessed by left atrial diameter (LAD) and left ventricular end-diastalic diameter (LVEDD) (echocardiography), ambulatory blood pressure (BP) measurements, plasma volume (PV) (Dextran 70) and inferiar caval vein diameter (IVCD) in 45 PD patients.

The use of the $75^{\text {th }}$ percentile of ECW:height $111.94 \mathrm{l} / \mathrm{m}$ ) abtained in the RTx patients as cul-off walue resulted in large differences in $L A D(45.7 \pm 4.3$ versus $42.8 \pm 5.2 \mathrm{~mm}$; $p<0.05)$. LVEDD $(47.5 \pm 4.9$ versus $53.7 \pm 4.3 \mathrm{~mm} ; p<0.0001)$ and $P V(2.7 \pm 0.5$ versus 3.7 t0.5 1; $p<0.0001$ ) between PD patients classified as either overhydrated of not overhydrated, whereas also LAD, IVCD and diastolic BP were significantly different between these groups. Using receiver-operating curves, the use of the $75^{\text {th }}$ percentile for ECW height predicted a LVEDD above $52 \mathrm{~mm}$ with $85 \%$ sensitivity and $62 \%$ specificity. In conclusion ECW: height assessed by MF-BIA bears a strong relation with hemodynamic abnormalities in PD patients and can be considered as relevant in the diagnosis of overhydration in PD patients. Still, no single value of fluid state in PD patients can be regarded as an absolute marker for overhydration. 


\section{Introduction}

In contrast to earlier beliefs, overhydration appears to be widespread in patients on peritoneal dialysis (PD) ${ }^{1.4}$ This is not only important in view of the relation between overhydration, left ventricular hypertrophy, and hypertension', ${ }^{1,2}$, but may even be important in terms of outcome. ${ }^{5}$ Nevertheless, an adequate estimation of fluid status in PD patients is notoriously difficult. Clinical parameters, such as aedema and distended jugulor veins only occur in cases of severe overhydration ${ }^{6,7}$, whereas blood pressure, though strongly related to fluid state, is neither a sensitive, nor specific tool to detect overhydration. ${ }^{1,7}$ The latter is due to the fact that other factors, such as activity of the renin-angiotensin and sympathefic nervous system, influence blood pressure in patients with end-stage renal disease ${ }^{7}$ and to the fact that the majority of PD patients use antihypertensive medication. ${ }^{8}$

In the assessment of fluid state, it would be of prime importance to achieve an adequate estimation of extracellular water (ECW). The extracellular compartment is very relevant from a hemodynamic point of view and bears a direct relation with blood pressure and cardiac abnormalifies.". Multifrequency bioimpedance analysis (MF-B|A), which estimates ECW by assessing the resistance of the body to an alternating current, has been widely evaluated in the assessment of fluid state in dialysis patients. ${ }^{9-12}$ Because of its ease in applicability and its reproducibility, MF-BIA would be an ideal method to use in daily clinical practice. Regrettably, in previous studies, significant discrepancies in the assessment of fluid status were observed between BIA and "gold-standard" tracer-dilution techniques, especially in overhydrated patients. ${ }^{9.10}$ Because of the strong relation observed between ECW assessed by MF-BLA and echocardiographic parameters found in a recent study by our group ${ }^{10}$, it would appear that MF-BIA could still play a role in the assessment of fluid state in PD patients. However, apart from the lack of absolute agreement with tracer dilution techniques, another problem with the use of MF-BIA is the lack of a useful cut-off point for the diagnosis of overhydration.

Aim of the present study was firstly to distillate cut-off values for ECW in PD patients by the use of a control group, and secondly to evaluate, the relevance of these cut-off values in PD patients by their relationship with hemodynamic parameters.

\section{Patients}

In this study, forty-four stable PD patients were included. Patients with recent complications (e.g. malignancy or surgery) or symptomatic congestive heart failure (NYHA III and higher) were excluded. Patient characteristics are displayed in Table 9.1. 
144 Chopter 9

Table 9.1. Patient demographics of peritoned dialysis patients

\begin{tabular}{lc} 
& Number $(\%)$ \\
\hline Male/Female & $31(71 / / 3(29)$ \\
Age (years) & Mean $\pm \mathrm{SD}$ \\
Height $(\mathrm{m})$ & $54.7 \pm 11.9$ \\
Weight $(\mathrm{kg})$ & $1.72 \pm 0.1$ \\
CAPD/CCPD & $76.7 \pm 14.5$ \\
Body surface area $\left(\mathrm{m}^{2}\right)$ & $33175) / 11(25)$ \\
Body mass index $\left(\mathrm{kg}^{2} \mathrm{~m}^{2}\right)$ & $1.9 \pm 0.2$ \\
Time on PD (months) & $25.9 \pm 4.2$ \\
Weekly Kt/N ure & $23.4 \pm 17.5$ \\
D/P creatinine & $2.4 \pm 0.7$ \\
Hennoglobin (mmol/L) & $0.67 \pm 0.11$ \\
Serum albumin (pmol/L) & $7.2 \pm 0.9$ \\
\hline
\end{tabular}

$C C P D=$ continuous cyclic peritoneal dialysis; $P D=$ peritoneal dialysis; $D / P=$ dialysate/ plasma creatinine ratio; $C A P D=$ continious ambulatory peritoneal dialysis.

Patients with severe cardiac failure were excluded because the underlying disease might severely influence relations between fluid overload, blood pressure and cardiac structure and therefore abscure potentially important relations. Dry-weight was assessed on clinical grounds according to the treating physician. All PD patients were treated according to the DOQI guidelines. ${ }^{13}$ As contral group were included $77 \mathrm{RTx}$ patients with a stable renal function (mean creatinine clearance $60.2 \pm 20.5 \mathrm{ml} / \mathrm{min}$ ) under maintenance immunosuppressive therapy for at least 2 years. ${ }^{14}$ Creatinine clearance in this group was calculated by the use of the formula of Cockroft and Gault ${ }^{75}$ (Table 9.2). Informed consent was obtained from each patient, and the study was approved by the Ethicall Committee of the University Hospital Maastricht.

Table 9.2. Patient demographics of RTx patients

\begin{tabular}{lc}
\hline & Number $(\%)$ \\
\hline Male/Female & $42(55) / 35(45)$ \\
Age (years) & Mean $\pm \mathrm{SD}$ \\
Height $(\mathrm{m})$ & $51.0 \pm 11.7$ \\
Weight $(\mathrm{kg})$ & $1.67 \pm 0.9$ \\
Body surface area $\left(\mathrm{m}^{2}\right)$ & $69.8 \pm 12.8$ \\
Body mass index $\left(\mathrm{kg} / \mathrm{m}^{2}\right)$ & $1.8 \pm 0.2$ \\
Creatinine clearance $(\mathrm{ml} / \mathrm{min})^{\circ}$ & $24.8 \pm 4.8$ \\
\hline
\end{tabular}




\section{Study design}

ECW measurements were obtained in RTx patients and normalized for body weight and height. Firstly, it was determined which parameter should be used as denominator, as the optimal normalisation procedure for ECW is not well defined. Histograms for ECW in RTx patients were constructed after correction for either weight, body surface area (BSA), or height (Figure 9.1A-9.1C). It appeared that the distribution of ECW:height and BSA approached the normal distribution much closer than ECW:body weight. As BSA and height appeared to be equivalent in this aspect, height was used as denominator in the normalization procedure for reasons of simplicity.

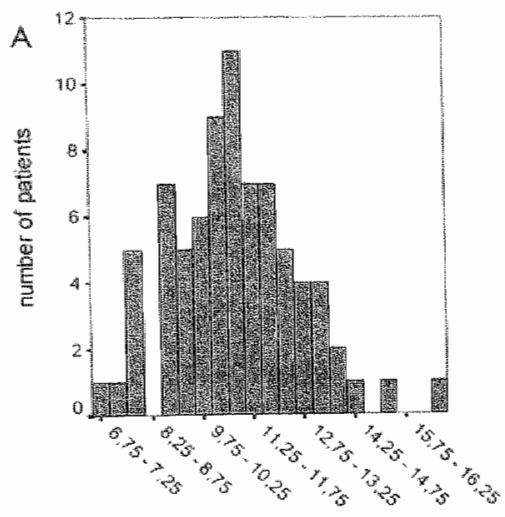

ECW :height: $(/ \mathrm{m})$

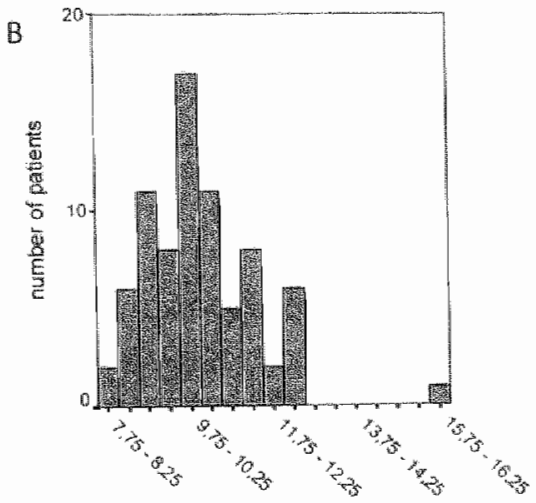

ECWNBSA (NMR2)

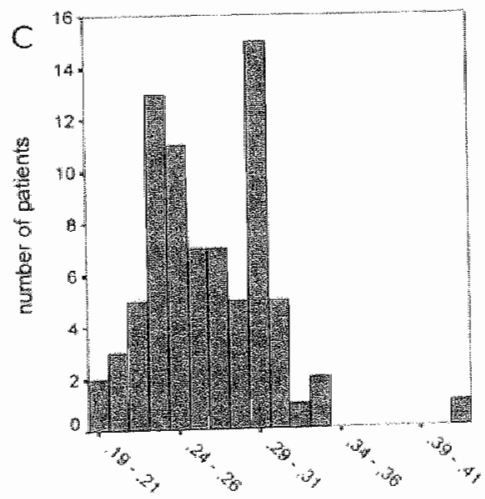

ECW weight (hikg)

Figure 9.1. Distribution of extracellular water (ECW) divided by height (A), BSA (B), and weight (C) in RTx patients. 
Hereafter, the $60^{\text {th }}, 75^{\text {th }}$, and $90^{\text {th }}$ percenflites for ECW:height were respectively used as cul-off value for overhydration. The thus derived graups were compared with regard to other parameters that are relevant in the assessment of fluid state, i.e. echocardiographic parameters, the diameter of the inferior caval vein (VCDI, plasma volume (PV), 24hour ambulatory blood pressure (BP) measurements, and the number of antihypentensives used.

\section{Study protocol}

Patients were admitted to the research centre at the dialysis department of the University Hospital Maastricht in the early morning after an overnight fast. If patients had a filled abdomen over the night. PD fluid was first drained before the measurements were started. After admission, MF-BIA measurements were performed and office BP was measured. During this study period, patients were not allowed to eat or drink. At noon, patients were allowed to eat a light meall, of which the total amount of fluid did not exceed $200 \mathrm{ml}$. Hereatter, echocardiography was performed, followed by 24-hour ambulatory blood pressure measurements.

\section{Multifrequency bioimpedance analysis (MF-BIA)}

Bioimpedance measurements were performed in a standard fasthion while the patient was lying supine on a flat, nonconductive bed. Multifrequency $15-500$ $\mathrm{KHz}$ ), alternating currents were introduced at distal electrodes on the hands (just proximal to the phalangeal-metacarpal joint in the middle of the dorsal side of the hand) and the feet (proximal to the transwerse (metatarsal) arch on the superior side of the fooll, and resistances were measured by proximal electrodes (to the wrist midway between the styloid process, to the ankle midway between the malleali). ECW was predicted from a general mixture theory (Cole-Cole model) ${ }^{16}$ : water compartments were directly calculated from resistance values, assuming specific resistances of ECW provided by the manufacturer (for men: $\rho E C W=215$, for women $\rho E C W=206,{ }^{17}$ The bioimpedance analyser used in this sludy was the Xitron $4000 B$ (Xitron Technologies Inc, San Diego, USA).

\section{Echocardiography}

Two-dimensional echocardiography was performed using a HP Sonos 5500 ultrasound system (Hewlett Packard, U.S.A.) with standard imaging transducers with a frequency varying from $\$ .6$ to $3.2 \mathrm{MHz}$. Parameters included in the analysis were left ventricular end-diastolic diameter (LVEDD) and left atrial diameter.

\section{Diameter of the inferior caval vein (IVCD)}

IVCD was also assessed with the HP Sonos 5500 ultrasound system (Hewleth Packard, U.S.A.). NCD was measured just below the diaphragm in the hepatic segment with the patients lying in supine position during 10 minutes. Simultaneaus echocardiographic recording was done. The diameter was 
measured before the $p$-wave and was corrected for body surface area. In earlier studies in hemodialysis patients, highly significant correlations between IVCD with right atrial pressure and PV were observed. ${ }^{18}$

\section{Plasma volume (PV)}

PV was determined by the disappearance of dextran-70 out of the circulation, after an intravenous injection. During one hour, every 15 minutes blood samples were taken to calculate a linear disappearance line, with an extrapolation of $\mathrm{PV}$ at $\mathrm{t}=0 .{ }^{19}$

\section{Ambulatory blood pressure measurements}

24-hours BP measurements were performed using a Spacelabs oscillometric BP monitor (Redmond, WA, USA). BP was measured every 15 minutes from 7 a.m till 11 p.m and every 30 minutes from 11 p.m till $7 \mathrm{a} . \mathrm{m}$. Measurements were only included if more than $85 \%$ of the readings were successful. If not, the measurement was repeated.

\section{Statistics}

Groups classified as overhydrated or not-overhydrated according to MF-BIA were compared using the Student-t test. The predictive value of ECW: height in the detection of left ventricular dilatation was assessed by receiver operating curves (ROC).

\section{Results}

Cut-off values, derived for the 60 th, 75 th and 90 th percentile of normalized ECW for height in RTx patients, were respectively $11.25,11.94$ and $13.5 \mathrm{l} / \mathrm{m}$ (see also Figure 9.1 a). The distribution of ECW:height in PD patients is displayed in Figure 9.2 (NB: note that absolute values for cut-off for ECW assessed by MFBIA are not comparable because of the discrepance between MF-BIA and tracer dilution measurement [chapter 3]).

Hemodynamic parameters, compared between PD patients whom were classified as overhydrated or not-overhydrated according to these percentiles are displayed in Tables 9.3-9.5. Almost all parameters differed greatly between PD patients classified in this way, especially when using the $75^{\text {th }}$ percentile of ECW:height obtained in RTx patients (see also Figure 9.3 and 9.4). The discriminatory ability of the $60^{\text {th }}$ and $90^{\text {th }}$ percentile appeared to be somewhat less, as the difference between same parameters lost significance when using this value as cut-off point. 
148 Chopter 9

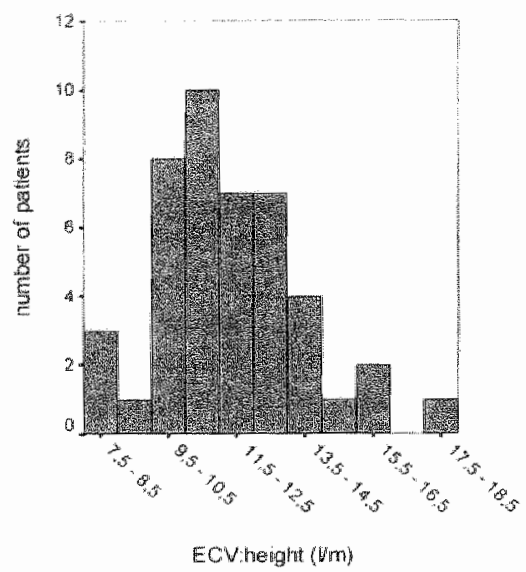

Figure 9.2. Distribution of extrocellular water (ECW) divided by height in peritoneal dialysis patients

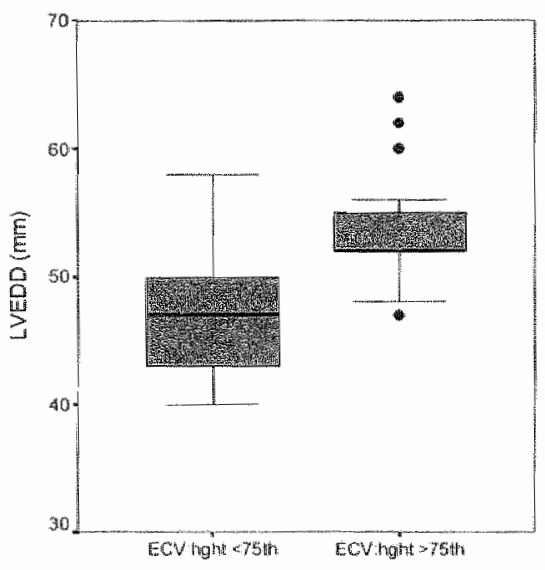

Figure 9.3. Left ventricular end-diastolic diameter (LVEDD) in peritoneal dialysis patients classified as averhydrated or not-overhydrated, according to the $75^{\text {th }}$ percentile for ECW:height abtained in RTx patients

ECW=extracellular water; Hght=height; Height< $<5^{\text {th }}=$ patients with ECW:height below the $75^{\text {th }}$ percentile of RTx patients; Height $>75^{\text {th }}=$ patients with ECW:height above the $75^{\text {th }}$ percentile of RTX patients. Box indicates the 25 th. .55 th percentile range (line in box =median). Capped bars indicate the 10th-90th percentile range. 


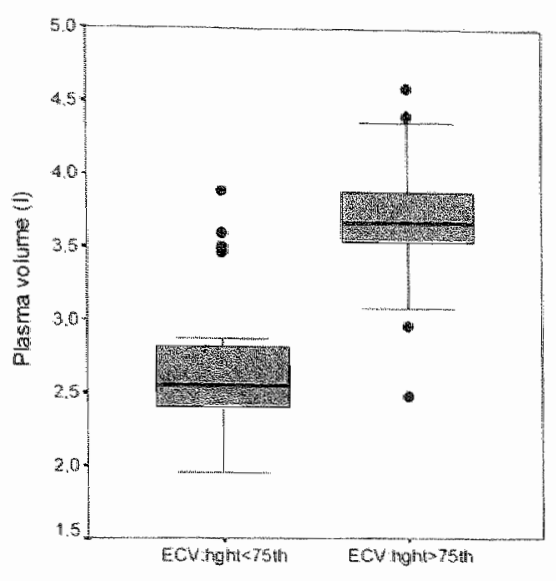

Figure 9.4. PV in peritoneal dialysis patients classified as overhydrated or notoverhydrated, according to the $75^{\text {th }}$ percentille for ECW: height obtained in RTx patients.

ECW=extracellular water; Hght=height; Height $<75^{\text {th }}=$ patients with ECW:height below the $7^{\text {th }}$ percentile of RTx patients; Height>75 with ECW: height above the $75^{\text {th }}$ percentile of RTx patients. Box indicates the 25 th- 75 th percentile range (line in box=median). Capped bars indicate the range of data excluding outliers.

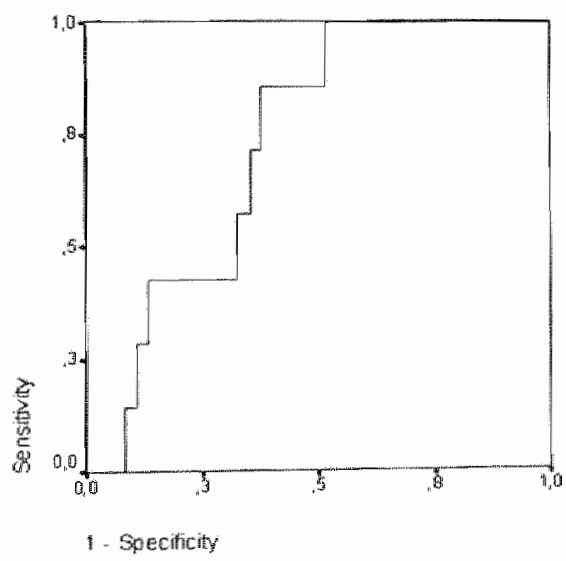

Figure 9.5. ROC for determination of sensitivity and specificity of the ECW:height in predicting a LVEDO $>52 \mathrm{~mm}$ 
Table 9.3. Hemodynomic parameters in PD patients, classified according to the $60^{\text {th }}$ percentile of ECW theight in RTx patients

\begin{tabular}{|c|c|c|c|}
\hline & ECW :hgt $\left.<160^{\mathrm{h} h}\right)$ & ECW hgt $\left.>160^{\text {thy }}\right\}$ & $\mathrm{p}$ \\
\hline$n$ & 8 & 36 & \\
\hline LVEDD (mm) & $46.5 \pm 5.9$ & $51.0 \pm 4.5$ & 0.04 \\
\hline $\mathrm{LAD}(\mathrm{mm})$ & $39.3 \pm 5.2$ & $45.1 \pm 4.4$ & 0.002 \\
\hline IVCD (mm) & $14.0 \pm 2.4$ & $17.2 \pm 3.9$ & 0.03 \\
\hline Plasmo volume (I) & $2.29 \pm 0.31$ & $3.29 \pm 0.67$ & 0.001 \\
\hline 24-h systolic BP (mmHg) & $124.0 \pm 14.2$ & $133.2 \pm 17.5$ & ns \\
\hline 24-h diastolic BP (mmitg) & $73.0 \pm 8.6$ & $81.5 \pm 11.3$ & ns \\
\hline number of antihypertensives. & $2.0 \pm 1.2$ & $1.8 \pm 1.2$ & ns \\
\hline
\end{tabular}

Table 9.4. Hemadynamic parameters in PD patients, classified according to the $75^{\text {th }}$ percentile of ECW:height in RTx patients

\begin{tabular}{|c|c|c|c|}
\hline & ECW $:$ hgt $\left.<175^{\mathrm{in}}\right)$ & ECW hat $>\left(75^{\text {in }}\right)$ & $p$ \\
\hline $\mathrm{n}$ & 25 & 19 & \\
\hline LVEDD $(\mathrm{mm})$ & $47.5 \pm 4.9$ & $53.7 \pm 4.3$ & 0.000 \\
\hline $\mathrm{LAD}(\mathrm{mm})$ & $42.8 \pm 5.2$ & $45.7 \pm 4.4$ & 0.047 \\
\hline IVCD $(\mathrm{mm})$ & $15.2 \pm 2.9$ & $18.1 \pm 4.3$ & 0.02 \\
\hline Plasma volume (I) & $2.69 \pm 0.54$ & $3.67 \pm 0.52$ & 0.000 \\
\hline 24-h systolic BP $(\mathrm{mm} H \mathrm{lg})$ & $127.6 \pm 17.1$ & $136.3 \pm 16.4$ & 0.09 \\
\hline 24-h diastolic BP $(\mathrm{mmHg})$ & $77.0 \pm 11.1$ & $83.7 \pm 10.7$ & 0.05 \\
\hline number of antihypertensives & $1.7 \pm 1.2$ & $2.1 \pm 1.1$ & ns \\
\hline
\end{tabular}

Table 9.5. Hemodynamic parameters in PD patients, classified according to the $90^{\text {th }}$ percentile of ECW:height in RTx patients

\begin{tabular}{|c|c|c|c|}
\hline & ECW :hgt $\left.<190^{\text {th }}\right)$ & ECW hgt> $\left(90^{\mathrm{h}}\right)$ & P \\
\hline n & 34 & 10 & \\
\hline LVEDD ( $\mathrm{mm}$ ) & $49.4 \pm 5.7$ & $53.0 \pm 4.5$ & 0.049 \\
\hline $\mathrm{LAO}(\mathrm{mm})$ & $42.8 \pm 5.2$ & $45.7 \pm 4.4$ & 0.03 \\
\hline $\mathrm{NCD}(\mathrm{mm})$ & $16.1 \pm 4.1$ & $18.1 \pm 2.7$ & ns \\
\hline Plasma volume $(1)$ & $2.88 \pm 0.60$ & $3.89 \pm 0.47$ & 0.000 \\
\hline 24-h systolic BP (mmHg) & $128.8 \pm 15.6$ & $140.3 \pm 20.1$ & 0.07 \\
\hline 24-h diastolic BP (mmHg) & $78.3 \pm 11.1$ & $85.4 \pm 10.8$ & 0.08 \\
\hline number of antihypertensives & $1.8 \pm 1.2$ & $2.0 \pm 0.8$ & ns: \\
\hline
\end{tabular}

$\angle V E D D=$ left ventricular end-diastalic diameter; $\angle A D=$ left atrial diameter; $I V C D=$ inferior cawal vein diameter; $\mathrm{BP}=$ blood pressure.

When the predictive value of the $75^{\text {th }}$ percentile of ECW: height $(11.94 \mathrm{l} / \mathrm{m})$ in detecting left ventricular dilatation was assessed by ROC, the area under the curve nearly reached significance (Figure 9.5) $(r=0.73, p=0.056)$. A ECW:height value of 11.94 was able to predict an LVEDD above $52 \mathrm{~mm}$ with a sensitivity of $86 \%$ and a specificity of $62 \%$. With the use of the other cut-off values $\left(60^{\text {th }}\right.$ or $90^{\text {th }}$ percentile) for $\mathrm{ECW}$ :height, it was not possible to achieve an area under the curve that approached significance. The use of these values to 
detect an overhydrated state resulted in an unacceptably low sensitivity or specificity.

\section{Discussion}

In this study, the relevance of cut-off values for ECW by MF-BIA was determined by assessing their agreement with other relevant variables related to fluid state. Especially when the $75^{\text {th }}$ percentile of ECW measurements obtained in stable RTx patients was applied as cut-off value, large differences in cardiac dimensions, PV, IVCD, and ambulatory BP measurements were observed in patients characterized as averhydrated or mot-overhydrated according to this cut-off value.

Though in our earlier experience, large differences between MF-BIA and tracer dilution techniques in the assessment of the absolute magnitude of fluid compartments were observed ${ }^{9.10,14}$, the present investigation was prompted by the fact that in a recent study we also observed a highly significant relation between MF-BIA measurements and LVEDD. ${ }^{10}$ Though the wide variability between MF-BIA and tracer dilution techniques on one hand, and the significant relation with cardiac structure would seem paradoxical, we hypothesize that a possible explanation resides in the fact that MF-BIA mainly assesses the fluid compartments that are actively implicated in the hemodynamic regulation. Roughly spoken, MF-BIA considers the body as three conductive cylinders (arms, legs, and trunk), connected in series. In conductors connected in series, those with the smallest cross-sectional area (the extremities) will determine most of the resistance whereas the part with the largest cross-sectional area (trunk) will contribute less, despite the fact that it may comprise a significant amount of body water. ${ }^{20,21}$ However, it has been shown that during stable conditions, much of the fluid stored in the splanchnic circulation is inactive ("unstressed") from a hemodynamic point of view. ${ }^{22}$

By performing ROC analysis, the $75^{\text {th }}$ percentile for ECW corrected for height $(11.94 \mathrm{l} / \mathrm{m})$ in RTx patients appeared to be more useful than the use of the $60^{\text {th }}$ or $90^{\text {th }}$ percentile in the diagnosis of an overhydrated state. However, although this value was able to predict an LVEDD above $52 \mathrm{~mm}$ with $85 \%$ sensitivity, its specificity in defecting left ventricular dilatation remained unsatisfactory $(62 \%)$. Nevertheless, it should be stated that LVEDD, like all other hemodynamic parameters related to fluid state in dialysis patients, is also influenced by various other factors, such as anaemia or intrinsic cardiac disease. Unfortunately, no "gold standard" marker for fluid state exists in the dialysis population. Therefore, absolute agreement is not to be expected from a pathophysiologic point of view. The absence of a "gold standard" is also the reason why we chose to include a variety of relevant markers to assess fluid state in PD patients.

Still, it will be clear that not one single cut-off value can be distilled to separate overhydrated from normohydrated patients. As often in clinical dilemmas, we strongly believe that a sliding scale exists between the normovolemic and 
hypervolemic state. Therefore, the values evoluated in this study should merely be regarded as signalling points which should attend the clinician to the possibility of overtydration and which might prompt a mare detailed evaluation. Although it was not the primary aim of the study, this paper again shaws the high prevalence of overhydration in PD patients. Indeed, ECW:height was above $75^{\text {tw }}$ percentile of RTx patients in more than $40 \%$ of the PD patients.

Apart from the use of RTx patients as control subjects, other potential points of criticism are the cross-sectional design of the study and the fact that the great majority of patients used vasaactive medication. It might indeed be argued that RTx patients do not represent an ideal control group due to the fact that in these patients, a complete normalisation of renal function is often not achieved. Nevertheless, it should be stressed that all RTx patients were in stable condition and had a mean creatinine clearance of $60.2 \pm 20.5 \mathrm{ml} / \mathrm{min}$, which makes it highly unlikely that abnormalities in fluid state due to renal disease per se wauld occur in this cohort. We believe it can be defended to use RTx patients as a control group, also because the use of healthy subjects without any history of renal disease as controls subjects for $\mathrm{PD}$ patients might also introduce flaws, e.g. because of their great difference in terms of body composition. In terms of age and body size, PD and RTx patients appeared to be well comparable.

The use of antihypertensive medication in the great majority of PD patients is common practice not only in our region, but also emerges from larger surveys. In view of the vulnerability of dialysis patients for cardiovascular events and the use of multiple ontihypertensive agents in many of our patients, we considered it unethical to stop these drugs for longer periods of time. Moreover, it is likely that stopping these drugs would only have increased the differences already observed in the present study.

On the other hand, we feel that a strong point of the sludy is the use of multiple relevant parameters related to fluid state, including PV measurements, echocardiography, MCD and ambulatory blood pressure measurements.

Therefore, we believe that the present data sthow that despite limitations in the assessment of fluid state, which were discussed in earlier studies ${ }^{90,14}$, MF-BIA can have on important role in the assessment of fluid state in PD patients, as the cutoff values assessed in the present study appeared to have strong hemodynamic nelewance. The $75^{\text {th }}$ percentile for ECW:height $\left.111.94 \mathrm{l} / \mathrm{m}\right)$ appeared to be the most useful in detecting overhydration, but should, also in view of its moderate specificity, never be regarded as an absalute value but always be interpreted in terms of the clinical picture. 


\section{References}

1. Konings CJAM, Kooman JP, Schonck M, Dammers $R$, Cheriex EC, PalmansMeuliemans A, Haeks APG, wan Kreel B, Gladziwa U, van der Sande FM, Leunissen KML. Fluid status, blood pressure, and cardiowascular abnormalities in patients on peritoneal dialysis. Perit Dial Int 2002;22:477-487

2. Lameire $N$. Van Biesen W.Importance of blood pressure and volume control in peritoneal dialysis patients. Perit Dial Init 2001 Mar-Apr;21:206-211

3. Enia G, Mallamaci F, Benedetto FA, Panuccio V, Parlongo $S$, Cutrupi S, Giacone $G$. Cottini E, Tripepi G, Malatino LS, Zoccali C. Long-ierm CAPD patients are volume expanded and display more severe left ventricular hypertrophy than haemodialysis patients Nephrol. Dial Transplant 2001; 16: 1459-1464.

4. Coles GA. Have we underestimated the importance of fluid balance for the survival of PD patients? Perit Dial Int 1997;17:321-326

5. Ates K, Nergizoglu $G$, Keven K, Sen A, Kutlay $S$, Erturk $S$, Duman N, Karatan 0 , Ertug AE. Effect of fluid and sodium remaval on mortality in peritoneal dialysis patients. Kidney lont 2001;60:767-776

6. Mujais S, Nalph K, Gokal R, Blake P, Burkart J, Coles G, Kawaguchi Y, Kawanishi $H$, Korbet $S$, Krediet $R$, Lindholm B, Oreopoulos D, Rippe B, Seligas R. Evaluation and management of ultrafiltration problems in peritoneal dialysis. International Society for Peritoneal Dialysis. Ad Hoc Committee on Ultrafiltration Management in Peritoneal Dialysis. Perit Dial Int 2000; 20 (S4): S5-521

7. Luik AJ, Kooman JP, Leunissen KM. Hypertension in haemadialysis patients: is it only hypervolaemia? Nephrol Dial Transplant 1997; 12: 1557-1560

8. Cocchi $R$, Esposi ED, Fabbri A, Lucatello A, Sturani A, Quarello F, Boero R, Bruno M. Dadone C. Favazza A, Scanziani $R$. Tommasi $A$, Giangrande A. Prevalence of hypertension in patients on peritoneal dialysis: results of an Italian multicentre study. Nephrol Dial Transplont 1999: 14: 1536-1540

9. Cox-Reijuen PL, Kooman JP, Soeters PB, van Der Sonde FM, Leunissen KM. Role of bioimpedance spectroscopy in assessment of bady water compartments in hemodialysis patients. Am J Kidiney Dis 2001; 38:832-838

10. Konings CJAM, Kooman JP, Schonck M, Cox-Reijwen PLm van Kreel B, Gladziwa U, Wirtz J, Gerlag PG, Hoorntje SJ, Wolters J, Heidendal GAK, van der Sande FM, Leunissen KML. Assessment of fluid status in peritoneal dialysis patients. Perit Dial int (in press)

11. Katzarski K, Charra B, Laurent G, Lopot F, Divino Filho JC. Nisell J, Bergstrom J. Multifrequency biaimpedance in assessment of dry weight in haemodialysis. Nephrol Dial Transplant. 1996; 11 (S2): 20-23.

12. Jaeger $1 \mathrm{Q}$, Mehta RL. Assessment of dry weight in hemadialysis: an overview. I Am Soc Nephrol. 1999;10:392-403.

13. NKF-DOQl dinical practice guidelines for hemadialysis adequacy. National Kidney Foundation. Am J Kidney Dis 1997; 30 (52): 515-566 
154 Chapter 9

14. van den Ham EC, Kooman JP, Christiaans MH, Nieman FH, Van Kreel BK, Heidendal GA, Van Hooff JP. Body composition in renal transplant patients: biompedance analysis compared to isotope dilution, dual energy $X$-roy obsorptiometry, and anthropometry. J Am Soc Nephrol. 1999; 10:1067.1079

15. Cockcroft DW. Goult MH. Prediction of creatinine clearance from serum creatinine. Nephron 1976; 16:31-41

16. De Lorenzo $A$, Andreoli $A$, Mathie J, Withers P. Predicting body cell mass with bioimpedance by using theoretical methods: a technological review. J Appl Physiol $1997 ; 82: 1542 \cdot 1558$

17. Operating manual Xitron 4000B bia-impedance spectrum analyser system. Xitron Technologies INC, San Diego CA, USA

18. Kouw PM, Kooman JP, Cheriex EC, Othof CG, de Vries PM, Leunissen KM. Assessment of postdialysis dry weight: a comparison of techniques. J Am Soc Nephrol 1993; 4: 98-104

19. Van Kreel BK, van Beek E, Spaanderman ME, Peeters LL. A new methad for plasma volume measurements with unlabeled dextran-70 instead of 125 -labeled albumin as an indicator. Clin Chim Acta 1998; 6: 71-80

20. Di lorio BR, Terracciano $V$, Bellizzi $V$. Bioelectrical impedance measurement: errors and antifacts. J Ren Nutr. 1999;9:192-197

21. Zhu F, Schnediz D, Kaufman AM, Levin NW Estimation of body fluid changes during peritoneal dialysis by segimental bioimpedance analysis. Kidney Int $2000 ; 57: 299-306$

22. Risoe C, Tan W, Smiselh OA. Effect of carotid sinus bororeceptor reflex on hepatic and splenic vascular capacitance in vagotomized dogs. Am J Physial. 1994 Apr;266(4 PH 2):H1528-533) 
Chapter 10

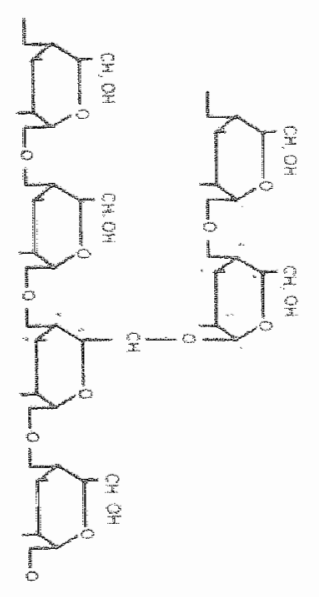

General Discussion 
156 Chapier 10 


\section{Introduction}

When the treatment adequacy of peritoneal dialysis (PD) is discussed, the main attention is devoted towards solute clearance. This is supported by data from the CANUSA study, which found a strang relation between total solute clearance and outcome in the PD population. These findings ore reflected in recent quality guidelines such as dialysis outcome and quality initiative (DOQ1), which propose strict targets for solute clearance in dialysis therapy. ${ }^{2}$ In contrast, the importance of optimizing fluid balance as a target far adequate dialysis has not received an equal amount of attention in literature, despite the recent publication of ad-hoc guidelines on ultrafiltration management in PD patients. ${ }^{3}$ This is somewhat surprizing, in view of the fact that also in PD patients cardiovascular mortality is greatly increased ${ }^{4}$, and because of the fact that studies in hemadialysis patients have shown that overhydration may predispose the patient to structural candiovascular abnormalities. "Indeed it has recently been suggested that part of the relation between residual renal function and outcome observed in the CANUSA study might be due to a beneficial effect on fluid state, whereas on the other hand, the relation between the peritoneal capacity for small solute clearance, reflected by the dialysate to plasma (D/P) creatinine ratio, and outcome might be due to the impaired fluid removal in so-called "highIransporters". With some exceptions very few studies have been performed in PD patients using detailed parameters for the fluid state. ${ }^{8}$ Goal of this paper is, as an update on the review by Coles in $1997^{\circ}$, to discuss current knowledge and new insights with regard to fluid state in the PD population.

\section{Cardiovascular abnormalities and fluid state in PD patients}

In hemodialysis (HD) patients, a strong relation has been observed between owerhydration, hypertension, and left ventricular hypentrophy (LVH) , this may be of considerable importance in view of the strong relation between $L V H$ and mortality, which is also observed in the PD population." In addition to LVH, also an increased arterial stiffness was found to be related to mortality in $H D$ patients. In chapter 2 , we also found arterial wall abnomalities in dialysis patients and patients with chronic renal failure. Allthough anterial wall abnormalities appeared to be somewhat more pronounced in HD patients compared to PD patients, it is not impossible that this is due to case-mix. More studies are needed to compare arterial wall abnomalities between HD and PD patients. In addition, also in PD patients, the importance of arterial wall stiffness was corroborated by the inwerse relation between arterial wall distensibility (the 
reciproke of stiffmess, concentric LVH, and systalic blood pressure described in chapter 4.

In general, in PD patients, far less hemodynamic studies have been performed compared to HD patients. This may be due to the fact that PD is often regarded as a more advantageous therapy regarding the maintenance of fuvid balance due to the confinuous peritoneal fluid removal and the better preservation of residual renal function. 10,11 In daily dinical practice, usually less attention is devoted towards sodium and fluid restriction compared to HD patients. Nevertheless, recent studies suggest that fluid balance may be less well preserved in PD patients than previously assumed, as the consumption of antihypertensive agents appears to be distressingly high in the PD population. 12,13 Previously, lssad et al. found an elevation of pulmonary artery pressure above $25 \mathrm{mmHg}$ in $36 \%$ of $\mathrm{PD}$ patients. "In agreement, we observed that in $37.5 \%$ of PD patients, extracellular water (ECW) was above the 90 th percentile of ECW in stable renal transplant patients (chapter 4 ). ${ }^{15}$ Moreover, in other studies, fluid state in PD patients certainly did not appear to be better maintained compared to HD patients. ${ }^{16,17}$

Abnormalities in fluid state are important with regard to outcome, as recently a relation between an impaired fluid and sodium removal with mortality was observed in PD patients. ${ }^{18}$ It should be acknowledged that this observation does not necessary imply a causal relationship due to the strong influence of peritoneal membrane characteristics on sodium and fluid removal. ${ }^{7}$ However, also in PD patients, abnormalities in fluid state appear to be directly related to both ambulatory blood pressure and eccentric LVH (chapter 4). ${ }^{15}$ Interestingly, overhydration may even be related to inflammation, as deseribed in chapter 5 where a significant relation between ECW and C-reactive protein was observed. ${ }^{19}$ Although these data should be regarded as preliminary, they are in agreement with the finding of an inflammatory state in patients with congestive heart failure, which improved after treatment with diuretics. ${ }^{20}$ An alternative explanation for this finding however might be a reduction in body cell mass by inflammation, which if undetected, may result in an incorrect assessment of "dry weight" and therefore in overhydration

\section{How to assess fluid state in PD patients}

The diagnosis of overhydration in PD patients is notoriously difficult. Clinical parameters, such as oedema, increased jugular venous pressure and pulmonary pressure rates, only occur in case of severe overhydration. Therefore, as highlighted by the ad-hac committee, an "oedema-free" state is certainly not equivalent with a state of normohydration. ${ }^{3}$ Blood pressure, though strongly influenced by fluid state, is neither sensitive nor specific due to the fact that blood pressure in dialysis patients is determined by many other factors, such as stiffness of the large arteries, and increased activity of vasopressor systems. ${ }^{20}$ This may explain why a subset of patients may suffer from hypertension without any evidence of fluid overload, even when assessed by detalled parameters. ${ }^{1522}$ 
Echography of the inferior caval vein is a relevant parameter in the assessment of fluid state in $H D$ patients ${ }^{23}$, but has not yet been validated in the PD population.

Although tracer dilution techniques can reliably assess fluid compartments in renal patients, its use is limited to research facilities. Therefore, there is a great need for a reliable non-invasive method that can diagnose overhydration in PD patients. Bioimpedance analysis (BIA), which can estimate fluid compartments by assessing the resistance of the body to an alternating current, would be an ideal method to use in daily clinical practice because of its ease in applicability and its reproducibility. Regrettably, significant discrepancies in the assessment of fluid state were observed between BIA and tracer dilution techniques, especially in overhydrated patients (chapter 3) ${ }^{24,25}$ This can be explained by the fact that BIA mainly assesses the resistance of the extremities, whereas the trunk is not well included in the measurements. ${ }^{26}$ Although it would appear that the use of segmental $B \mid A$, which also includes the resistance of the trunk ${ }^{26}$, would alleviate this problem, there still appears to be a discrepancy with tracer dilution techniques in the assessment of fluid compartments (chapter 3). ${ }^{25}$

Abnormalities in fluid state may also interfere with the assessment of body composition in PD patients, as lean body mass/fat-free mass, whether assessed by DEXA, MF-BIA, or anthropometry, is unpredictably influenced by changes in ECW (chapter 6). Therefore, when assessing changes in body composition in PD patients, we propose to correct lean body mass/fat free mass for ECW obtained by tracer dilution techniques.

With regard to the assessment of fluid state in PD patients, MF-BIA may still be relevant, because of the strong relation observed between extracellular volume and echocardiagraphic parameters found in chapter $3 .^{25} \mathrm{~A}$ problem still is the lack of a useful cut-off point for the diagnosis of overhydration. As described in chapter 9 , the $75^{\text {th }}$ percentile of ECW:height $(11.9 \mathrm{l} / \mathrm{m})$, assessed by MF-BIA, for stable renal transplant patients appeared to be relevant as a cut-off point for overhydration in PD patients, as this value was found to have discriminatory value with regard to differences in plasma volume and echocardiographic parameters.

\section{What is known about the determinants of fluid state in PD patients?}

In recent literature, the main attention has been devoted towards peritoneal membrane characteristics as a culprit for overhydration in PD patients. This is logical, because of the strong relation between the $D / P$ creatinine ratio and impaired ultrafiltration capacity. ${ }^{7.27}$ The hemodynamic importance of peritoneal membrane characteristics is further corroborated by the observed relation between ultrafiltration failure and ambulatory blood pressure. ${ }^{28}$ Also in chapter $5, D / P$ creatinine ratio was weakly, but significantly related to an increase in extracellular volume during a four-months follow-up period. However, a factor, which is at least equally as important, is the residual renal function (RRF). We also observed a significant inverse relation between RRF and extracellular 
wolume assessed by the bromide dilution technique (chapter 5)." In those patients with absent RRF, ECW was significantly higher despite the use of more concentrated glucose solutions.

in general, during prolonged PD treatment, solute clearance through the peritoneal membrane tends to increase, leading to an increase in glucose absorption and less effective ultrafittration. ${ }^{28}$ On the other hand RRF tends to decrease. The influence of both peritoneal membrane characleristics and RRF on fluid balance may present an explanation for earlier studies that found an impaired blood pressure control and more severe LVH in patients on long-term PD treament. ${ }^{30.31}$ It is lempting to speculate that the findings of Lameire et al.", who also observed an increase in plasma wolume and blood pressure during the fourth and fifth year of PD treatment ${ }^{8}$, can be attributed to either changes in peritoneal membrane characteristics, a decline in RRF, or a combination of both. Thus, available evidence suggests that bath peritoneal membrane characteristics and RRF are of importance in the maintenance of fluid balance in PD patients. In those patients with negligible RRF, it appears to be difficult to maintain a normovolemic state with the use of conventional glucose containing solutions and withou\# special emphasis on sodium or fluid restriction.

\section{How to improve fluid balance in PD patients}

Improving fluid balance may result in improved blood pressure control ${ }^{32.34}$ and probably, a reduction in $L V H .^{5}$ In patients with remaining RRF and significant diuresis, diuretics should be applied." In order to increase peritoneal ultrafiltration, usually more concentrated glucose solutions are prescribed, which leads to more effective ultrafitration because of the larger osmotic gradient. Long-term exposure to glucose and glucose degradation products may have detrimental effects on the peritoneal membrane ${ }^{23,35}$ probably due to stimulation of neoangiogenesis. ${ }^{36}$ Moreover, peritoneal glucose absorption may lead to abnormalities in the lipid profile and hyperinsulinemia. ${ }^{37}$ In addition, peritoneal glucose prescription may have an impact on the nutritional state of the patient. In chapter 7, a significant relation was observed between changes in fat mass, assessed by dual energy $X$-ray absorptiometry (DEXA) during a four-month period, and peritoneal glucose prescription (submitted data). In addition, also a decrease in body cell mass was observed in those patients with the highest peritoneal glucose prescription, in combination with a reduced protein catabolic rate (chapter 7). This would mirror experimental data, in which a strong effect of peritoneal glucose solutions on appetite in rats was observed. ${ }^{38}$

The use of automated PD has been advacated to improve the fluid balance, especially in those patients with a high $\mathrm{D} / \mathrm{P}$ creatinine ratio. The rationale for this approach is the more effective fluid removal due to short cycles, which use the advantage of the high osmotic gradients in the beginning of the dwell. 39 These short cycles also have the disadvantage of an increase in sodium sieving, which could lead to a reduction in sodium removal in the lang run. ${ }^{40}$ Some studies 
even showed a higher left ventricular mass and impaired blood pressure contral in patients on continuous cyclic PD compared to CAPD patients. ${ }^{41.42}$ However, these studies only included a small number of patients and were cross-sectional in nature. Therefore, when interpreting these data, the possibility of case-mix on the results has to be taken into account.

There appears to be a need for alternatives for glucose-containing solutions, The use of the glucose polymer icodextrin results in at least equal ultrafiltration compared with $3.86 \%$ glucose solutions without the disadvantages of glucose absorption. ${ }^{33.43}$ In contrast to glucose solutions, the ultrafiltration gradient for icodextrin is smaller but longer maintained. Whereas the beneficial effect of icodextrin solutions on peritoneal ultrafiltration is well described ${ }^{43-47}$, few studies have assessed the effect of icadextrin on fluid state and hemodynamic variables. In patients on continuous cyclic PD, Woodrow et al. abserved a reduction in extracellular volume, assessed by BIA, and an improvement in blood pressure control when using icodextrin for the long dwell. ${ }^{33}$ Moreover, in the randomized study in $40 \mathrm{PD}$ patients described in chapter 8 , we observed a significant reduction in ECW of 1.7 in the icodextrin group compared to an increase of 0.91 in the contral group during a follow-up period of 4 months. Moreover, left ventricular mass decreased significantly in the icodextrin group

This leaves us the choice of patients whom would benefit most from the effect of icodextrin. Studies until now showed that the relative effect of icodextrin on peritoneal ultrafiltration is largest in those patients with a high $D / P$ creatinine clearance or those with impaired peritoneal ultrafiltration. ${ }^{46,47}$ We observed the largest decrease in ECW in patients who were most overhydrated. Nevertheless, there will remain a subgroup of, mainly anuric, patients in whom it is not possible to maintain a normovolemic state. In these patients, strict sodium and fluid restriction should be adhered to or alternatively, transfer to hemodialysis should be considered.

A word of caution should be applied with regard to possible underhydration, as a significant decrease in RRF was abserved in a study in which strict volume control was achieved by salt restriction and use of hypertonic glucose solutions ${ }^{34}$, as well as in the patients treated with icadextrin, described in chapter 8.

\section{Future prospects}

Abnormalities in fluid state appears to be widespread in PD patients, which may have a major influence on blood pressure and left ventricular structure. Especially patients with a high peritoneal transport state and those with declining RRF may be at risk for overhydration. It would therefore pivotal to preserve both RRF and peritoneal membrane function as long as possible. Although a decline in RRF is mainly an inherent consequence of the underlying renal disease, one should be very careful in refraining from the use of all possible nephrotoxic agents, but also in preventing underhydration. With regard to the preservation of membrane integrity, much research is being devoted to the evaluation of newer peritoneal solutions with either substifutes for glucose or with less glucose 
162 Chopter 10

degradation products and a more physiological buffer profile. Although the use of these solutions resulted in an improvement of markers of mesothelial cell furnover and a reduction in peritoneal inflammation, it remains to be determined whether this will also lead to a reduction in ultrafiltration failure in the long-term. 


\section{References}

1. Churchill DN, Thorpe KE, Nolph KD, Keshaviah PR, Oreopoulos DG, Page D. Increased peritoneal membrane transport is associoted with decreased patient and technique survival for continuous peritoneal dialysis patients. The Canada-USA (CANUSA) Peritoneal Dialysis Study Group. IAm Soc Nephrol 1998;9: 1285-1292

2. NKF-DOQ! clinical practice guidelines for hemodialysis adequacy. National Kidney Foundation. Am J Kidney Dis 1997; 30 (S2): \$15-\$66

3. Mujais S, Nolph K, Gokal R, Blake P, Burkart J, Coles. G, Kawaguchi Y, Kawanishi $H$, Korbet $S$, Krediet $R$, Lindholm B, Oreopoulas D, Rippe B, Selgas $\mathbb{R}$. Evaluation and management of ultrafiltration problems in peritoneal dialysis. International Society for Peritoneal Dialysis Ad Hoc Committee on Ultrafiltration Management in Peritoneal Dialysis. Perit Dial Int 2000; 20 (S4): S5-S21

4. Lameire N, Vanholder RC, Van Loo A, Lambert MC, Vijt D, Van Bockstaele L, Vageleere P. Ringoir SM. Cardiovascular diseases in peritaneal dialysis patients: the size of the problem. Kidney Int Suppl 1996; 56: $\$ 28-536$

5. Ozkahya M, Ok E, Cirit M, Aydin S, Akcicek F, Basci A, Darhout Mees EJ. Regression of left ventricular ypertrophy in haemodialysis patients by ultrafiltration and reduced salt intake without antihypertensive drugs. Nephrol Dial Transplant 1998; $13: 1489$ 1493

6. Bargman JM, Tharpe KE, Churchill DN. Relative contribution of residual renal function and peritoneal clearance to adequacy of dialysis: A reanalysis of the CANUSA study. I Am Soc Nephrol 2001; 12: 2158-2162

7. Wang $T$, Heimburger $O$, Waniewski J, Bergstrom J, Lindholm B. Increased peritoneal permeability is associated with decreased fluid and small-solute removal and higher mortality in CAPD patients. Nephrol Dial Transplont 1998; 13: 12421249

8. Lameire $N_{1}$ Van Biesen W.Importance of blood pressure and volume control in peritoneal dialysis patients. Perit Dial Int 2001:27: 206-21.1

9. Coles GA. Have we underestimated the impontance of fluid balance for the survival of PD patients? Penit Dial Int 1997; 17:321-326

10. Burkan JM. What is the evidence that peritaneal dialysis is underutilized as on ESRO therapy? Semin Diol 2002; 16:157-161

11. Cannafa JB, Isles CG, Briggs JD, Junor BJR. Comparison af bload pressure control during hemodialysis and CAPD. Dial Transplant 1986; 15:675-679

12. Cocchi R, Esposfi ED, Fobbri A, Lucatello A, Sturani A, Quarello F, Boero R, Bruno M. Dadone C, Favazza A, Scanziani R, Tommasi A, Giangrande A. Prevalence of hypertension in patients an peritoneal dialysis: results of an Italian multicentre study. Nephral Dial Tronsplont 1999; 14: 1536-1540

13. Velasquez MT, Lew SQ, von Albertini B. Mishkin GJ, Bosch JP. Conirol of hypertension is better during hemodialysis than during continuous ambulatory peritoneal dialysis in ESRD patients. Clin Nephral 1997; $48: 34 \pi-345$ 
14. Issad B, Mouquet C. Bitker MO, Allovache M, Baumelou A, Rottembourg J, Jacobs C. Is overhydration in CAPD patients a contraindication to renol transplantation? Adv Perit Dial 1994; 10: 68-72

15. Konings CIAM, Kooman JP, Schonck $M$, Dommers $R$, Cheriex $E$, PalmonsMeulemans A, Hoeks. APG, van Kreel B, Gladziwa U, van der Sande FM, Leunissen KML. Fluid status, blood pressure, and cordiovascular abnormalities in patients on peritomeal dialysis. Perit Dial Int 2002 (in press)

16. Enia $G$, Mallomaci $F$, Benedetto FA, Panuccio V, Parlongo $S$, Cutrupi $S$, Giacone $G_{2}$ Cottini $\mathbb{E}$, Tripepi $G$, Malatino LS, Zoccali C. Long-term CAPD patients are volume expanded and display more severe left ventricular hypertrophy than haemodialysis patients. Nephrol Dial Transplant 2001; 16:1459-1464.

17. Plum J, Schoenicke G, Kleophas W, Kulas W, Steffens F, Azem A, Grabensee B. Comparison of body fluid distribution between chronic haemodialysis and peritoneal dialysis patients as assessed by biophysical and biochemical methods. Nephrol Dial Transplont 2001; 16: 2378-2385

18. Ates K, Nergizoglu $G$, Kewen K, Sen A, Kullay S, Erturk S, Duman N, Karatan $O$, Ertug AE.Effect of fluid and sodium removal on mortality in peritoneol dialysis patients, Kidney Int 2001; 60:767-776

19. Hameleers $P$, Konings CJAM, Kooman JP, van der Sande FM, Leunissen KML. Relation between peritoneal transport, inflammation and fluid state in patients on peritoneal dialysis. Perit Dial int 2002; 22: S46

20. Niebauer J, Volk HD, Kemp M, Dominguez M, Schumann RR, Rauchhaus M, PooleWilson SD. Endotoxin and immune activation in chronic hear failure: a prospective cohort study. Lancet 1999; 353 : 1838-1842

21. Luik AJ, Kooman JP, Leunissen KM. Hypertension in haemodialysis patients: is it only hypervolaemia? Nephrol Dial Transplant 1997; 12: 1557-1560

22. Lang $S M$, Walfram $G$, Gerzer $R$, Sehiffl $H$. Characterization of subtypes of hypertension in CAPD patients by cyclic guanosine monophosphate. Perit Diall Int $1999 ; 19: 143-147$

23. Kouw PM, Kooman JP, Cheriex EC, Othaf CG, de Vries PM, Leunissen KM. Assessment of postdialysis dry weight: a comparison of techniques. I Am Soc Nephroil 1993; 4:98-104

24. Cox-Reilwen PL, Kooman JP, Soeters PB, van Der Sande FM, Leunissen KM. Role of biompedance spectroscapy in assessment of bady water compartments in hemodialysis patients. Am J Kidney Dis 2001; 38: 832.838

25. Konings CJAM, Kooman JP, Schonck M, Cox-Reijuen PLm van Kreel B, Gladziwa $U$, Wirtz J, Gerlag PG, Hoontie SI, Wolter's I, Heidendal GAK, van der Sande FM, Leunissen KML. Assessment of fluid status in peritoneal dialysis patients. Perit Dial Int (in press)

26. Zhu F, Schneditz D, Kaufman AM, Levin NW. Estimation of body fluid changes during peritoneal dialysis by segmental bioimpedance analysis. Kidney Int 2000; 57: $299-306$

27. Tzamaloukas AH, Saddler MC, Murata GH, Mathotra D, Sena P, Simon D, Hawkins KL. Morgan K, Nevarez M. Wood B, et al. Symptomatic fluid retention in patients on continuous peritoneal dialysis. J Am Sac Nephrol 1995; 6: 198-206 
28. Bos W1, Struik DG, van Olden RW, Arisz L, Krediet RT. Elevated 24 hour blood pressure in peritoneal dialysis patients with ulfrafiltration failure. Adv Perit Dial 1998; 14: 108-110

29. Davies St, Phillips L. Naish PF, Russell Gl. Peritoneal glucose exposure and changes in membrane solute transport with time on peritoneal dialysis. I Am Soc Nephrol $2001: 12: 1040-1051$

30. Menon MK, Naimark DM, Bargman JM, Vas SI, Oreopoulos DG. Long-term blood pressure contral in a cohort of peritoneal dialysis patients and its association with residual renal function. Nephrol Dial Transplant 2001; 16: 2207-2213

31. Takeda K, Nakamoto M, Baba M, Tanaka T, Yasunaga C, Nishihara $G$, Matsua K, Urabe M. Echocardiographic evaluation in long-tem continuous ambulatory peritoneal dialysis compared with the hemodialysis patients. Clin Nephrol 1998; 49: 308-312

32. Jones $\mathrm{CH}$, Wells L, Stoves J, Farquhar F, Woodrow G.Can a reduction in extracellular fluid volume result in increased serum albumin in peritaneat dialysis patients? Am J Kidney Dis 2002; 39:872-875

33. Woodrow G, Oldroyd B, Stables G, Gibson J, Tumey JH, Browniohn AM. Effects of icodextrin in automated peritoneal dialysis on blood pressure and bioelectrical impedance analysis. Nephrol Dial Transplant 2000; 15: 862-866

34. Gunal Al, Duman S, Ozkahya M, Toz H, Asci G, Akcicek F, Basci A. Strict volume control normalizes hypertension in peritoneal dialysis patients. Am I Kidney Dis. $2001 ; 37: 588-593$

35. Kredief RT, Lindholm B, Rippe B. Pathophysialogy of peritoneal membrane foilure. Perit Dial Int 2000; $20($ (S4): S22-42

36. de Vriese AS, Mortier S, Lameire $\mathrm{NH}$. Neoangiogenesis in the peritoneal membrane: does it play a role in ultrafiltration failure?. Nephral Dial Traspl $2001 ; 16: 2143$ 2745 .

37. Bredie SJ, Bosch FH, Demacker PN, Stalenhoef AF, van Leusen R. Effects of peritoneal dialysis with an overnight icodextrin dwell on parameters of glucose and lipid metabolism. Perit Dial int 2001;21:275-281

38. Zheng $\mathrm{ZH}$, Sederholm F, Anderstam B, Qureshi AR, Wang T, Sadersten P, Bergstrom $J$ "Lindholm B. Acute effects of peritoneal dialysis solutions on appetite in non-uremic rats. Kidney Int $2001 ; 60: 2392-2398$

39. Diaz-Buxo JA. Continuous cycling peritoneal dialysis, PD plus, and high-flow automated peritoneal diallysis: a spectrum of therapies. Perit Dial lint 2000; 20 Suppl 2: $593-97$

40. Struijk DG, Krediet RT. Sodium balance in automated perihoneal dialysis. Perit Dial Int 2000; $20(52): 5101-105$

41. Wang MC. Tseng CC, Tsai WC. Huang Jl. Blood pressure and left ventricular hypertrophy in patients on different peritoneal dialysis regimens. Perit Dial Int 2001 ; $21: 36-42$

42. Ortega O, Gallar P, Carreno A, Gutierrez M, Rodriguez!, Oliet A, Vigil A, Gimenez E. Peritoneal sodium mass removal in continuous ambulatory peritoneal dialysis and automated peritoneal dialysis: influence on blood pressure control. Am I Nephral $2001: 21: 189-193$ 
43. Mistry CD, Gokal R, Peers E.A randomized multicenter dinical trial comparing isosmolar icodextrin with hyperosmolar glucose solutions in CAPD. MIDAS Study Group. Multicenter Investigation of Ladextrin in Ambulatory Peritoneal Dialysis. Kidney Int 1994:46:496-503

44. Posthuma N, ter Wee PM, Donker AJ, Oe PL, Peers EM, Verbrugh HA. Assessment of the effectiveness, safety, and biocompatibility of icodextrin in automated peritoneal dialysis. The Dextrin in APD in Amsterdam (DIANA) Group. Perit Dial int 2000; 20 (Suppll 2): S106-S113

45. Plum J, Gentile S, Verger C, Brunkhorst R, Bahner U, Faller B, Peeters J, Freida P. Struik DG, Krediet RT, Grabensee B, Tranceus A, Filho JC. Efficacy and safety of a $7.5 \%$ icodextrin peritoneal dialysis solution in patients treatied with automated peritoneal dialysis. Am J Kidney Dis 2002; 39:862-871

46. Johnson DW, Arnd M, OShea $A_{r}$ Watt R, Hamilton J, Vincent K Icodextrin as salvage therapy in peritoneal dialysis patients with refractory fluid overload. BMC Nephrol 2001; $2: 2$

47. Araujo Teixeira MR, Pecoits-Filho RF, Romao Junior JE, Sabbaga E, Marcondes MM, Abensur $H$. The relationship between ultrafiltrate volume with icodextrin and peritoneal transport pattern according to the peritoneal equilibration test. Perit Dial Int 2002; $22: 229-233$ 
Chapter 11

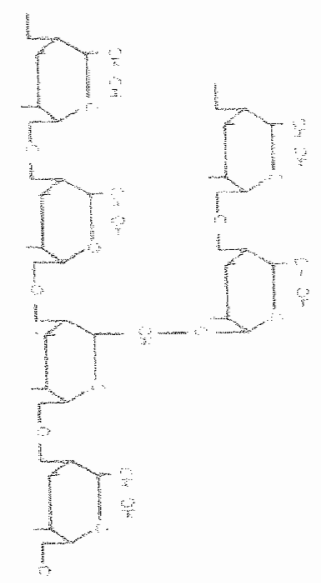

Summary 
168 Chapter 11 


\section{Summary}

The main aims of this thesis were firstly to study the prevalence of abnomalities in fiuid state and cardiovascular structure in peritoneal dialysis (PD) patients and secondly to assess the relation between fluid state, blood pressure and cardiovascular structure in these PD potients. Thirdly the influence of the peritoneal membrane transport state and residual renal function on fluid state and cardiovascular structure was studied. Forthly, the relation between these parameters and body camposition was assessed, also in view of the peritoneal glucase prescription needed to maintain a stable fluid state. Lastly, the effect of icodextrin on fluid state, cardiovascular structure and bady composition was assessed in relation to the peritoneal membrane characteristics and fluid state of the treated PD potient.

In chapter 1, an introduction to the thesis was given with a review of the literature. Both cardiovascular disease and malnutrition are impartant predictors of martality in PD patients. Observational studies also showed that both a higher permeability of the peritoneal membrane to small solutes (high transport state) and residual renal function were related to outcome in this population. It has been suggested that part of the relation between these factors and outcome might be related to abnormalities in fluid state. In case of a high transport state, this might be due to the increased glucose absorption from the peritoneal fluid, leading to a reduction in the osmotic gradient needed for peritaneal fluid removal. The presence of a high peritoneal transport state and a loss in residual renal function might also have implications for nutritional state. This because the increased peritoneal glucose concentrations needed to maintain ultrafitration may result in a reduction in appetite leading to a decrease in lean body mass, but also on the other hand also in an increase in body fat mass.

Nevertheless, until now, there are very few studies that assessed fluid state and body composition in relation to peritoneal membrane charaderistics and residual renal function.

A recently introduced pertioneal solution with glucose polymers (icodextrin) was found to result in more effective ultrafiltration compared to conventional giucose solutions because of the application of an oncotic gradient. Mevertheless, at present there are no randomized studies that assessed the influence of icodextrin on fluid state, cardiowascular structure and body composition in PD patients. There is also a paucity of data with regard to the selection of patients in whom icodextrin would be most effective.

In chapter 2, arterial wall properties were assessed in patients with chronic renal failure, peritoneal dialysis patients, hemodialysis patients, and healthy controls, 
The main finding of this chapter was the presence of a reduced anterial distensibility in patients with renal disease. In patients with chronic renal failure, arterial distensibility was related to the degree of renal insufficiency. Although arterial distensibility appeared to be somewhat higher in PD patients compared to hemodialysis patients, the potential influence of case-mix on this observation should not be neglected. Surprisingly, intima media thickness as a surrogate marker of atherosclerasis did not differ between renal patient and controls in this study. This does however not necessarily implicate that atheroslerosis is not increased in these patients with chronic renal failure. Data from the literature suggest that atherasclerosis in renal patients might be different in character and is more related to deposits of calcified products in the arterial wall.

In chapter 3 , the relation between fluid state, assessed by various tracer dilution methods , blood pressure (24-hour ambulatory measurements), and cardiac structure was assessed. A significant relation was observed between fluid state with diastolic blood pressure and eccentric left ventricular hypertrophy, whereas arterial distensibility was inversely related to systolic blood pressure and concentric left ventricular hypertrophy. Moreaver, using stable renal transplant patients as a control group, more than one third $(37.5 \%)$ of PD patients appeared to be overhydrated. This chapter shows that abnormalities in fluid state are widespread in PD patients, which may have important consequences for the blood pressure and cardiac structure.

In chapter 4, it was investigated whether multifrequency bioimpedance measurements, which are able to assess the intra- and extracellular compartments by measuring the resistance of the body to an alternating current, could substitute tracer dilution techniques in the assessment of fluid state. It was shown that despite a good correlation between the bramide dilution method and bioimpedance techniques, wide variations in the estimation of the absolute magnitude of body compartments were found, which actually appeared to be related to the relative nognitude of these compartments. Although this might be explained by the fact that mainly the resistance of the extremities is assessed by the so-called whole-body approach, also the use of segmental bioimpedance measurements, which takes the resistivity of the trunk seperately into account, did not improve the agreement with tracer dilution techniques. Still $B / A$ measurements might not be without relevance, because these were significantly related to other relevant hemodynamic parameters, such as left ventricular end. diastolic diameter.

In chapter 5 , determinants of fluid state in continuous ambulatory PD (CAPD) patients were investigated both in a cross-sectional and a langitudinal design, with special emphasis on peritoneal transport state and residual renal function. Because of the possible disturbance of different treatment prescription on these parameters, patients on continuous cyclic PD were not included in this study. In the cross-sectianal part, a large difference in fluid state was observed between patients with and without significant residual renal function, despite the use of 
much higher dialysate glucose prescriptions. Peritoneal Iransport state was found to be weakly, but significantly, related to changes in extracellular volume during the follow-up period of 4 months. This chapter corroborates the importance of both residual renal function and peritoneal transpart state in the volume homeostasis of CAPD patients.

In chapter 6, the influence of fluid state on the agreement of techniques to assess bady composition was assessed. Extracellular walume, as a component of lean body mass, varied widely between indwidual patients. Moreower, the effect of fluid state on the assessment of body composition was further shown by the relation between lean body mass and leff ventricular end-diastalic diameter, which held true for dual energy $X$-ray absorptiometry, multi-frequency bioimpedance analysis (MF-BIA), as well as anthropometry. This chapter stresses the fact that lean body mass should be corrected for extraceliular volume, assessed by tracer dilution techniques, when assessing body composition in PD patients.

Chapter 7 addressed the ralation between peritoneal transport state and residual renal function with nutritional state in a cross-sectional and longitudinal design. No relation between both variables and nutritional parameters was observed, expect for an inverse relation between D/P creatinine ratio and serum albumin. Nevertheless, peritoneal glucose prescription was significantly related to an increase in bady fat mass during the follow-up period, but also to a decline in body cell mass (lean body mass corrected for extracellular volumel. The results of this chapter suggest that peritoneal glucose prescription can have a negative effect on bady composition.

In chapter 8 , the influence of the polyglucose solution, icodextrin, on fluid state and cardiac parameters in a randomized design, with a follow-up period of 4 months is descibed. Prescription of icodextrin during the long dwell resulted in a significant decrease in extracellular water and left ventricular mass. This was however not translated in a change in blood pressure, which might be due to the multifactorial causality of the latter parameter. The effect of icodextrin on extracellular volume was not related to the $D / P$ creatinine ratio, but strongly related to the initial fluid state of the patient. Fat mass did not change during the sludy period. Summarizing, this chapter shows that prescription of icodextrin during the long dwell results in an improvement in fluid state, especially in overhydrated potients.

In chapter 9, an attempt was made to validate cut-off values for the diagnosis of overtydration in PD patients obtained by multifrequency bioimpendance andysis. The $75^{\text {th }}$ percentile of ECW height $(11.91 / \mathrm{m})$ for stable rend transplant patients appeared to be relevant as a cut-off point for overhydration in PD patients, as this value was found to have a discriminatory value with regard to differences in plasma volume and echocardiographic parameters. Nevertheless 
$172 \mid$ Chopter 11

the relatively wide overlap between these parameters necessitates a continuous use of this cut-off value.

In chapter 10, the results of the present thesis are discussed and related to findings in the literature. 
Chapter 12

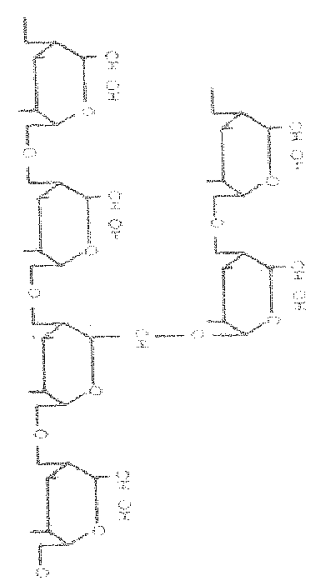

Samenvatting 
17.4 Chapter 12 


\section{Samenvatting}

De nier speelt een zeer belangrijke rol bii het instandhouden van een constant volume en samenstelling van de lichaamsvloeistoffen. Bij een afgenomen functie van de nier kunnen derholve ernstige verstoringen in het interne milieu van de patiënt ontstaan, zoals een accumulatie van afvalstoffen en een verstoring van de zout- en waterhuishouding in het lichaam. Bii een ernstige storing in het functioneren van de nier kan derhalve nierfunctievervangende therapie noodzakeliik ziin. De meest toegepaste vormen van nierfunctievervangende therapie zijn hemodialyse en peritoneaal dialyse.

Bij hemodialyse wardt de samenstelling en het volume van het interne milieu enkele malen per week gecorrigeerd door contact tussen bloed en dialysevloeist of (een gezuiverde oplassing bestaande wit water, zouten en buffers), welke zijn gescheidem door een halfdoorlaatbare (semipermeabele) membraam. Het basale principe van hemadialyse berust op diffusie (uitwisseling op basis van concentratieverschillen) russen het bloed en dialysevloeistof. Het teveel aan lichaamsvolume wordt verwijderd door middel van drukverschillen tussen bloed en dialysevloeistof (ultrafiltratie).

Bii peritoneaal dialyse (PD) word het buikvlies (peritoneum) als semipermeabele membraan gebruikt. Via een katheter wordt steriele dialysevloeistof in de buik gebracht. Vervolgens vindt uitwisseling van opgeloste stoffen en water plaats. tussen het bloed en de dialysevloeistof. Het overtollig lichcamswater wordt verwijderd door in de dialyse vloeistof een hogere glucose concentratie aan te brengen ten opzichte van het bloed, hetgeen een aanzuigende werking heeft voor water vanuit het bloed (osmose). Na enige tijd wardt de verzadigde dialysevloeistof via de katheter vit de buikholte (peritoneaalholte) verwijderd. Door deze cyclus enkele malen per dag, gedurende 7 dagen per week, te herhalen, vindt er een meer geleidelijke correctie van het interne milieu plaats. Buiten dit feit is een ander voordeel van PD dat deze in principe door de patiënt zelf verricht wordt. Wel is de kans op het optreden van buikvliesontstekingen verhoogd en kan de aanwezigheid van de hoge concentraties glucose de structuur van het buikvlies nadelig beïnvloeden.

Ondanks de effectiviteit van de verschillende vormen van nierfunctievervangende therapie is de gemiddelde overleving van dialysepatiènten verminderd ten opzichte van patienten zonder nierziekten. Factoren welke gerelateerd zijn aan de prognose van dialysepatiënten zijn ander meer afwijkingen van het hart- en vaatstelsel (cardiovasculaire atwijkingen) en ondervoeding. Deels zijn deze complicaties inherent aan het nierlijden zelf. Echter, de dialysebehandeling zelf kan deze factoren ook beinvloeden. 
In tegenstelling tot patienten die behandeld worden met hemodialyse, zijn er relatief weinig gegevens over de determinanten van cardiovasculaire afwijkingen en stoornissen in de voedingstoestand bij PD patienten.

Bii hemodialysepatienten is aongetoond dat afwijkingen in de volumestatus (de relatieve hoeveetheid wocht in hef lichaom) en hage bloeddruk (hypertensie) een belangrike rol spelen bij hel ontstaan van cardiovasculaire atwikingen. Aangezien de verwijdering van overtallig vocht geleidelijk en continu verloopt bij $\mathrm{PD}$, werd waak aangenamen dat de volumestatus bii patienten behandeld met deze techniek minder afwijkend zou zijn. In de recente literatuur is echter wijtel gerezen aan deze aanname. Er is echter nag slechts weinig onderzoek verricht naar de relatie tussen afwilkingen in de volumestatus, hoge bloeddruk (hypertensie), en cardiovasculaire afwilkingen bij PD patiënten. Een andere factor welke nog weing is bestudeerd bii deze patiëntengroep is de aanwezigheid van afwikingen aan het slagaderlik systeem (arteriële systeem). Bij hemodialysepatienten is aangetoond dat een afgenomen soepelheid (distensibiliteit) van de grote arteriem en negatieve relatie heeft met de overleving. Bij PD patiënten zijn echter vrijwel geen gegevens bekend betreffende de soepelheid van de grote arteriën.

Uit de literatuur is bekend dat zawel bij hemodialyse- als bij PD patiënten stoormissen in de voedingstoestand frequent optreden. Een mogelijk belangrijke factor bilif PD patiènten is de aanwezigheid wan hoge glucoseconcentraties in de peritoneaal dialyse vloeistof. Theoretisch zou opname van glucose uit de dialysevloeistoffen kunnen leiden tot een toename van vetweefsel, doch aan de andere kant ook tot een afgenomen eiwitinname door een negatief effect op de eetlust. Er ziin echter nog weinig gegevens voorhanden betreffende de invloed van glucoseopname vanuit het dialysaat op de voedingstoestand van PD patiënten.

In hoofdstuk 1 van dit proefschrift wordt een algemene inleiding gegeven met een overzicht van de huidige literatuur betreffende cardiovasculaire complicaties en stoornissen in de voedingstoestand bij PD patiënten.

Tevens wordt ingegaan op het belang wan de doorlactbaarheid (permeabiliteit) van het peritoneum en de restrierfunctie bij de prognose van deze patięntengroep. De toegenomen permeabiliteit lijkt deels samen te hangen met de continue blootstelling wan het peritoneum aan hoge concentraties glucose.

In de literatuur is a angetoond dat zowel een toegenomen permeabiliteit van het peritoneum als een sterk afgenomen restmierfunctie (waorbil dus de overgebleven functie van de nier vrijwel nithil is) een negatieve relatie hebben met de overleving wan PD patiënten. Er is in de litenatuur gesuggereerd dat deze relatie deels verklaard zou kunnen worden doar afwijkingen in de volumestatus (overhydratie). Bij een toegenomen permeabiliteit van het peritoneum zal de glucose vanuit de peritoneaalholte sneller in hef lichaam worden opgenomen en zal derhalve de osmotische (concentratie) gradient, welke nodig is voor de verwijdering van vocht uit het lichaam, te snel afnemen. Door de afgenomen diurese (urinehoeveelheid) bij patiënten met een vrijwel afwezige restnierfunctie 
bestaat er ook meer kans op overtydratie, hetgeen zou kunnen bijdragen aan hypertensie en cardiovasculaire afwikingen. Een toegenomen permeabiliteit van het peritoneum en een afgenomen resinierfunctie kunnen ook consequenties hebben voor de voedingstoestand van PD patiènten. Dif omdat de toegenomen glucosebehaefie in de dialysevloeistof, welke benodigd is om voldoende ultrafiltratie (vochtwerwijdering) te bewerkstelligen, kan leiden tot een toename van de vetmassa en een afname van de eetlust (zie boven). Tot heden zijn er echter zeer weinig studies verricht naar de relatie tussen de permeabiliteit van het peritoneum en de restnierfunctie mel cardiovasculaire atwrikingen en stoornissen in de lichaamssamenstelling.

Recent is er een nieuwe peritonead dialyse wloeistof, icodextrin, ontwikkeld, die bestaat uit glucase polymeren (ketens) welke minder snel in het lichaam worden opgenomen en derhalve een meer effectieve ultrafiltratie zouden kunnen bewerkstelligen. Tevens kan met het gebruik wan deze vloeistof de peritoneale blootstelling aan glucose afnemen. Tot heden ziin er echter slechts zeer weinig vergelikkende studies verricht naar het effect van icodextrin op de volumeslatus en de lichaamssamenstelling van PD patiënten.

In dit hoofdstuk werd tevens de doelstelling van dit proefschrift viteengezet.

De doelstelling van deze thesis was ten eerste om afwijkingen in de volumestatus en het cardiovasculaire systeem nader in kaart te brengen en de onderlinge relatie fussen deze factoren nader te bestudieren. Tevens werd de relatie tussen de permeabiliteit van het peritoneum en de restnierfunctie met zowel cardiovasculaire als voedingsparameters bestudeerd. Als laatste werd hef effect van icodextrin op de volumestatus, cardiovasculaire struetuur en de lichaamssamenstelling bestudeerd.

In hoofdstuk 2 werd de arteriële distensibiliteit (soepelheid) en de dikte van de vaatwand (intima-media dikte) van de halsslagader (arteria carotis) bestudeerd bij patiënten behandeld met hemodialyse, bij PD patiënten, bij patiënten mel chronisch nierfalen die nog niet met een dialysetechniek worden behandeld en bij een gezonde controle groep. Ten opzichte van de controlegroep was de arteriele distensibiliteit bij nierpatienten afgenomen. Bif patienten met chronisch nierfalen was deze afname gerelateend aan de ernst van de nierfunctie. Bij PD patiënten leek de ofname van arteriële distensibiliteit iets minder uitgesproken ten opzichte van patienten behandeld met hemodialyse, hetgeen echter aok mogelik verklaard kan worden door een verschil in samenstelling tussen beide graepen. De intima media dikte was niet verschillend fussen nierpatienten en controles.

In hoofdstuk 3 werd de relatie tussen overhydratie, hypertensie (24-uurs ombulante bloeddrukmefing en cardiavasculaire afwijkingen onderzocht bij stabiele PD patiënten. Er werd een relatie aangetoond tussen de valumestatus, bestudeerd middels dilutiemethoden (waarbij de concentratie van toegediende merkerstoffen in het bloed gemeten wordt), de diastolische bloeddruk en een toegenomen diameter wan het hat lexcentrische linker ventrikethypertrofiel. De arteriële distensibiliteit was negatief gerelateerd aan de systolische bloeddruk en 
een toegenomen wanddikte wan het hart Iconcentrische linker ventrikelhypertrofie). Ook bleek dat 24-uurs ambulante bloeddruk metingen veel beter gerelateerd waren aan structurele afwijkingen van het hart in vergelïking met een eenmalige spreekkamer bloeddrukmeting.

Tevens bleek, met niertransplantatiepatiënten met een stabiele nierfunctie als contralegroep, bij $37.5 \%$ van de PD patiënten overhydratie aanwezig.

Aangezien het gebruik wan dilutiemethoden bij het bestuderen van de volumestatus kostbaar en in de dagelijkse praktilk moellik vitvoerbaar is, werd in hoofdstuk 4 bestudeerd of de multifrequente biaimpedantie (MF-BIA) methode bruikbaar is bill PD patiénten. Met MF-BIA wordt de weerstand in het lichaam (impedantie) ten opzichte van een wisselstroom bij meerdere frequenties bepaald. Vanuit de gemeten impedantie bij wisselende frequenties kan hel volume van verschillende lichaamscompartimenten (totad lichaamswater en extracellulair water) worden bepadd. Alhoewel het volume van de lichaamscompartimenten, zoals respectievelïk gemeten middels MF-BIA en dilutiemethoden, sterk aan elkaar gerelateerd was, werden toch relatief grate afwijkingen gevonden. De mate van de afwilking tussen beide methodes was gerelateerd aan de relatieve grootte wan de bestudeerde lichaamscompartimenten. Dit zou mede verklaard kumnen worden door het feil dat de impedantie van de romp middels MF-BIA niet goed gemeten kan worden. Het gebruik van een modificatie van de BIA techniek, te weten segmentale BIA, waar de impedantie van de romp apart gemeten wordt, leidde echter nief tot een verbetering van de overeenkomst met de dilutiemethoden. MF-BIA zou echtier toch wan belang kunnen zijn bij de bepaling van de volumestatus van PD patiënten, aangezien de relatieve grootte van de lichaamscompartimenten toch gerelateerd bleek aan de diameter van het linker ventrikel tharkamer).

In hoofastuk 5 werden zawel de inwloed van de perneabiliteit van de peritoneaalmembraan en de restnierfunctie op de volumestatus van PD patienten bestudeerd. Beide factoren bleken gerelateerd aan de valumestatus, bepaald middels dilutiemethoden. Met name bleek er een groot verschil in volumestatus aanwezig tussen patiënten met vrijwel afwezige restnierfunctie en patiënten mei nog aanwezige restnierfunctie, ondanks het feit dat de gebruikte glucosecancentraties in het dialysaat bij de eerste groep veel hager was. Het onderzaek in dit hoofdstuk suggereent een belangrilke rol woor zowel een toegenomen peritoneale permeabiliteit als een afgenomen restnierfunctie bij hel ontstaan van overhydratie bij PD patiënten.

Afwijkingen in de volumestatus zouden ook een invloed kunnen hebben op de betrouwbaarheid van methoden welke gebruikt worden om de lichaamssamenstelling van PD patienten the meten. In hoofdstuk 6 werd de inwloed van de volumestatus op verschillende technieken (Dual $X$-ray absorptiometry, MF-BIA en anthropometrie), welke frequent vaor dit doel gebruikt worden, bestudeerd. Afwijkingen in de volumestatus bleken deze 
methoden duidelijk te beïnvloeden. Dit hoofdstuk benadrukt het feit dat methoden welke warden gebruikt om de lichaamssamenstelling bij PD patiënten te meten, gecorrigeerd moeten worden voor afwijkingen in de volumestatus.

In hoofdstuk 7 werd de invloed van de permeabiliteit van de peritoneaalmembraan en de restnierfunctie op de lichaamssamenstelling van PD patiënten bestudeerd, waarbii geen directe relatie tussen deze parameters kon worden aangetoond. Wel bleek de dagelijkse glucosetoediening van het dialysaat gerelateerd aan een toename van de vetmassa en een afname van de lichaamscelmassa bii PD patiënten. Het laatste zou verklaard kunnen worden door de geobserveerde relatie van peritoneale glucosetoediening met een afname van de eiwitinname. De resultaten van dit hoofdstuk suggereren dat de absorptie van glucose vanuit het dialysaat een negatieve invloed op de lichaamssamenstelling van PD patiënten kan hebben.

In hoofdstuk 8 werd de invloed van icodextrin, een glucosepolymeeroplossing. op de valumestatus en cardiovasculaire parameters bestudeerd in een gerandomiseerde (vergeliikende) studie. Bij de patiëntengroep welke icadextrim kreeg voorgeschreven werd een afname van het extracellulaire water en de linker ventrikel massa gevonden. Het effect van icodextrin was het meest vitgesproken bii patiënten met een relatief toegenomen extracellulair volume. Tijdens de studie traden geen veranderingen in de vetmassa op. De resultaten van dit hoofdstuk tonen aan dat icadextrin een gunstig effect op de volumestatus bii PD heeft en suggereert dat dit effect het meest uitgesproken is bii overgehydreerde patiënten.

Klinisch is het van groot belang is om bij PD patiënten afwijkingen in de volumestatus op eenvoudige wijze te kunnen vaststellen. In hoofdstuk 9 werd onderzocht of de relatieve grootte van het extracellulair volume, bepaald middels MF-BIA, behulpzaam zou kunnen ziin bij de diagnose van overhydratie bij PD patiënten. Hierbii werden transplantatiepatiënten met een stabiele nierfunctie als controlegroep gebruikt. Alhoewel het mogelijk bleek een relevante waarde te destilleren, lijkt deze foch met de nodige voorzichtigheid geinterpreteerd te moeten worden. 


\section{Verklarende woordenlijst}

Ambulante bloeddrukmeting

\author{
Cardiovasculair \\ Concentrische hypertrofie \\ Diallysat
}

Diurese

Excentrische hypertrofie

Extracellulair water

Gerandomiseerde studie

Hypertensie

lcodextrin

Impedantie

MF-BIA
Hierbil kan de bloeddruk gedurende een bepaalde periode automatisch gemeten worden. Onder meer geschikt voor het meten van de bloeddruk in de thuissitualie gedurende een langere periode (b.v. 24 uur)

hell hart en vaatstelsel betreffend

toegenomen wanddikte van de hartlkamer

gezuiverde waterige woeistof met opgeloste stoffen, gebruikt om het interne milies van dialysepatienten te corrigeren. Bï hemodialyse is stroomt deze vloeistof langs een kunstnier. Bij peritonead dialyse wordt sleriele vloeistof via een katheter in de buikholte gebracht

onderdruk

uitwisseling op basis van cancentratieverschillen hiermee kunnen de grootte van verschillende watercompartimenten gemeten worden. Basaal principe van deze methoden is dat de patient een vaste hoeveelheid van een merkerstof (broom of deuterium) krigt toegediend. Deze stof verdeelt zich over hel betreffende licharmscompartiment fbroom: extracellulair volume; deuterium: totaal lichaamswater). Door na een bepaalde periade, warin de merkerstof zich over het ticharmscompartiment verotent heett, de concentratie in hel bloed te meten, kan de grootte van het lichaamscompartiment berekend worden

urineproduktie

vitzetting van de (linker) harkamer water dat zich buiten de cel bevindt vergelikkende studie met een controlegroep hoge bloeddruk

peritoneale dialysevloeistof met glucose polymeren (worden minder makkelijk door het buikwlies geabsorbeerd) weerstand tegen wisselstroom multifrequente bioimpedantie thierbij wordt de volumestatus en de lichaamssamenstelling bepaald middels meting wan de weerstand van het lichaam voor een wisselstroom) 
Osmose

\section{Overhydratie}

Peritoneadholte

Peritoneum

Permeabiliteit

Polymeren

Semipermeabel

Systole

Ultrafiltratie

Ventrikel

Volumestatus aranzuiging van water door concentratieverschillen van opgeloste stoften

teveel aam lichaamswater look wel overwulling genaamd)

buikholte

buikvlies

doorlaatbaarheid

ketens

halfdoorlactbaar

bovendruk

verwijdering van vocht door drukwerschillen

hartkamer

de relatieve hoeveelheid vocht in het lichaom 


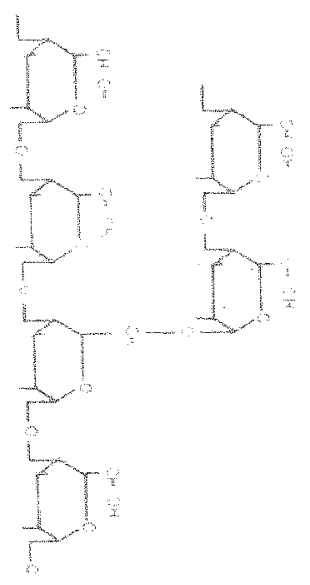

Dankwoord 


\section{Dankwoord}

Hef schrijven van een proefschrift is een traditie waarin het dankwoord niet mag ontbreken. Een proefschrift kan slechts tot stand komen met de hulp van zeer velen en het is een utopie te denken dat het lukt om iedereen voldoende te bedanken. Met de kennis van deze wetenschap zal ik tach trachten om iedereen die bii de totstandkoming van dit proefschrift betrokken is geweest te bedanken. voor diegenen die ik hier vergeet te noemen, bij voorbact mijn excuses voor deze omissie.

Allereerst wil ik alle patiënten bedanken die hebben mee gedaan aan dit onderzoek. Ik besef dat het voor patiënten met een chronische nierziekte een grote opgave is om aan een dergelijke intensieve studie deel te nemen. Echter de motivatie van de deelnemende patiënten was indrukwekkend en getuigde van een grote mate van solidariteit met de mede-patiënten. Hiervoor nogmaals miin dank en grote waardering. Ook de controle personen, waaronder vele ouders van vrienden en bekenden alsook collega's wil ik bedanken voor hum bereidwilligheid om aan deze studie mee te werken.

Prof. dr. K.M.L. Leunissen, beste Karel, ik wil je bij deze graag bedanken voor alle energie en stimulatie die je als promotor in deze studie hebt gestoken. Je goede humeur en tomeloze inzel ziin tekenend voor de goede werksfeer die je hebt weten te creëren op de afdeling nefrologie in het azM. Dit heeft er mede toe bijgedragen dat het voor mij een groot plezier was om bij je op de afdeling werkzaam te mogen zijn en mijn promotie-onderzoek te mogen verrichten. Nogmaals hiervoor mijm harlelijke dank!

Dr. J.P. Kooman, beste Jeroen, voor jouw eindeloze inzet met betrekking tof deze promotie schieten woorden tekort om je te bedanken. De snelheid waarmee iii wetenschappeliike gegevens weet te doorgronden is nagenoeg onnavalgbaar en indrukwekkend. Het enthousiasme waarmee iii wetenschap bedrifft heeff er voor een groot deel toe bijgedragen dat deze promotie zo snel is afgerand. Nogmaals miln eindeloze dank en ik hoop dat we in de toekomst nog veel onderzaek samen vanuit Maastricht en Eindhoven kunnen opzetten, om te beginnen natuurlijk met een vervolgstudie van ons CAPD project. Maar nu eerst eens die fles Chassagne-Montrachet opentrekken!

Dr. F.M. van der Sande, beste Frank, ik wil je bij deze graag bedanken voor je geduld en begeleiding bij deze promotie. Op onze kamer (of eigenlijk jouw kamer natuurlijk, waar ik nietsvermoedend bleek te ziin ingetrokken) op de dialyse afdeling hebben we alle promotie-leed met elkaar gedeeld. Het was voor mif een eer om eerst bil jouw promotie paranimf te mogen zijn, en ben zeer vereerd dat ii nu bij deze promotie co-promotor kunt zijn. 
Een speciaal woord van dank will ik richten to Marc Schonck; iili stond aan de basis van het CAPD onderzoek en was medebedenker van het protocol. Je bereidwilligheid om vanuit Hoom aan dit onderzoek mee te werken heb ik zeer gewaardeerd, ik weet hoe moeilijk het voor je is geweest om als auteur van het CAPD protocol de studies van afstand te moeten volgen. Je sportieve en correcte houding in deze heeft bij mii zeer grote waardering opgewekt, nogmaals miin hartelijke dank voor de goede samenwerking.

Als voorzitter van de beoordelingscommissie wil ik natuurlijk ook Prof. $\mathrm{dr}$. ir. A.P.G. Hoeks hartelijk bedanken voor de voortvarendheid waarmee deze taak werd verricht. Beste Arnold, het was voor mij een grote eer am met je te mogen samenwerken, één van de mensen die aan de wieg wan de wall track heeft gestaan.

De overige leden van de beoordelingscommissie: Prof. dr. P.J.E.H.M. Kitslaar, Prof. dr. R.Th. Krediet, Prof. dr. N. Lameire en dr.ir. A.M.W.J. Schals wil ik allen hartelïk danken voor hun bereidwilligheid om het manuscript van dit proefschrift te beoordelen.

Naluurlijk wil ik hier ook alle verpleegkundigen van de dialyse afdeling in het azM bedanken voor hun gastvrijheid en geboden gezelligheid tijdens mijn verblijf bij jullie op de afdeling. Door jullie goede zorg voor de patiënten was er bijna iedere dag een zgn. "vlaai-alarm", met bijbehorende koffiepauze. Pierre en Michel, mijn hartelijke dank om bij jullie op de afdeling mijn onderzaek te mogen verrichten. In het bijzonder wil ik ook alle PD verpleegkundigen bedanken (zonder overigens de andere verpleegkundigen te kort te willen doen), te weten (in alfabetische volgorde): Jaap, Luud, Mariette, Peter en last but not least Sabine. Jullie enthousiasme voor het T34 protocol heeft er toe bilgedragen dat alle experimenten goed verliepen en dat alle patiënten met plezier naar het azM kwamen om te participeren in ons onderzoek (getuige het lage aantal drop-outs). Hiervoor nogmaals mijn grote dank en waardering.

Verder wil ik natuurlik iedereen van de technische dienst, tw. Pief Claessens, Leo Nijssen en Paul Bocken hartelijk bedanken voor de goede service die zij voortdurend geboden hebben, wij hebben hierbij nooit een tevergeefs beroep op jullie gedaan, en dit op niet altijd even makkelijke tijdstippen (altiid net voor "sluitingstijd"). Nogmaals dank voor deze goede support.

Alle nefrologen binnen de regio die patiënten hebben geincludeerd vaor deze studie wil ik graag hartelijk bedanken voor hun bereidwilligheid om mee te werken aan dit ambitieuze CAPD onderzoeksprotocol. Eén van de redenen dat alle studies zo snel konden worden afgewerkt is het feit dat er vanuit de participerende ziekenhuizen zoveel patiënten werden doorgestuurd am in het $a z M$ te worden geïncludeerd. Ik denk dat dit kenmerkend is voor de goede samenwerking tussen alle nefrologen binnen onze regio. $1 \mathrm{k}$ wil dan ook graag alle nefrologen die patiënten hebben geïncludeerd van harte danken voor hun 
inzet met betrekking tot dit proefschrift te weten Hons Wolters, Leon Frenken, Wim Verstoppen, Paul Gerlag en Joris Wirtz.

Sehr wiel dank möchte ich auch an Dr. Ulrich Gladziwa richten. Seinen Enthousiasmus für unserem studium war unnagfolgbahr, und die Suzammenarbeit war, wie immer, hervorragend.

Verder wil ik Dr. Dirk Struijk nog in het bijzonder bedanken. Beste Dirk, het was voor ons een grote eer om met je samen magen te werken, en witeindelijk bleek het concept om nog een aantal "high transporters" wanuit jullie kliniek te includeren zeer succesvol te ziin getuige de conclusies in hoofdstuk 5 en 7 . Hiervoor nogmads miln hartelijke dank.

Nel Cox-Reijven wil ik hantelik danken voor de prettige samenwerking waarin de segmentele BlA's werden verricht. Oak Eugenie van der Ham wil ik hartelijk danken voor het vrijelijk beschikbaar stellen van alle gegevens met betrekking tot de door jou onderzochte transplantatiepatiënten. Eugenie, nogmaals bedankt en veel succes met je promotie, hopelijk kunnen er nog veel patiënten vanuit Eindhoven in jouw studie geincludeerd worden.

Beste Ruben Dammers, voor jouw een apart dankwoord; het enthousiasme waarmee $\ddot{j i}$ alle wall track metingen in zeer katte tijd wist te bewerken was echt onvoorstelbaar en ik wil je hiervoor op deze plaats nogmaals hartelijk bedanken. Verder wens ik je natuurlik alle succes met je eigen promotie en verdere opleiding toe.

Dr. B. van Kreel en natuurlijk Lou Donselaer wil ik hartelijk danken voor de goede samenwerking met chemie 4 in het azM. Ook hier werd ik altijd even enthousiast ontvangen als er weer een meting werd verricht. Jullie bereidwillige samenwerking heeft zeker de vaart in de studie gehowden. Voor iedereen op chemie 4, nogmaals miin hartelike dank vaor de goede en plezierige samenwerking.

Dr. Cheriex, Andrea Palmans en Jas Habets wil ik hartelijk danken voor hun bereidwilligheid om op dezelfde dag dot onze patienten in hef azM aanwezig waren direct een echocardiografie te verrichten, en voor de hoge goede kwaliteit van de door jullie verrichte echo's. Hiervoor nogmoals mijn hortelijke dank.

Een speciaal woord van dank wil ik ook richten tot mijn opleider binnen de nefrologie, Prof. dr. J.P. wan Hooff. Beste Hans, bedankt voor je steun aan het onderzoek dat ik bij jullie binnen de werkgroep heb kunnen verrichten. Ook natuurlik mijn hartelike dank voor de financiële support zoals het beschikbaar stellen van de laptop warop bina alle data van deze thesis zijn ingevoerd. Aanvankelijk sprak men binnen de werkgroep over die lelijke paarse laptop met Duitse Windows versie, echter een jaar later wilde plots iedereen een dergelijke 
laptop. Nogmaals mijn hartelijke dank voor je onvoorwaardelijke support en vertrouwen.

Alle collega's op de afdeling nefrologie van het azM wil ik hartelijk danken voor de goede samenwerking en preftige werksfeer waarin we konden samenwerken. Beste Hans, Elly en Maarten; bii deze nogmaals mijn hartelijke dank voar de goede samenwerking met de subsectie transplantatie yon het azM. Hans, ik wens je samen met Sabine veel succes in de toekomst en veel geluk en voorspoed in je huwelijk, want door de ISBP in Celle was ik helaas niet aanwezig op jullie bruiloft, hiervoor mijn excuses. Zoals je weet vraagt een promotie vele offers.

Willi, ik will je graag bedanken voor de goede samenwerking in het azM, waaronder natuurlik de CAPD poli die daags tevoren altiid door ons samen werd voorbereid (mijns inziens de gezelligste poli van Nederland!). Ik wens je natuurlijk veel succes in Venlo. Een speciaal woord van dank wil ik ook richten aan Charles, we hebben samen veel promotie-lief en leed gedeeld en vele metingen, zoals die in Tilburg, samen verricht. Het was prettig om met je samen te werken en ik wens je natuurlijk ook veel succes met je verdere promotieonderzoek. Alle andere fellows op de afdeling nefrologie, walaronder Mariëlle Gelens, Mariëlle Krekels en Marc Hermans wil ik bij deze ook hartelijk danken voor de prettige samenwerking en wens hen allen ook veel succes toe in de toekomst. En natuurlijk het secretariaat, Anke, Marleen en Etiënne; ook jullie wil ik bedanken voor de prettige samenwerking.

En dan is er natuurlijk nog iemand in het azM die absoluut niet vergeten mag worden, de fantastische Tiny Wouters. Beste Tiny, eenmaal mett mijn manuscript biil je aangeland begrip ik de vitspraak 'veilige haven' pas goed. De rust en de ervarenheid waarmee je in korte tijd van ieder manuscript iets moois weet te maken is werkelijk fantastisch. Kortom na alle jaren stress was dit eindelijk even een rustpunt in het hele promotiecircus, even uitpuffen, want het komt wel goed allemaal! Tiny nogmaals bedankt voor al je inzel (zelfs in vakantietijd) en succes nu er in korte tijd zo vlak voor de kerst nog een aantal promoties moeten worden afgerond.

Verder wil ik mijn opleiders in de interne geneeskunde, te weten Dr. C. van der Heul en Prof. dr. H.F.P. Hillen hartelijk danken voor de mogelijkheid die ze mi hebben geboden om me te bekwamen in de interne geneeskunde. Een speciad woord van dank wil ik hierbij richten tot Cees van der Heul. Beste Cees, mijn opleidingstijd in Tilburg heb ik als zeer inspirerend ervaren en ik denk dat het bijna onmogelijk is om elders in een dergelijk goede sfeer zo veel werkervaring op te doen. Gezelligheid en een goede dosis humor zijn mijns inziens noodzakeliike ingrediënten voor een goede opleidingstijd. Bepaalde begrippen zoals de 'rode bankjes' van weleer, alsook de grappen op het ochtend-rapport zullen mii nog lang bijbliiven. Zo ook de afscheidsborrel waar tot mijn grote verbazing deze rode bankjes plots weer opdoken. Ik wil dan ook alle internisten 
in Tilburg en collega arts-assistenten hartelik danken voor deze mooie opleidingstijd.

Een bijzonder woord wan dank will ik richten tot Wiek Rensma en Fred Apperloo. Beste Wiek en Fred, jullie hebben mij angespoord om verder fe gaan in de nefrologie en gezien de prettige samenwerking in Tilburg en hef feit dat we onze eerste studies rond arteriele vaatstitheid in Tilburg hebben verricht, hebben jullie beiden aan de bakermat van dit proefschrift gestaan. Ik hoop dan aok dat we in de toekomst binnen onze regio nog veel onderzoek samen kunnen opzetten. Nogmaals dank voor jullie stimulerende rol en enthousiasme. Dit geldt notuurtik ook voor de verpleging en het secretariaat van de dialyse afdeling in Tilburg, alwaar ik altijd zeer hartelifk werd onthaald als ik weer eens een meting kwam verrichten. Een speciaal woord wan dank wil ik ook richten aan het secretariaat van de internisten in Tilburg. Door jullie andersteuning kwamen altijd de juiste patiënten gegevens boven tafel. Met name Janine, secretaresse van Dr. Rensma dient hierbil speciaal vernoemd te worden, voordat ik de patient gezien had was deze door jouw enthousiasme al geincludeerid in de Wall Track studie. Hiervoor nogmaals mijn hartelike dank!

Speciale dank gaat aok vit naar Yes en Michiel; wij doorstonden samen een fantastische opleidingstijd in Tilburg en ik ben dan ook zeer trats dat jullie, als collega's en als vrienden, bij mijn promotie paranimf zijn, ook al zitten jullie hier nief direct in de regio. Ik wens jullie veel succes en geluk in het verdere leven en ga enan uit dat we elkaar ook in de toekomst regelmatig zullen zien om onze vriendschap te bestendigen.

De maatschap interne geneeskunde van het Catharina Ziekenhuis in Eindhoven wil ik bedanken voor de gasturipheid en de goede collegiale werksfeer die ik aldaar geniet sinds mijn intrede in april 2002. Een speciaal woord van dank gaat uit naar Steven Hoorntie en Petra Douwes-Dradijer, mijn directe calleganefrologen. Onze gezellige besprekingen met uiltgebreide maatschappelike bespiegelingen geven an hoe goed de intercollegiale werksteer is. Het is voor mij dan ook een grote eer om met jullie te mogen samenwerken op de wolledig nieuwe en prachtige dialyse afdeling in het Catharina Ziekenhuis die in april van dit jaar werd geopend. Ik hoop in de naaste toekomst nog vele jaren intensief in deze goede werksfeer met jullie te mogen samerwerken.

Zeer veel dank ben ik verschuldigd aan mïn ouders die mij de mogelijkheid hebben geboden om me te laten studeren en me verder te ontwikkelen. Een bijzonder woord van dank aan mijn wader aan wie dit proefschrift is opgedragen en die zo trots was op het feit dal ik geneeskunde ging studeren. Ik vind het ontzettend jammer dat hij uiteindelijk deze kroon op zovele jaren studie niet meer mee kan maken. Ma, ik weet dat je erg ongerust was toen ik op 17 . jarige leeftijd naar Amsterdam vertrok om de wereld te verkennen. Uiteindeliik na vele avonturen en omzwervingen ben ik veilig in Eindhoven terechtgekomen. lk hoop dat dit je geruststelt. Ik will dan ook mijn moeder als ook mijn 
schoonouders, Herbert en Mieke van harte bedanken voor hun oprechte steun en interesse in mijn werk.

Lieve Marion, al sinds onze inmiddels histarische ontmoeting in 1985 in Amsterdam op de Vosmaerstraat hebben we een zeer goede relatie. Of de broodrooster echt kapof was zullen we natuurliik nooit meer kunnen achterhalen, wel staut vast dat we sinds die tijd voor-en tegenspoed samen hebben gedeeld. Afgelopen jaren waren zowel voor mij als woor jou erg zwaar qua studiebelasting, een periode die nu in december met een doctors- en een MBA titel wordt afgesloten. Ik hoop dat na alle verhuizingen en omzwervingen eindelijk een rustiger tiijd aanbreekt.

En dan natuurlijk de twee am wie het uiteindelijk allemaal gaat: Lotte en Veerle, ik hoop dat jullie erg gelukkig worden in Eindhoven, metl ons, op de nieuwe school, dicht bij opa en oma. En dat we straks wat meer tijd voor elkaar zullen hebben om samen naar het Genneperpark te gaan naar de voor jullie zo favoriete speeltuin met de grote schommel! 


\section{Curriculum vitae}

Stijn Konings werd op 12 augustus 1963 in Roosendaal (NB) geboren. Alhier werd het St. Norbertus college doorlopen, daarna volgde de studie geneeskunde te Amsterdam. In 1991 was hii kortdurend werkzaam in het West Fries Gasthuis te Hoorn, waarna hij tot 1992 werkzaam was in het Universitaire Ziekenhuis te Antwerpen. Vervolgens was hij werkzaam in het St. Elisabeth Ziekenhuis te Tilburg op de afdeling interne geneeskunde. Hier werd gestart met de opleiding inwendige geneeskunde (opleider Dr. C. van der Heul) en werden de eerste studies opgestart die deel vitmaken van dit proefschrift. In 1998 werden de werkzaamheden voorlgezet in het azM te Maastricht (opleider Prof. dr. H.F.P. Hillen) en werd tevens het aandachtsgebied nefrologie doorlopen [opleider Prof. dr. J.P. van Hooff). In oktober 2000 volgde de registratie als internist-nefroloog. Vanaf oktober 2000 tot en met maart 2002 was thii verbonden can de afdeling nefrologie van het azM te Maastricht als onderzoeker. Een groot gedeelte van de in dit proefschrift beschreven studies bii CAPD patiënten werden in deze tijal binnen de ROZON verricht. Vanaf april 2002 is hii werkzaam als internist-nefroloog in het Cataharina Ziekenhuis te Eindhoven. Hij woont samen met Marion Hinderdael, samen hebben zii 2 dochters: Lotte en Veerle. 